INTERNATIONAL MONETARY FUND

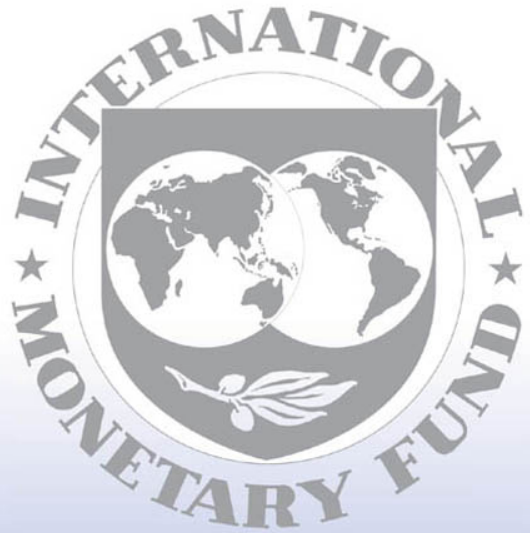

Staff

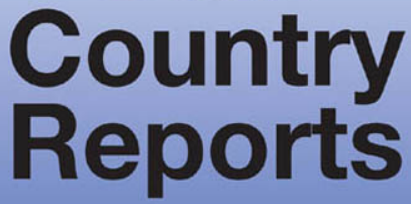




\section{Liberia: Poverty Reduction Strategy Paper}

Poverty Reduction Strategy Papers (PRSPs) are prepared by member countries in broad consultation with stakeholders and development partners, including the staffs of the World Bank and the IMF. Updated every three years with annual progress reports, they describe the country's macroeconomic, structural, and social policies in support of growth and poverty reduction, as well as associated external financing needs and major sources of financing. This country document for Liberia is being made available on the IMF website by agreement with the member country as a service to users of the IMF website.

Copies of this report are available to the public from

International Monetary Fund $\bullet$ Publication Services

$70019^{\text {th }}$ Street, N.W. • Washington, D.C. 20431

Telephone: (202) 623-7430 • Telefax: (202) 623-7201

E-mail: publications@imf.org • Internet: http://www.imf.org

Price: $\$ 18.00$ a copy

\section{International Monetary Fund \\ Washington, D.C.}


This page intentionally left blank

CInternational Monetary Fund. Not for Redistribution 


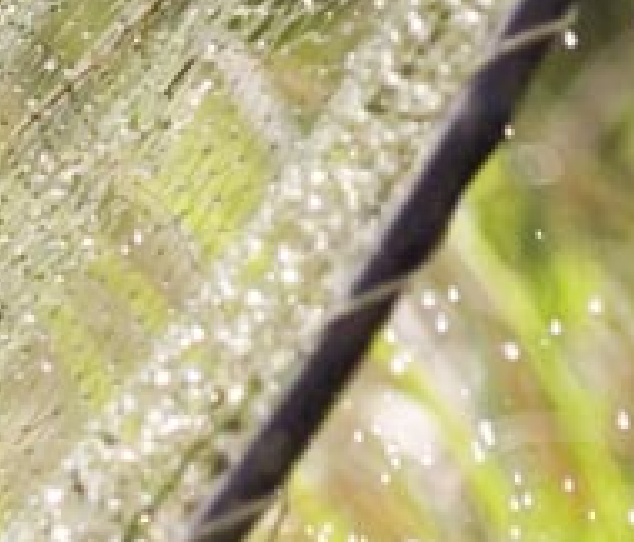

mol 190

Poverty Reduction Strategy bis.
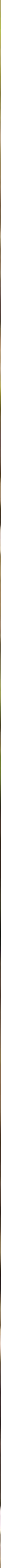

\section{Republic of Liberia}

CInternational Monetary Fund. Not for Redistribution 


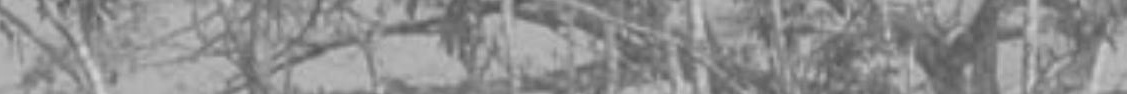
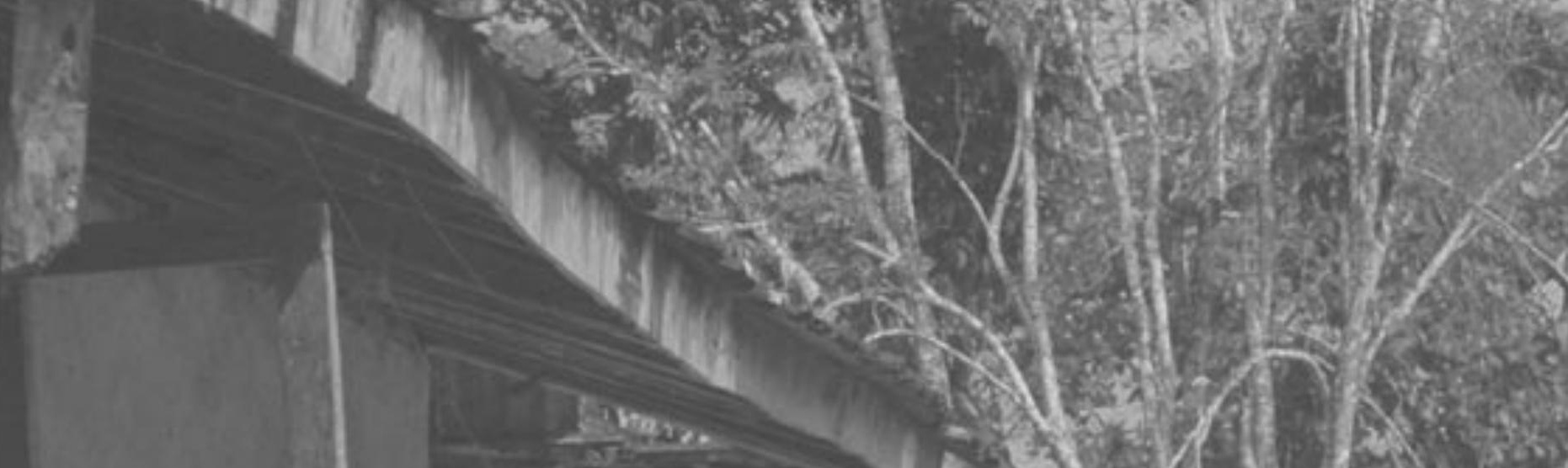

8
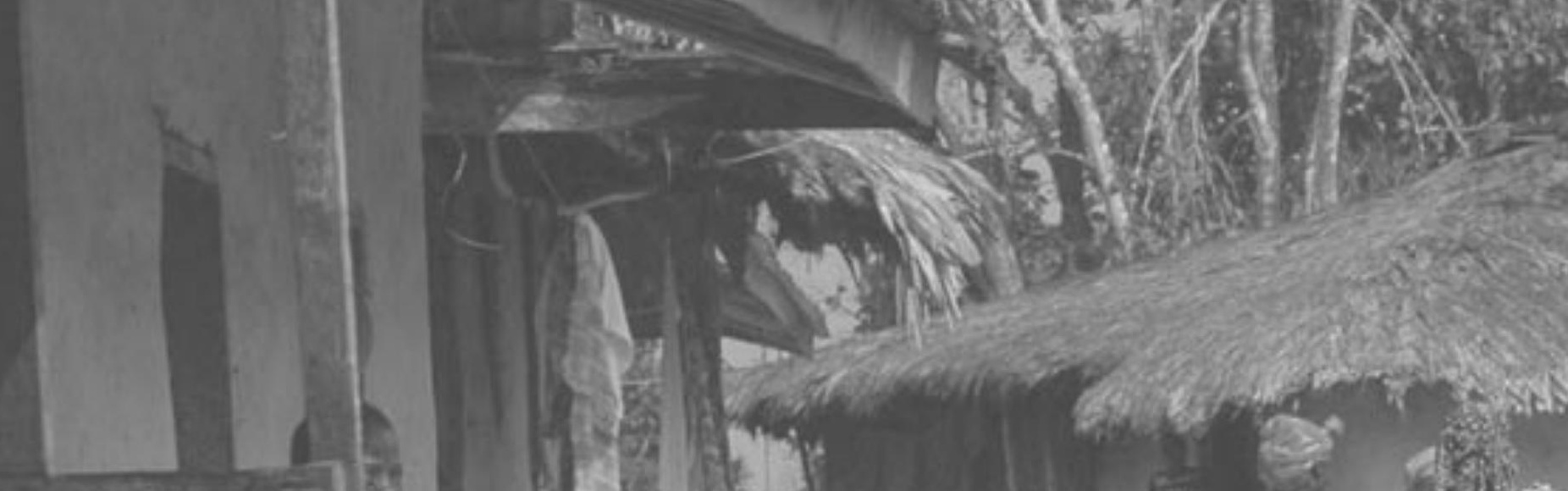

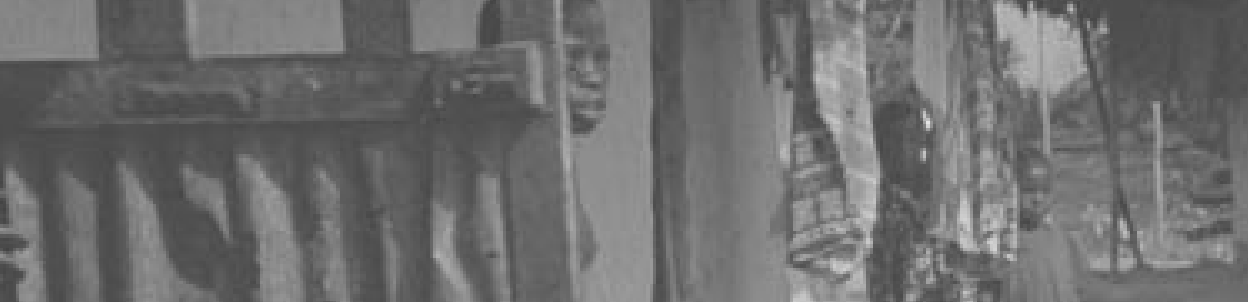

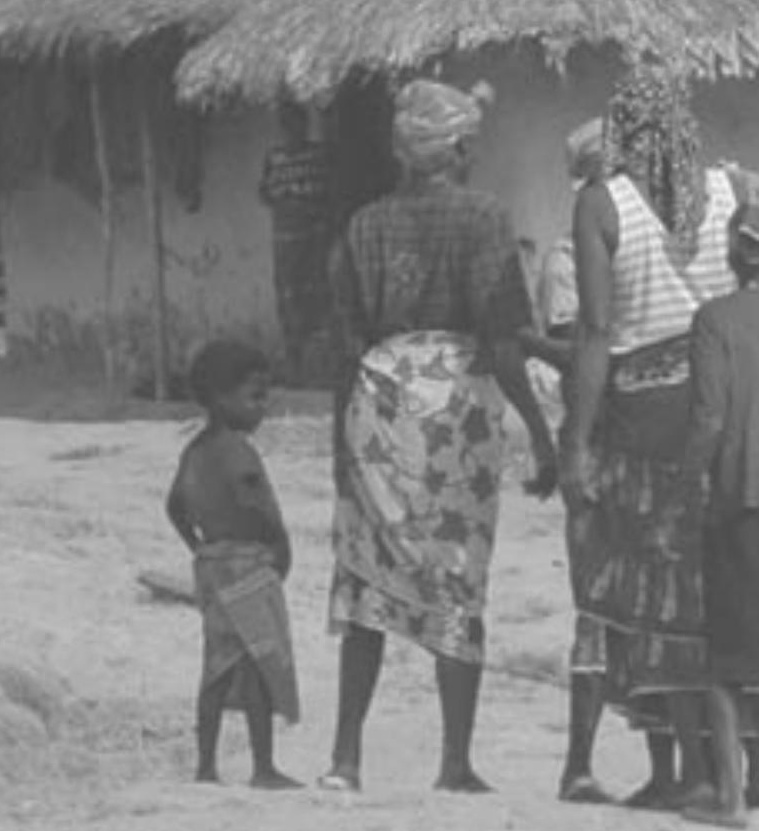

4
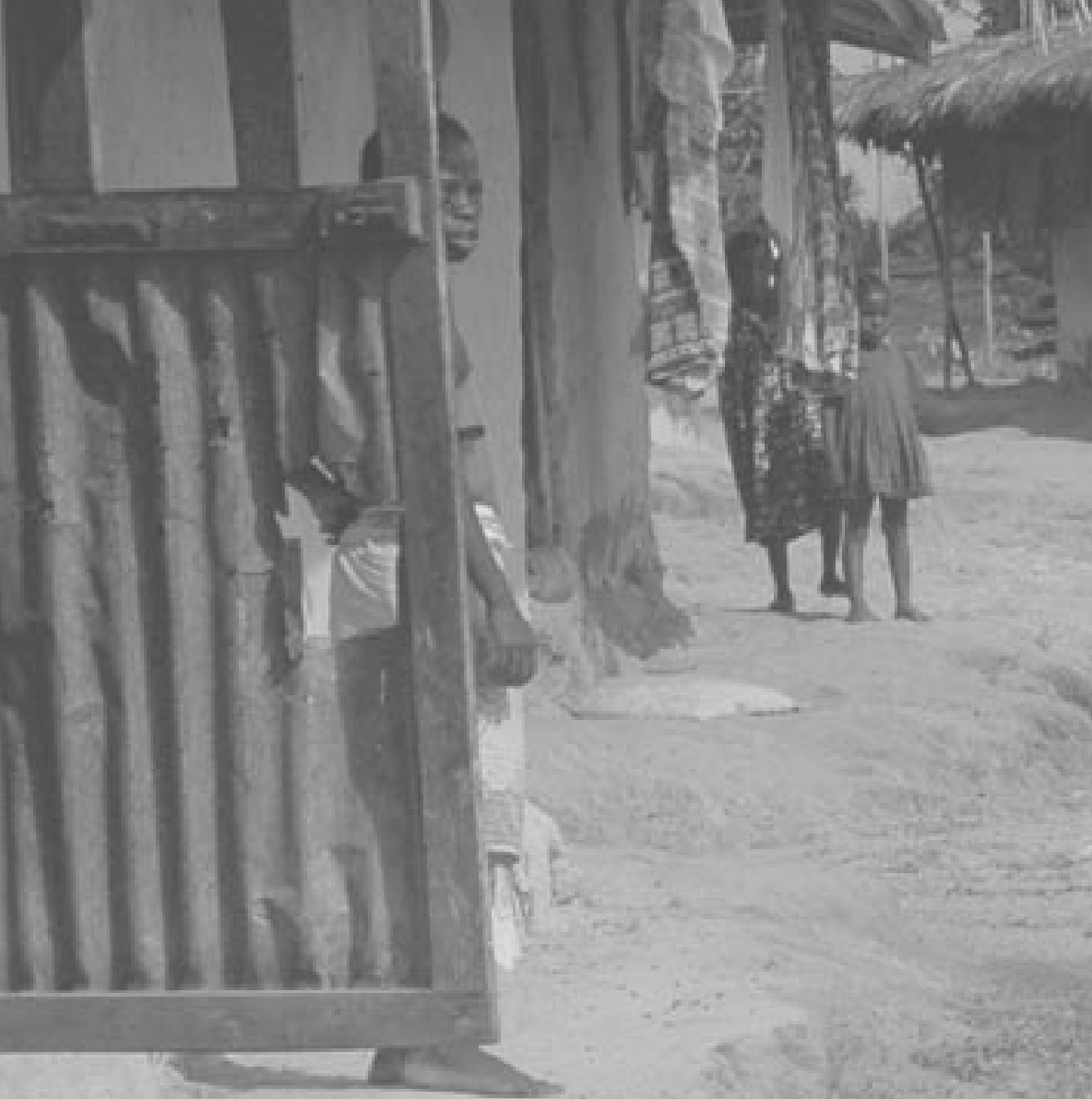

ase

M

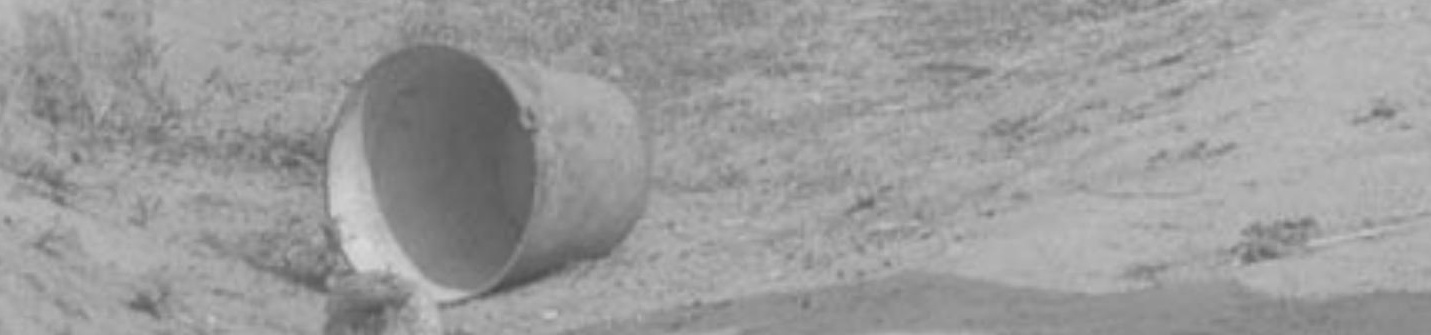




\section{Liberia Poverty Reduction Strategy}




\section{HISTORY AND CURRENT CONTEXT}

Letter from Ellen Johnson Sirleaf

President, Republic of Liberia

Acronyms

1. From Conflict to Recovery …..................................

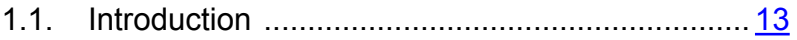

1.2. Conflict and Collapse .....................................

1.3. Initial Actions and the Emerging Recovery ........

1.4. Implementing the PRS ...............................

2. The Road Ahead: A Vision for Liberia's Future ........... $\underline{20}$

3. Poverty in Liberia: The Current Context ................... 24

3.1. Introduction .............................................. 24

3.2. Methods of Measuring Poverty and Sources of

3.3. Income and Consumption Dimensions

of Poverty ............................................... $\frac{25}{28}$

3.5. Liberia and the Millennium Development

Goals

3.6. Conclusion

$\frac{32}{33}$

4. Building the Foundation for Rapid, Inclusive and

Sustainable Economic Growth

4.1. Introduction …...............................................

4.2. Liberia's Growth Potential …………….........

4.3. A Three-Pronged Growth Strategy ...................

4.4. Liberia's Initial Growth Acceleration ..................

5. The Poverty Reduction Strategy Development

Process .............................................................. 4

5.1. Introduction ...........................................

5.2. Institutional Mechanism and PRS Group

Structure .................................................

5.3. The Four Pillars ........................................

5.4. A Participatory and Consultative Process .......... $\underline{45}$

\section{Annexes}

Cross-Cutting Issue Strategy Brief: Gender Equity .........163

Cross-Cutting Issue Strategy Brief: Peacebuilding .......... $\frac{170}{176}$

Cross-Cutting Issue Strategy Brief: Environment ............ $\frac{176}{181}$

Cross-Cutting Issue Strategy Brief: HIV and AIDS ..........181

Cross-Cutting Issue Strategy Brief: Children and Youth ...185

\section{Priority Action Matrices}

Peace and Security

$\underline{57-58}$

Food and Agriculture

$\frac{76}{77}$

Forestry

Mining

Land and Environmental Policy

Private Sector Investment

Financial Sector Issues

Labor and Employment

State-Owned Enterprises, Parastatals, and Regulatory

Agencies

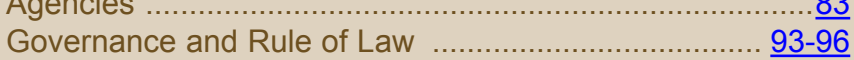

Roads and Bridges ...........................................

Transportation ……...............................................

Energy
6. Pillar I: Consolidating Peace and Security 49

6.1. Introduction ................................................... 49

6.2. Major Goals and Objectives ........................... 50

6.3. Restructuring and Reforming Security Institutions

6.4. Strengthening Human and Personal Security ... 53

6.5. Building and Maintaining Regional Peace and Security

7. Pillar II: Revitalizing the Economy …........................ 59

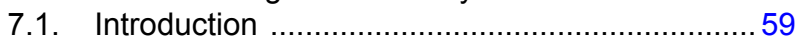

7.2. Agriculture and Food Security ...........................6 60

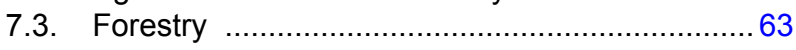

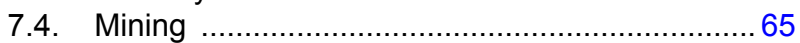

7.5. Land and Environmental Policy ......................... 67

7.6. Stimulating Private Sector Investment and Development in Downstream Production, Manufacturing, Trade, and Services ................69 69

7.7. Revitalizing Financial Services ........................ 71

7.8. Generating Productive Employment .................. 73

7.9. Management of State-Owned Enterprises, Parastatals and Regulatory Agencies 74

8. Pillar III: Strengthening Governance and the Rule of Law .... 84

8.1. Introduction ................................................. 84

8.2. Enhancing Participation in and Ownership of Government

8.3. Building Effective and Efficient Institutions ........ 89

8.4. Strengthening and Enhancing the Effectiveness and Integrity of Legal and Judicial Institutions .. 91

8.5. Expanding Access to Justice and Enhancing the Protection and Promotion of Human Rights ...... 92
Post and Telecommunications

Water and Sanitation

Public Buildings and Housing 117

Health

Education

Growth and $120-121$

Monitoring and Evaluation

\section{Boxes}

Building Peace in Liberia

Main Public Consultation Messages from the Counties

Gender Based Violence in Liberia

Liberia Reconstruction Trust Fund

$\frac{46}{54}$

Real GDP Growth Assumptions

Mt. Coffee Hydroelectric Facility

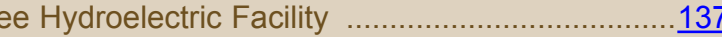

The National Strategy for the Development

of Statistics ............................................................ 152

Tapping Dormant Human Capital: Changing Minds,

Changing Attitudes 161

The Concept of Gender 
9. Pillar IV: Rehabilitating Infrastructure and Delivering Basic Services

9.1. Introduction $\frac{97}{97}$

9.2. Roads and Bridges .....................................

9.3. Transportation ....................................... $\frac{101}{103}$

9.4. Energy ……..........................................

9.5. Post and Telecommunications ...................... 104

9.6. Water and Sanitation ................................ $\frac{106}{107}$

9.7. Public Buildings and Housing ......................

9.8. Health .....................................................

9.9. Education ……............................................

10. The Macroeconomic Policy Framework .................... 124

10.1. Introduction ...........................................

10.2. Public Financial Management ......................

10.3. Fiscal Policy ..................................................

10.4. Monetary and Exchange Rate Policy ..............

10.5. External Trade and Balance of Payments .......

11. Costing the Poverty Reduction Strategy …............... 134

11.1. Introduction ............................................ 134

11.2. Cost Estimates …......................................

11.3. Government Financing ...............................

11.4. Aggregate Costs and the Gross

Financing Gap

11.5. Moving Forward

138

$\underline{139}$

12. Building Capacity 141

12.1. Introduction ..............................................

12.2. Civil Service Reform .................................. 142

12.3. Building Capacity in Senior Management: SES and TOKTEN

144

12.4. Building Capacity in the Education Sector ....... 144

12.5. Building Capacity in the Health Sector ............ 145

13. Monitoring and Evaluation 147

13.1. Introduction .........................................

13.2. Context ................................................... $\frac{147}{148}$

13.3. Indicators ...............................................

13.4. Institutional Framework for Monitoring Impact ...................................... 149

13.5. Monitoring Deliverables .............................. 150

13.6. Strengthening the Foundation for Future Analyses 151

13.7. Building County-Level M\&E Structures ............153

14. Risks and Constraints

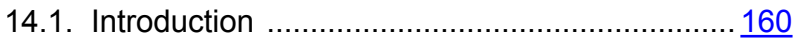
$\frac{160}{160}$

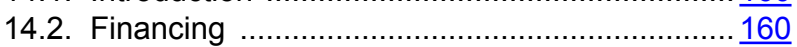

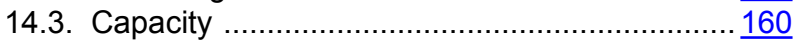

14.4. External Stability ......................................

14.5. Internal Stability ..........................................

14.6. Effects on Growth Projections ....................... 162
The Concept of Peacebuilding

Tables

1.1: Value Added by Sector in Liberia, 1987-2005 ..........16

3.1: Poverty Lines for Liberia, 2007 ................................

3.2: Liberia 2007 Poverty Profile ...............................

3.3: $\quad$ Basic Health Indicators …........................................

3.4: Education and Literacy ..................................

3.5: "Status at a Glance" Liberia and the MDGs ..............

4.1: Growth in Value Added by Sector in Liberia, 2004-2007

7.1: Sectoral Real GDP Projections 2007-2011 ….............60

7.2: Forestry Production and Revenue ……..................

10.1: Liberia - Key Macroeconomic Indicators 2007-2011

10.2: Revenue Projections FY 2006/2007 -

FY 2010/2011

10.3: External Trade and Balance of Payment Indicator 2007-2011

11.1: Costs by Sector for Fiscal Years 2008/2009 through 2010/2011
11.2: GoL Revenues for PRS, FY 2008/2009 through

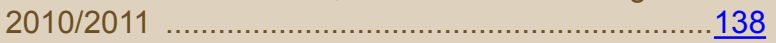

11.3: PRS Gross Financing Gap, FY 2008/2009 through 2010/2011

13.1: PRS Monitoring and Evaluation Indicators ..... 155- $\underline{159}$

\section{Figures}

1.1: Evolution of GDP Per Capita, 1960-2007 ...............14

3.1: Poverty Head Count .........................................

5.1: The PRS Coordination Structure …….....................

5.2: Liberia Reconstruction and Development Committee

5.3: Organizational and Management Structure of Pillars and Working Groups

5.4: The Four Pillars as a Strategic Framework ..............

9.1: Status of Roads and Bridges in Liberia as of December 2007 $\underline{99}$

13.1: Flow of M\&E Data …...................................... 150

13.2: County Coordination Framework and Reporting Structure

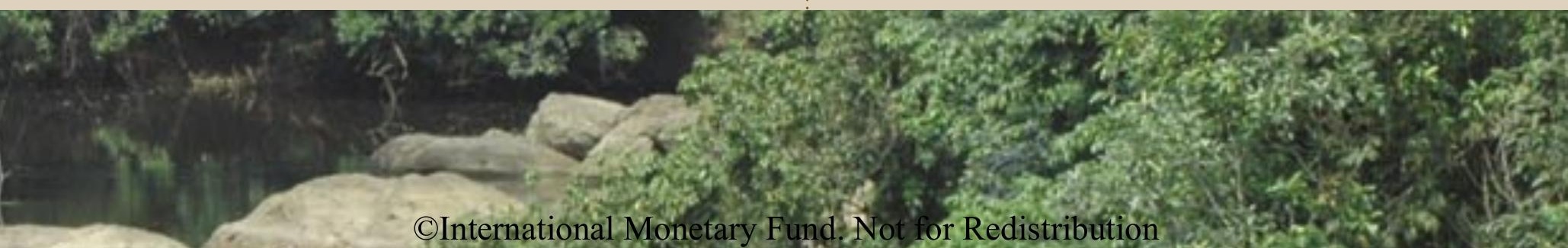


This page intentionally left blank

CInternational Monetary Fund. Not for Redistribution 


\section{Letter from the President}

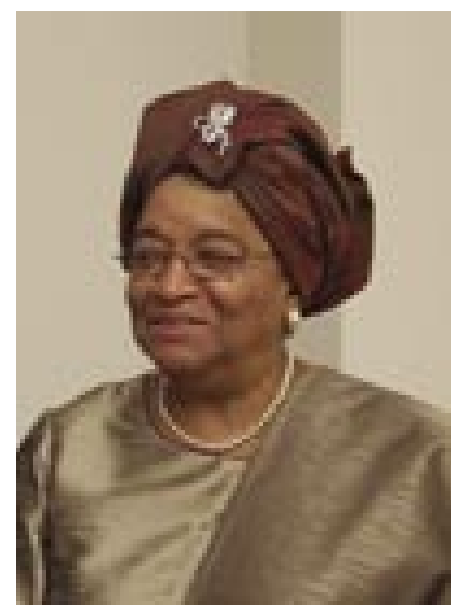

This Poverty Reduction Strategy (PRS) is truly ours - home grown by all of us. This roadmap for our future reflects the inputs of citizens from all of Liberia's 15 counties, from market sellers in Ganta to government Ministers in Monrovia, from women and men, boys and girls, members of every political party, every age group, every tribe, and every sector.

The process of developing the PRS is a sign of how far Liberia has come in a few short years. The ideas in this document emerged from an unprecedented series of county consultations, where we broke from our history of Monrovia-dominated government and truly listened to the people of our great nation. The process has been open, collaborative, and peaceful, proving that we Liberians can and do resolve our differences amicably.

In those county-level meetings across the country, Liberians spoke of building a country where a child can live in safety, go to a school with qualified teachers, get clean water and medicine, and study by electric light. The PRS lays the groundwork for making sure that the child's parents have a fine road to carry their goods to market, and can participate in a local government that is vested with increasing responsibility and resources.

Reducing poverty is not something this government can do alone. It is something we all must do. The private sector - businesses small and large - will increasingly be the engine of growth and jobs. Civil society will continue to serve as a watchdog. The Legislature will be responsible for passing the legislation to build our reform efforts into the bedrock of our institutions.

Our development partners deserve many thanks for the support given as we crafted the PRS. We ask them now to refocus their policies and programs in alignment with the strategy. Their help will be needed to meet the unfunded portion, to give us the ability to build the roads, and the schools, and the clinics of which we dream.

Perhaps the most difficult task falls to the citizens of Liberia. Government can strive to create an enabling environment, but our people must seize these opportunities and work hard to make our collective dream a reality. I believe that our people will do just that.

I am confident that this PRS - representing as it does the hard work and input of all Liberians will be a framework that will guide us toward rapid, inclusive, and sustainable development.

Ellen Johnson Sirleaf

President, Republic of Liberia 


\begin{tabular}{|c|c|}
\hline$A B C$ & Abstinence, Be faithful, use Condoms \\
\hline ACC & Anti-Corruption Commission \\
\hline ACDB & Agriculture Cooperative and Development Bank \\
\hline AFL & Armed Forces of Liberia \\
\hline ALP & Accelerated Learning Program \\
\hline ART & Antiretroviral Therapy \\
\hline BIN & Bureau of Immigration and Naturalization \\
\hline BoB & Bureau of the Budget \\
\hline BOT & Build-Operate-Transfer \\
\hline BPHS & Basic Package of Health Services \\
\hline CARI & Central Agricultural Research Institute \\
\hline CBL & Central Bank of Liberia \\
\hline CDA & County Development Agenda \\
\hline CDSC & County Development Steering Committee \\
\hline CDW & Consolidation, Drawdown and Withdrawal \\
\hline CEO & County Education Officer \\
\hline CET & Common External Tariff \\
\hline CFSNS & Comprehensive Food Security and Nutrition Survey \\
\hline CNDRA & Center for National Documents, Records and Archives \\
\hline CPA & Comprehensive Peace Agreement \\
\hline CSA & Civil Service Agency \\
\hline CSPro & Census and Survey Processing System \\
\hline CSU & County Statistics Unit \\
\hline CWIQ & Core Welfare Indicators Questionnaire \\
\hline DDA & District Development Agenda \\
\hline DDRR & Demobilization, Disarmament, Rehabilitation and Reintegration \\
\hline DEO & District Education Officer \\
\hline DFID & UK Department for International Development \\
\hline DHS & Demographic and Health Survey \\
\hline DOTS & Directly Observed Treatment, Short-course \\
\hline ECOWAS & Economic Community of West African States \\
\hline EITI & Extractive Industries Transparency Initiative \\
\hline EPA & Environmental Protection Agency \\
\hline EPP & Emergency Power Program \\
\hline ERC & Economic Revitalization Committee \\
\hline ERU & Emergency Response Unit \\
\hline $\mathrm{FBO}$ & Food Business Operator \\
\hline FDA & Forestry Development Authority \\
\hline
\end{tabular}




\begin{tabular}{|c|c|}
\hline FFI & Flora and Fauna International \\
\hline FIA & Financial Institutions Act \\
\hline GBV & Gender Based Violence \\
\hline GAC & General Auditing Commission \\
\hline GC & Governance Commission \\
\hline GEMAP & Governance and Economic Management Assistance Program \\
\hline GEWG & Gender Equity Working Group \\
\hline GFSM & Government Finance Statistics Manual (IMF) \\
\hline GoL & Government of Liberia \\
\hline GSA & General Services Administration \\
\hline GST & Goods and Services Tax \\
\hline $\mathrm{HIC}$ & OCHA Humanitarian Information Center \\
\hline HIPC & Highly Indebted Poor Countries Initiative \\
\hline IBS & Infrastructure and Basic Services \\
\hline IDP & Internally Displaced Persons \\
\hline IFMIS & Integrated Financial Management Information System \\
\hline IMF & International Monetary Fund \\
\hline iPRS & Interim Poverty Reduction Strategy \\
\hline IUCN & International Union for Conservation of Nature \\
\hline KPCS & Kimberley Process Certification Scheme \\
\hline LC & Land Commission \\
\hline LCG & Liberia Coast Guard \\
\hline LD & Liberian Dollar \\
\hline LDAA & Liberia Domestic Airports Agency \\
\hline LEAP & Liberia Employment Action Program \\
\hline LEEP & Liberia Emergency Employment Program \\
\hline LEC & Liberia Electricity Corporation \\
\hline LEITI & Liberia Extractive Industries Transparency Initiative \\
\hline LIPA & Liberia Institute of Public Administration \\
\hline LISGIS & Liberia Institute for Statistics and Geolnformation Services \\
\hline LNP & Liberia National Police \\
\hline LRC & Liberia Revenue Code \\
\hline LRDC & Liberia Reconstruction and Development Committee \\
\hline LRRRC & Liberia Repatriation, Reintegration and Rehabilitation Commission \\
\hline LSS & Life Saving Skills \\
\hline LSVTC & Liberia Swedish Vocational Training Center \\
\hline LTA & Liberia Telecommunications Authority \\
\hline LTC & Liberia Telecommunications Corporation \\
\hline LWSC & Liberia Water and Sewer Corporation \\
\hline M\&E & Monitoring and Evaluation \\
\hline MCC & Monrovia City Corporation \\
\hline
\end{tabular}




\begin{tabular}{|c|c|}
\hline MCIMS & Mining Cadastre Information Management System \\
\hline MDA & Mineral Development Agreement \\
\hline MFA & Ministry of Foreign Affairs \\
\hline MIA & Ministry of Internal Affairs \\
\hline MICAT & Ministry of Information, Culture and Tourism \\
\hline MNS & Ministry of National Security \\
\hline $\mathrm{MoCl}$ & Ministry of Commerce and Industry \\
\hline MoD & Ministry of Defense \\
\hline MoE & Ministry of Education \\
\hline MoF & Ministry of Finance \\
\hline MoGD & Ministry of Gender and Development \\
\hline MoHSW & Ministry of Health and Social Welfare \\
\hline MolA & Ministry of Internal Affairs \\
\hline MoJ & Ministry of Justice \\
\hline MoL & Ministry of Labor \\
\hline MLME & Ministry of Lands, Mines and Energy \\
\hline MoP\&T & Ministry of Post and Telecommunications \\
\hline МoT & Ministry of Transport \\
\hline MOU & Memorandum of Understanding \\
\hline MoYS & Ministry of Youth and Sports \\
\hline MPEA & Ministry of Planning and Economic Affairs \\
\hline MPW & Ministry of Public Works \\
\hline MRU & Mano River Union \\
\hline MSME & Micro, Small, and Medium Enterprise \\
\hline MW & Megawatt \\
\hline NAA & National Airport Authority \\
\hline NAC & National AIDS Commission \\
\hline NACP & National AIDS Control Program \\
\hline NBI & National Bureau of Investigation \\
\hline $\mathrm{NCHE}$ & National Commission for Higher Education \\
\hline NEC & National Establishment Census \\
\hline NEP & National Employment Policy \\
\hline NFS & National Fire Service \\
\hline NHA & National Housing Authority \\
\hline NHSB & National Housing Savings Bank \\
\hline NIMAC & National Information Management Center \\
\hline NMML & New Minerals and Mining Law \\
\hline NOCAL & National Oil Company of Liberia \\
\hline NPA & National Port Authority \\
\hline NSC & National Security Council \\
\hline NSDS & National Statistics Development Strategy \\
\hline
\end{tabular}




\begin{tabular}{|c|c|}
\hline NSSRL & National Security Sector Strategy for the Republic of Liberia \\
\hline NTGL & National Transitional Government of Liberia \\
\hline $\mathrm{OCHA}$ & UN Office for the Coordination of Humanitarian Affairs \\
\hline ONSA & Office of the National Security Adviser \\
\hline OVC & Orphans and other Vulnerable Children \\
\hline PEP & Post-exposure Prophylaxis for HIV \\
\hline PFM & Public Financial Management \\
\hline PLWHA & People Living with HIV and AIDS \\
\hline РMTCT & Prevention of Mother-to-Child Transmission \\
\hline PPA & Participatory Poverty Assessment \\
\hline PPCA & Public Procurement and Concessions Act \\
\hline PPCC & Public Procurement and Concessions Commission \\
\hline PPP & Public-Private Partnership \\
\hline PRGF & Poverty Reduction and Growth Facility \\
\hline PRS & Poverty Reduction Strategy \\
\hline RIA & Roberts International Airport \\
\hline RMTC & Road Maintenance Training Center \\
\hline SAR & Search and Rescue \\
\hline SCC & Stakeholders Consultative Committee \\
\hline SEA & Sexual Exploitation and Abuse \\
\hline SES & Senior Executive Service \\
\hline SEZ & Special Economic Zone \\
\hline SME & Small and Medium Enterprise \\
\hline SOE & State-Owned Enterprise \\
\hline SPSS & Statistical Package for the Social Sciences \\
\hline $\mathrm{SRH}$ & Sexual and Reproductive Health \\
\hline SSS & Special Security Service \\
\hline STI & Sexually Transmitted Infection \\
\hline TOKTEN & Transfer of Knowledge through Expatriate Nationals \\
\hline $\mathrm{TRC}$ & Truth and Reconciliation Commission \\
\hline UCMJ & Uniform Code of Military Justice \\
\hline UNDP & United Nations Development Programme \\
\hline UNGASS & United Nations General Assembly Special Session on HIV and AIDS \\
\hline UNHCR & United Nations High Commissioner for Refugees \\
\hline UNMIL & United Nations Mission in Liberia \\
\hline UNPOL & United Nations Police \\
\hline UNSC & United Nations Security Council \\
\hline VAT & Value Added Tax \\
\hline VCT & Voluntary Counseling and Testing \\
\hline VPA & Village Profile Assessment \\
\hline WATSAN & Water and Sanitation \\
\hline
\end{tabular}





\section{Part 1: \\ History and Current Context}

\section{Chapter One}

\section{From Conflict to Recovery}

\subsection{Introduction}

L iberia is on the move. After decades of economic mismanagement and fourteen years of brutal civil war, Liberia's national nightmare is over. The country has been at peace since 2003. Two rounds of free and fair elections in 2005 led to the inauguration of a new government in January 2006 . The economy is expanding rapidly, with growth accelerating to over 9 percent in 2007 . Roads and buildings are being rebuilt, health clinics and schools are re-opening and agricultural production is increasing. The Government is introducing a broad set of policies to foster peace, accelerate reconstruction and development, and build strong systems of governance. There is a long way to go, but Liberia has launched its recovery and is poised for rapid, inclusive, and sustainable development in the years to come.

${ }^{2}$ Liberia's Poverty Reduction Strategy (PRS) articulates the Government's overall vision and major strategies for moving toward rapid, inclusive and sustainable growth and development during the period 2008-2011. Specifically, the PRS will be implemented between April 1, 2008 and June 30, 2011 (the end of the 2010/2011 fiscal year). This period is of critical importance as Liberia shifts from post-conflict stabilization to laying the foundation for inclusive and sustainable growth, poverty reduction, and progressing toward the Millennium Development Goals (MDGs). The PRS builds on the Government's first 150-day action plan and its interim PRS (iPRS), and has been formulated through broad-based consultation with Liberian citizens in cities, towns, and villages throughout the country, members of the business community, civil society groups, the Legislature, and international partner organizations. The Government sees the three-year PRS not as an end in itself, but as the next step in a process toward long-term development that will continue well beyond 2011, when it will develop the next phase of its strategy.

${ }^{3}$ This opening chapter provides the context for the PRS by describing the conflict and economic collapse, the transition beyond conflict, and the initial progress achieved during the past two years. It stresses that for Liberia to be successful, it cannot simply recreate the economic and political structures of the past, which produced widespread income disparities, economic and political marginalization, and deep social cleavages, and ultimately fuelled the conflict. Liberia must create much greater economic and political opportunities for all its citizens and ensure that growth and development are widely shared, with the benefits spread much more equitably throughout the population. It must also directly address the consequences and legacies of decades of destruction, division and distrust, recognize and respond to the structural risk factors that predispose the country to violent conflict, and identify opportunities for institutionalizing peace. 


\subsection{Conflict and Collapse}

${ }^{4}$ The starting point for Liberia's PRS is the country's initial recovery from its long and brutal civil conflict. The war killed an estimated 270,000 people, created hundreds of thousands of refugees and internally displaced persons (IDPs), and shattered the lives of thousands of others. It destroyed basic institutions of governance as well as significant physical infrastructure and social capital. The economy collapsed, impoverishing much of the Liberian population.

${ }^{5}$ The origins of the conflict can be traced to two broad factors. First, significant portions of society were systematically excluded and marginalized from institutions of political governance and access to key economic assets. The founding constitution was designed for the needs of the settler population, with less consideration and involvement of the indigenous people. In the early days, land and property rights of the majority of Liberians were severely limited. Later, marginalization was perpetuated by the urban-based policies of successive administrations. Political power was concentrated in Monrovia and primarily at the level of the Presidency. Most infrastructure and basic services were concentrated in Monrovia and a few other cities. Marginalization of youth and women and the mismanagement of national resources were widespread, which contributed to stark inequalities in the distribution of benefits.

${ }^{6}$ The over-concentration of power bred corruption, restricted access to the decision-making process, and limited the space for civil society participation in governance processes. The consequence was a high level of resentment toward the ruling elite, which in part led to the bloody military coup of 1980 and its initial support among the people. The military and successive governments however failed to correct the ills of society and magnified the problems.

Second, economic collapse helped to propel the crisis. Liberia's economy posted steady economic growth averaging 4 to 7 percent per year through the 1960s, but most of the gains were also concentrated within the elite, and the majority of Liberians saw little benefit. The economy began to unravel in the 1970s with the combination of a sharp increase in world petroleum prices and a decline in the prices of key export commodities. By the latter part of the decade all indicators pointed to a looming crisis. Unemployment and consumer prices, and particularly food prices, all rose at alarming rates, while growth stagnated, and tensions rose sharply.

Figure 1.1 Evolution of GDP per capita, 1960-2007 (constant 2004 US\$)

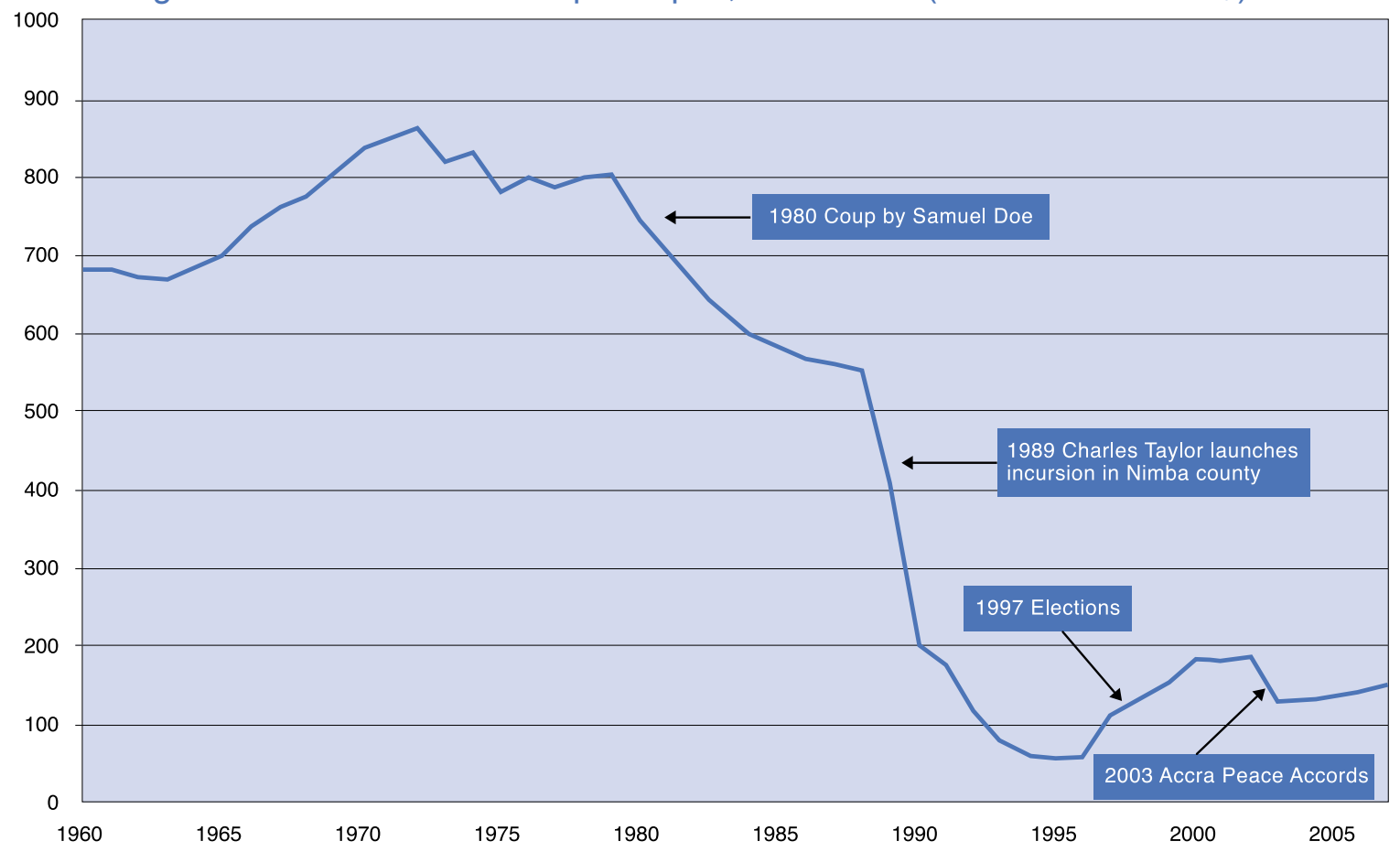

Source: World Bank, World Development Indicators 
${ }^{8}$ The April 1980 coup d'état marked the beginning of Liberia's steep descent into crisis. A decade of mismanagement and dictatorship led to the outbreak of civil war in late 1989 and 14 subsequent years of chaos, plunder, and violence which did not end until the arrival of international peacekeepers, the ousting of the Taylor Government, and the signing of the Accra Comprehensive Peace Agreement (CPA) in 2003.

${ }^{9}$ The damage and negative consequences of the conflict were enormous. Commercial and productive activities ceased as various warlords looted and vandalized the country. Families were shattered; entire communities were uprooted; and social, political, economic, and traditional governance systems were destroyed. There was a massive exodus of skilled and talented individuals from the country. The economy completely collapsed. GDP fell a catastrophic 90 percent between 1987 and 1995, one of the largest economic collapses ever recorded in the world (Figure 1.1). By the time of the elections in 2005 , average income in Liberia was just one-quarter of what it had been in 1987, and just one-sixth of its level in 1979.

${ }^{10}$ The decline was felt across the board (Table 1.1). Agricultural production dropped as people fled their farms and the supporting infrastructure collapsed, mining and timber activities shut down, rubber plantations closed, manufacturing essentially stopped, and services ground to a halt. Production of iron ore and timber, as well as mining and panning, ceased completely. Rice production fell 76 percent between 1987 and 2005, financial services fell 93 percent, and electricity and water fell 85 percent. Transportation and communication, trade and hotels, and construction all fell around 69 percent. Only the production of charcoal and wood increased as Liberians turned to these products to meet their basic energy needs.

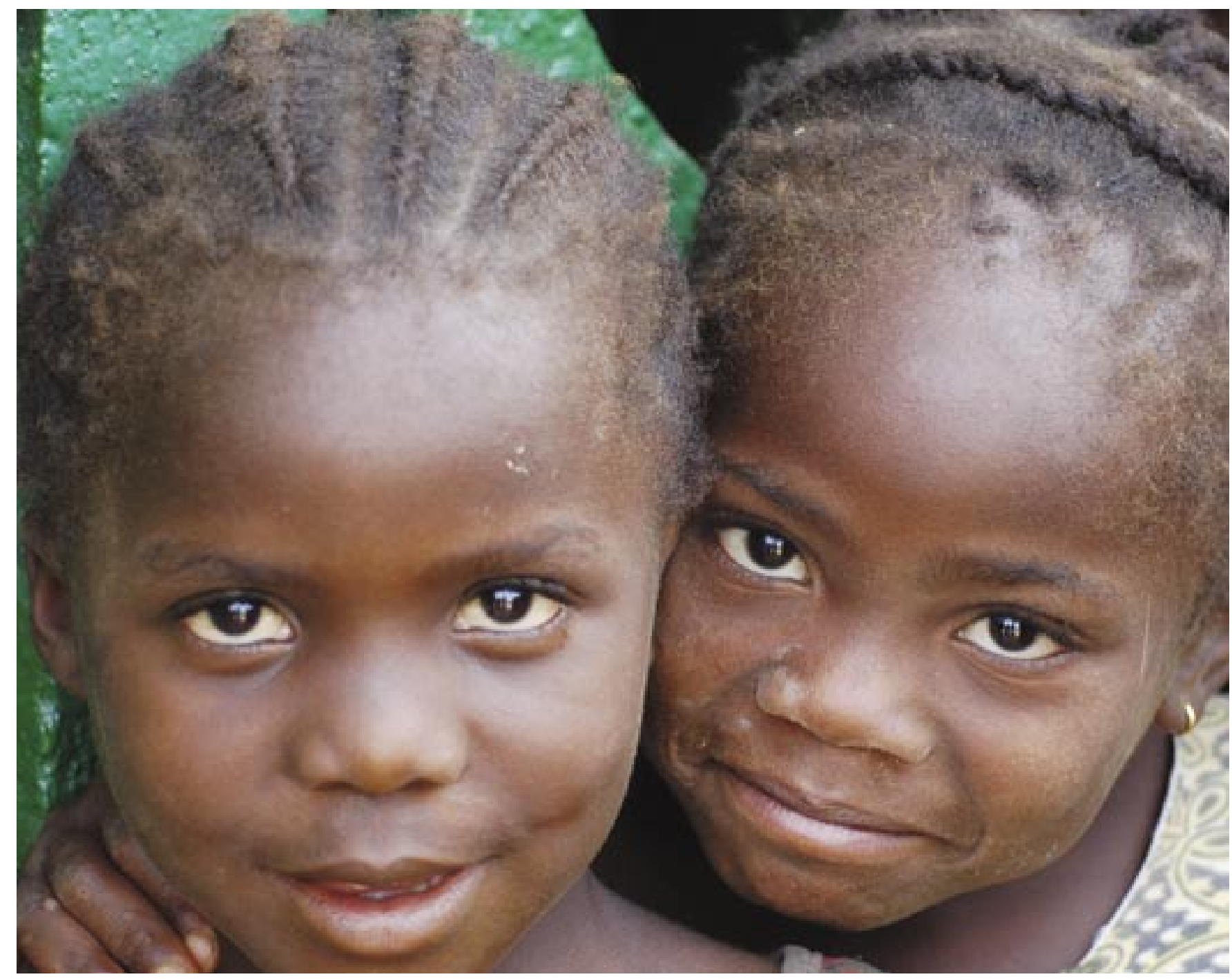




\begin{tabular}{|l|r|r|r|}
\hline & \multicolumn{1}{|c|}{1987} & \multicolumn{1}{|c|}{$\mathbf{2 0 0 5}$} & Decline (\%) \\
\hline Real GDP & $\mathbf{1 1 6 7 . 0}$ & $\mathbf{4 0 1 . 7}$ & $\mathbf{6 5 . 6}$ \\
\hline Agriculture \& fisheries & $\mathbf{3 6 8 . 7}$ & $\mathbf{1 7 7 . 9}$ & $\mathbf{5 1 . 8}$ \\
\hline Rubber & 59.9 & 41.5 & 30.7 \\
\hline Coffee & 0.9 & 0.1 & 90.8 \\
\hline Cocoa & 5.9 & 1.2 & 79.5 \\
\hline Rice & 117.1 & 28.4 & 75.7 \\
\hline Cassava & 57.4 & 44.0 & 23.3 \\
\hline Other & 127.6 & 62.7 & 50.9 \\
\hline Forestry & $\mathbf{5 6 . 6}$ & $\mathbf{5 9 . 0}$ & $\mathbf{- 4 . 3}$ \\
\hline Logs \& timber & 34.4 & 0.0 & 100.0 \\
\hline Charcoal \& wood & 22.2 & 59.0 & -166.2 \\
\hline Mining \& panning & $\mathbf{1 2 4 . 9}$ & $\mathbf{0 . 7}$ & $\mathbf{9 9 . 4}$ \\
\hline Iron ore & 116.2 & 0.0 & 100.0 \\
\hline Other & 8.7 & 0.7 & 91.9 \\
\hline Manufacturing & $\mathbf{8 6 . 9}$ & $\mathbf{5 1 . 7}$ & $\mathbf{4 0 . 5}$ \\
\hline Cement & 23.0 & 14.9 & 35.5 \\
\hline Beverages \& beer & 52.5 & 33.7 & 35.9 \\
\hline Other & 11.4 & 3.2 & 71.8 \\
\hline Services & $\mathbf{5 2 9 . 9}$ & $\mathbf{1 1 2 . 3}$ & $\mathbf{7 8 . 8}$ \\
\hline Electricity \& water & 18.2 & 2.7 & 85.3 \\
\hline Construction & 39.0 & 8.0 & 79.4 \\
\hline Trade, hotels, etc & 71.5 & 19.2 & 73.1 \\
\hline Transportation \& communication & 89.5 & 27.6 & 69.2 \\
\hline Financial institutions & 141.8 & 10.0 & 93.0 \\
\hline Government services & 129.0 & 31.5 & 75.6 \\
\hline Other services & 40.9 & 13.3 & 67.4 \\
\hline & & & \\
\hline
\end{tabular}

Source: Government of Liberia and IMF staff estimates

${ }^{11}$ Basic infrastructure was destroyed. Many roads are now impassable, which seriously constrains economic recovery, as well as the provision of basic services such as health and education. The grossly inadequate road infrastructure also impedes peacebuilding efforts by limiting economic opportunities, constraining the ability of police and other security forces to operate effectively, and weakening national cohesiveness and integration. There was no electricity or piped water in the country for 15 years until the new Government turned on some water and electricity in Monrovia in July 2006. Unemployment soared, and poverty increased sharply, with nearly 64 percent of Liberians now living below the poverty line. ${ }^{1}$ Schools, hospitals, and clinics are badly damaged, and most government buildings are in shambles. Today there are only 51 Liberian physicians to cover the nation's public health needs, approximately one for every 70,000 Liberians. About 70 percent of school buildings are partially or wholly destroyed, and over half of Liberian children and youth are estimated to be out of school. A whole generation of Liberians has spent more time at war than in the classroom. Public finances collapsed, with annual revenue falling to US $\$ 85$ million, allowing per capita public expenditure of about US $\$ 25$, one of the lowest levels in the world. The Government defaulted on its debts in the mid-1980s, and by 2006 external debt had soared to US $\$ 4.5$ billion, equivalent to 800 percent of GDP and 3,000 percent

\footnotetext{
${ }^{1}$ As derived from the 2007 CWIQ survey. (See Chapter Three.)
} 
of exports. Domestic debt and arrears added an additional US\$900 million, of which about US $\$ 300$ million was ultimately deemed valid by external auditors.

\subsection{Initial Actions and the Emerging Recovery}

${ }^{12}$ Liberia began to stabilize and recover following the 2003 peace agreement. United Nations peacekeepers and others in the international community contributed significantly to consolidating the peace, assisting with the successful 2005 elections, and supporting Liberia's recovery efforts. The new Government introduced a strong set of policy reforms to spur reconstruction and development, and the economy is on the rebound. Economic growth reached an estimated 5.3 percent in 2005, an estimated 7.8 percent in 2006, and further accelerated to an estimated 9.5 percent in 2007 . Many storefronts are newly painted, shelves are restocked, and business is expanding. Families are repairing their homes. Hotels and restaurants are re-opening. Trucks are lining up at building supply stores and small construction projects are evident throughout the country. Road construction is underway, and schools and clinics have reopened. Road and port traffic has increased markedly. Agricultural production is recovering, and foreign investment is rising.

${ }^{13}$ Most importantly, hope has been restored. While many challenges lie ahead, Liberians are optimistic about the future for the first time in decades. This hope and optimism was exhibited by the enthusiasm of citizens during the PRS consultative process, some of whom walked for more than 15 hours to attend district and county-level meetings.

${ }^{14}$ The programs and policies implemented by the new Government and its international partners have helped stimulate the recovery. The Government's initial aims were to implement mutually reinforcing policies aimed at political stability, inclusive economic recovery and the restoration of basic services. It began to rehabilitate institutions, rebuild infrastructure and invest in health and education programs. Its initial strategy was articulated in the plan for the Government's first 150 days and in the iPRS. Both were organized around a framework with four basic Pillars, upon which the PRS is also based:

- expanding peace and security;

- revitalizing the economy;

- strengthening governance and the rule of law; and

- rehabilitating infrastructure and delivering basic services.

${ }^{15}$ Expanding peace and security. The Government has begun to rebuild the full range of its security forces and has made substantial progress in reintegrating refugees and IDPs, with strong support from its international partners. It has demobilized and reintegrated over 90,000 ex-combatants-11,780 of whom were children-through formal reintegration programs, and deactivated or retired

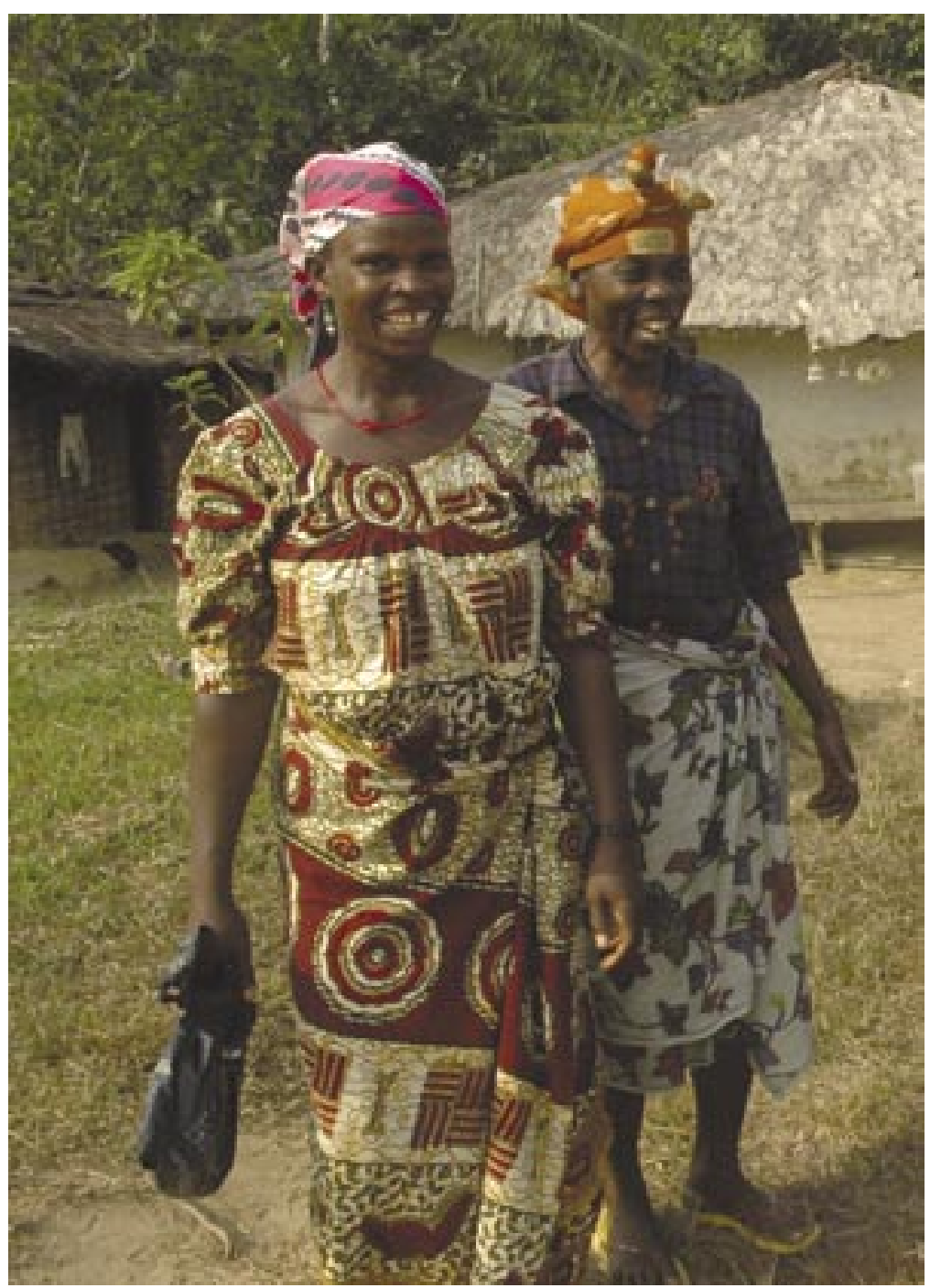


over 17,000 members of the Armed Forces of Liberia (AFL), the Liberian National Police (LNP), and the Special Security Service (SSS). At the same time, it has begun to recruit and train the new AFL and police force. Over 1,100 AFL recruits (of an eventual 2,000) have already completed their first phase of training, and more than 3,500 police officers have completed academy training. The government has renovated the Police Academy Training Facilities and concluded plans for the construction of 10 county headquarters and 15 police depots around the country. Alongside its international partners, the Government has provided support and temporary cash assistance to over 108,000 exiled refugees and 325,000 registered IDPs. In addition, tens of thousands more have returned to their communities outside of formal programs. The Government is currently preparing itself for large numbers of refugees being repatriated from the West Africa sub-region, including approximately 40,000 who were hosted in Ghana.

${ }^{16}$ Revitalizing the economy. The Government has taken a range of measures to overhaul its financial management systems and to spur renewed economic activity. It moved quickly to introduce a cashbased balanced budget and new expenditure control mechanisms, and strengthened enforcement and collection of customs duties and other taxes. As a result of these and other steps, revenues for the FY 2007/2008 are expected to be more than double the amount for FY 2005/2006. The Government endorsed and is implementing the Governance and Economic Management Assistance Program (GEMAP), which provides international experts to support several key financial agencies of the Government. It also successfully implemented two IMF Staff-Monitored Programs under which it made significant improvements in public finances and in monetary and exchange rate polices, paving the way to full restoration of normalized relations with the IMF in March 2008. It also joined the Extractive Industries Transparency Initiative (EITI) to strengthen accountability and transparency in managing funds generated through natural resource-based activities. To further strengthen financial management, the Government submitted legislation to formally merge the Bureau of the Budget with the Ministry of Finance, as well as legislation to limit the discretion of the Government to change budget allocations between ministries and agencies without approval of the Legislature to a cumulative total of 30 percent. The latter was recently adopted by the legislature after reducing the threshold to twenty percent.

${ }^{17}$ To begin the revitalization of key economic activities, the new Government in early 2006 immediately cancelled all forestry contracts and reviewed 95 contracts and concessions granted by the National Transitional Government of Liberia, and subsequently passed a Forest Reform Act to strengthen oversight and regulation of the forestry sector. These steps paved the way for the United Nations Security Council to lift the sanctions on Liberian timber exports, and should lead to a rapid recovery in the timber sector during the PRS period. The Government completed negotiations with ArcelorMittal and the Firestone Rubber Company to revise major concession agreements to increase the benefits for the Liberian people and concluded new agreements to re-start oil palm production. It distributed over 40,000 tools and 20 metric tons of seed rice to some 33,000 farmers throughout the country in 2006, with even larger amounts in 2007. It worked to increase employment throughout the country through community development projects, food for work programs, road building programs, urban cleanup projects, and the revitalization of agriculture. The Government has also made strong initial progress in dealing with its debt situation. It formulated and began implementation of a comprehensive domestic debt resolution strategy, cleared its long-standing arrears to the World Bank, the African Development Bank, and the IMF, signed a new three-year agreement with the IMF, and reached the Decision Point under the Heavily Indebted Poor Countries' (HIPC) Initiative.

${ }^{18}$ Strengthening governance and the rule of law. The Government moved quickly to introduce a requirement that the President, all Cabinet Ministers, and all commissioned officers publicly declare their assets, and submitted to the Legislature a new Code of Conduct for all public officials. It developed and began to implement a comprehensive anti-corruption strategy, which included the submission of legislation to establish an Anti-Corruption Commission with prosecutorial powers. It took a strong stance against impunity by initiating court proceedings against a range of former senior government officials. It also began the process of civil service reform, including the removal of more than 7,000 "ghost" employees from the Government payroll, and the settling of civil servants' arrears for periods ranging between six to eighteen months. The Government recognizes that many of the governance problems 
of the past have their roots in the excessive concentration of power in the Executive and in Monrovia. Toward that end, it has worked to strengthen the Legislature by, among other steps, giving it more power over budgetary issues, introducing measures on a wide range of issues for legislative approval, increasing its administrative budget, and establishing a Women's Legislative Caucus with membership from both Upper and Lower Houses. To begin the process of decentralization, County Support Teams were established to support County Superintendents and Assistant Superintendents in all 15 counties. Children's Assemblies and a National Children's Parliament were also formed to ensure children's participation in governance issues.

${ }^{19}$ Rehabilitating infrastructure and delivering basic services. The Government initiated the rehabilitation of four major highways, many secondary roads, as well as bridges, culverts, and drainage facilities in several areas around the country. Electricity connections and pipe-borne water were restored to some parts of Monrovia for the first time in 15 years. Government has rebuilt and reopened many schools throughout the country, and provided over 13,000 pieces of school furniture. To encourage families to send their children to school, it abolished tuition and fees for public primary schools, and significantly reduced tuition and fees for public secondary schools, leading to a 44 percent increase in school enrolments. To rehabilitate public health services, it restored services to over 350 health facilities around the country, and rehabilitated more than 20 clinics and several hospitals and health centers. It immunized over 95 percent of children under five against measles, distributed over 125,000 mosquito nets, and trained over 3,500 health workers in malaria case management. The Government also provided HIV and AIDS prevention services to the general population, particularly to high risk groups, as well as treatment and care services to people living with HIV and AIDS.

\subsection{Implementing the PRS}

${ }^{20}$ As the above achievements and others show, Liberia has made substantial progress in the last two years. Many challenges lie ahead, but with strong support from its partners and the eager participation of the Liberian people, the Government has laid the foundation for rapid, inclusive and sustainable growth and development in the years to come. With the country at peace and the initial recovery now clearly under way, Liberia is committed to developing institutions and supporting practices and attitudes that strengthen the prospects for peace. It is well-positioned to continue expanding economic opportunities, delivering basic services throughout the country, and re-building an accountable government that is focused on poverty reduction. It will do so in a manner sensitive to the needs of women, children and persons with disabilities, and to the challenges of environmental degradation and HIV and AIDS.

${ }^{21}$ The reform agenda in this PRS is ambitious. While each reform is considered to be achievable, there are many factors that may affect the ability of the Government to successfully implement the whole PRS. These include:

- the ready availability and coordinated disbursement of financing;

- leadership, administrative and technical capacity;

- external stability and economic contagion effects;

- internal security; and

- the realization of economic growth projections.

${ }^{22}$ The chapters that follow set out the strategy, as well as the potential risks and constraints in more detail. 


\section{The Road Ahead: A Vision for Liberia’s Future}

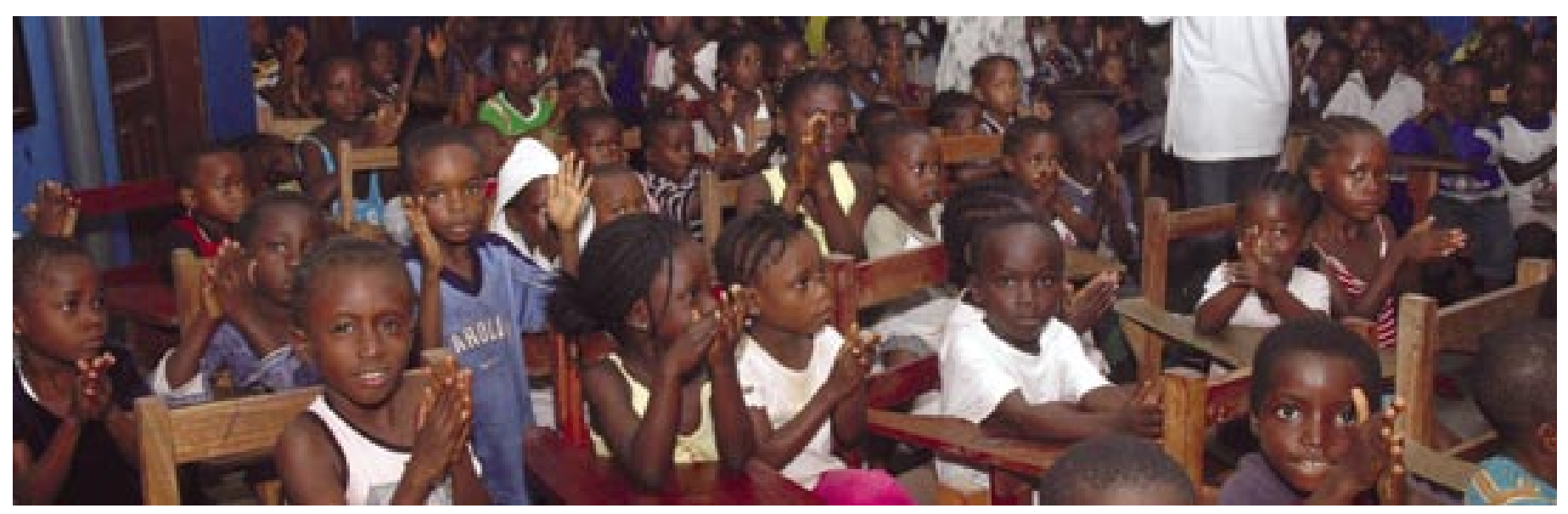

${ }^{1}$ The 2005 elections were a watershed in Liberia's history. The people of Liberia declared loudly and clearly that they wanted an end to war and government mismanagement, and a new beginning based on peace, inclusive economic opportunities, and respect for justice and basic human rights. Liberians want security, freedom, and opportunity: security in their everyday lives, freedom from abuse and oppression, and the opportunity to provide for their families. After more than two decades of misrule, violence and economic collapse, the people have now taken the first bold steps on the long road in this new direction.

${ }^{2}$ Liberians want to build a new nation that is peaceful, secure, and prosperous, with democratic and accountable governance based on the rule of law, and with abundant employment and other economic opportunities. The Government's central objectives over the next three years are to firmly establish a stable and secure environment across Liberia; to be on an irreversible path toward rapid, inclusive and sustainable growth and development; to rebuild the capabilities of and provide new opportunities for Liberia's greatest asset - its people; and to establish responsible institutions of justice, human rights, and governance.

${ }^{3}$ The new Liberia aims to acknowledge and begin to move beyond the divisions, marginalization, and exclusion of the past and to create circumstances where differences are discussed, not fought over. Liberia cannot simply recreate the economic and political structures of the past. It must respond to the deep wounds of the civil war while taking strong steps to establish the foundation for sustained stability and peace in the future. It must therefore create much greater economic and political opportunities for all Liberians, and not simply for a small elite class. Liberia must ensure that the benefits from growth, and the provision of basic health and education services, are spread much more equitably throughout the population, including to women, children and youth, persons with disabilities, and other marginalized groups. It must address the social consequences of the war, including gender based violence (GBV) and the transmission of HIV and AIDS, which continue to permeate society today. It must grant more political power to the counties and districts, build transparency and accountability into government decision-making, and create stronger checks and balances across all three branches of government. Achieving these goals will require the participation and strong commitment of all the Liberian people, including those in the Diaspora, working with the Government, Liberia's international partners, the private sector, and civil society groups.

${ }^{4}$ As a cornerstone of this new Liberia, the Government will continue to consolidate peace, stability, and security throughout the country, and will deepen and build on the more than four years of peace since the end of the conflict. Liberians are deeply grateful for the contribution of the United Nations peacekeepers in helping to maintain the peace and security necessary to hold landmark elections and estab- 
lish the basis for economic recovery. Looking forward, the country is preparing for the eventual departure of the peacekeepers and the transition toward having its own well-trained, professional security forces under civilian control to serve the people of Liberia. A major part of this effort is rebuilding the Armed Forces of Liberia. But the Liberian people also desire basic security and safety at a community level, so the Government is actively rebuilding and strengthening the police and other security-related personnel. The results are already beginning to show: Liberians now crowd the marketplaces, basic human rights are more widely respected, and investors are showing they believe in the country's stability.

\section{Building Peace in Liberia}

Durable and lasting peace is the sine qua non of Liberia's transformation and development. While progress has been made since the end of the war, the causes and results of conflict are still alive and present in the political, social and economic environments. Through the PRS, the Government is consciously and deliberately demonstrating its commitment to building a culture of better and more inclusive governance and economic growth, addressing the factors that could breed conflict, and healing a nation that is deeply damaged from war.

Peace-building in Liberia embodies a vision of a society that is peaceful, respects and protects the rights of citizens and ensures that disputes and tensions which are normal to any society are handled in a way that prevents their escalation into organized violence. While the causes of violent conflict in Liberia are multifaceted, deep-rooted and complex, there are six key issue areas that require focused attention throughout all components of the PRS to mitigate their potential to mobilize groups for violent action: land conflicts; the condition of youth especially with regard to employment; political polarization; mismanagement of natural resources; the relationship between the state and its citizens; and weak and dysfunctional justice systems.

Strengthening peace will require both conflict-sensitive implementation of the PRS and a range of complementary, strategic interventions to address conflict factors and enable development. Over the PRS period, with initial support from the Peace Building Fund, the Government will focus on building the capacity of leaders and institutions to develop and implement conflictsensitive policies and programs. With an understanding of conflict issues and methods for addressing them, the Government can set a strong foundation for lasting peace and stability in Liberia.

${ }^{5}$ At the same time, Liberia must establish a strong economy with robust employment growth, widespread opportunities for all citizens, and a vibrant private sector, as described in more detail in Chapter Four. It is only through sustained increases in income, coupled with access to improved health and education services, that the poorest Liberians can gain the foothold to climb out of poverty. The Government wants to build an open, strong, competitive economy sustained by strong international trade linkages and significant local and foreign private investment.

${ }^{6}$ Liberia's growth strategy has three prongs: rebuilding roads and other critical infrastructure; reviving the traditional engines of growth in mining, minerals, forestry, and agriculture; and establishing a competitive business environment to help diversify the economy over the medium term.

- First, Liberia must rebuild its infrastructure, particularly roads. The PRS consultative process revealed that across the country, Liberians' number one priority is better roads. Participants saw roads as essential for creating jobs and new economic opportunities, revitalizing agriculture, reducing prices, strengthening local governance, facilitating access to health and education services, connecting the population to service centers, increasing the effectiveness of the police and other security forces, and helping to maintain peace.

- Second, Liberia must quickly revive its traditional sources of economic growth - rubber, tim- 
ber, mining and cash crops - and ensure that the benefits accrue to all Liberians in a sustainable manner. Concession contracts will therefore differ from the past and the Government will seek to increase the participation of Liberian micro, small and medium enterprises (MSMEs) in the supply chains and value chains of these key growth sectors. The Government is working hard to revitalize agriculture as the bedrock of the economy, as agriculture provides livelihoods for the majority of Liberians. It believes that a vibrant agricultural sector is central to reducing poverty, providing food security, and ensuring progress toward the Millennium Development Goals.

- Third, the Government will continue to take strong steps to diversify the economy over the medium term into the competitive production of labor-intensive downstream products, manufactured goods, and services. It aims to create an open economy with low tariff and non-tariff barriers, strong linkages to international markets, minimal government intervention except where necessary to address market failure, and low levels of red tape and unproductive regulation.

${ }^{7}$ In all of these activities, the private sector will be the main driver of growth. The term 'private sector' as applied in the PRS encompasses a wide array of enterprises, from micro businesses to local industrial companies to large natural resource concessions. While attracting foreign investment is critical to growing the economy, the aim is also to empower domestic entrepreneurs to conduct business and create jobs for others, thereby growing the size and purchasing power of the Liberian middle class.

${ }^{8}$ The Government will focus only on services that the private sector cannot or will not offer at an appropriate price, such as maintaining safety and security, ensuring the rule of law, providing infrastructure and other public goods, providing basic services for the poor, and establishing a regulatory environment conducive to long-term development.

${ }^{9}$ Economic growth alone will not lead to rapid reductions in poverty. The PRS consultative process revealed the importance that Liberians attach to improved education and health services, as well as employment opportunities. The Government is determined to build institutions that can provide quality social services across the country, both to immediately benefit Liberians and to build the foundation for a stronger and more highly skilled labor force in the future. The Government will work to build a public education system that provides better local control over schools, raises the quality of teachers, and promotes learning achievement among all students. It will continue to revitalize health services to increase access, fight major diseases, and reduce malnutrition and maternal and child mortality.

${ }^{10}$ In addition to promoting prosperity and improving the delivery of basic services, the Government is determined to help all Liberians move beyond the divisions of the past and establish the foundation for responsible institutions of justice, human rights, and governance. The Government wishes to build an inclusive and highly participatory democracy with strong systems of governance in which rights are respected (especially those of women, children and youth, and persons with disabilities), people are engaged in the governance process, institutions serve the public good, and national resources are used for the benefit of all.

${ }^{11}$ Achieving these goals requires building new systems of government, based on accountability, transparency, and the rule of law. There are three key pieces to this effort: strengthening the core capabilities of the executive branch, building the capacity of the Judiciary and Legislature and enhancing their oversight role, and progressively decentralizing government functions across the counties. First, Liberia aims to build a smaller, better paid and more professional civil service. The Government will continue to place a high priority on rebuilding its human capacity, since doing so is central to achieving all of its objectives. It will fight corruption throughout the public service and build effective systems for financial oversight and accountability, including encouraging the development of stronger civil society groups. Second, it will strengthen the judicial and legislative branches of government, and move Liberia away from a system of concentrated executive powers that fostered many of the abuses of the past. Third, it will work to build capacity within local government and progressively shift economic and political power to the counties and communities, so they will be empowered to participate effectively in decision-making and take control of local issues and development processes. 
${ }^{12}$ These goals are ambitious. They will not be fully accomplished in the three-year time frame of the PRS. But during the next three years, Liberia is determined to make significant progress and build on its strong start in this new direction. Doing so will require the strong commitment of all government actors, their partners, the private sector, and civil society organizations. Most importantly, it will require the continued efforts of the Liberian people, including those in the Diaspora. Liberia's future is primarily in the hands of its people, not the Government or its partners. The programs and initiatives described in the remainder of this document are aimed at bringing together all the key actors to build the foundation for poverty reduction, growth, and inclusive development.

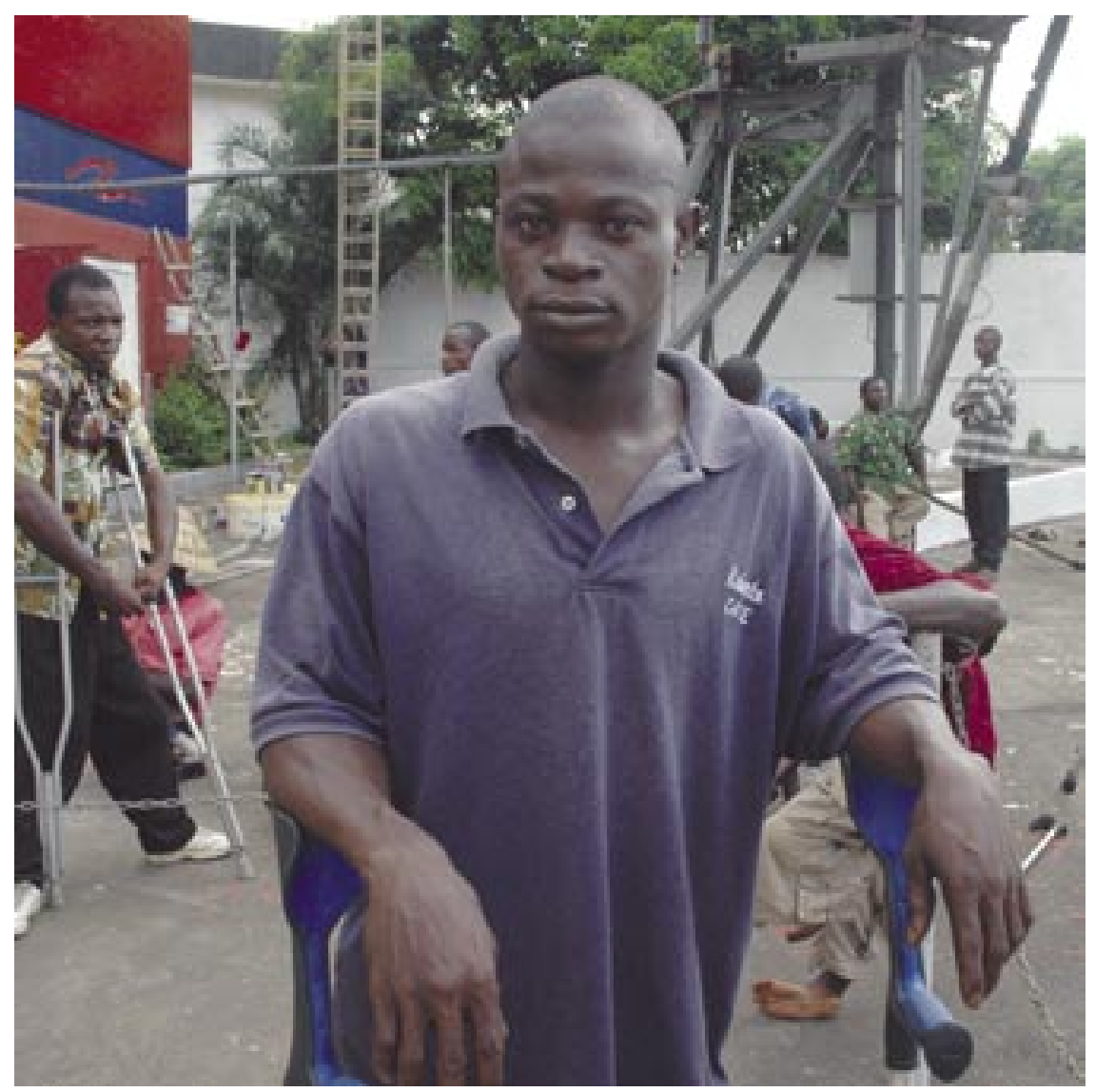




\section{Poverty in Liberia: The Current Context}

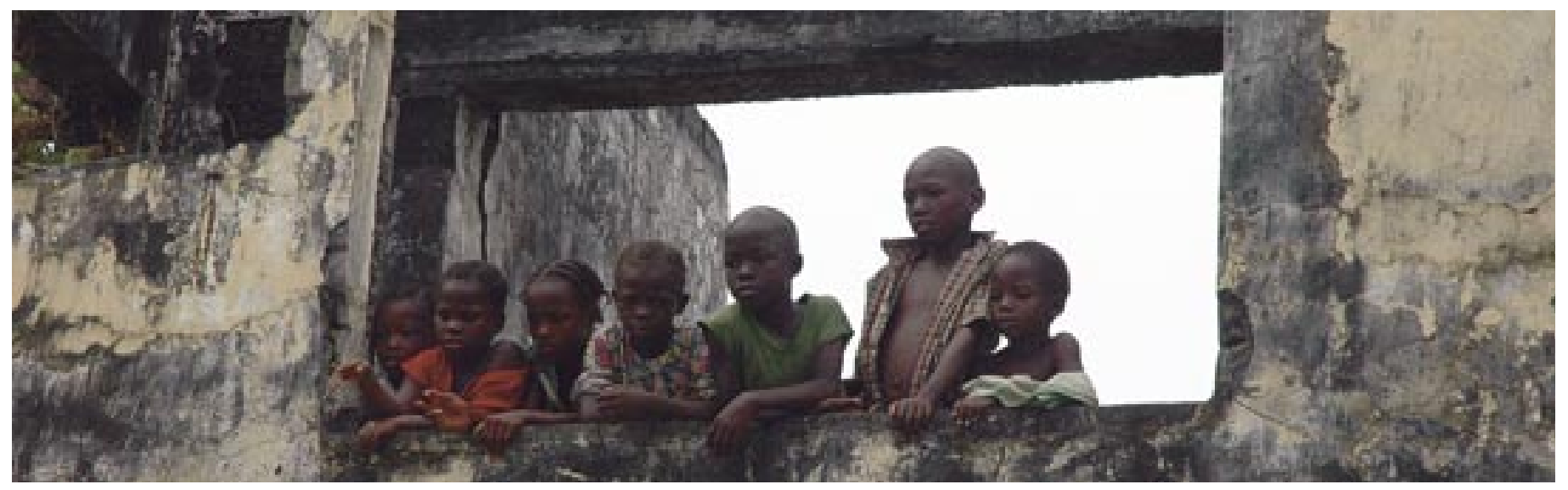

\subsection{Introduction}

${ }^{1}$ Years of conflict and mismanagement have left Liberia one of the poorest countries in the world, with GDP per capita estimated at US\$190.2 Poverty is pervasive, and is particularly acute in rural areas and the most remote corners of the country. Poverty has many dimensions, including low levels of income and consumption, poor nutrition and food security, low health and education indicators, and inadequate infrastructure. It is reinforced by inequities, especially in access to justice and economic opportunities. This chapter examines the available information on key characteristics of poverty in Liberia.

\subsection{Methods of Measuring Poverty and Sources of Data}

${ }^{2}$ When Liberia developed its interim PRS (iPRS) in late 2006, there was little reliable information on poverty across the country. In preparation for the full PRS in 2007, three new sources of data became available. First, the Liberian Institute of Statistics and Geolnformation Services (LISGIS) carried out a Core Welfare Indicator Questionnaire (CWIQ) survey in collaboration with various partners. ${ }^{3}$ The CWIQ surveyed 3,600 households, covering every region, demographic group, income level, and household type. It gathered detailed information on both objective measures and perceptions of poverty. It focused primarily on consumption, and collected complementary data on household composition by size and age, education levels, occupation, and access to basic services.

${ }^{3}$ Second, the 2007 Liberia Demographic and Health Survey (LDHS) collected data from a nationally representative sample of over 7,000 households between December 2006 and April 2007.4 The LDHS focused on population and health, and included information on fertility levels and preferences, family planning practices, sexual activity, nutrition levels, maternal and child health, domestic violence, and awareness and prevalence of HIV and AIDS.

${ }^{4}$ Third, a Participatory Poverty Assessment (PPA) survey was conducted, ${ }^{5}$ which elicited perceptions of poverty based on direct information provided by the Liberian people themselves. The PPA complements other surveys by providing a basis to qualitatively define poverty across all 15 counties.

${ }^{5}$ The information from these three sources, combined with other data and analyses, provide an initial

\footnotetext{
${ }^{2}$ Government and IMF staff estimates based on incomplete data. (See box, Chapter Ten.)

${ }^{3}$ Core Welfare Indicators Questionnaire Survey 2007: Preliminary Results, LISGIS, December 10, 2007.

${ }^{4}$ LISGIS, MoHSW, NACP, and MEASURE DHS (Macro International), Liberia Demographic and Health Survey 2007: Preliminary Report, July 2007.

${ }^{5}$ References to PPA connote data drawn from LISGIS, First Revised/Edited Draft Liberia PPA Preliminary Analysis, March 5, 2008
} 
outline of the nature and scope of poverty in Liberia. In all three cases, however, the results should be seen as preliminary. They can be compared with earlier estimates of poverty, but only with caution, as earlier approaches used different methodologies and their results may have been skewed by effects related to the conflict.

${ }^{6}$ LISGIS and other institutions are therefore in the process of collecting more detailed data on the correlates and causes of poverty, and their trends over time. Of particular importance will be the March 2008 Population and Housing Census, ${ }^{6}$ the first national census since 1984. Despite these limitations, the data that are now available provide solid initial estimates of the dimensions of poverty in Liberia in 2007.

\subsection{Income and Consumption Dimensions of Poverty}

\subsubsection{Measuring Rural and Urban Poverty Lines}

${ }^{7}$ The CWIQ survey focused on consumption (per equivalent adult) rather than income, for two reasons. First, consumption is better measured in household surveys than income, especially since net income is difficult to measure where most of the population works in the informal sector. Second, consumption is a better indicator than income of welfare and a household's standard of living.

${ }^{8}$ The survey calculated rural and urban poverty lines based on the cost of basic needs, in two parts. First, it estimated urban and rural food poverty lines derived from the cost of a food basket providing 2,400 Kcal per day per adult equivalent. Second, it computed non-food poverty lines by estimating the non-food spending of households whose food expenditures were within five percent of the food poverty line. The total poverty line is the sum of the two, while the food poverty line is the basis for measuring "extreme" poverty. The poverty line estimates are shown in Table 3.1.

Table 3.1: Poverty Lines for Liberia, 2007 (annual, per equivalent adult)

\begin{tabular}{|c|c|c|c|c|c|c|}
\hline & \multicolumn{2}{|c|}{$\begin{array}{c}\text { Food Poverty Line } \\
\text { (Extreme Poverty) }\end{array}$} & \multicolumn{2}{c|}{ Non-Food Poverty Line } & \multicolumn{2}{c|}{ Total Poverty Line } \\
\hline & LD & USD $^{*}$ & LD & USD $^{*}$ & LD & USD $^{*}$ \\
\hline Rural & 14,514 & 242 & 6,910 & 115 & 21,424 & 357 \\
\hline Urban & 14,431 & 241 & 15,793 & 263 & 30,224 & 504 \\
\hline
\end{tabular}

* based on an exchange rate of LD/USD $=60 / 1$.

Source: CWIQ 2007

\subsubsection{Estimates of the Extent of Consumption Poverty}

${ }^{9}$ The main finding of the CWIQ is that 63.8 percent of Liberians live below the poverty line (Table 3.2). This implies that 1.7 million Liberians are living in poverty. Of these, about 1.3 million people are living in extreme poverty, equivalent to 48 percent of the population. Poverty is higher in rural areas (67.7 percent) than in urban areas (55 percent). ${ }^{7}$ Since about 70 percent of the population lives in rural areas, about three-quarters (73 percent) of the poor live in rural areas.

\footnotetext{
${ }^{6}$ Data collect

7 In Liberia, the urban areas are defined as the capitals of the 15 counties and Monrovia.
} 
Table 3.2: Liberia 2007 Poverty Profile (based on consumption per equivalent adult)8

\begin{tabular}{|l|c|c|c|c|c|c|c|c|}
\hline \multicolumn{4}{|c|}{ Poverty Headcount } & \multicolumn{2}{c|}{ Share of the Population } & $\begin{array}{c}\text { Number of } \\
\text { Poor }\end{array}$ & $\begin{array}{c}\text { Contribution to } \\
\text { Poverty }\end{array}$ \\
\hline & Urban & Rural & National & Urban & Rural & National & National & National \\
\hline National & $\mathbf{5 5 . 1}$ & $\mathbf{6 7 . 7}$ & $\mathbf{6 3 . 8}$ & $\mathbf{1 0 0}$ & $\mathbf{1 0 0}$ & $\mathbf{1 0 0}$ & $\mathbf{1 7 2 5 8 0 6}$ & 100 \\
\hline $\begin{array}{l}\text { Urban/rural } \\
\text { location }\end{array}$ & & & & & & & & \\
\hline Urban & 55.1 & - & 55.1 & 30.9 & - & 30.9 & 459570 & 26.6 \\
\hline Rural & - & 67.7 & 67.7 & - & 69.1 & 69.1 & 1266236 & 73.4 \\
\hline Region & & & & & & & & \\
\hline Greater Monrovia & 48.5 & - & 48.5 & 71.4 & - & 22 & 288695 & 16.7 \\
\hline North Central & 57.5 & 68.9 & 68.1 & 8.1 & 48.2 & 35.8 & 660129 & 38.3 \\
\hline North Western & 82.4 & 75.5 & 76.3 & 3.7 & 12.8 & 10 & 206547 & 12 \\
\hline South Central & 74.4 & 55.9 & 58.9 & 8.9 & 19.9 & 16.5 & 262678 & 15.2 \\
\hline South Eastern A & 76.7 & 76.6 & 76.7 & 5.6 & 10.2 & 8.8 & 181713 & 10.5 \\
\hline South Eastern B & 79.2 & 65.9 & 67.2 & 2.3 & 9 & 6.9 & 126044 & 7.3 \\
\hline $\begin{array}{l}\text { Age of the } \\
\text { individual }\end{array}$ & & & & & & & & \\
\hline Less than 10 & 57.5 & 65.4 & 63.3 & 25.0 & 30.9 & 29.1 & 498036 & 28.9 \\
\hline 10 thru 19 & 57.6 & 72.5 & 67.4 & 26.5 & 22.7 & 23.8 & 434748 & 25.2 \\
\hline 20 thru 29 & 51.1 & 66.1 & 61.0 & 18.2 & 15.6 & 16.4 & 270650 & 15.7 \\
\hline 30 thru 39 & 50.8 & 65.1 & 60.2 & 13.7 & 11.9 & 12.4 & 202640 & 11.7 \\
\hline 40 thru 49 & 52.7 & 69.4 & 64.3 & 9.3 & 9.4 & 9.4 & 163259 & 9.5 \\
\hline 50 thru 59 & 57.2 & 67.3 & 64.5 & 4.2 & 4.8 & 4.6 & 80699 & 4.7 \\
\hline 60 and Over & 60.3 & 68.0 & 66.2 & 3.1 & 4.7 & 4.2 & 75775 & 4.4 \\
\hline $\begin{array}{l}\text { Gender of the } \\
\text { head }\end{array}$ & & & & & & & & \\
\hline Male & 54.1 & 68.8 & 64.6 & 70 & 76.2 & 74.3 & 1297787 & 75.2 \\
\hline Female & 57.2 & 64.1 & 61.6 & 30 & 23.8 & 25.7 & 428019 & 24.8 \\
\hline
\end{tabular}

Source: Calculated using CWIQ 2007, LISGIS

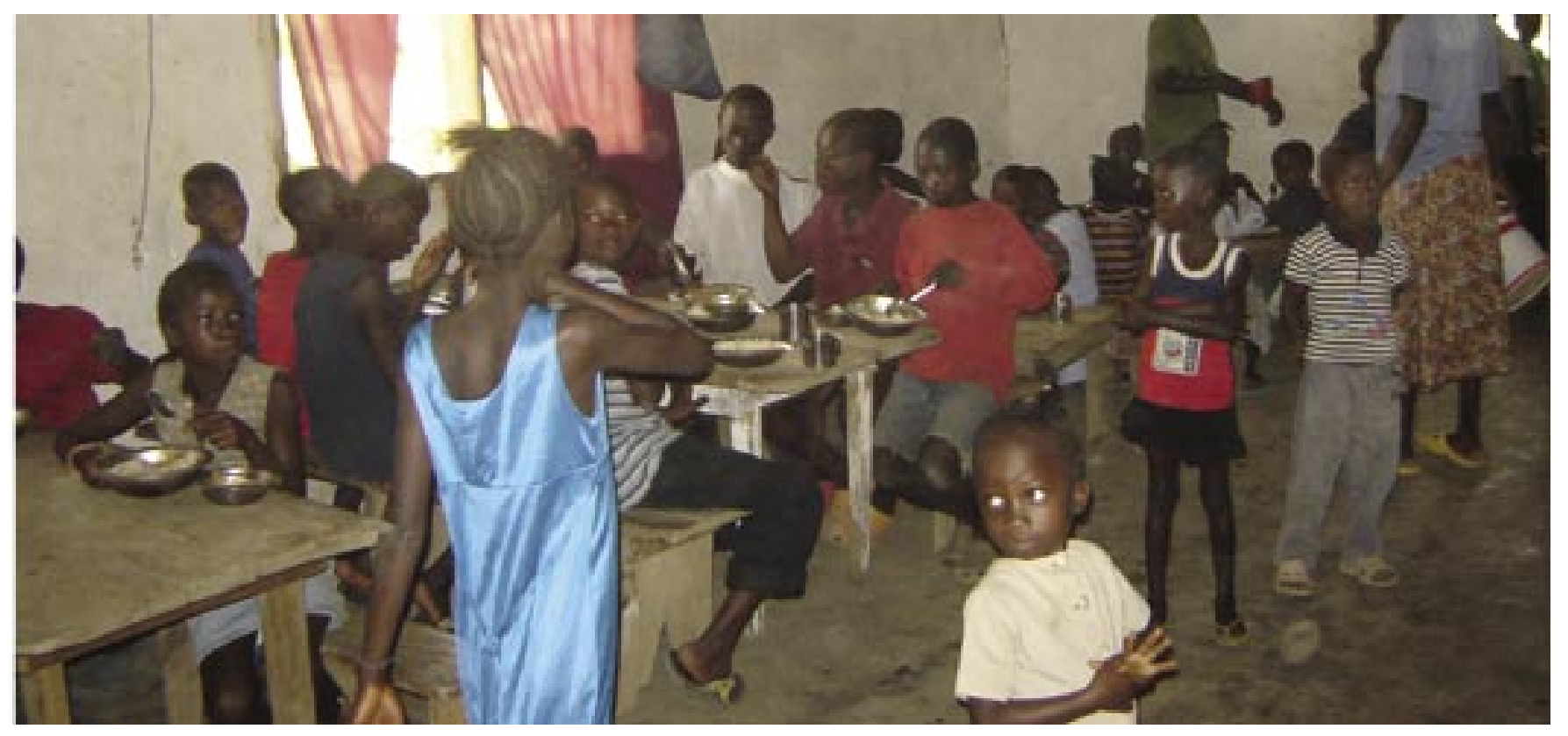

8 More demographic and other information will be available on completion of the 2008 Census.

CInternational Monetary Fund. Not for Redistribution 
${ }^{10}$ The poverty headcount indices are highest in the Southeastern A region (77 percent) and Northwestern region (76 percent), followed by the North Central region (68 percent) and the Southeastern $B$ region (67 percent) (see Figure 3.1). The North Central region, which contains a much larger share of the population than other regions, has by far the largest number of people living in poverty: 660,000, or about 38 percent of the national total. These statistics are consistent with findings of the PRS County Consultations.

Figure 3.1: Poverty Head Count9

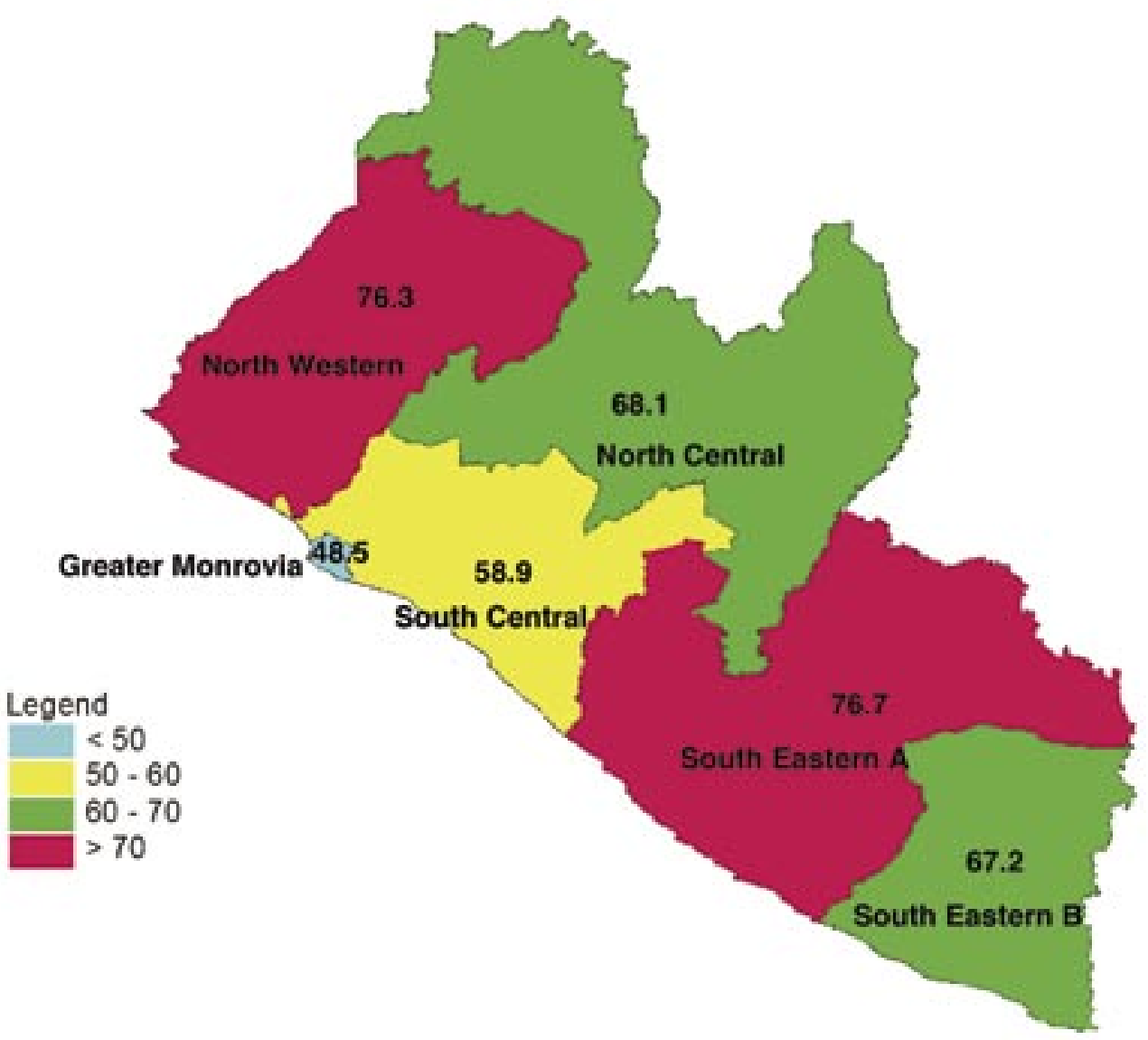

Source: LISGIS 2007

${ }^{11}$ According to the CWIQ results, there are only small differences in poverty measures by the gender of the head of the household, small enough to fall within the sampling margin of error. The survey finds that 65 percent of male-headed households live below the poverty line, compared to 62 percent of female-headed households. Similarly, the PPA found that women are perceived as having a lower poverty incidence than men (42 percent to 53 percent). Over two-thirds of PPA respondents perceive men and women to have equal opportunities for employment. Some believe women are favored in the workplace and that they are more likely to participate in economic activity (particularly agricultural labor) to provide food for the family. Despite the perceptions, the reality is that women remain vulnerable to poverty in many dimensions. The majority of female labor in Liberia is unpaid and concentrated in the informal sector, and this work is characterized by insecurity and low productivity. While Liberian women are very active in the labor market, the nature of their work may not necessarily lead them to a sustained path of poverty reduction. Moreover, the incidence of gender based violence (GBV) is high in Liberia (particularly rape and sexual assault, especially of minors), limiting women's and girls' ability to cope with poverty and lead a safe life (See box on GBV, Chapter Six). ${ }^{10}$ When other non-income

\footnotetext{
9 The North Western region comprises Bomi, Gbarpolu and Grand Cape Mount counties. The North Central region comprises Bong, Lofa and Nimba counties. The South Central region comprises Grand Bassa, Margibi and Montserrado counties. The South Eastern A region comprises River Cess, Sinoe and Grand Gedeh counties. The South Eastern B region comprises Grand Kru, Maryland and River Gee counties. The Greater Monrovia region comprises the city of Monrovia and its suburbs.

10 LISGIS, First Revised/Edited Draft Liberia PPA Preliminary Analysis, March 5, 2008
} 
dimensions of poverty are taken into account, the vulnerability of women and girls becomes even more apparent, as described below.

${ }^{12}$ There is relatively little variation in the incidence of poverty across age groups, although at $67.4 \%$ the percentage below the poverty line is highest among children/youth aged 10-19. (See Table 3.2.) A higher level of education of the household head is associated with lower levels of poverty, and poverty levels are highest for those engaged in fishing, crop farming, mining/quarrying, and those who are unemployed or inactive. By contrast, poverty levels are lowest for those in the banking and financial sector, followed by employees of utilities, and poverty levels are lower where heads of households have a second occupation.

\subsubsection{Household Perceptions of Poverty}

${ }^{13}$ The results of the CWIQ survey and the PPA are broadly similar, which increases confidence in the overall emerging picture.

- First, households were asked about the level of income or consumption they deemed necessary in order to satisfy one's needs. ${ }^{11}$ The average answers were close to the computed poverty lines: LD 21,540 annually for rural households and LD 29,420 annually for urban households.

- Second, the share of the population in which the head of the household said he or she was "living with difficulty" (as opposed to "living carefully," "living reasonably well," or "living very well") was 58 percent, broadly similar to the headcount index of 63.8 percent. ${ }^{12}$ In addition, 48 percent of CWIQ respondents perceived their households to be "threatened by poverty". ${ }^{13}$ Families perceived to be living in extreme poverty cite loss of a parent, inadequate government support, illiteracy/limited education, lack of farming equipment, lack of access to credit, and large family size as reasons for their plight. ${ }^{14}$

- Third, in rural areas, farmers, hunters, female-headed households, returnees and disabled persons are perceived to be the poorest, while former warlords, ex-combatants and their relatives are perceived to be the best off. In urban areas, the uneducated, unskilled workers, orphans/youth, disabled persons, returnees and large families are perceived to be the poorest. By contrast, government officials, owners of big businesses, NGO workers, and professionals are perceived to be the wealthiest. 15 This is similar to the CWIQ, which found the well-educated to be financially better off and more traditional laborers and socially disadvantaged to be poorer.

- Fourth, perceptions differed between rural and urban areas in answering the question 'What does it mean to be poor?' According to the PPA, the rural population perceives poverty as a lack of material objects, roads, market access, social structures and services, employment, housing, food and a large family size. In the urban areas, people associate poverty with unemployment, low income, high costs for medicine and education, limited market access and sanitation.

\subsection{Non-Income Dimensions of Poverty}

${ }^{14}$ The situation with respect to non-income dimensions is mixed. While the majority of Liberians-particularly the rural poor-perceive the security situation to be much better now than it was a year ago, they continue to express major concerns with the lack of access to basic services, markets, and food; high unemployment rates; poor housing; quality and coverage of basic infrastructure; and the quality of gov-

\footnotetext{
11 CWIQ, 2007

12 CWIQ, 2007

13 LISGIS, First Revised/Edited Draft Liberia PPA Preliminary Analysis, March 5, 2008

14 LISGIS, First Revised/Edited Draft Liberia PPA Preliminary Analysis, March 5, 2008

15 LISGIS, First Revised/Edited Draft Liberia PPA Preliminary Analysis, March 5, 2008
} 
ernance. There are some areas of progress: gross primary school enrolment is high at approximately 90 percent, and under- 5 mortality is on the decline. 16

\subsubsection{Infrastructure}

${ }^{15}$ Liberia's infrastructure was severely damaged by the war. Most Liberians have no access to electricity, improved water and sanitation facilities, acceptable housing, or decent roads. Weak infrastructure undermines income earning opportunities, limits access to health and education facilities, raises the price of goods and services, and weakens food security. Women and children bear a large burden as a result of poor infrastructure, as they must spend more time carrying water and other goods; are more vulnerable to crime; and have less access to health facilities, raising the risk of child and maternal mortality. Persons with disabilities are also disproportionately disadvantaged.

${ }^{16}$ Perhaps the most critical infrastructure problem is roads, which Liberians across the country consistently placed at the top of their priorities during PRS consultations. Currently there is only around 700 $\mathrm{km}$ of paved road surface, almost all of which is damaged, and $1600 \mathrm{~km}$ of unpaved roads, which are mostly in need of repair. Farm-to-market access is of paramount concern, and parts of the country remain cut off during the rainy season. It takes at least an hour for most rural dwellers to access a food market or the nearest potential transport option. Roads are central to reducing poverty, as they open up income-earning opportunities for the poor, improve access to health and education facilities, reduce transport costs and commodity prices, and help strengthen local governance.

${ }_{17}$ Other transportation infrastructure is equally weak. Many bridges have been damaged and need rebuilding or repair. The limited railway network has not been operational for nearly 20 years. Civil aviation is limited to Monrovia with only UN flights operating upcountry. The Port of Monrovia is operational, but badly damaged and in need of urgent repairs.

${ }^{18} \mathrm{At}$ the time of the election, there had been no electricity (except from small private generators) or piped water anywhere in Liberia for 15 years. The Government restored power to parts of Monrovia in July 2006, and a further expansion is expected in April 2008. Most Liberians use palm oil, kerosene and candles for light. While significant progress has been made since the end of the war, still only 25 percent of Liberians have access to safe drinking water and just 15 percent have access to human waste collection and disposal facilities. ${ }^{17}$ Most residents do not treat or boil their water, which has grave implications for the health and nutritional status of the population. Garbage collection is minimal to nonexistent. 18

${ }^{19}$ Many Liberians live in sub-standard housing. The war sparked massive internal displacements, with Monrovia hosting the majority of the IDPs. There is a huge mismatch between the number of urban dwellers and available social services, leading to overcrowding, deteriorating living conditions, and the growth of slums and illegal home occupation. Over a third of the population cannot afford to honor their rent payments, contributing to a high incidence of squatting.

\subsubsection{Food Security and Nutrition}

${ }^{20}$ Food insecurity is high in Liberia and is evident in the poor nutritional status of the population. The Comprehensive Food Security and Nutrition Survey (CFSNS) carried out in March 2006 found that 11 percent of households in rural/semi-urban Liberia are food insecure, while the figure reaches as high as 28 percent in the areas most affected by the war and displacements. Additionally, 40 percent of the population was found to be either highly or moderately vulnerable to food insecurity. The geographically isolated counties in the Southeast are particularly vulnerable to chronic food insecurity. Female-headed households (and the children who live in them) are also more food insecure and spend a greater proportion of their income on food than male-headed households. Over two-thirds of households report

\footnotetext{
${ }^{16}$ Gross primary school enrol $\square$

17 Extrapolated by the joint Government-NGO Working Group on Water and Sanitation using a 2004 UNICEF survey as the base. These are the baseline indicators for the Government's strategic objectives in Water and Sanitation, including the MDGs.

18 LISGIS, First Revised/Edited Draft Liberia PPA Preliminary Analysis, March 5, 2008
} 
${ }^{21}$ Two out of five Liberian children are growth-stunted and almost 20 percent are underweight. According to one estimate, the failure to resolve key nutritional problems facing children and women in Liberia could lead to economic productivity losses of more than US\$431 million over the next nine years. Additionally, anemia, vitamin A deficiency and low body weight are serious factors contributing to child and maternal morbidity and mortality. 20

${ }^{22}$ Food insecurity and malnutrition are primarily caused by poor access to health, water and sanitation services, inad-

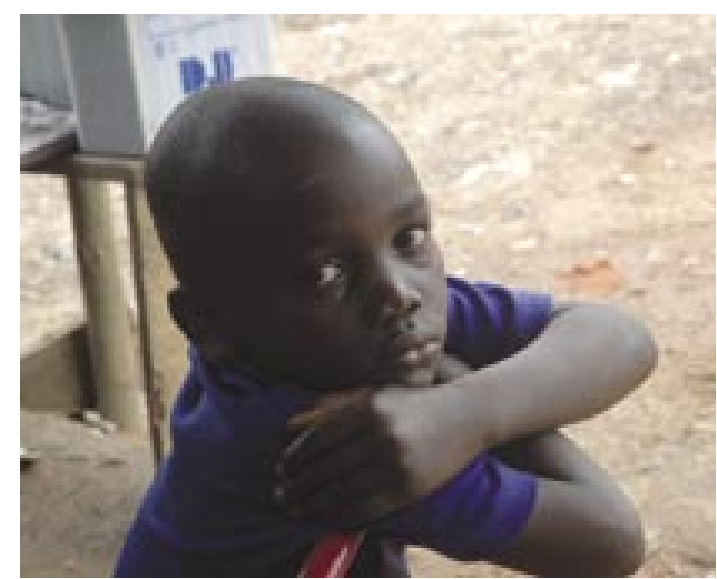
equate care of mothers, infants and young children, and limited availability and access to food resulting from low agricultural productivity, poor road infrastructure and limited income generating opportunities. Low agricultural productivity is due in part to the majority (53 percent) of rural farms being small, ranging in size from 1 to 4.9 acres. ${ }^{21}$ Also, about 45 percent of rural households do not own land,22 which limits their access to capital for investment, production and income.

\subsubsection{Health}

${ }^{23}$ Poor health contributes significantly to poverty in Liberia, and health systems are in a state of disrepair in the aftermath of the conflict. Life expectancy at birth is just 45 years. ${ }^{23}$ There are only 51 Liberian physicians and 297 nurse midwives (excluding trained traditional midwives) to cover public health needs. Out of the 325 health facilities available before the war, about 95 percent were partially or wholly destroyed. A survey undertaken in 2006 indicated that only 10 percent of communities reported having a health facility within the community, and more than 50 percent of PPA respondents claim to have no health facility in their community. ${ }^{24}$ Liberians' major concerns about the health sector revolve around their lack of financial and physical access to healthcare, as well as quality of healthcare delivery. In general, healthcare is more accessible and of better quality in urban areas than rural areas.

${ }^{24}$ Several key health indicators have begun to improve since the end of the conflict, but remain poor. In particular, infant and under-five mortality rates have fallen sharply since 1999/2000 (Table 3.3). The infant mortality rate fell from 117 to 72 deaths per 1,000 live births, while under-five mortality fell from 194 to 111 deaths per 1,000 births. These declines can be attributed primarily to the end of the conflict, the restoration of basic services in some areas and increased immunization.

${ }^{25}$ Maternal mortality remains high and appears to have increased in recent years from 578 (Year 2000) to 994 (Year 2007) deaths per 100,000 live births. ${ }^{25}$ The main health factors contributing to the high level of maternal mortality include the acute shortage of skilled labor, inadequate emergency obstetric care, inefficient referral systems, poor nutritional status of pregnant women, high fertility rates and extremely high numbers of teenage pregnancies. Moreover, less than half of births are attended to by health professionals. (See Table 3.3.)

${ }^{26}$ Although the total fertility rate in Liberia has decreased over the past two decades, fertility remains high at 5.2 children per woman and fertility in rural areas is significantly higher than in urban areas (6.2 chil-

\footnotetext{
19 LISGIS, First Revised/Edited Draft Liberia PPA Preliminary Analysis, March 5, 2008

20 Data in this paragraph come from MoHSW/AED/World Food Program, Nutrition Policy Analysis using PROFILES: Investing in Nutrition to Reduce Poverty, December 2007.

${ }^{21}$ CWIQ, 2007

22 CWIQ, 2007

23 Data in this paragraph come from the 2006 CFSNS, except as noted.

24 LISGIS, First Revised/Edited Draft Liberia PPA Preliminary Analysis, March 5, 2008

25 LDHS, 2000 \& 2007
} 
dren per woman as compared to 3.8).2 Preliminary information from the 2007 LDHS suggests a high unmet need among married women for both spacing and limiting births. In Lofa County, one of those most affected by conflict, a reproductive health survey revealed a teenage pregnancy rate of over 68 percent among 15 to 19 year olds. ${ }^{27}$ This is a very high rate, especially in a country in which 51 percent of the population is below 25 years of age.

${ }^{27} \mathrm{HIV}$ prevalence is estimated at 1.5 per cent. ${ }^{28}$ The rate was found to be higher for women (1.8 percent) than for men (1.2 percent). Paradoxically, the HIV prevalence rate was recorded to be higher among persons with some level of education (2.1 percent for persons with secondary or higher levels of education and 1.3 percent for persons with only a primary level of education) than for persons with no form of education (1.0 percent). The likely explanation is that persons with some form of education are mostly based in urban areas, where the prevalence rate is higher. Although the HIV prevalence rate is higher for persons between the ages of 25 to 39 years, about 0.9 percent of young people 15 to 19 years old and 1.4 percent of persons 20 to 24 years old were found to be HIV positive.

${ }^{28}$ Earlier sources of data, especially antenatal hospital records, indicated higher infection rates among pregnant women aged 15 to 24 years of age. While the results remain controversial, studies of these records showed an increase from 4.2 percent in 1994 to 12.9 percent in 2000. According to the PPA survey, a majority of people understand how HIV and AIDS spreads, and cite condoms or monogamy as prevention mechanisms. The vast majority (84 percent) feel compassion for people living with HIV and AIDS, although many are afraid that association with PLWHAs might lead to infection.29 More information on the HIV prevalence rate is expected to be received during the PRS period.

\section{Table 3.3: Basic Health Indicators}

\begin{tabular}{|l|c|c|}
\hline Indicator & $1999 / 00$ & 2007 \\
\hline Mortality Rates & & \\
\hline Infant (per thousand) & 117 & 72 \\
\hline Under 5 (per thousand) & 194 & 111 \\
\hline Maternal (per 100,000 live births) & 578 & 994 \\
\hline Births Attended by Health Professional* (\%) & & \\
\hline National & 50.9 & 46.4 \\
\hline Rural & 82.4 & 78.8 \\
\hline Urban & 36.7 & 32.2 \\
\hline
\end{tabular}

*Doctor, nurse, midwife, or physician's assistant.

Source: LDHS 2007 and LDHS 1999/2000

\subsubsection{Education}

${ }^{29}$ Liberia's educational system is beginning to improve, but remains weak. About 70 percent of schools were damaged or destroyed during the war, and most schools lack books and other basic equipment. Many teachers have little or no training, and teacher attendance is low, at least partly due to low wages. In addition, there are substantial rural-urban differentials in education. However, there is little differential by gender in net primary enrolment (38 percent male to 37 percent female) and secondary school enrolment (16 percent

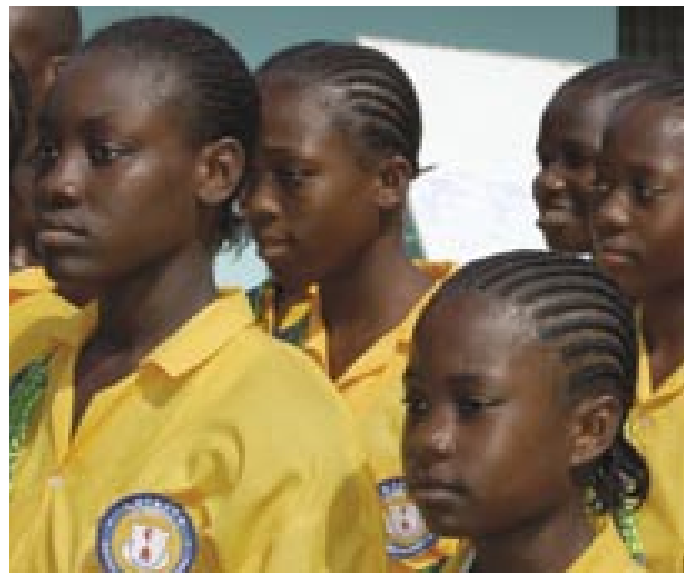

\footnotetext{
${ }^{26}$ LDHS, 2007

27 CDC, JSI, and UNFPA, 2007

28 LDHS, 2007

29 LISGIS, First Revised/Edited Draft Liberia PPA Preliminary Analysis, March 5, 2008
} 
male to 14 percent female).30 In spite of these gains among youth, adult literacy rates display a gap: outside of Monrovia, only about one-third of women are literate, compared to about 60 percent of men.

Table 3.4: Education and Literacy

\begin{tabular}{|l|c|c|c|c|c|}
\hline & $\begin{array}{c}\text { Net Primary } \\
\text { School } \\
\text { Enrolment } \\
\text { (ages 6-11) (\%) }\end{array}$ & $\begin{array}{c}\text { Net Secondary } \\
\text { School Enrolment } \\
\text { (ages 12-17) (\%) }\end{array}$ & \multicolumn{2}{|c|}{$\begin{array}{c}\text { Adult Literacy Rate, 15+ years } \\
\text { (\%) }\end{array}$} \\
\cline { 1 - 5 } & 37 & 15 & 69 & 41 & 55 \\
\hline Total & 48 & 25 & 85 & 63 & 74 \\
\hline Urban & 33 & 10 & 61 & 31 & 45 \\
\hline Rural & & & & & \\
\hline Region & 50 & 27 & 88 & 67 & 77 \\
\hline Greater Monrovia & 31 & 12 & 64 & 34 & 49 \\
\hline North Central & 49 & 11 & 54 & 31 & 42 \\
\hline North Western & 26 & 12 & 63 & 33 & 48 \\
\hline South Central & 34 & 7 & 56 & 28 & 42 \\
\hline South Eastern A & 46 & 12 & 76 & 39 & 57 \\
\hline South Eastern B & & & & & \\
\hline
\end{tabular}

Source: CWIQ 2007

${ }^{30}$ Public primary gross school enrollments have increased by 82 percent in the last two years but remain low. Secondary and tertiary enrollment rates are even lower. Costs remain a barrier to education, despite the Government's Free and Compulsory Primary Education initiative. Many schools still collect unofficial fees, and the costs of uniforms and other supplies make education unaffordable for many families. In addition, many Liberians criticize the quality of educational facilities, including the availability of textbooks and qualifications of teachers.

\subsection{Liberia and the Millennium Development Goals}

${ }^{31}$ The Millennium Development Goals (MDGs) are a set of eight goals that the international community has agreed to try to achieve by 2015 to respond to some of the world's major development challenges. The eight goals range from halving extreme poverty to halting the spread of HIV and AIDS to providing universal primary education. They were established in 2000 and normally use 1990 as the benchmark for measuring progress for the 25-year period 1990-2015.

${ }^{32}$ Achieving the MDGs will be a challenge for many developing countries, but it will be even more difficult for Liberia because of the legacy of the war. While most countries were making at least some progress toward the Goals between 1990 and 2003, Liberia was moving dramatically backwards and losing the capacity needed to achieve the Goals. All of Liberia's indicators were worse in 2000 than they were in 1990. Thus, to achieve any of the Goals, Liberia must make larger gains in a shorter period of time than almost any other country. Nevertheless, the Government has been making steady progress toward the MDGs through a series of policies implemented in the 150-Day Action Plan and iPRS.

${ }^{33}$ Liberia's status on the eight MDG goals and the likelihood that it will achieve the MDGs by 2015 is shown in Table 3.5. This overview was compiled using data from the CWIQ, the LDHS, the Comprehensive Food Security and Nutrition Survey (CFSNS, 2006), the UN Statistical Database and other sources. Due to significant demographic changes and the unreliability of data compiled during the 
period of the conflict, the base year for trend projections is the year 2000 or the closest year possible.

${ }^{34}$ The first and most important Goal is to reduce poverty by half by 2015 . In Liberia's case, this would imply reducing the poverty headcount index from 63.8 percent to about 32 percent over the next seven years. Unfortunately, this is not realistically possible - it would require the fastest reduction in poverty ever recorded in the world.

${ }^{35}$ Nevertheless, Liberia can achieve a reduction in poverty that is at least consistent with the spirit of the MDGs. The original intent of the MDGs was to reduce the poverty rate by 50 percent over 25 years or roughly 2 percent per year. In the case of Liberia, a 2 percent annual reduction in a headcount index of 63.8 percent translates into a reduction of approximately 1.3 percentage points per year, 31 or about 4 percentage points over the three years of the PRS. This would bring the poverty headcount index to about 60 percent by 2011. Liberia can, and should, achieve this rate of poverty reduction (or even faster) during the PRS period and beyond, based on the projected economic growth rate (over 10 percent annually) and the policy actions described in this strategy. So while Liberia will not achieve the MDG on poverty per se by 2015 , it is likely to achieve progress consistent with the MDGs.

${ }^{36}$ With respect to the other MDGs, the outlook is similar; Liberia is likely to achieve progress consistent with or better than the MDGs, but in most cases it will not actually achieve them by 2015. Despite the obstacles, according to UN trend analysis, 32 Liberia is likely to achieve several sub-targets of the MDGs on time (See Table 3.5.):

- Halving the proportion of people that suffer from hunger;

- Eliminating gender disparities in primary and secondary education;

- Reducing by two-thirds the under-five mortality rate;

- Halting the spread of HIV and AIDS; and

- Halving the number of people without access to safe drinking water.

\subsection{Conclusion}

${ }^{37}$ Two key points emerge from this discussion. First, in the aftermath of the war, Liberia's poverty statistics are grim. Almost two-thirds of Liberians live below the poverty line, and the share is even higher in rural areas. Indicators on health, education, water, food security and infrastructure are all poor. Women are particularly vulnerable to poverty, especially in rural areas, both because of the precarious nature of women's employment and because of more limited access to basic services like health, education, and infrastructure.

${ }^{38}$ Second, since the end of the conflict Liberia has made important progress in the effort to reduce poverty. Incomes are growing, school enrolments are increasing, health clinics are reopening, and infant mortality rates are falling. The outlook is positive for further progress during the PRS period.

${ }_{39}$ The key to reducing poverty in Liberia during the PRS period will lie in achieving rapid, inclusive, and sustainable growth, as described further in Chapters Four and Seven. But rapid growth alone will be insufficient. All of the elements of Liberia's reconstruction and development strategy play a role: consolidating peace and security, revitalizing the economy, strengthening governance and the rule of law, and rebuilding infrastructure and delivering basic services. The specific details of the Government's strategy and its relationship to the poverty challenge are described in Chapters Six through Nine.

\footnotetext{
31 That is, $0.02 * 63.8 \approx 1.3$.

32 United Nations, Liberia Draft Millennium Development Goals Report 2007
} 


\section{Goal \#1: Eradicate extreme poverty and hunger}

Halve, by 2015, the proportion of people whose income is below the poverty line

Halve by 2015 , the proportion of people that suffer from hunger
$64 \%(2007)$

$64 \%(2007)$

$\sqrt{2}$

$+2$

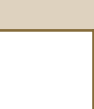

\begin{tabular}{|c|c|c|}
\hline Unlikely & Improving & Weak \\
\hline Likely & Improving & Weak \\
\hline
\end{tabular}

\section{Goal \#2: Achieve Universal Primary Education}

Ensure that, by 2015, children everywhere, boys and girls alike, will be able to complete Net primary enrolment: $37.3 \%(2007)$

Unlikely

Improving

Weak a full course of primary schooling

\section{Goal \#3: Promote gender equity and empower women}

Eliminate gender disparity in primary and secondary education, preferably by 2005 , and in all levels of education no later than 2015

\section{Net primary enrolment: $37.5 \%$ boy, $37.1 \%$ girl (2007); net secondary enrolment: $16 \%$ boy, $14.2 \%$ girl (2007)}

\section{Goal \#4: Reduce child mortality}

Reduce by two-thirds, between 1990 and 2015, the under-five mortality rate

$194 / 1,000(1999 / 2000)$

Goal \#5: Improve maternal health Reduce by three-quarters, between 1990 and 2015 , the maternal mortality ratio $578 / 100,000$ live births (1999/2000)

\begin{tabular}{l|l|l} 
Likely & Improving & Weak \\
& & \\
\end{tabular}

\section{Goal \#6: Combat HIV and AIDS, malaria and other diseases}

Have halted by 2015 and begun to reverse the spread of HIV and AIDS

Have halted by 2015 and begun to reverse the incidence of malaria and other major diseases
HIV prevalence $1.5 \%$ (2007), malaria prevalence $66 \%$ among children under five 33

\section{Goal \#7: Ensure environmental sustainability}

Integrate the principles of sustainable devel- $\quad$ Insufficient data opment into country polices and programs and reverse the loss of environmental resources

Halve, by 2015 , the number of people without sustainable access to safe drinking water and basic sanitation

Have achieved by 2020 a significant improvement in the lives of at least 100 million slum dwellers

\section{Goal \#8: Develop a global partnership for development}

Deal comprehensively with the debt problems of developing countries through national and international measures in order to make debt sustainable in the long term
HIPC Decision Point reached March 2008

\begin{tabular}{|l|l|l|}
\hline Likely & Improving & Weak \\
\hline Unlikely & Improving & Weak \\
& & \\
\hline
\end{tabular}

Safe drinking water coverage $25 \%$, basic sanitation coverage $15 \%$ $(2008)^{*}$ Insufficient data
Probably

Improving

Weak

Weak

Worsening Weak

Unlikely

Worsening

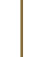




\section{Building the Foundation for Rapid, Inclusive and Sustainable Economic Growth}

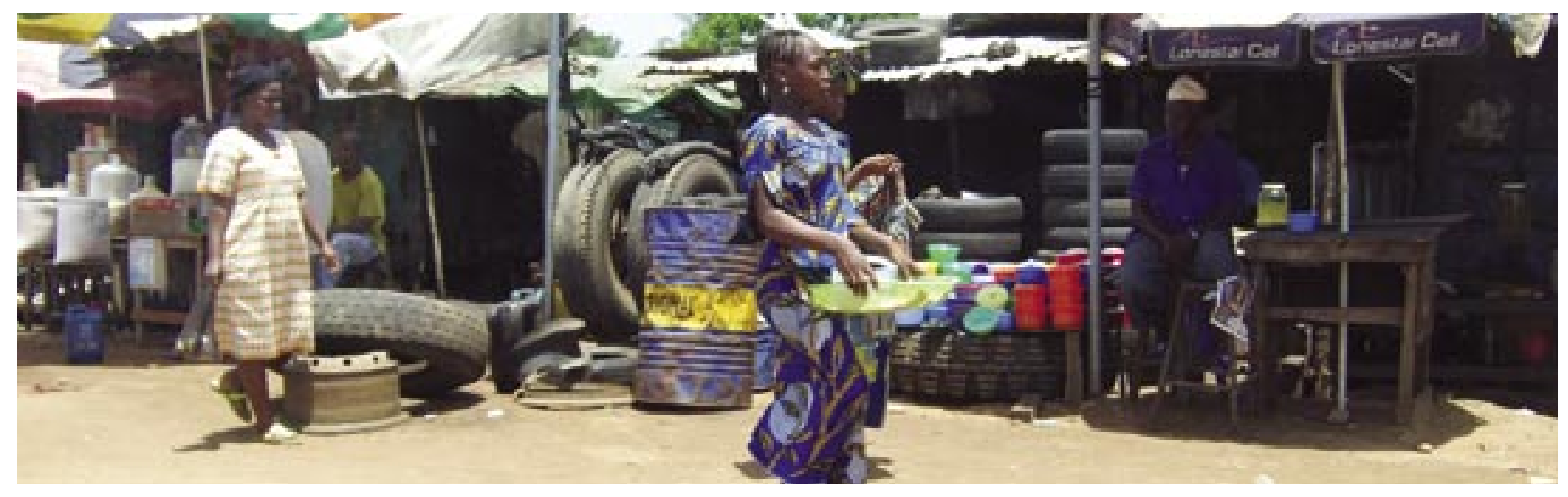

\subsection{Introduction}

${ }^{1}$ At the core of Liberia's poverty reduction strategy is rapid, inclusive and sustainable economic growth. Only through growth can individuals, households, and communities earn the income necessary to obtain the basic things they want and need: food, clothing, shelter, health care, education, and other vital goods and services. Sustained growth is also critical for making progress toward the MDGs, including reducing infant and maternal mortality, and increasing school enrolment.

${ }^{2}$ But economic growth alone does not guarantee poverty reduction and stability. Worldwide experience also shows that the structure of growth is critical; to reduce poverty and achieve the MDGs, growth must be equitable and widely shared, and create employment and economic opportunities for the poor. It must reach traditionally excluded and vulnerable groups, including the poor in isolated villages, women, children and youth, and persons with disabilities. Moreover, to reduce poverty, rapid growth must be accompanied by increased access to basic services and more inclusive governance and political structures.

${ }^{3}$ Liberia's economic history before the conflict became a classic but sad example of "growth without development", ${ }^{34}$ a story that the Government is determined not to repeat. In the decades leading up to the conflict, the country recorded relatively rapid growth. But most of the income was channeled to a small elite and there was relatively little poverty reduction for the majority of Liberians. The inequities in growth were a major source of the resentment that fueled the conflict.

${ }^{4}$ Liberia faces a range of challenges in building the foundation for rapid, inclusive and sustainable growth, including dilapidated infrastructure, weak education and health systems, malnutrition, high unemployment (especially of young men and women and persons with disabilities), inadequate skills and professional capacity, and weak governance systems. But the Government is committed to facing these challenges and creating much more equitable and inclusive economic and political structures, generating opportunities for historically marginalized groups, and widely sharing the benefits of growth and development. Liberia's economic growth strategy will focus on creating widespread private sector opportunities for unskilled and semi-skilled workers, including the unemployed, disenfranchised young men and women, and persons with disabilities, through a robust agricultural sector, down-stream pro-

34 Robert W. Clower, George Dalton, Mitchell Harwitz, and A.A. Walters, Growth Without Development: An Economic Survey of Liberia, Evanston: Northwestern University Press, 1966. 
cessing of natural resources, and in the longer term through competitive labor-intensive manufactures and services. The Government will establish a policy framework that keeps business costs low, supports long-term productivity growth, and strengthens the environment for both local and foreign investment in activities that can help integrate Liberia into competitive global markets. The private sector will be the primary driver of growth, from small family farms and roadside shops to medium and large-sized investments in agriculture, mining, construction, hotels, financial services and increasingly, light manufacturing.

\subsection{Liberia's Growth Potential}

${ }^{5}$ Liberia has a rich natural resource base, including fertile lands for agriculture and tree crops, extensive forestry resources, iron ore, gold, diamonds, and the ocean and coastal areas. Natural resource-based industries have the potential to create significant numbers of jobs, provide substantial budget revenues, and initiate rapid growth.

${ }^{6}$ Agriculture is critical, since it can create employment and income opportunities for the majority of the Liberian people, particularly young men and women. A robust agriculture sector will enhance food security, both by providing food and income to farmers and by keeping food prices low for the rest of the country. There is significant potential for growth in agriculture over an extended period, as both total output and farm yields are very low in the aftermath of the conflict. Production in traditional food crops such as rice and cassava has already begun to rebound. Rehabilitating and expanding Liberia's road network will be central to connecting farmers to markets, raising output, reducing prices for food and critical inputs, and stimulating supporting activities throughout the rural areas.

${ }^{7}$ Over the medium term, rubber, palm oil, coffee, cocoa, and other cash crops have major potential. The aging stock of rubber trees and the poor state of many plantations may constrain growth in the near term. A key challenge is to replant trees and rehabilitate the plantations to provide the basis for sustained growth over the medium term. It also will be important to improve governance in the rubber sector, formalizing those plantations that currently operate outside the law and taxation system. The production of timber and forest products should also accelerate over the next few years as new concession agreements are signed, now that UN sanctions on timber have been lifted following the Government's introduction of strong control and monitoring measures. Once again, an efficient road network will be central to sustained growth in these sectors.

${ }^{8}$ Iron ore, diamonds, and other mining activities will begin to expand rapidly in the next few years, led by the ArcelorMittal iron ore mine concession, which is expected to bring Liberia US\$1.5 billion in investment. The mining of iron ore once accounted for more than 10 percent of Liberia's GDP, but production ceased during the war. It will take several years to reach full capacity as rail and port facilities are rebuilt, but the process is now underway. Gold and diamond extraction can also expand quickly, with the latter recently boosted by the lifting of UN sanctions.

${ }^{9}$ Growth in these sectors will be complemented by expansion in construction activities, hotels, restaurants, retail trade, electricity, and other services. These activities can create significant numbers of jobs for unskilled and semiskilled workers, both men and women, and are therefore critical to ensuring that growth is inclusive and equitable. Construction is booming throughout the country as roads, bridges, houses, and other facilities are repaired or rebuilt. Other services are already rebounding quickly, and are likely to expand rapidly during the next several years.

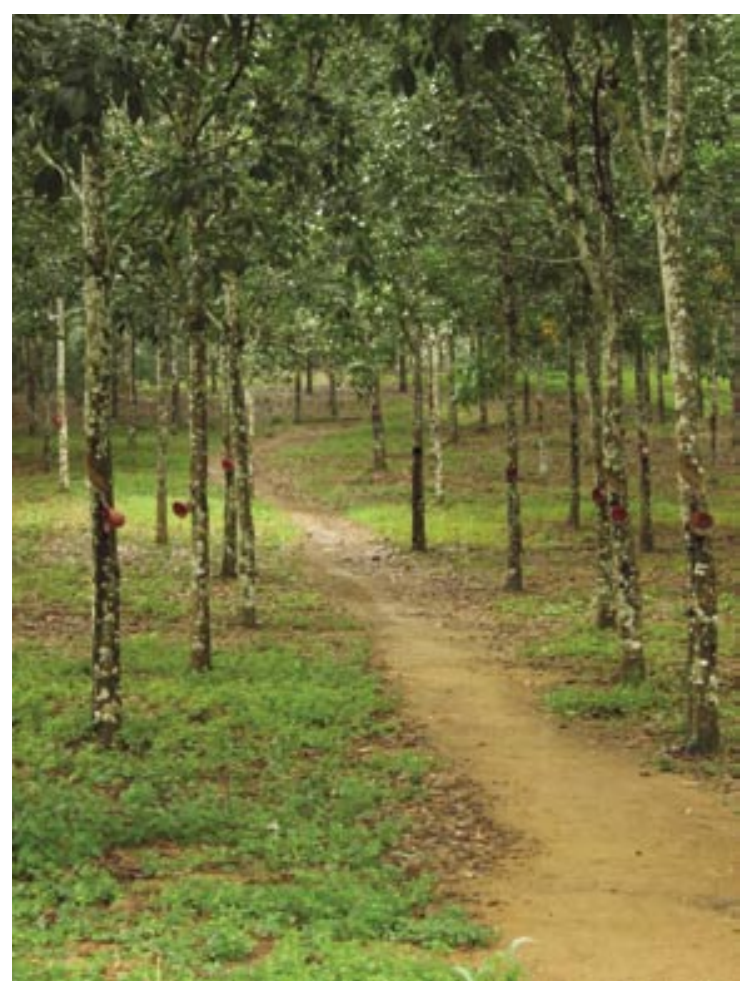


${ }^{10}$ These traditional engines of growth are critical for the initial recovery. But Liberia must take steps to ensure that the benefits are widely shared, and begin to build a much more diversified economy over time to achieve even more inclusive and sustainable growth.

${ }^{11}$ Three steps are critical to ensure that the benefits from natural resources are widely shared, and Liberia is already taking initial steps in each area.

- First, the Government is committed to negotiating concession contracts that balance competitive returns for the investor with the need for sustained revenues for the people of Liberia. The secretive, special deals of the past that benefitted a few to the detriment of the majority will be replaced by transparent agreements with fairer terms and stronger mechanisms to ensure the proper distribution and spending of funds.

- Second, Liberia will ensure that all payments to, and revenues received by, the Government (including all royalty and tax payments) are publicly, transparently, and fully reported. The Government has already taken a major step forward in this area by becoming a candidate country under the Extractive Industries Transparency Initiative (EITI).

- Third, concession revenues will be used to promote public welfare by financing investments in roads, education, health, water, and other areas. These investments will create direct social and economic benefits for all Liberians including women, youth, and persons with disabilities. Concessionaires will be responsible for some provision of infrastructure and basic services inside the concession area. By creating new opportunities and expanding Liberians' capabilities, concessionaires play an important role in ensuring that growth is inclusive and sustainable.

${ }^{12}$ Although Liberia is endowed with rich natural resources that can help spur growth during the next several years, the country must aim to diversify the economy in order to sustain growth over time and to create new economic opportunities for Liberians across the country. Even if there are some successful developed country examples, few developing countries that have relied heavily on natural resource exports have achieved sustained economic growth over the last several decades. Natural resource production can create opportunities for corruption and generate so-called "Dutch Disease": real appreciation of the currency, a loss of competitiveness, and weaker incentives for other export activities. Moreover, they typically do not generate sustained growth in productivity over time, which is the key to sustained wage and income growth.

${ }^{13}$ Thus, while building on its comparative advantage in natural resources, Liberia will aim over the medium-to-long term to diversify into and increase the share of labor-intensive downstream processed products, other manufactures, and services as the basis for generating sustained growth in productivity, skill levels, wages, and income. Producing for export is essential, as export markets can expand, provide competition to ensure efficiency, and provide access to new technologies that are central to productivity growth.

${ }^{14}$ Liberia has the potential for economic activity in agro-processing, horticulture, furniture and other downstream wood products, and downstream rubber products, and eventually in service industries. While wide-scale industrial development will not be achieved in the PRS implementation period, the strategy will lay the groundwork for diversifying the economy into activities that can eventually create significant numbers of jobs throughout the country for low-skilled and semi-skilled workers.

${ }^{15}$ It is likely to take many years for the Liberian economy to diversify in this direction, but the Government is already taking purposeful steps to lay the necessary foundation. The key is to reduce production costs as much as possible to allow firms to compete. With the appropriate environment, Liberian firms could compete on regional and world markets for export.

${ }^{16}$ An important first step in reducing costs and creating a competitive environment is rebuilding infrastructure, especially roads, the ports and power supplies. Another will be rebuilding Liberia's education and health systems and its professional capacity in both the public and private sector. A particular challenge 
will be the absorption of the many young Liberians who were denied an education and had their transition from childhood to adulthood interrupted by war.

${ }^{17}$ At the same time, the Government is committed to simplifying procedures, limiting discretionary and concentrated powers, reducing red tape, facilitating customs and port clearance, and eliminating unnecessary regulations. It will consider developing one or more Special Economic Zones (SEZs) to promote foreign direct investment, reduce production costs, diversify production, and facilitate the integration of Liberian firms into regional and global markets. Liberia has begun to revise its tax and investment codes with a view toward balancing the need for revenues with the need to increase economic efficiency and competitiveness, as well as reducing discretion in the provision of tax incentives. Liberia plans to reduce its income tax and duty rates while broadening the tax base and strengthening tax administration.

\subsection{A Three-Pronged Growth Strategy}

${ }^{18}$ The structure of the Liberian economy and its potential for growth necessitates a three-pronged growth strategy.

- First, rebuild basic infrastructure, especially roads. Roads are critical for connecting Liberian farm communities to markets and reducing both the time and cost to move goods and services across the country. In the aftermath of the conflict, many communities are isolated for most, if not all, of the year. Roads reduce the costs of all products that rural communities purchase and increase the income they earn from their production. An expanded, efficient road network will create new economic opportunities for the rural poor throughout Liberia, including unemployed young men and women and persons with disabilities, and will make export products more competitive. Such a road network will also enhance security, facilitate decentralization of government services, and open access to health and education. In surveys and consultative meetings throughout the country, Liberians consistently pointed to roads as their number one priority. In addition, the rehabilitation and development of the energy sector is an integral part of the reconstruction and development strategy which, together with rebuilding ports and improving water supplies, will also reduce costs and make Liberian firms more competitive.

- Second, restore production in rubber, timber, mining, cash crops and other key natural resource products, and ensure that the benefits accrue to the nation as a whole and not to just a few. Liberia is not a poor country; it is a rich country that has been poorly managed. Going forward, it must manage its resource base to ensure the benefits are transparent and widely shared, that natural resources are utilized in a sustainable manner, and that natural resource production does not undermine the incentives for growth in other sectors.

- Third, reduce production costs to encourage diversification of the economy over the medium-tolong term into competitive production of labor-intensive downstream products, manufactured goods, and services. Liberia has the potential to export to the West African region, Europe, the United States and other large markets in a range of products that can stimulate significant job growth. It must rebuild its infrastructure, reduce unnecessary regulations, encourage competition, eliminate red tape, and shorten the time and costs for port and customs clearance. It must implement a tax system that balances the need for revenues with the need for efficient, low-cost production. It also must rebuild its health and education systems, and its public and private sector professional capacity, in order to create opportunities for all Liberians to compete on global markets. Macroeconomic management will be central; Liberia must ensure that natural resource exports and aid flows do not lead to an appreciation of the real exchange rate that can undermine export competitiveness. 


\subsection{Liberia's Initial Growth Acceleration}

${ }^{19}$ This three-pronged growth strategy is feasible, although the third prong can only bear fruit significantly beyond the three-year PRS implementation period. As Table 4.1 shows, the economic recovery is off to a strong start. GDP expanded 2.6 percent in 2004 and 5.3 percent in 2005 . Following the inauguration of the new Government, GDP growth jumped to 7.8 percent in 2006, and accelerated to 9.5 percent in 2007.

${ }^{19}$ Agricultural production has been increasing, particularly the production of rice and cassava. Rice production has expanded by 25 percent in two years, and cassava production has grown 35 percent. Rubber production (which accounted for 10 percent of GDP in 2005) declined in 2006, which significantly slowed the overall GDP growth rate, but it recovered in 2007 , with rubber exports up significantly.

${ }^{20}$ Construction has been a key driver of growth over the last two years, expanding by a cumulative 40 percent in 2006 and 2007. Construction activity is likely to continue to grow in the near future as buildings, roads, and other infrastructure are repaired and rebuilt. In addition, retail trade, hotels, restaurants, communications, transport, and some limited financial services are already expanding quickly and are likely to continue increasing as donor funds are disbursed, remittances from abroad grow, and related activities expand. Manufacturing of beer and beverages also added to the initial spurt of growth.

${ }^{21}$ Importantly, the rapid acceleration of growth has been achieved without any expansion of forestry or mining. As significant new investments come on line in these activities, Liberia is poised for even more rapid growth during the PRS period. These opportunities are described in more detail in Chapter Seven.

${ }^{22}$ Liberia faces many challenges in generating rapid, inclusive and sustainable growth, and success is far from guaranteed. But with the right policy framework as laid out in the second half of this PRS and the strong commitment of the Government, the Liberian people and Liberia's partners, the country has great potential to achieve these goals. 


\begin{tabular}{|c|c|c|c|c|}
\hline & $\begin{array}{c}2004 \\
\text { Est. }\end{array}$ & $\begin{array}{c}2005 \\
\text { Est. }\end{array}$ & $\begin{array}{c}2006 \\
\text { Est. }\end{array}$ & $\begin{array}{c}2007 \\
\text { Est. }\end{array}$ \\
\hline Real GDP & 2.6 & 5.3 & 7.8 & 9.5 \\
\hline Agriculture \& fisheries & 7.5 & 6.0 & 4.4 & 7.3 \\
\hline Rubber & 82.7 & 24.6 & -25.0 & 26.0 \\
\hline Coffee & 1.0 & 2.0 & 2.0 & 2.0 \\
\hline Cocoa & 274.5 & -47.7 & 5.0 & 5.0 \\
\hline Rice & 1.0 & -10.0 & 15.0 & 10.0 \\
\hline Cassava & 1.0 & 19.0 & 24.0 & 10.0 \\
\hline Other & -8.3 & -1.3 & 5.3 & -5.0 \\
\hline Forestry & -40.3 & -6.2 & 2.9 & 1.0 \\
\hline Logs \& timber & -95.0 & -100.0 & 0.0 & 0.0 \\
\hline Charcoal \& wood & -8.3 & -3.2 & 2.9 & 1.0 \\
\hline Mining \& panning & 49.5 & -15.0 & 0.0 & $1,614.6$ \\
\hline Iron ore & 0.0 & 0.0 & 0.0 & 0.0 \\
\hline Diamonds & 0.0 & 0.0 & 0.0 & $186,156.6$ \\
\hline Other & 49.5 & -15.0 & 0.0 & $1,350.0$ \\
\hline Manufacturing & 97.7 & 8.2 & 16.0 & 3.9 \\
\hline Cement & 189.4 & 34.0 & -8.0 & 0.0 \\
\hline Beverages \& beer & 94.8 & 0.3 & 27.7 & 5.0 \\
\hline Other & 1.0 & 2.0 & 5.0 & 5.0 \\
\hline Services & 19.2 & 9.9 & 12.0 & 10.4 \\
\hline Electricity \& water & 1.0 & 2.0 & 20.0 & 15.0 \\
\hline Construction & 5.0 & 6.0 & 25.0 & 15.0 \\
\hline Trade, hotels, etc & 3.0 & 5.0 & 20.0 & 15.0 \\
\hline Transportation \& communication & 5.0 & 2.0 & 7.0 & 7.0 \\
\hline Financial institutions & 2.0 & 2.0 & 7.0 & 10.0 \\
\hline Government services & 132.6 & 32.5 & 10.0 & 10.0 \\
\hline Other services & 4.0 & 2.0 & 10.0 & 7.0 \\
\hline
\end{tabular}

Source: Government of Liberia and IMF staff estimates 


\section{Process}

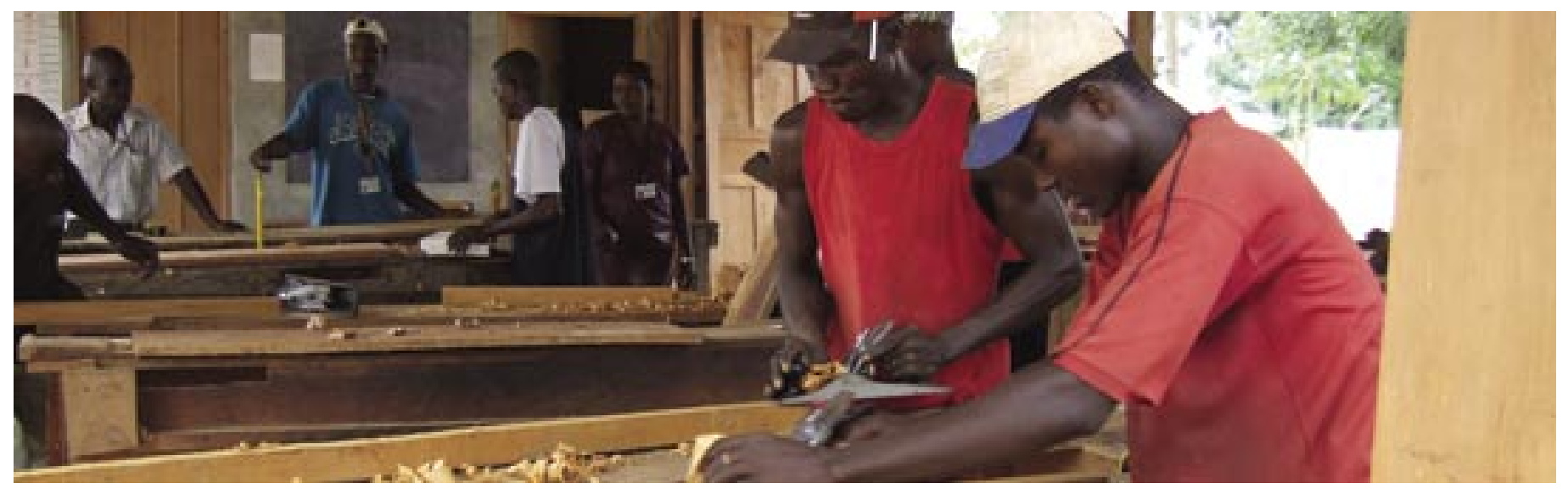

\subsection{Introduction}

${ }^{1}$ Liberia's PRS is built on the foundation of the Government's 150-Day Action Plan and its iPRS. The PRS is part of a longer-term continuum of the Government's strategy for rapid, inclusive and sustainable growth and poverty reduction, including progress toward achieving the MDGs. The PRS covers the three-year period from April 2008 to June 2011, coinciding with the end of the 2010/2011 fiscal year. Since Liberia cannot achieve all of its long-term development goals during the three-year period of the PRS, the Government is planning on developing a follow-on PRS beginning in 2011. Thus, the PRS represents the next stage in a systematic and strategic approach for development management and for longer-term poverty reduction, transformation, and development.

${ }^{2}$ Prior to the iPRS and PRS processes, no previous Government had formally and systematically consulted with the Liberian people to elicit their views on issues of national development. Liberian communities therefore had no way to fully voice their concerns, aspirations, and priorities. The war generated deep cynicism about government, and most of the population disengaged from the predatory and violent regimes they had come to associate with it.

${ }^{3}$ To gain a deep understanding of people's concerns and priorities, and to build national consensus on a shared vision of national development, the Government designed a PRS process that was more participatory and consultative than any other in the country's history. In particular, the Government adopted an inclusive institutional mechanism and PRS group structure, and solicited and incorporated individual contributions from ministries and agencies, the Legislature, the Judiciary, donors, civil society, the private sector and the population more generally. Overall, the PRS is better informed, more targeted and more likely to be effectively implemented because of the consultative and participatory processes on which it was built.

\subsection{Institutional Mechanism and PRS Group Structure}

${ }^{4}$ The PRS process adopted an inclusive governance structure, consisting of seven main hierarchical but interactive components (see Figure 5.1). The Cabinet sits at the apex of the structure and is responsible for the final endorsement and ongoing ownership of the PRS on the part of the Government. 


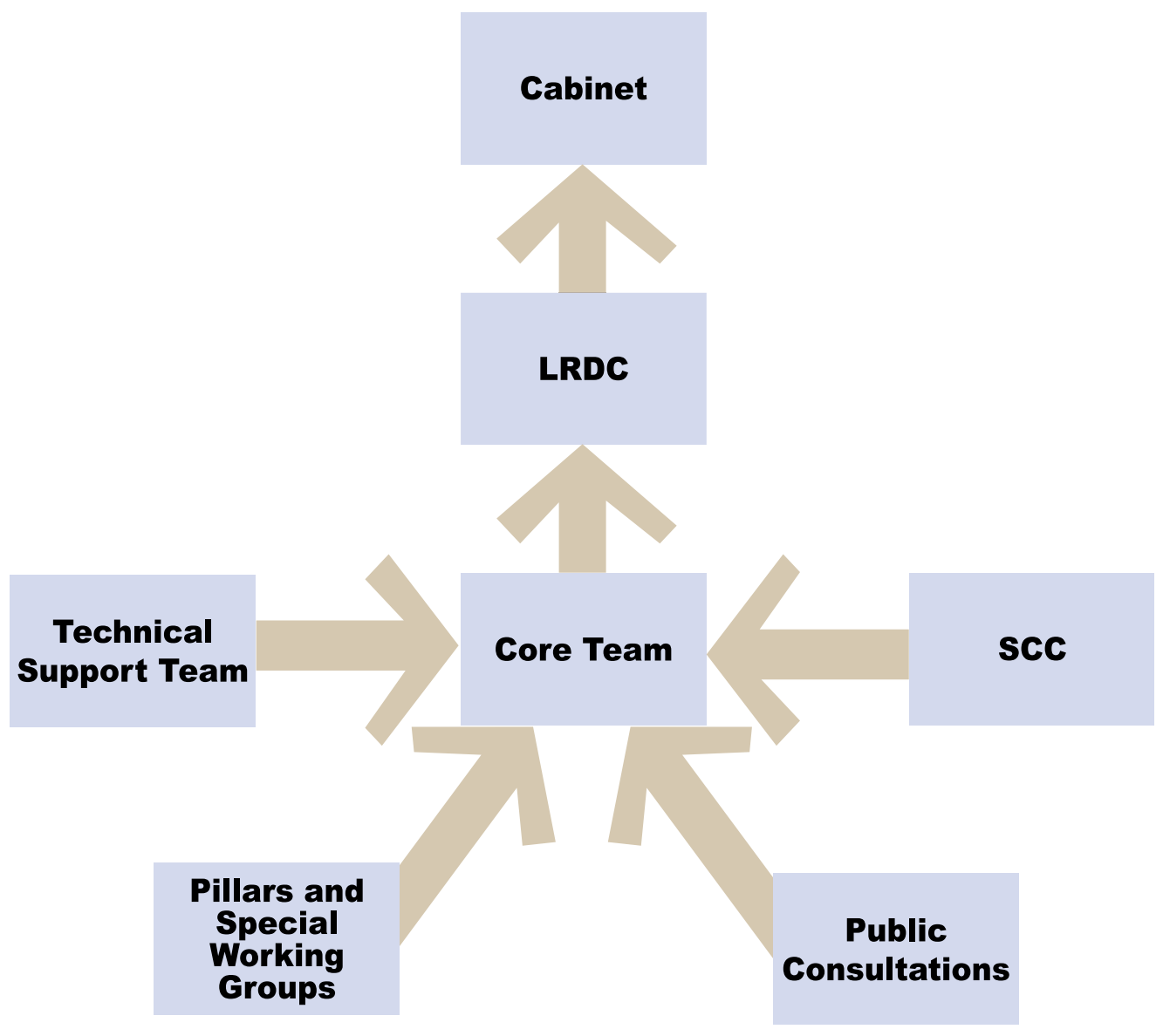

${ }^{5}$ Immediately below the Cabinet sits the Liberia Reconstruction and Development Committee (LRDC). The LRDC is the main Government-partner forum that coordinates Liberia's national reconstruction agenda (Figure 5.2). The LRDC Steering Committee is chaired by the President and consists of the Ministers of Defense, Finance, Planning and Economic Affairs, and Public Works, as well as major partners including the United Nations, the United States, China, the World Bank Group, the European Commission, the IMF, the African Union and ECOWAS, and is supported by a small Secretariat. The Steering Committee is designed to make broad policy decisions in relation to the national reconstruction and development agenda, and to ensure coordination across key ministries and between the Government and its partners.

Figure 5.2 Liberia Reconstruction and Development Committee (LRDC)

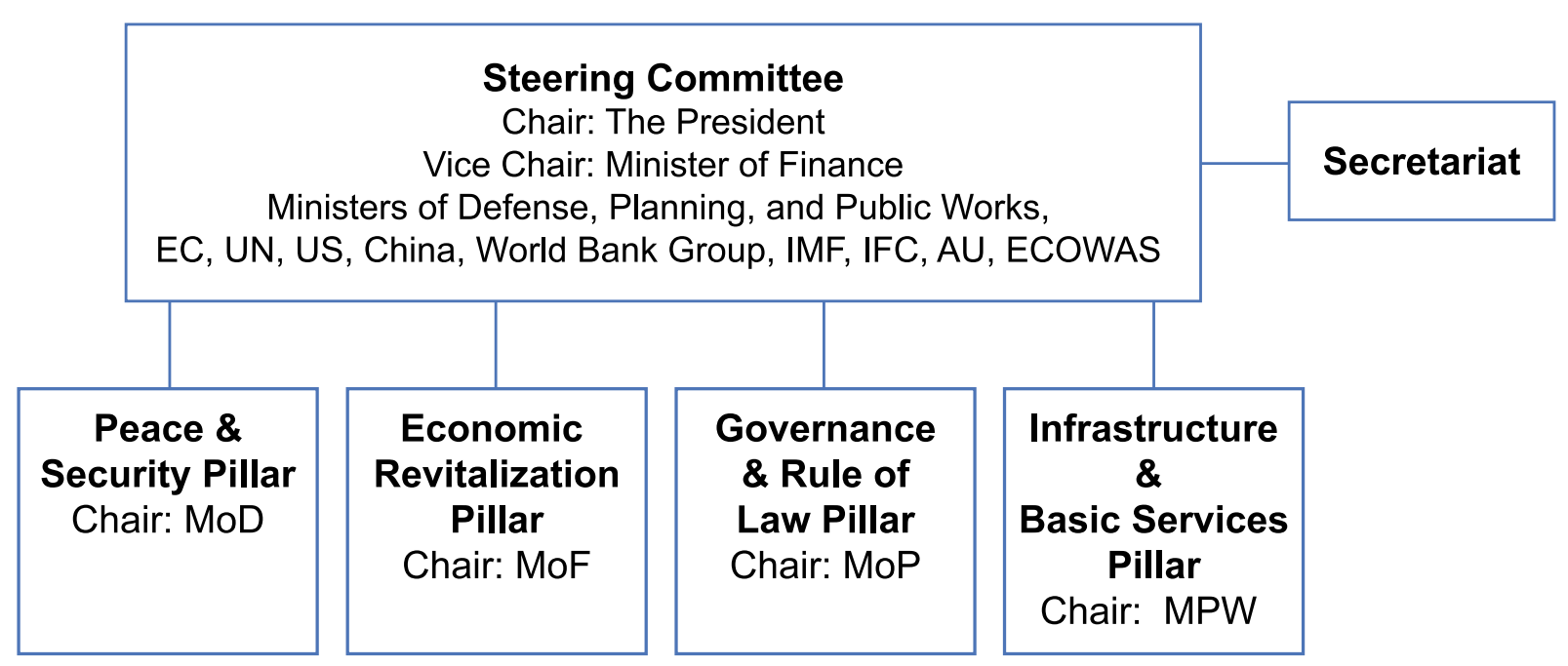


${ }^{6}$ The more detailed work of the LRDC is carried out on a regular basis in four Pillars that are chaired by the four Ministers in the Steering Committee and that are responsible for the substantive work in each of the four key areas of the national development framework: consolidating peace and security, revitalizing the economy, strengthening governance and the rule of law, and rehabilitating infrastructure and delivering basic services. The Pillars consist of representatives of the relevant Government ministries and agencies alongside donors and UN agencies.

${ }^{7}$ The Steering Committee of the LRDC and the Cabinet provided overall policy guidance to the PRS process, ensured the necessary political support in preparation and drafting, and will be responsible for PRS coordination and oversight during the implementation period.

${ }^{8}$ The PRS preparation process was led by the Minister of Finance, who established a PRS Core Team to assure the quality, policy coherence and strategic coordination of and consultation for the PRS process. The Core Team included the Minister of Planning and Economic Affairs, the Minister of Public Works, the Minister of Defense, the Director General of the Liberian Institute of Statistics and Geolnformation Services (LISGIS), and the National Coordinator of the LRDC Secretariat. The chairs of the six cross-cutting working groups created as part of the preparation process (see below) also participated in the Core Team.

${ }^{9}$ The Core Team received advice and substantive input from the Stakeholders Consultative Committee (SCC), which consisted of a broad group of PRS stakeholders, including representatives from working groups, civil society, the private sector, development partners, officials from the counties, the Legislature and the Judiciary. A Technical Support Team provided technical and logistical support to the PRS process as a whole.

${ }^{10} \mathrm{~A}$ wide range of working groups carried out the analyses and dialogue that underpin the PRS, as shown in Figure 5.3. Most groups worked on sector-specific strategies under one of the four key Pillars, while others addressed critical cross-cutting issues (such as children and youth, environment, gender equity, HIV and AIDS, monitoring and evaluation, and peacebuilding). The working groups developed much of the Pillar-specific policy, whereas the cross-cutting working groups provided analysis and inputs in relation to issues relevant to several Pillars. All of these working groups included participation from a broad group of stakeholders, including members of the Legislature, civil society, the private sector, and the general public, and were operated in a manner that emphasized open and participatory dialogue.

\subsection{The Four Pillars}

${ }^{11}$ The four Pillars of Liberia's PRS represent the core strategic areas at the foundation of generating inclusive and sustainable growth and addressing the poverty challenge in all its dimensions (see Figures 5.3 and 5.4). The four Pillars represent an organizing framework to establish key priorities, allocate scarce resources across competing demands, and achieve Liberia's most important development goals. 


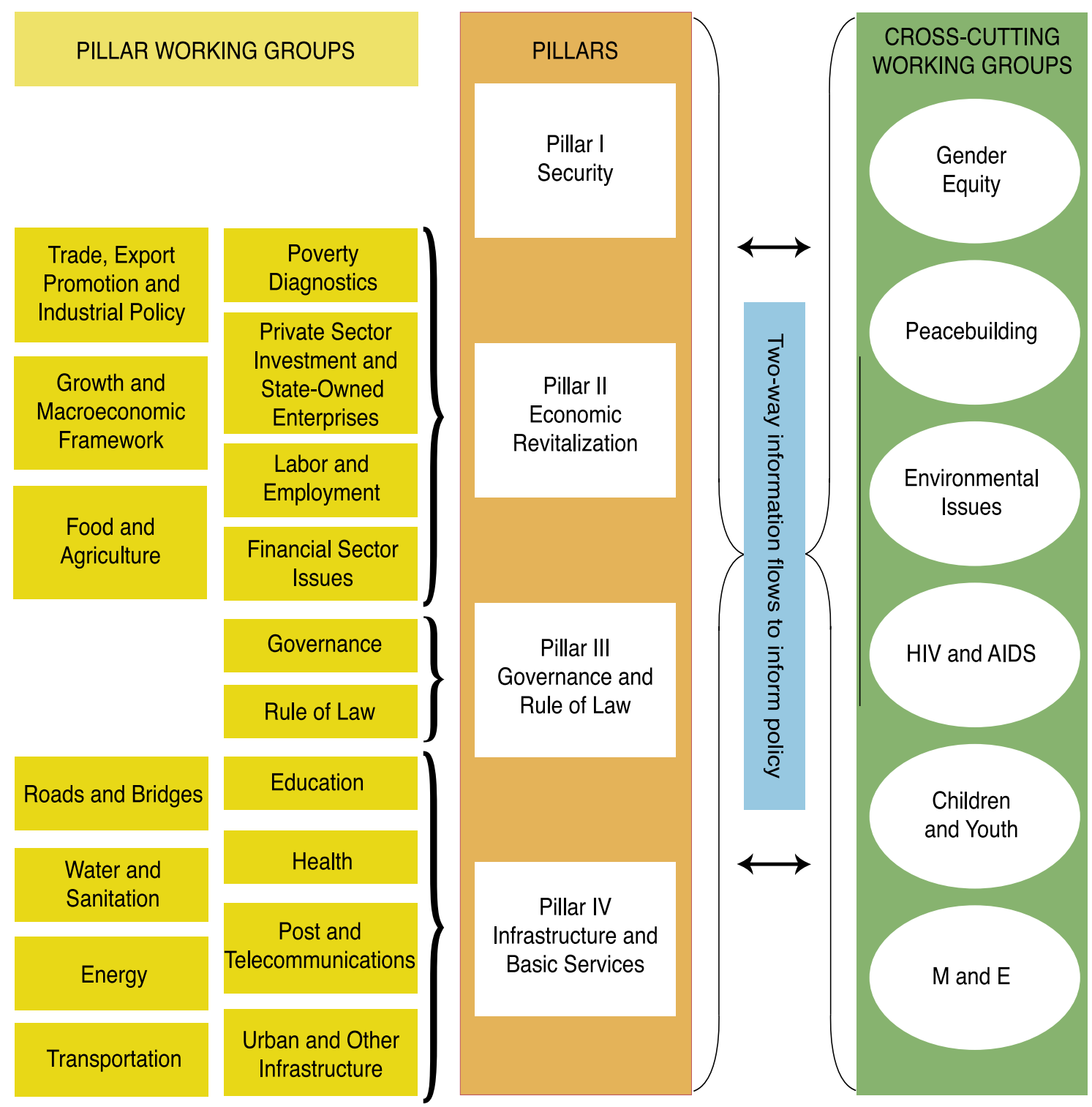

${ }^{12}$ The four Pillars are mutually reinforcing. Progress in one area facilitates progress in the others. Peace and security are pre-requisites for sustained economic progress and a reduction of poverty. Without peace, economic growth and poverty reduction cannot proceed. Likewise, peace and national security will be severely threatened if chronic poverty continues to rise. Sustainable peace will largely depend upon the ability to create inclusive economic opportunities and deliver basic social services throughout the country. Similarly, basic infrastructure is required for broad-based growth and delivery of services nationwide, and provides the basis for decentralized governance systems. Governance and the rule of law provide the institutional base for strong economic performance and poverty alleviation, and the justice that is needed to ensure that grievances are settled through dialogue within the political system, as opposed to violence.

${ }^{13}$ As the linkages in Figure 5.4 show, success in addressing issues within the four Pillars is expected to facilitate job creation and improved service delivery. The Pillars form the essential building blocks for realizing the vision of rapid, inclusive and sustainable economic growth and poverty reduction, and progress toward achieving the MDGs. 


\section{Intervention Pillars}

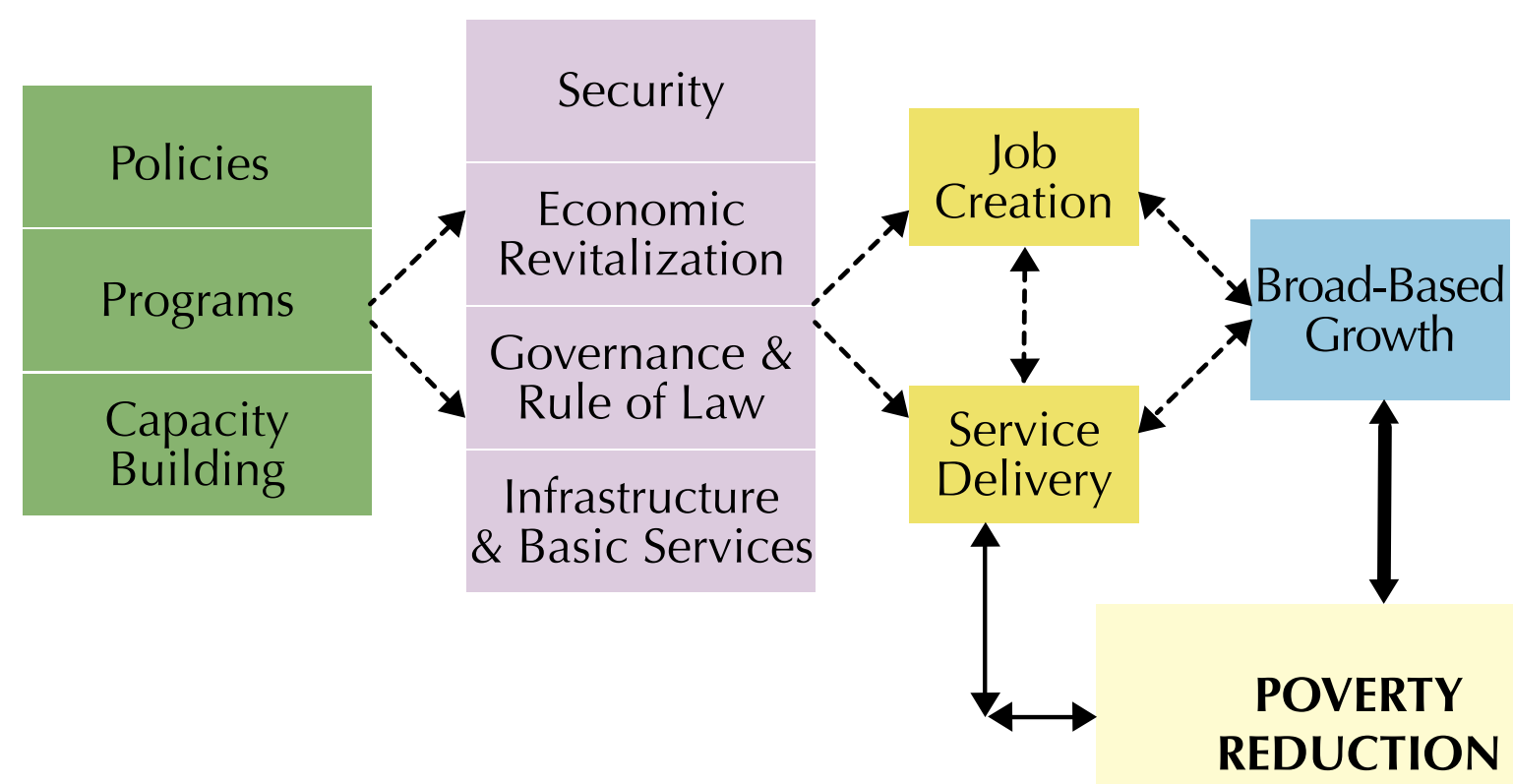

\subsection{A Participatory and Consultative Process}

${ }^{14}$ The structure and mechanisms described above facilitated a participatory and consultative process that was comprehensive and inclusive. The participation and consultation occurred at many levels.

\subsubsection{Public Consultations}

${ }^{15}$ The PRS involved an extensive and continuing process of public consultation designed to gain a deep understanding of the citizens' aspirations, expectations, and priorities, to build national consensus around the country's development strategy, and to obtain stakeholders' buy-in to the PRS.

${ }^{16}$ The public consultations for the PRS included two-day working sessions in each of Liberia's 15 counties, during which local participants formulated their respective County Development Agendas (CDAs), and then identified development-related concerns and priorities for the PRS. The CDAs themselves built on earlier district-level consultations and the preparation of District Development Agendas (DDAs). ${ }^{35}$ This process of soliciting input from the counties on the national PRS after each county and district had just developed their individual development agendas allowed for maximum consistency across district, county and national level policies and programs, and ultimately produced a more holistic national development agenda.

${ }^{17}$ The process enabled all citizens to contribute to the development of the PRS. All members of a particular district were invited to attend the district-level consultations. At the county level, meetings included legislative members, traditional leaders, farmers and business people, women, children and youth, persons with disabilities, and local non-governmental organizations, and the public at large. The inclusive nature of the consultations meant that all participants had the opportunity to have their voices heard and incorporated into the PRS process.

${ }^{18}$ In addition to these events, other focused consultations were held throughout the country around topics

35 In addition to their direct contribution to the development of the PRS, the DDAs and CDAs will serve as a mechanism for continued input and consultation on policy issues beyond the PRS period. 
of interest to specific groups of citizens such as women, children and youth, and also around specific issues, such as land use.

${ }^{19}$ The outputs of all of these consultations included the identification of local problems and concerns, as well as recommended action plans. Pillars and working groups then considered these outputs in defining their Pillar, sector or thematic strategies. The PRS Core Team subsequently distributed a draft of the PRS to the counties, with three regional outreach consultations undertaken to solicit feedback on the strategy as a whole and to ensure that issues raised at the county consultations had been incorporated into the PRS. The PRS Core Team undertook similar outreach consultations focused on the Legislature, civil society, and private sector actors with respect to the draft PRS. These consultations enabled these groups to provide further input into the PRS in addition to their participation in the broader public consultations, the SCC, and across the various working groups.

\section{Main Public Consultation Messages from the Counties}

\section{National Security}

While many noted that security had improved since the war, participants in the county consultations identified several common internal security concerns. The most frequently cited were sexual violence and rape, drugs, and theft. County discussions also revealed widespread dissatisfaction with the security and police apparatus. In particular, Liberians noted a shortage of qualified security and police personnel, incidence of police corruption, and low levels of public confidence and trust in the police.

\section{Economic Revitalization}

During the discussion around the economic revitalization pillar, participants listed agriculture, roads, and access to finance as their highest priorities. Specifically, participants cited a lack of agricultural inputs, lack of training, and outdated farming methods as issues in the agricultural sector. A shortage of storage and processing facilities, poor roads, and lack of transportation were discussed as key issues in access to markets. Concerns were voiced about the absence of banking facilities in the counties and the lack of credit facilities. Many in the counties voiced concerns about environmental degradation, illegal mining and logging associated with natural resource concessions. With regard to taxes, participants complained that taxes are taken to and spent in Monrovia in a less-thantransparent manner, and that the Government has not done enough to explain its tax policies.

\section{Governance and Rule of Law}

County consultations revealed concerns over the prevalence of corruption at all levels of government, the prevalence of child labor, and problems with land tenure. On the issue of decentralization, Liberians expressed frustration with the process of selection of county officials, and complained that payments are too centralized, and that government contracts are rarely extended to local firms. Many raised concerns regarding rule of law, particularly around the lack of knowledge about laws (specifically the rape law), judicial corruption, lack of legal aid, poor monitoring and enforcement, and the practice of resorting to traditional means of justice. Citizens complained of frequent delays and abandoned cases in the court system, and the high incidence of mob justice and human rights violations.

\section{Infrastructure and Basic Services}

The concern most frequently cited across nearly all counties was the shortage and poor state of roads. People also noted the shortage of safe drinking water and electricity. In the education sector, they expressed concern over the shortage and inadequacy of educational facilities, the shortage of trained teachers, and the under-representation of girls in schools. Likewise, in the health sector, concerns were raised about the shortage of trained medical personnel, the lack of health care facilities and ambulances. 


\subsubsection{Stakeholders Consultative Committee (SCC)}

${ }^{20}$ The SCC was inaugurated early in the PRS process and was influential in directing it. Its contributions gained credibility because of the participation of representatives from civil society, the Counties, the Legislature, the various working groups and development partners. Toward the end of the PRS process, the SCC met for a day-long review of the PRS, an event that built on all other consultations and ensured that the final PRS reflects the contributions of Liberian society as a whole.

\subsubsection{Pillar and Working Groups}

${ }^{21}$ The organization of the Pillar and working groups was based on the existing LRDC Pillar architecture, and involved a wide variety of stakeholders, including relevant Government ministries and agencies, civil society, the private sector, and other development partners. Each Pillar and its respective working groups produced strategy papers, undertook costing of different actions, discussed indicators for use in $\mathrm{M} \& \mathrm{E}$, and laid the groundwork for the sequencing and prioritization of policy in the final PRS. A broad group of stakeholders then vetted the strategy papers to ensure the PRS represented the consensus of all stakeholders. This output, together with the public consultations, was the launching point for the actual drafting of the PRS. Working groups continued to meet periodically throughout the remainder of the PRS process to review drafts of the PRS, as well as to provide further insight into the issues discussed within their working group strategy briefs.

\subsubsection{Participatory Poverty Assessment}

${ }^{22}$ A Participatory Poverty Assessment (PPA) was conducted during the PRS process to gain a deeper understanding of perceptions of poverty based on information provided by the Liberian people themselves. The PPA allowed for direct information on the country's poverty profile (to complement the DHS and CWIQ surveys, as described in Chapter Three), the priorities of the people at a grassroots level, and the impact of reform measures.

${ }^{23}$ The next four chapters spell out the Government's broad strategies in each of the four Pillars to respond to the poverty diagnostics, the concerns of the Liberian people, and to lay the foundation for rapid, inclusive and sustainable growth and poverty reduction. At the end of each of these four chapters, as well as in Chapters Ten and Thirteen, Priority Action Matrices are included to set out the particular actions that the Government will undertake in the relevant areas, the responsible ministries or agencies, and the delivery dates. 


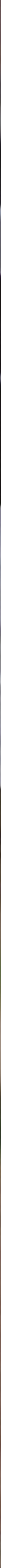




\section{Part 2:}

\section{The Strategy}

\section{Chapter Six}

\section{Consolidating Peace and Security}

\subsection{Introduction}

${ }^{1}$ ecurity in Liberia has been a major concern since independence. Security forces have been used to intimidate and at times terrorize the population and intervene in the political process without respect for due process of law. The security forces contributed to a system in which economic benefits and political power accrued to the elite, leaving the majority of Liberians in insecurity and poverty. The civil conflict compounded these problems, as security forces became major contributors to violence, destruction, and denial of justice.

${ }^{2}$ When the current Government assumed office, it was confronted with a combination of more than a century of defective security sector governance, the legacy of a decade and a half of civil war, the lack of good governance, poor economic and natural resources management, the instability of the immediate sub-region, and the lack of strategies to address these situations. Key problems included a lack of professionalism, absence of control by democratically elected officials, absence of accountability to the rule of law, weak oversight, and inadequate resources. At the regional level, intra-state conflicts have been a major problem in West Africa and the Mano River Union sub-region for more than a decade. Liberia was the epicenter of that conflict.

${ }^{3}$ Although the security situation has improved dramatically in the last few years, there is still a long way to go. The police force, the armed forces, and all other security forces need to be completely rebuilt. The process of broad security sector reform is off to a strong start, but must be completed as UNMIL begins to gradually draw down its peacekeepers over the next few years.

${ }^{4}$ This is therefore the immediate focus of the National Security Sector Strategy for the Republic of Liberia (NSSRL) and its attendant Implementation Matrix (NSSRL-IM), which are inextricably linked with the PRS process. Like the PRS, the NSSRL was developed using a consultative process to ensure local ownership of the strategy and reflects the interrelationships between security, poverty, justice and peace. The past has shown how the vicious cycle of poverty, marginalization and inequity can drive conflict and further poverty. Accordingly, the Government's approach to addressing key sources of conflict, including poverty, will take into account the multidimensional nature of peace and security.

${ }^{5}$ During the PRS county consultation process, many people pointed to crime - particularly rape, theft, and drug abuse - and lack of faith in the security agencies as important challenges. These issues continue to be key security and rule of law concerns and highlight the close connection between the 
Governance and Rule of Law Pillars, and their institutional frameworks. Gender based violence (GBV) was used as weapon of war during the two-decade period of unrest. It remains widespread in Liberia, and was another significant security concern highlighted during county consultations.

${ }^{6}$ The situation of Liberian youth was another major concern expressed at the county level; the prevailing increasing the risk of a return to violence. Coupled with the breakdown of traditional values and norms as a result of the war, the situation of youth is a potentially volatile security challenge.

${ }^{7}$ Another major challenge is completing the process of reintegrating both refugees and internally displaced persons (IDPs) and ensuring that displaced persons are back in their communities with sustainable livelihoods. The conflict displaced an estimated 500,000 persons throughout the country, of which eighty percent constituted women and children. ${ }^{36}$ During the immediate post-conflict period, more than 300,000 registered IDPs resided in 35 recognized IDP camps, predominantly in the suburbs of Monrovia. Between November 2004 and April 2007, an inter-agency operation assisted 326,990 IDPs to return and resettle in their counties of origin or preference, thereby enabling the complete closure of all 35 recognized displacement camps. With respect to refugees, of a total of 233,364 registered camp-based Liberian refugees in neighboring asylum countries, 157,467 have been voluntarily repatriated and reintegrated in their various counties of origin or preferred areas of return. Another 75,797 registered Liberian refugees currently remain in countries across West Africa, although approximately 40,000 are expected to begin returning from Ghana in September 2008.

\subsection{Major Goals and Objectives}

${ }^{8}$ The central goal for the security sector is to create a secure and peaceful environment, both domestically and in the sub-region, that is conducive to sustainable, inclusive, and equitable growth and development.

${ }^{9}$ In pursuit of this goal, the Government will focus on achieving three key objectives:

- Build and maintain effective national security institutions based in law and subject to civilian authority that are capable of defending Liberia and its inhabitants. As the UNMIL peacekeeping force draws down, the Government must build capable and professional security forces. Consistent with the NSSRL, the Government will restructure and refocus all security institutions and correctly train personnel in line with acceptable international standards, including promotion of gender equity and justice, accountability, ethical behavior, and professional conduct under full democratic civilian control. It will deploy security forces throughout the country to meet the security needs of the entire population. It will recruit new personnel via transparent and equitable vetting processes that reflect Liberia's diverse ethnic, gender and religious representation, with qualified personnel selected and promoted on merit, and receiving appropriate pay. The Government will aim for at least 20 percent of the security forces to be women, and for women to be represented appropriately at all levels of authority. It will ensure that all training curricula fully incorporate gender considerations and issues, and place special emphasis on protection of women and children.

- Build public confidence in the abilities of the security forces to maintain peace and security, comply with and enforce International Human Rights Laws and other norms, and protect against domestic and transnational crimes. The security forces must consolidate the transition from war to peace through pursuit of democracy, good governance and human security. They will also act impartially to safeguard people from violence and crime, allow their participation in decision-making, protect their basic rights, and help build an environment conducive to economic opportunity for all Liberians. Incidents of corruption and police brutality will be reduced, and security forces will adopt community policing, problem solving and crime prevention methods that are sensitive to issues confronting marginalized groups, including women, youth, and persons with disabilities. Special emphasis will be placed on addressing issues of GBV (See box below.).

36 Data in this paragraph comes from LRRRC, 2007 
- Promote domestic and sub-regional peace and security through close cooperation, coordination and adoption of best practices. Liberian security forces are aiming to adopt systems and practices that are consistent with other ECOWAS and MRU sub-region countries so as to facilitate regional and sub-regional cooperation and improve Liberia's security and stability. Such cooperation has direct potential effects on poverty as it represents a precondition for economic cooperation.

${ }^{10}$ To achieve these objectives, the Government will pursue policies and programs in three areas: Restructuring and reforming security institutions, strengthening human and personal security, and building and maintaining regional peace and security.

\subsection{Restructuring and Reforming Security Institutions}

${ }^{11}$ Restructuring and reforming security institutions are central to Liberia's national security. In the past, national security institutions were characterized by a lack of professionalism and accountability, gross abuse of human rights, adoption of unconventional practices in security functions, hiring untrained individuals to render national security services, and poor security management.

Presently the general population enjoys security protection that is largely dependent upon UNMIL resources and expertise. To build a strong new Liberian security architecture force, the Government and its partners are developing a sector-wide security implementation plan to bring Liberian led and owned coordination and cohesion to developmental efforts. This includes conducting training and building capacity in all of the key Liberian national security institutions based on internationally recognized and acceptable curricula with gender sensitive modules. Specifically the Government and its partners are training:

- 2,000 soldiers for the Armed Forces of Liberia (AFL);

- 3,500 National Police officers;

- 500 Emergency Response Unit (ERU) officers for the LNP as a specialized armed anti-crime unit;

- 91 civilian staff for the Ministry of National Defense;

- 2,000 Bureau of Immigration and Naturalization officers;

- 200 National Security Agency (NSA) officers; and

- a significant number of officers for the Special Security Service (SSS) and the Liberia National Fire Service (LNFS).

${ }^{12}$ The transformed institutions will be fully subjected to civilian management and oversight, especially legislative oversight. This is essential because of the prolonged years of war and mismanagement, which factionalized the sector and undermined its image and the public confidence. The Government will work to create civilian oversight mechanisms to ensure that law enforcement and security agencies adhere to high ethical standards and professional conduct. It will establish a complaint procedure to enable proper and independent pursuit of complaints about unlawful activities by security personnel.

${ }^{13}$ The roles of the various security institutions during the PRS period and various institutional reforms are set out in full detail in the NSSRL-IM and are summarized as follows:

The National Security Council (NSC), chaired by the President and comprising all the Ministers of Government, will continue to be the highest security coordinating body in the country with sole responsibility for national security policy issues. The Government will develop a county- and district-based security mechanism which will report to the NSC, enabling effective and accountable security coordination between the Government and local government, civil society, and traditional leaders. This mechanism will facilitate the consideration of people's security concerns at the appropriate level and the passing on of those concerns to the Government for further action where appropriate. This mechanism will 
${ }^{14}$ The Government aims to build an efficient process for the assessment and rapid dissemination of accurate intelligence in order to properly support senior decision-makers. The goal is to build a mechanism to provide multi-agency intelligence assessments that are coordinated and objective. This will enable the strategic management and exchange of intelligence among agencies to keep the Government abreast of developing national security threats. Periodic security threat reviews shall be conducted to help in preparing appropriate security responses. In addition, the National Security Agency (NSA) will continue to serve as Liberia's lead agency for national intelligence and counter-intelligence, as well as the focal point for intelligence-gathering and provision of counter-intelligence for the Office of the President. Over the PRS period, NSA and other intelligence-gathering bodies shall be further developed to better respond to changing domestic, regional, and global threats according to a system of National Intelligence Requirements (NIRs).

${ }^{15}$ In order to rationalize and reform the structure of the security apparatus, the Government will seek to repeal the laws that created the National Bureau of Investigation (NBI) and the Drug Enforcement Agency (DEA) and transfer some of their related duties, responsibilities and operations to the LNP. It will also propose the repeal of the statute that created the Ministry of National Security (MNS) and merge the operational functions and re-vetted personnel of the MNS with the NSA. This will eliminate excessive duplication and overlapping of functions, reduce bureaucracy, and increase law enforcement efficiency and accountability.

${ }^{16}$ The LNP will be the primary operational agency responsible for internal security, and will be restructured to ensure greater effectiveness and efficiency. In particular, the LNP will reassess its recruitment and vetting practices, before being expanded to address shortages of personnel across the country. They will be better trained to address personal crime, to reduce incidents of corruption and police harassment, and to strengthen the confidence of the local communities in the police, as discussed below. The LNP will also receive a new specialist-trained armed branch to be called the Emergency Response Unit (ERU) to deal with situations requiring the controlled use of arms. The new AFL will be trained for the unusual event that they are needed to support the civil administration, in which case they would be subject to civilian control. However, any deployment of the military in support of the civil administration will be regulated by clear and legally accepted principles to ensure clear lines of command and control.

${ }^{17}$ The AFL will be restructured to make it a viable and sustainable force that can defend the territorial integrity of Liberia against external aggression and assist in response to natural disasters. A separate Defense Policy will be prepared to address the duties and functions of the Armed Forces of Liberia in greater detail.

${ }^{18}$ The Government will establish a professional mentor relationship in the new Officers Corps for the AFL, with properly vetted and trained officers capable of leading an armed force in a democratic postconflict environment. This mentoring arrangement will be designed to reverse the deep-seated public mistrust of the Liberian military. To implement this program, the Government will seek well-trained personnel with good human rights records to lead the new AFL during this democratic post-conflict era, including personnel from the dissolved AFL and possibly from other military forces in the region. The Government will also work with neighboring countries to establish mentoring relationships between senior members of the security forces.

${ }^{19}$ The Liberia Coast Guard (LCG) will be revitalized to ensure the security of Liberia's maritime borders and natural resources therein. This will represent another significant security sector contribution to reducing poverty-assisting revenue generation and protection for the Liberian economy. Such revitalization will include training of the LCG to tackle smuggling and to conduct Search and Rescue (SAR) activities, while working within an integrated regional maritime security network.

${ }^{20}$ Liberia's land borders and entry points need to be adequately protected to prevent illegal entrants, trafficking of narcotic substances, child trafficking, and other illegal activities. Development and restructur- 
ing of the Bureau of Immigration and Naturalization (BIN) will be a key element of government strategy to address these concerns. All the restructuring plans for the development of the security services including those of the Bureau of Corrections, Liberia National Fire Service (LNFS), Special Security Service (SSS) and the Customs and Excise Service will be expressed in full detail in the NSSRL-IM as referred to in the PRS Security Pillar matrix at the end of this chapter.

${ }^{21}$ In restructuring and reorganizing its national security institutions, the Government will address the structural discrimination that occurs in incentive systems, operational structures, and bureaucratic procedures against women, persons with HIV and AIDS, persons with disabilities and others. Discrimination has a negative impact on the morale and performance of new recruits, undermines delivery and quality of services, and affirms destructive attitudes and practices such as GBV. Institutional reform will ensure the adoption of justice and equality as core values and allow for equal access and protection both within the security sector agencies and for the citizens that they exist to serve. Toward this end, all agencies in the sector will adopt a Code of Conduct covering issues such as discrimination and domestic violence, a Sexual Harassment Policy, and other related personnel policies, and they will take steps to ensure that appropriate mechanisms are established to handle violations of these policies. The security agencies will develop HIV and AIDS policies, including providing information on prevention, counseling, and treatment options. To ensure that gender concerns are incorporated to build an inclusive working environment, each agency will include a gender-sensitive syllabus into training curricula and a Gender Advisor will be appointed in each agency to identify opportunities for capacity building of female personnel. Disability-sensitive modules will also be included in the training curricula for all security institutions to improve skills and service delivery to persons with disabilities.

\subsection{Strengthening Human and Personal Security}

${ }^{22}$ The Government is responsible for protecting the citizens of Liberia from threats or physical violence that endanger their basic survival, be it from within the country or from other countries, or from violent individuals or groups. Focusing on human security requires that the Government take a broad view of security that recognizes the importance of human rights, good governance and access to economic opportunity, education and health care.

${ }^{23}$ Though the threat of an armed conflict has reduced, increases in armed robbery and related secondary crimes (particularly rape) and vigilantism are significant threats to individual and community security. This problem is linked to high unemployment among ex-combatants and ex-servicemen. The PRS consultative process revealed substantial public concern about personal crime at the county level. There is also a strong link between crime, unemployment, lack of investor confidence and insecurity.

${ }^{24}$ The police and other security agencies will be trained to cooperate closely in a structured system of national, county and district-level security committees, which also involve local government, is important in gaining the confidence of local communities to combat crime and underpin the rule of law and is a key ongoing part of the Government's efforts to improve human and economic security. In particular, the LNP will formulate prevention programs to combat crimes, especially armed robbery. It will conduct community crime sensitization

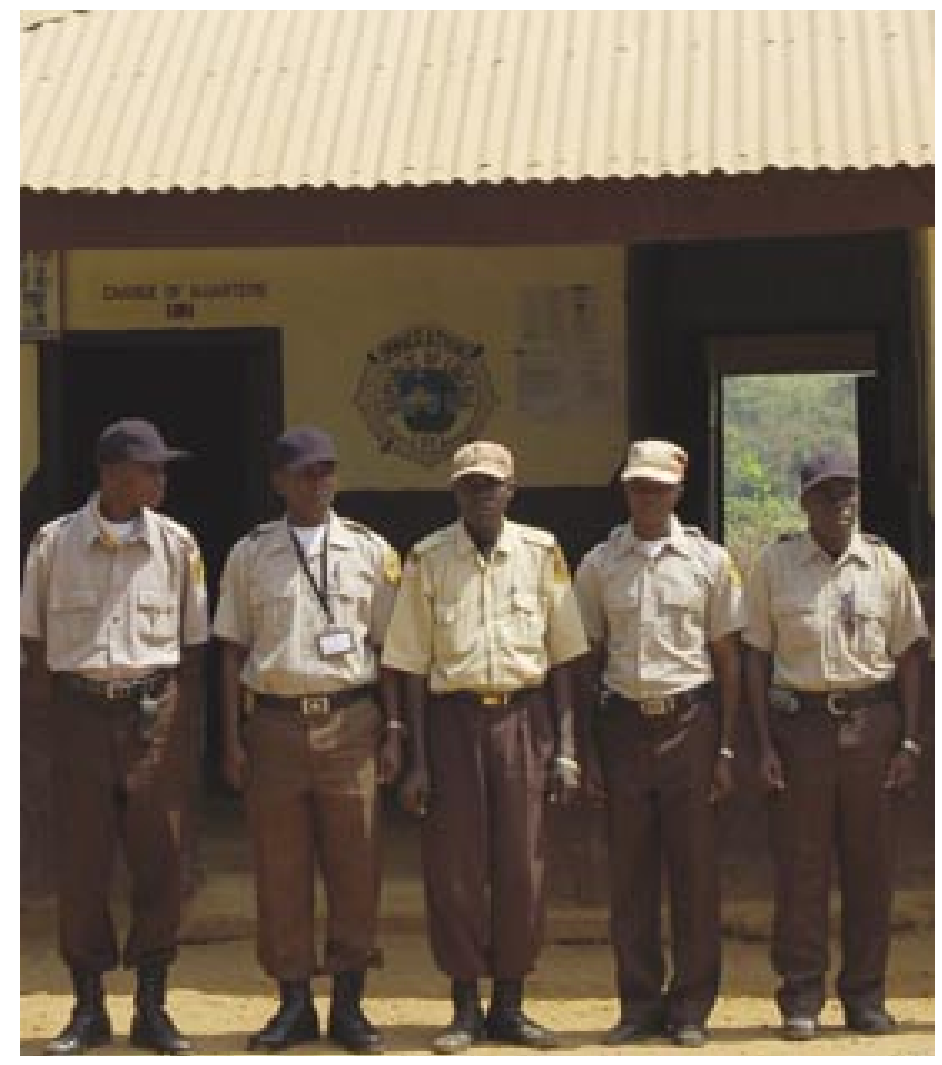




\section{Gender Based Violence in Liberia (GBV)}

GBV continues to be a major problem, particularly for adolescent girls. Recent studies conducted in ten of the fifteen counties indicate a high prevalence of GBV, which appears to be embedded in a combination of cultural beliefs and behavior acquired during the war years. During the conflict, the perpetrators of GBV were mainly members of the various fighting forces; more recently the perpetrators are ex-combatants, community or family members, teachers and husbands/partners.

GBV impacts the physical and psychosocial wellbeing of survivors long after the abuses are committed. The predominant social and economic consequences of rape are stigmatization by the community and families, divorce/partner abandonment, transmission of sexually transmitted infection including HIV, and unwanted pregnancy. Because of stigmatization, many GBV survivors are unwilling to seek medical/professional help or even to report the assault. In addition, they are deterred by the difficulty and danger of reporting due to gaps in legal, protection, health and psychosocial services that fail to ensure confidentiality and supportive services that GBV survivors need. In many instances, survivors and their families feel that those providing services demonstrate insensitive behavior, including blaming the survivor.

According to the LNP, rape and other sexual offenses rank among the most common crimes reported nationwide. But challenges within the legal/justice, security, health and psychosocial sectors prevail, including lack of data, weak legal and protection systems, shortages of human resources, limited technical capacity, and few financial resources.

To address the gaps, the Government has formed the National GBV Task Force, as well as a GBV Secretariat within the Ministry of Gender and Development. It developed a National GBV Plan of Action to provide appropriate skills to health professionals; improve documentation and reporting on clinical evidence; reform the legal system to deal more efficiently and expeditiously with violence; establish systems and outreach services for survivors; and ensure that women and girls have access to economic and social empowerment programs. Much progress has been made, but a great deal of human, financial and logistical resources are still needed to ensure that lasting change can take place.

campaigns regularly to educate communities about basic measures of preventing armed robbery, as well as specialized programs to involve women in crime prevention and to support to victims of crime. The LNP will increase its presence at night via foot and mobile patrols at the community level, and will expand its presence across the country as staff size allows. It will also develop strategies and training programs to respond quickly to cases of local unrest, land conflict, or ethnic clashes. Given that the history of police-citizen relationships is one characterized by fear and mistrust, a new emphasis on involving local communities and adoption of more citizen-friendly policing methods will improve policecitizen relationships. The LNP and other security agencies will formulate policies to reduce the incidence of corruption, police brutality, and other ethical violations.

${ }^{25}$ Specific measures will be put in place to strengthen the security sector agencies, in particular LNP, to implement the National Plan of Action against Gender Based Violence. In addition to gender-sensitive training for all personnel, emphasis will be placed on strengthening the Women and Children Protection Division in LNP and its units at the county level. The LNP and the judicial services will train staff in appropriately handling cases of sexual exploitation and abuse, and also develop clear guidelines for referral and case management for GBV cases. Training will also be undertaken to raise awareness of the rights and special needs of persons with disabilities. National and community-based mechanisms to prevent violence, abuse and exploitation of children and youth will also be developed.

${ }^{26}$ Drug trafficking is an emerging threat in West Africa, including Liberia. Two recent and significant drugs seizures off the West African coast confirm that Liberia, like some of its West African neighbors, 
may be targeted as a transit point for shipping heroin and cocaine to the US and Europe. Marijuana is also cultivated domestically. The high level of young unemployed is a potential source of cheap drug runners, and the lack of a functioning coastguard and perceived weak airport, port and land border security make Liberia attractive to drug traffickers. Drugs are inextricably linked with other domestic crimes, posing threats to rural communities and development activities. As part of security restructuring, Government will merge the Drugs Enforcement Agency (DEA) with the LNP and strengthen its counternarcotics capability via provision of standardized training, logistics, and modern equipment. The Bureau of Immigration and Naturalization (BIN), the Coast Guard, Airport Security and other security agencies will buttress the LNP's efforts in combating the traffic in illegal drugs through the provision of improved intelligence cooperation and greater vigilance and collaboration at airport, seaport, and land borders. Overcrowded prisons and a weak bail system also pose security threats. Those least able to pay bail are often the ones remanded in custody (in many cases for minor offences), thereby overfilling the Monrovia Central Prison. Serious criminals such as drug dealers, who pose a greater threat to the community, can afford to pay bail and avoid prison custody. The apprehended criminals reappear on bail to intimidate both LNP officers and witnesses. This seriously deters LNP's efforts to remove hard core criminals from the streets and improve security. The Government therefore intends to renovate existing correction facilities/structures and construct additional facilities to address prison overcrowding. The Government will seek to amend the Penal Law of Liberia to ensure that serious criminal offenses become non-bailable offenses. As discussed in Chapter Eight, the juvenile justice system will be reformed and its capacity built to adequately protect the rights of minors in line with the "parens patriae" philosophy. Government will ensure that the skills of juvenile officers of the LNP are improved in line with professional standards.

${ }^{27}$ Fires resulting in death and destruction of property are an all-too-often occurrence. Most houses lack electricity and the widespread use of candles and coal pots increases the risk of fire. In addition, the fire service is inadequately equipped. Inability to provide fire protection damages the confidence of the people and investors. The Government is keen to ensure that the National Fire Service of Liberia (NFS) is provided with the needed logistics and contemporary firefighting equipment, and to train fire fighters to effectively provide the necessary fire prevention education and protection. The Government will therefore conduct periodic national fire prevention sensitization campaigns to educate the population. Training exercises will be conducted for personnel of the NFS using a curriculum that conforms to international standards. There will also be regular refresher training for fire fighters to upgrade their skills in contemporary techniques.

${ }^{28} \mathrm{~A}$ range of issues related to land and property ownership continue to pose security threats. Communal land and boundary disputes between ethnic and clan groups have historically been a source of interethnic conflicts. Land appropriation and tenure arrangements work to the disadvantage of historically marginalized groups, creating resentment, Concessions awarded to foreign firms in the past have often ignored the rights of local communities. Local communities' claims to forest resources and illegal occupation of private land holdings also threaten to spark violent conflicts and over-burden already weak local and national conflict resolution mechanisms. The next chapter discusses the specific steps that the Government plans to take in this area, including reviewing some concession agreements, and establishing a Land Commission.

${ }^{29}$ Liberia's recent history shows the potential threat posed by ethnic hatred and tension. The war exacerbated hatred, tension and mistrust, and ethnicity can be easily politicized. The Government will seek to address these issues to maintain the peace. In particular, the Government will conduct a tribal/ethnic conflict diagnostic assessment to determine specific ethnic tension concentrations. The assessment will inform the tribal/ethnic reconciliation program formulation process.

${ }^{30}$ To promote respect for and protection of human rights, soldiers and officers of security and law enforcement agencies will be legally responsible for ensuring that human rights are not abused and that no act of human rights abuse will go with impunity. Human rights violators will be arrested, charged appropriately, and tried in a court of competent jurisdiction in line with Liberian law. The curricula of the AFL and other security institutions will strongly emphasize human rights education to prepare them for effective enforcement of human rights, including issues related to gender based violence. Soldiers 
caught violating human rights will be sent to the Court Martial Board to ensure justice in accordance with the Uniform Code of Military Justice (UCMJ). Other security officers who violate human rights will be subject to the due process of law to ensure respect for and protection of human rights.

${ }^{31}$ The process of retiring ex-servicemen and re-integrating ex-combatants has gone well, but some still pose a lingering security threat. About 17,000 ex-servicemen have been retired from the army, police, SSS and other agencies. Although the Government has made the required severance payments, some continue to demand more benefits. The Government's Disarmament, Demobilization, Reintegration and Rehabilitation (DDRR) program, completed in 2004, demobilized 103,019 ex-combatants. However, there are believed to be 9,000 ex-fighters who remained outside the Rehabilitation and Reintegration program. Some reportedly went to the Ivory Coast and are still at large. Some have fought in Guinea and Sierra Leone and represent a continuing national and regional security threat. Separately, there are others who are only now claiming to be ex-combatants and who were never registered as such under the DDRR process.

${ }^{32}$ Both ex-servicemen and ex-combatants constitute national and local threats where they feel marginalized and excluded. As restructuring of the security sector continues in line with the NSSRL, further retirement of excess staff will also be required. The Government is considering a series of measures to ensure that their concerns are addressed and to facilitate their proper reintegration into society. The establishment of the Veterans' Bureau is one such effort, providing education and employment programs. The lifespan of the National Commission on Disarmament, Demobilization, Rehabilitation and Reintegration (NCDDRR) has also been extended to address specific issues associated with the rehabilitation and reintegration of the ex-combatants, though support for the NCDDRR will end during 2008. In addition, the Government's economic strategy and capacity building initiatives (discussed in Chapters Seven and Twelve, respectively) aim to generate employment opportunities that will help diffuse the threats that stem from household economic insecurity.

${ }^{33}$ While the sudden, unanticipated return of approximately 40,000 Liberian refugees from Ghana presents a significant challenge, the Government intends to conclude the process of refugee repatriation and reintegration during the PRS period. As part of this program, tripartite conferences will be held between UNHCR, the Government of Liberia and the governments of countries where Liberians have sought refuge, to develop durable solutions. The Government will also ensure that basic social services are available through community empowerment and assistance programs, including services relating to income generation, education, agriculture and temporary shelter.

${ }^{34}$ In all of its security agencies, the Government will build systems for accountability and governance to assure that security personnel adhere to high standards of professional conduct and ethical behavior. Leaders of the security agencies will work closely with political leaders and civil society to increase the level of public monitoring. They will work with local leaders to create county- and district-level committees, coordinated with local government and other community leaders, to provide a forum through which security issues can be addressed locally.

\subsection{Building and Maintaining Regional Peace and Security}

${ }^{35}$ Over the last fifteen years, the Mano River basin has been an unstable sub-region. Liberia was at the epicenter of this instability, as the Liberian civil war extended to neighboring Sierra Leone. Guinea and Cote d'Ivoire have also suffered instability. Against this regional backdrop, Liberia is attempting to reform and to address wider sub-regional issues as part of its national security policy, since fragility of immediate neighboring states poses a potentially significant problem. In the absence of regional stability, trade between neighboring countries breaks down, with the result that national economies stagnate and poverty is not reduced. The Government will work to cement the growing bilateral and multilateral security cooperation between member states of the Mano River Union (MRU), ECOWAS, and the African Union, to meet the many transnational organized crime and security threats that require international collaboration. 
${ }^{36}$ The AFL will, in due course, participate fully in international peace and security arrangements including the ECOWAS Standby Force (ESF), African Union Standby Force (ASF), UN Peacekeeping, and others, so as to advance their professionalism. This will be done bearing in mind the uncompromised statutory responsibility to safeguard the integrity, sovereignty and political independence of Liberia's territory and resources.

${ }^{37}$ Finally, the Government will seek the support of countries within ECOWAS and the African Union, as well as UNMIL and other international partners, to assist the LNP in becoming a functioning part of the greater sub-regional security, intelligence and law enforcement effort.

\section{Issue}

Priority Interventions

Delivery Date

Lead Ministry I Agency

Goal: To create a secure and peaceful environment, both domestically and in the sub-region, that is conducive to sustainable, inclusive, and equitable growth and development.

\section{Strategic objective 1: To provide strategic and statutory guidance for security institutions}

The sector suffers from overlapping and duplication of security functions among security institutions, lack of accountability, and defective management of the security sector.
Formulation and Implementation of NSSRL-IM consistent with the PRS Cycle and annual validation exercises with associated costings

Streamline security institutions to curb proliferation of agencies

Repeal and amend statutory provisions of streamlined security agencies and that of host agencies in line with the NSSRL and National Security Architecture

Formulate Standard Operating Procedures for the new architecture

Execute and monitor the Concept of Operation (Con-Ops) of national security agencies, including national security exercises

Review NSSRL and NSSRL-IM in line with end of the three-year PRS period Include gender sensitive, disabilities sensitive, and environment sensitive modules in curricula of security institutions

\begin{tabular}{|c|c|}
\hline April 2008-April 2010 & $\begin{array}{l}\text { MoJ, LNP, BIN, } \\
\text { NFS, Corrections, } \\
\text { NSA, SSS, MoD } \\
\text { AFL, ONSA }\end{array}$ \\
\hline April-December 2008 & MoJ, MoD, NSC \\
\hline December 2008 & MoJ, MoD, NSC \\
\hline December 2008 & Security Institutions \\
\hline December 2010 & $\begin{array}{c}\text { MoD, MoJ, Security } \\
\text { Institutions }\end{array}$ \\
\hline December 2010 & Security Pillar \\
\hline December 2008 & MoD, MoJ, MoGD, \\
\hline
\end{tabular}




\section{Strategic objective 2: To build the capacity of security institutions}

Training is still needed for some security institutions, and security institutions lack logistics, equipment, and adequate remuneration for operation.
Reassess the ongoing vetting process and other practices relating to the recruitment, training, and deployment of LNP personnel, including consideration of establishing meritbased standards, entry requirements, accountable procedures for promotion and assignment, a Civilian Oversight Board and mentorship programs

Establish the National Coast Guard pending enactment of the Defense Act

Complete initial force development, including mentoring programs, of the Armed Forces of Liberia

Prepare curriculum and training modules, train officers and fire fighters of the National Fire Service (NFS)

Train the Emergency Response Unit (ERU) of the LNP

Deactivate, vet and recruit, and train officers of the Bureau of Immigration and Naturalization (BIN)

Recruit and train officers of the National Security Agency (NSA)

Conduct an operational needs assessment of security institutions

Prepare a medium-term budget for each national security institution to meet operational needs

\begin{tabular}{|c|c|}
\hline April-December 2008 & MOJ, LNP \\
\hline July 2008 & MoD \\
\hline December 2010 & MoD \\
\hline December 2009 & NFS \\
\hline December 2009 & LNP \\
\hline December 2010 & BIN \\
\hline December 2009 & NSA \\
\hline June 2008 & $\begin{array}{l}\text { AFL, LNP, BIN, } \\
\text { NSA, NFS, SSS }\end{array}$ \\
\hline December 2008 & $\begin{array}{l}\text { BoB, MoF, MoD } \\
\text { MoJ, Security } \\
\text { Institutions }\end{array}$ \\
\hline
\end{tabular}

Strategic objective 3: To provide adequate territorial protection and law enforcement services to the general population of Liberia

Inadequate presence of security officers throughout Liberia, security institutions are not yet in full control of security responsibility.

\begin{tabular}{|l|c|c|}
\hline $\begin{array}{l}\text { Enhance Community-Oriented Policing } \\
\text { to improve relations between civilians } \\
\text { and security institutions }\end{array}$ & December 2008 & MoJ, LNP \\
\hline $\begin{array}{l}\text { Prepare comprehensive deployment } \\
\text { plans for security institutions }\end{array}$ & December 2008 & Security Institutions \\
\hline $\begin{array}{l}\text { Execute deployment plans for security } \\
\text { institutions }\end{array}$ & December 2010 & Security Institutions \\
\hline $\begin{array}{l}\text { Regular situational and scenario } \\
\text { exercises in preparation for national } \\
\text { security forces to take over security } \\
\text { responsibilities from UNMIL }\end{array}$ & December 2010 & Security Institutions \\
\hline $\begin{array}{l}\text { Provide adequate human and per- } \\
\text { sonal security, especially for women } \\
\text { and girls of school age and persons } \\
\text { with disabilities, including ensuring } \\
\text { more speedy prosecution of violations } \\
\text { against human security }\end{array}$ & $2008-2011$ & MoD, MoJ \\
\hline
\end{tabular}

\section{Strategic objective 4: To ensure institutional participation in security governance and functions}

Civilians and local authorities are excluded from participating in security governance.

Female participation in security functions is inadequate.
Develop a county-based security mechanism to coordinate and promote local management of peace and security, including civilian and local government participation in security governance

Reinforce the initiative to realize 20 percent women's participation in the military and various security agencies
December 2008

MoD, MoJ, MIA

December 2010

MoGD, MoD, MoJ 


\section{Revitalizing the Economy}

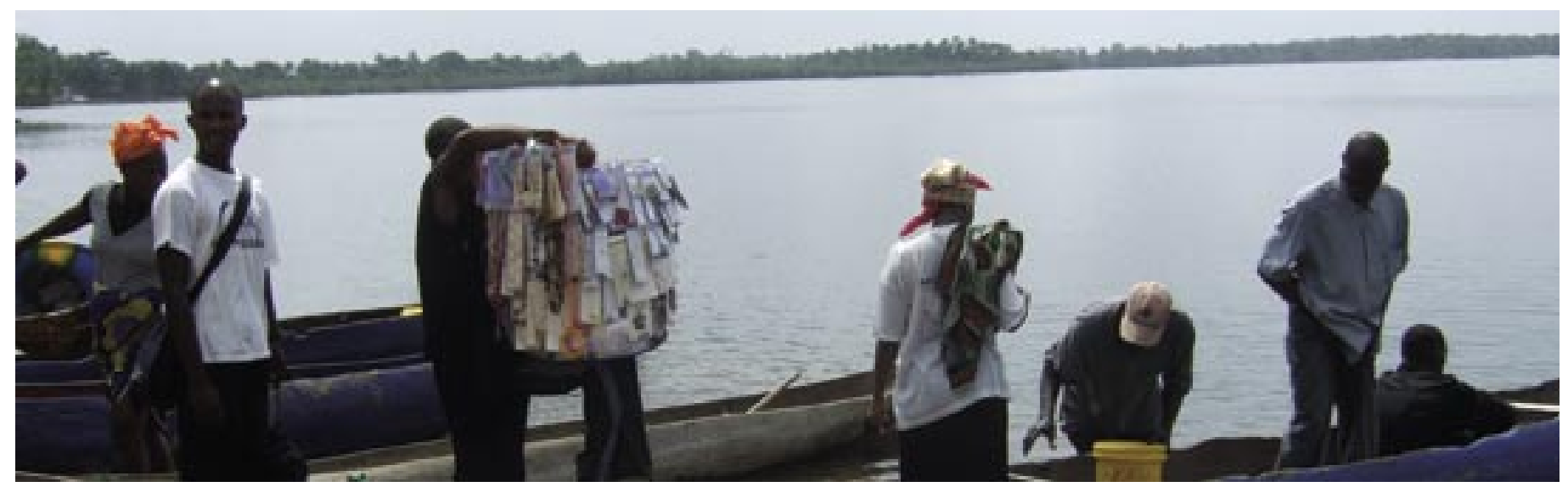

\subsection{Introduction}

${ }^{1}$ Liberia's central economic goal over the next three years is to firmly establish a stable and secure environment and to be on an irreversible path toward rapid, inclusive and sustainable growth and development. The achievement of this goal will have direct positive effects on the other three Pillars, as inclusive growth reduces internal security threats related to household insecurity, lessens the pressure on infrastructure and basic services, and facilitates the improvement of governance and the rule of law.

${ }^{2}$ As explained in Chapter Four, the Government's strategy for accelerating economic growth has three prongs: (1) rebuilding basic infrastructure, especially roads; (2) restoring production in the leading natural resource sectors, while ensuring the benefits are widely shared; and (3) reducing production costs to establish the foundation for diversification of the economy over time into competitive production of downstream products, and eventually manufactures and services. The first of these is described primarily in Chapter Nine; the latter two are discussed in this chapter.

${ }^{3}$ According to government estimates produced in conjunction with the IMF, economic growth is expected to accelerate to 9.6 percent in $2008,10.3$ percent in 2009 , and 14.8 percent in 2010 , before tapering off to 12.3 percent in $2011 .{ }^{37}$ Growth will be driven primarily by the reopening of the forestry and mining sectors, which nearly ceased production due to the war and UN sanctions, complemented by construction and other services. Growth is likely to decelerate after 2011 (although it will remain robust by historical standards) when the initial natural resource investments are more fully on stream. The projected growth rates are shown in Table 7.1.

${ }^{4}$ For Liberia to achieve its key objectives, rapid growth alone is not enough - it must be widely shared throughout society. The Government is committed to generating much more inclusive economic opportunities for historically marginalized groups, including disenfranchised young men, people living in rural areas, women, and persons with disabilities.

${ }^{5}$ The basis of this strategy will be private sector-driven growth, supported by public sector actions aimed at strengthening market functions. While attracting foreign investment is critical to growing the economy, the aim is ultimately to empower domestic entrepreneurs to conduct business and create jobs for others, thereby growing the size and purchasing power of the Liberian middle class. The Government will focus on what the private sector cannot or will not do at an appropriate price, such as maintaining

37 Unless otherwise noted, the historical and projected rates of overall and sector growth provided in this chapter are drawn from the Macroeconomic Framework developed in 2007-2008 by the Government in collaboration with IMF staff. 
safety and security, ensuring the rule of law, providing certain infrastructure and other public goods, and providing basic services for the poor. It will aim to introduce policies that facilitate the expansion and functioning of markets and to establish a regulatory environment that is conducive to long-term growth. More direct interventions will be infrequent, and where they do occur, they will be based on pressing need, and be time-bound with clear exit strategies and targeting mechanisms based on sound assessment of both potential market-retarding and market-promoting impacts. These assessments will take into account Liberia's particular situation and its current transitioning from an emergency phase to a development phase.

Table 7.1: Sectoral Real GDP Projections 2007-2011

\begin{tabular}{|c|c|c|c|c|c|}
\hline & $\begin{array}{c}2007 \\
\text { Est. }\end{array}$ & $\begin{array}{l}2008 \\
\text { Proj. }\end{array}$ & $\begin{array}{l}2009 \\
\text { Proj. }\end{array}$ & $\begin{array}{l}2010 \\
\text { Proj. }\end{array}$ & $\begin{array}{l}2011 \\
\text { Proj. }\end{array}$ \\
\hline & \multicolumn{5}{|c|}{ Annual percentage change } \\
\hline Real GDP & 9.5 & 9.6 & 10.3 & 14.8 & 12.3 \\
\hline \multicolumn{6}{|l|}{ Of which: } \\
\hline Agriculture \& fisheries & 7.3 & 3.6 & 3.7 & 3.8 & 3.8 \\
\hline Forestry & 1.0 & 22.1 & 10.0 & 15.6 & 14.9 \\
\hline Mining \& panning & 1614.6 & 73.5 & 106.4 & 78.2 & 51.1 \\
\hline Manufacturing & 3.9 & 3.9 & 3.9 & 24.3 & 5.0 \\
\hline \multirow[t]{2}{*}{ Services } & 10.4 & 9.5 & 9.0 & 8.2 & 8.2 \\
\hline & \multicolumn{5}{|c|}{ Percent share of total real GDP } \\
\hline Real GDP & 100.0 & 100.0 & 100.0 & 100.0 & 100.0 \\
\hline \multicolumn{6}{|l|}{ Of which: } \\
\hline Agriculture \& fisheries & 42.0 & 39.8 & 37.4 & 33.8 & 31.2 \\
\hline Forestry & 12.9 & 14.4 & 14.4 & 14.5 & 14.8 \\
\hline Mining \& panning & 2.5 & 4.0 & 7.5 & 11.7 & 15.8 \\
\hline Manufacturing & 13.2 & 12.5 & 11.8 & 12.7 & 11.9 \\
\hline Services & 29.3 & 29.3 & 28.9 & 27.3 & 26.3 \\
\hline
\end{tabular}

Source: Government of Liberia and IMF staff estimates

\subsection{Agriculture and Food Security}

${ }^{6}$ Agriculture provided the mainstay of the economy throughout the Liberian conflict and has accounted for over half of GDP in the postwar period (compared to one-tenth in the late 1970s). A large proportion of the economically active population of Liberia is engaged either directly or indirectly in smallholder subsistence agriculture or fisheries. Women and children are particularly dependent on the agricultural sector. Revitalizing the agricultural sector is crucial to overall economic recovery, ensuring that growth is inclusive, promoting peace and stability, and sustaining poverty reduction.

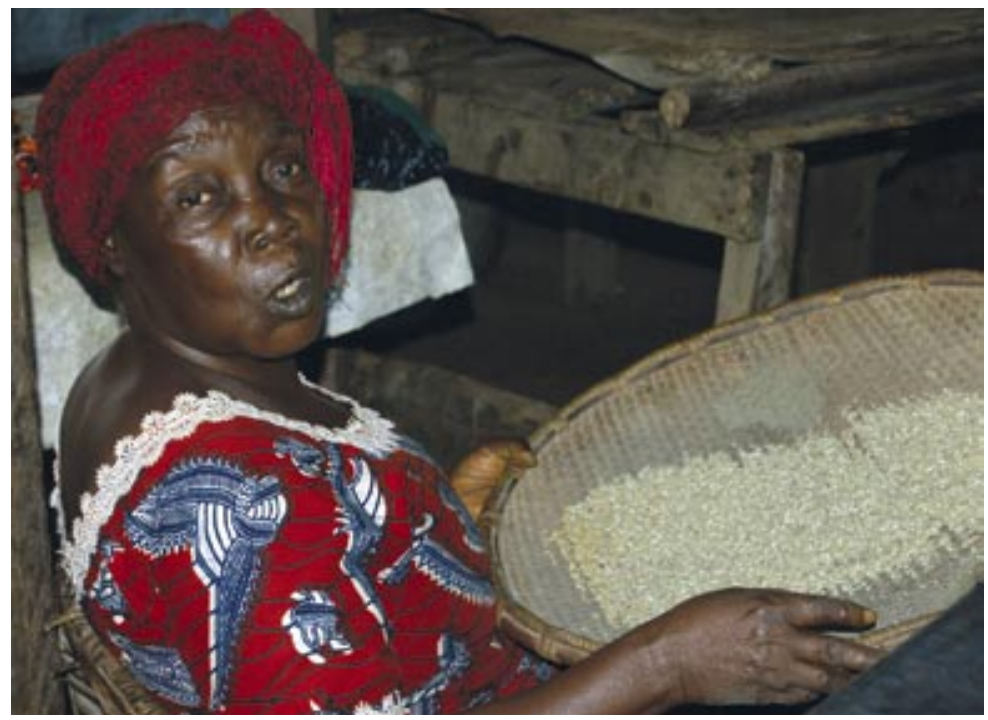
Historically, agricultural performance has been limited by structural constraints, poor policies and armed conflict. As a result, in 2006 some 81 percent of the rural population was found to be either moderately vulnerable (41 percent) or highly vulnerable to food insecurity (40 percent), while 11 percent of the rural population was food insecure and only 9 
percent was food secure. Chronic malnutrition rates had reached 39 percent for children under five. ${ }^{38}$ Even cash and/or food crop producers were considered likely to be food insecure, suggesting that food production for auto-consumption still does not often enable many households to meet their food needs. ${ }^{39}$

${ }^{7}$ The key challenges for transformation of the agriculture sector are:

- increasing food crop yields by adopting new techniques and technologies;

- improving access to seeds, fertilizers, and other inputs, and strengthening linkages to output markets, primarily by rebuilding farm-to-market roads;

- restoring value chains and increasing community and MSME participation in supply and value chains;

- providing food assistance to vulnerable groups that are severely food insecure;

- strengthening key agricultural institutions that were destroyed during the conflict;

- slowing the extent of illegal fishing and increasing the value added from catches;

- slowing deforestation, slash-and-burn cultivation, and tree cutting for firewood and charcoal, which degrade habitats and deplete natural resources; and

- providing greater opportunities for women and youth in agriculture, especially in the formal sector.

${ }^{8}$ Women are major players in the agricultural sector, where they constitute the majority of small-holder producers and the agricultural labor force in general. Women produce some 60 percent of agricultural products, carry out 80 percent of trading activities in rural areas, and play a vital role in linking rural and urban markets through their informal networks. Despite this deep involvement in agriculture, they represent a tiny fraction of participants in the formal sector. They also have less access to productive inputs than men, including land, skills training, basic tools and technology.

${ }^{9}$ Despite its challenges, Liberian agriculture has tremendous potential. Developments in world markets have sharply raised the demand and international prices for agricultural commodities. Petroleum price increases have diverted large amounts of grain, sugar, and vegetable oils to ethanol and bio-fuel production. Environmental concerns over the use of fossil fuels have reinforced this shift. High and rising incomes in Asia and the Middle East have increased the demand for animal feed to support rising consumption of animal-based products. Additional pressure has emerged through the diversion of productive farm land, especially in Asia, to industrial and other uses. The consequence of these developments has been a sharp upward shift in the price of all agricultural commodities. Liberia, with its huge potential for producing palm oil, rubber, rice, cassava and other agricultural products, is ideally placed to take advantage of these opportunities, which offer the prospect of supporting the sustained expansion of farm-based employment and incomes. These benefits will spill over to other rural economic activities such as marketing, processing, and storage.

${ }^{10}$ The central goal for the agricultural sector during the PRS period is to revitalize the sector in order to contribute to inclusive and sustainable economic development and growth, and to provide food security and nutrition, employment and income, and measurable poverty reduction.

${ }^{11}$ Specifically, the Government will strive to expand agricultural production by about 3.6 percent per annum during the first two years of the PRS period. This will be based on a strong supply response in

38 CFSNS, 2006, quoted in CWIQ, 2007

39 CWIQ, 2007 
the food crop sector, with traditional crops such as rice and cassava recovering strongly. Production of non-traditional export crops such as vegetables is also expected to expand rapidly. With support measures being put in place, the tree crop sector will also start recovering by 2009 , with cocoa, coffee and oil palm taking the lead. Rubber production, a critical component of agricultural growth, is expected to plateau or decline for some years before starting to recover toward the end of the PRS period.

12 The fisheries and livestock sectors will show some marginal increase during the first year of the PRS. The fisheries sector is likely to accelerate faster than livestock because the recovery measures being undertaken are shorter-term and more easily achievable. Total agricultural production is expected to expand by 6 percent by the end of 2010 and in 2011 . To realize the expected growth and achieve the central goal, the Government will focus on three strategic objectives.

${ }^{13}$ First, it will aim to develop more competitive, efficient, and sustainable food and agricultural value chains and linkages to markets. Redefining the role of the state and creating space for private sector-led agriculture (with smallholders at the core) will be at the forefront of the Government's approach to agricultural development. Government interventions will focus on creating a stable environment for private investment, with limited involvement in production and marketing functions. It will aim to clarify property rights and strengthen the security of land tenure, as discussed in more detail in section 7.5. The Government will clarify incentives to promote foreign and domestic investment in the sector and strengthen efforts to ensure adequate agricultural financing, particularly to smallholder farmers. Where there is a need for the Government to directly support essential inputs (mainly improved seeds and fertilizer) to increase production, it will carefully target the most needy (women and smallholders) in order not to retard the development of input markets. The Government will focus on farmer-based and other community organizations in its efforts to build production and marketing capacity amongst smallholders. It will place a high priority on linking smallholders to markets (local, regional and international), the increased participation of MSMEs in the supply chains and value chains, and establishing new institutional arrangements to ensure smallholders benefit from tree crop production. Access to markets will be a major factor in determining which feeder roads are to be rehabilitated first, and the Government will support critical local marketing infrastructure to reduce post-harvest losses. Finally, to ensure that growth is more inclusive than in the past, the Government expects all agricultural concessions to include out-grower schemes appropriate to the subsector, including-in the case of rubber-the creation of formal ties between out-growers and processors.

${ }^{14}$ Second, it will strive to improve food security and nutrition, especially for vulnerable groups, including pregnant and lactating women and children under five. As discussed in Chapter Three, 40 percent of Liberians are either highly or moderately vulnerable to food insecurity. High levels of food insecurity and child malnutrition impede socio-economic development and poverty reduction; by one estimate, poor nutrition could lead to productivity losses of US $\$ 431$ million over the next nine years. ${ }^{40}$ To address these issues, the Government will work to improve access to markets by rebuilding roads, facilitating access to inputs, and increasing market competitiveness and efficiency. The Government will also ensure the wellbeing of vulnerable households which are unable to take advantage of emerging opportunities by developing a targeted social safety net program.

${ }^{15}$ Interventions will also be undertaken with respect to the fisheries and livestock industries to increase available food and to strengthen institutional frameworks. As was recommended in the recent draft Diagnostic Trade Integrated Framework Study, ${ }^{41}$ recovery measures for fisheries will include improving the monitoring, control and surveillance of Liberian waters, finalizing the establishment of a competent authority to facilitate trade to the European Union and the United States, and preparing for a Fisheries Partnership Agreement with the European Union. The Government will also implement programs to rehabilitate fish ponds. For livestock, a restocking program will be undertaken focusing on small ruminants.

${ }^{16}$ Notwithstanding these interventions, disaster mitigation, risk reduction and early warning of food secu-

\footnotetext{
40 MOHSW/AED/World Food Program, Nutrition Policy Analysis using PROFILES: Investing in Nutrition to Reduce Poverty, December 2007

41 World Bank, Liberia Diagnostic Trade Integration Study: Fisheries (Draft), January 2008
} 
rity issues will be critical. The Government will therefore monitor trends in food security and malnutrition to inform decision making and a timely response to emerging problems.

${ }^{17}$ Third, it will strengthen human and institutional capacity. The Government will aim to establish functional, efficient and effective institutions to provide needed services, to create a strong enabling environment, and to reduce vulnerability. It will re-establish its role as custodian of Liberia's natural resources, with special attention to transparency and sustainability in land use, and will promote farmer-based organizations (FBOs) as representatives of farming communities and will ensure their role in locallevel planning. FBOs will play a key role in defining the kinds of services to be provided and will be the main mechanism for building the capacity of farmers. The Government will focus agricultural research and extension services on the needs and priorities identified by the FBOs. It will abolish all statutory monopolies and focus public institutions on their regulatory functions only. It will develop a sector monitoring framework involving all stakeholders to track progress and measure results.

${ }^{18}$ The Government will also undertake measures to expand the role of women in the agricultural value chain and increase women's participation in non-traditional segments of the economy and the labor market. It will incorporate gender issues in rural strategies and programs to ensure that they support the role of women, create opportunities for women in non-traditional rural activities, including women with disabilities, and enhance women's access to productive assets and services in the agricultural value chain. It will aim to facilitate married and single women's participation in farmer field schools and other rural community organizations. It will also explore options to create and strengthen the institutional capacity of female producer associations.

${ }_{19}$ In seeking to achieve the PRS objectives, the Government will use its existing strengths, i.e., expand existing production systems before introducing new ones. It will focus most immediately on food security. To support production, it will also aim to ensure that sufficient critical inputs are available (preferably through the market, although other modalities may be required) and to make basic improvements in the marketing chain. It will begin to rebuild essential capacity in public institutions as a precursor to wider institutional reform. Over the medium and long term, it will aim to rebuild a comprehensive agricultural extension system and in particular to expand national research capacity in the context of regional initiatives.

\subsection{Forestry}

${ }^{20}$ Prior to 2003, the forestry sector was a major contributor to economic growth in Liberia. Total log and timber production per annum peaked at 1 million cubic meters, with a value of approximately US $\$ 100$ million. An average of 7,000 persons was employed in the sector. Forestry contributed approximately 50 percent of Liberian export earnings and about 20 percent of GDP.

${ }^{21}$ In 2003 the United Nations Security

Council imposed sanctions on Liberian log and timber exports because of poor governance in the sector and its role in fueling the conflict. In particular, the Government lacked control over forest areas, revenues were being assigned to individuals rather than Government accounts, human rights abuses were being committed by sector operators, and forest area ownership was often duplicated.

${ }^{22}$ After a legal review of the sector, the new Government declared all timber contracts null and void and instituted reform measures that were accepted by the UNSC

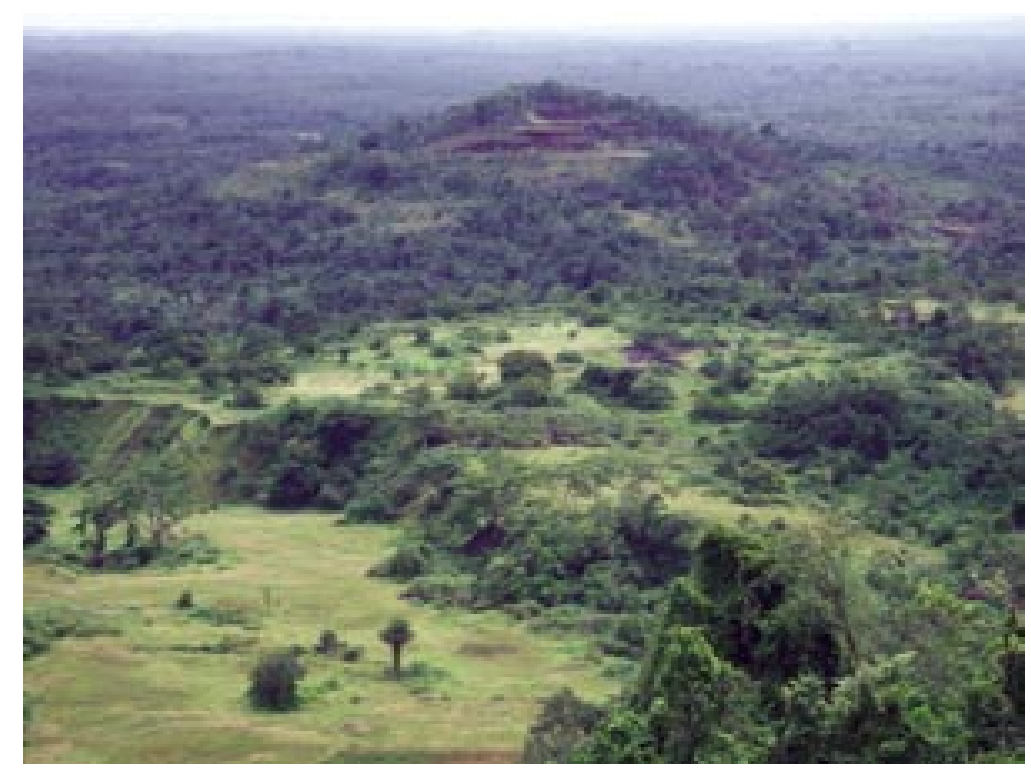


and led to the lifting of the sanctions in 2006. The reform measures included the enactment of a new forest reform law, forest land use planning, forest institutional reforms, and transparent control of timber production through a chain of custody system. The legal framework and the ground rules have now been laid for sustainable forest management and the economic revival of the sector. Timber production is expected to start in 2008 and steadily increase to a sustainable level by 2012 .

${ }^{23}$ The central goal for forestry over the PRS implementation period is for the sector to become a source of higher incomes for the rural population, ensuring that the benefits are shared equitably, and that adequate environmental and other regulatory safeguards are in place to ensure sustainability.

${ }^{24}$ The Forestry Development Authority (FDA) aims to balance conservation, community and commercial uses in implementing forestry policy. It will focus on the following strategic objectives:

- developing commercial forestry, including by encouraging value-added forestry products, to be a significant source of revenue generation and growth for local people, MSMEs, and the nation at large;

- using community forest management techniques to identify viable economic opportunities for communities from forest resources and providing extension and technical assistance in community forest management;

- conserving protected and important biologically diverse areas, with an emphasis on providing sustainable livelihoods for communities at the fringes of the forest, and promoting tourism;

- enhancing environmental benefits from forestry reserves through an analysis of potential markets for trading in carbon credits; and

- implementing a Chain of Custody Management Contract to induce transparency and protect revenue generation, as well as to maintain a forestry database of pertinent information on available fauna and flora species.

${ }^{25}$ Forestry production is projected to grow substantially during the PRS period from 30,000 cubic meters $\left(\mathrm{M}^{3}\right)$ to more than $1,300,000 \mathrm{M}^{3}$ (see Table 7.2 below), with approximately 2.9 million hectares of forest being used for commercial and community forestry and 1.2 million hectares allocated for conservation and tourism. Rural employment in this sector is targeted at 5,000 for the three year PRS period.

${ }^{26}$ The Government will continue to strengthen the chain of custody system and promote good governance and transparency, in particular by participating in the Extractive Industries Transparency Initiative, under which Liberia is the first country to have it applied to the forestry sector. As a result of these measures, the prospects for revenue growth are strong. Revenues are projected to grow from half a million US dollars in fiscal $2007 / 2008$ to US\$24 million in $2009 / 2010$. This will be supported by a shift toward more value-added timber products over the course of the PRS.

\section{Table 7.2: Forestry Production and Revenue}

\begin{tabular}{|c|r|r|r|r|r|r|}
\hline Forestry Production and Revenue & $\mathbf{2 0 0 7 - 2 0 0 8}$ & $\mathbf{2 0 0 8 - 2 0 0 9}$ & $\mathbf{2 0 0 9 - 2 0 1 0}$ & $\mathbf{2 0 1 0 - 2 0 1 1}$ & Total \\
\hline Production (in '000 M³) & 44 & 809 & 1,055 & 1,419 & 3,329 \\
\hline Revenue (in 000 'USDs) & 526 & 24,283 & 36,686 & 46,110 & 107,607 \\
\hline
\end{tabular}

Source: Government of Liberia and IMF staff estimates

${ }^{27}$ Concession contracts for commercial forestry (as well as for other agricultural products) will differ from past agreements in several ways. The Government is committed to negotiating concession contracts 
that balance competitive returns for the investor with the need for sustained revenues for the people of Liberia. Concession revenues received by the Government will be used to promote public welfare by financing investments in roads, education, health, water, and other areas such as infrastructure and basic services.

${ }^{28}$ The Government will undertake community-based natural resource management reforms that focus on boosting economic activity through the sustainable utilization of timber products, non-timber forest resources, and agro-forestry products, while also improving environmental management and conservation. It will establish practical mechanisms to enable communities to become directly involved in forest management and to participate in the equitable sharing of benefits stemming from commercial logging. It will conduct market and value chain analyses to identify likely timber and non-timber forest products that could be promoted through community and MSME forest activities. It will make special efforts to create new opportunities for women in the forestry sector and will also explore the potential for environment-related industries such as eco-tourism, game ranching, and recreation areas. These activities are targeted to increase rural incomes, reduce poverty and build local capacity to maintain and restore forest coverage in the country. To do so the Government will enhance coordination between the FDA and the EPA and other ministries and agencies.

\subsection{Mining}

${ }^{29}$ Mining and panning activities are expected to grow rapidly during the PRS period, from near zero production in 2005/06 to almost 12 percent of GDP. ${ }^{42}$ Such growth in the mining sector has the potential to contribute significantly to employment, income generation and infrastructure development. The major contributor to this growth will be the resumption of the mining and exporting of iron ore. Iron ore was the mainstay of the Liberian economy between 1960 and 1980, contributing more than 60 percent of export earnings and about 25 percent of GDP.

${ }^{30}$ The ArcelorMittal mining operations are expected to initiate the revival of iron ore production when it makes its first projected shipment of 2-4 million tons in 2010. Production at other mines currently out for bid, such as the Western Cluster and Bong Mines, is expected to commence production in four to five years.

${ }^{31}$ Gold and diamond mining in Liberia consists largely of alluvial and small-scale operations, with estimates of over 100,000 artisanal miners in Liberia. The sector faces major challenges with unrecorded production, poor working conditions, and a variety of environmental and social problems. During the PRS period, small-scale operations will be encouraged through the support of cooperative schemes, with an emphasis on formalizing

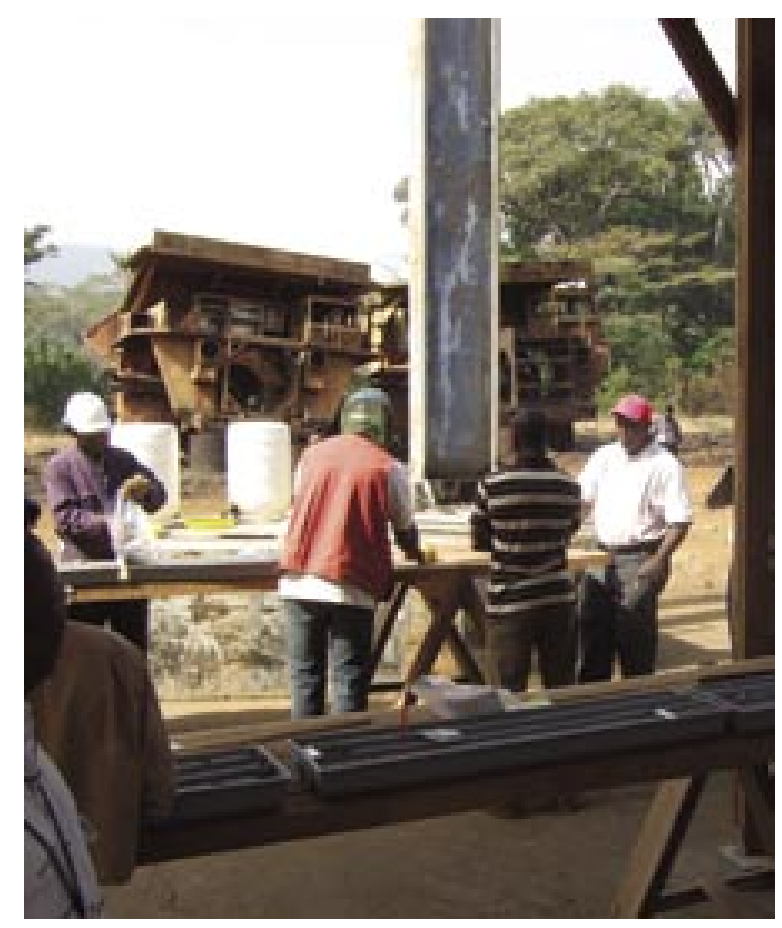
their activities and reducing the potential for the sector to fuel future conflict. Efforts must be undertaken to improve the efficiency of recovery methods of alluvial mining and production from medium- to large-scale operations which should increase revenues during the PRS period.

${ }^{32}$ There are 26 exploration companies currently holding 53 licenses. Total Government revenues realized from exploration activities for 2007 were approximately US $\$ 1.9$ million. About 44 new licenses are expected to be issued which could yield additional annual revenue of US $\$ 1.2$ million. Some of these

42 The data in Section 7.4 are drawn from the 2007 MLME document The Liberian Mineral Sector: Brief Overview of Status and Prospects for Growth, as well as estimates from ArcelorMittal and IMF staff. 
companies are expected to convert their exploration activities into Mineral Development Agreements (MDAs) during the PRS period. Plans are also underway for development of a discovery of approximately 1.5 million ounces of gold by Mano River Resources in Grand Cape Mount County. This mine, which will be Liberia's first mechanized gold mine, is expected to be established within two years.

${ }^{33}$ The major policy challenge in the mining sector is to develop a national mining sector framework and MDAs that promote growth that is not just rapid, but also inclusive and sustainable, while at the same time minimizing the negative social and environmental impacts of mining activities. In particular, the Government is aiming to develop mining concession contracts that differ from those of the past by better balancing competitive investor returns with the need for robust revenues, and ensuring that local communities share in the benefits through direct and indirect employment, access to new infrastructure, and programs targeted at diversification of activities and local economic development beyond the life of the mine.

${ }^{34}$ It is also important that royalty and tax payments, as well as their distribution, are fully reported in a transparent manner. This will help to ensure that Liberia's resource wealth in mining, as well as in forestry and potentially in crude oil, are used for the benefit of all Liberians, and not to fuel conflict. In addition to the aforementioned LEITI, the Kimberly process will assist in ensuring that the proceeds from diamond exports are not fuelling conflict.

${ }^{35}$ These challenges are made more difficult by overlaps and conflicts between different pieces of legislation that govern the sector, and by the lack of adequate logistics, personnel and funding that constrain proper governance, particularly in relation to field monitoring and technical audit functions.

${ }^{36}$ The Government's central goal for the mining sector is to rapidly expand mining as an engine of economic growth and social development, with mining expected to grow to nearly 12 percent of GDP in 2011, and to ensure that the benefits from mining activities are widely shared. The Government will aim to diversify the mining sector into new and downstream activities, and to improve its support to local miners.

${ }^{37}$ To achieve this goal, the Government will review and adjust the existing enabling environment for mining sector development. In particular, it will eliminate the overlaps and conflicts between different pieces of legislation, including the conflict between the Public Procurement and Concession Act (PPCA) and the New Minerals and Mining Law (NMML) Act of 2000 regarding the granting of exploration licenses and mining leases. In addition, it will harmonize the NMML and the Forestry Law with respect to mining concession rights and protected zones. It will submit by May 2008 a new fiscal regime for mining and petroleum as part of the proposed pensions to the 2000 Revenue Code. It will also adopt and implement a national mining sector framework with input from communities and stakeholders' groups that will include the following elements:

- A National Mineral Policy that will provide a guiding framework for decision makers in the management of Liberia's mineral resources. The Policy will advocate the optimal development and utilization of these resources, including iron ore, gold and diamonds, through transparent and accountable financial arrangements, the development of local infrastructure, a reduction of adverse social and environmental impacts of mining activities, and the targeting of illegal mining.

- A Model Mineral Development Agreement (MDA) that will define clear terms and provisions for mining operations, including fiscal, legal, infrastructure, and social and environmental issues. Upon finalizing the Model MDA, the Government will aim to conclude MDAs for the Western Cluster, Bong Mines, Kitomo, Goe Fantro, and Amlib projects, as well as advance the establishment of new mining projects.

- A Mining Cadastre Information Management System (MCIMS) that will improve management of the mining licensing system by clearly defining property boundaries. The MCIMS will promote transparency in awarding mineral titles to minimize conflicts, and will ultimately be linked to a national land-use registry.

${ }^{38}$ To improve support to local miners, the Government's legal and regulatory reforms will include developing favorable regulations for small-scale mining and the initiation of sensitization and awareness campaigns. 
${ }^{39}$ In addition to these legal and regulatory reforms, the Government will consider a restructuring of the Ministry of Lands, Mines, and Energy to address the lack of important functional groups, including a mining cadastre office responsible for the issuance and management of mineral licenses and leases; a policy formulation and development group; a group with responsibility for community development and conflict management; and an artisanal and small-scale mining extension service. The Government will also consider implementing the recommendations of the Governance Commission, which included separation of the responsibilities for the functions of lands, mines and energy within the Ministry.

${ }^{40}$ Regarding capacity, the Government will develop technical audit functions to enable it to verify production and payments due from mining companies under their contracts once mining activities commence. The MLME will also give special attention to making regional offices operational as soon as possible so as to enable provision of services to mining companies and artisanal miners at the regional level.

\subsection{Land and Environmental Policy}

${ }^{41}$ Poverty, land, and the environment are inextricably linked. The rural poor of Liberia depend almost entirely upon land and other natural resources for their livelihoods, including their food, fuel, shelter, water and medicines. Unequal access to and ownership of land and other resources have contributed significantly to economic and political inequities throughout Liberia's history, and have exacerbated tensions and conflict. The existing systems of land acquisition favor the wealthy and the elite. Women in particular have had limited land and resource rights. Poverty and the paucity of technical skills leave most Liberians with limited options and few incentives to protect the natural resource base, and make coping with and adapting to environmental changes more difficult. These issues may become even more difficult in the near future as global warming changes climatic patterns, which may affect coastal flooding and rainfall.

${ }^{42}$ Access to land and its resources and security of tenure are essential for economic revitalization, growth, and poverty reduction. Smallholder farmers, who make up the majority of Liberia's rural population, require access and security of tenure to move beyond subsistence farming into more profitable and sustainable livelihoods that will achieve food security and increased export crop production. Commercial users of land and its resources also need security of tenure for investments. Establishing a working system to promote the reconciliation of land disputes during the PRS period, and which can also improve public perceptions about mechanisms and the Government's capacity for dealing with land conflicts, will have a significant impact on promoting private sector participation in the economy and the overall stabilization of Liberia.

${ }^{43}$ In Liberia, the main engines of growth for the next several years are natural resource-based activities - principally mining, timber production, and rubber and other plantations. None of these activities can expand without affecting the resources upon which the rural poor depend. Moreover, new investment in

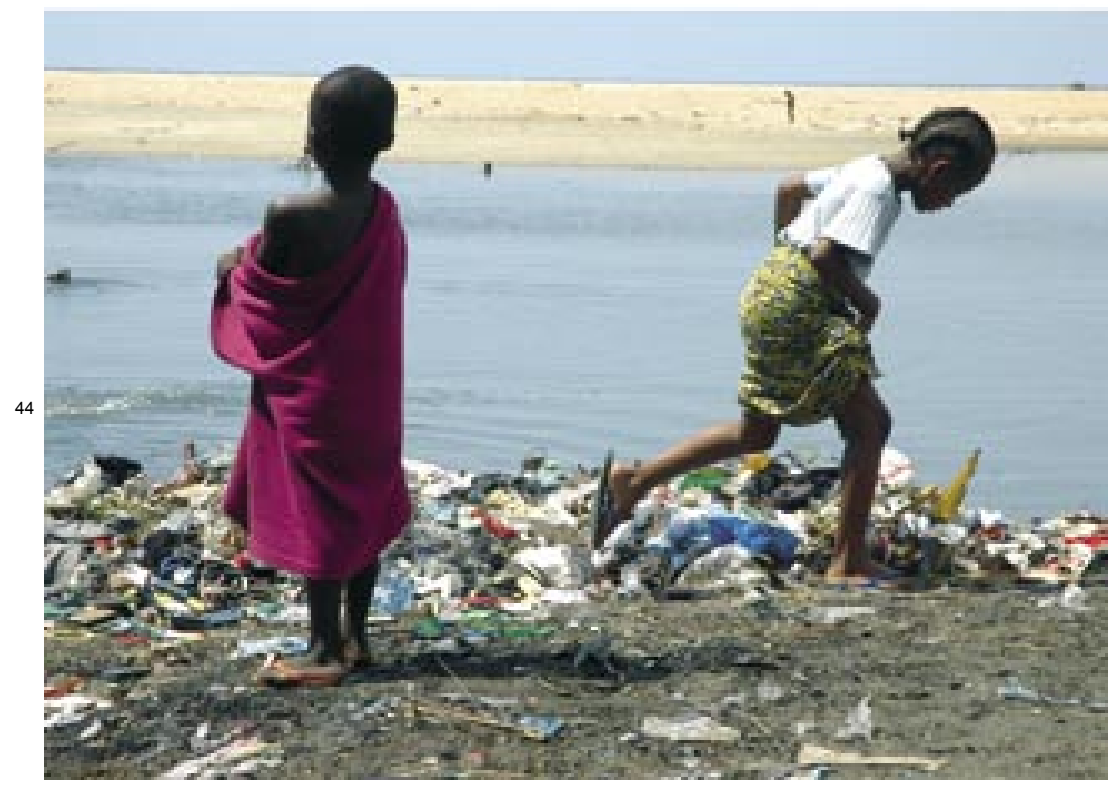
almost any area depends crucially on clear property rights. In addition, the limitations on who can own land in Liberia and the uncertainty about land titling both add to the costs and risks of investments in a wide range of activities, and create prohibitive barriers to investment in some cases.

Land policy is one of the most sensitive and important policies for Liberia in the quest for rapid, inclusive and sustainable growth, and for consolidating peace and security. The challenges, however, are many and complex. There is no comprehensive national policy or strategy on land allocation 
and use, whether for private users, community, concessions, or Government. Laws pertaining to land are outdated and do not serve the country's development goals. In the past, concession agreements have had inconsistent provisions, often providing land areas significantly in excess of what can reasonably be developed, while local communities have experienced significant land pressure. Current provisions for the access to land and security of tenure by communities under customary tenure are inadequate. Residents feel that their livelihoods and security are threatened by current laws and practices, and those subject to customary law do not have equal protection as provided by the 1986 Constitution.

${ }^{45}$ The judicial system is over-burdened and without sufficient capacity to adjudicate land matters in a timely manner and as a result, fraud is common and entrenched. Moreover, the administration and management of land is inadequate and outdated. Land records are in disarray, are located in several places, and are open to tampering and fraud. There are overlapping or conflicting functions of ministries and agencies, and capacity is extremely limited.

${ }^{46}$ The Government's primary goal with respect to land is to develop a comprehensive national land tenure and land use system that will provide equitable access to land and security of tenure so as to facilitate inclusive and sustainable growth and development, and ensure peace and security.

${ }^{47}$ To achieve this goal, the Government's strategic objectives and priority actions include:

- Promoting equitable and productive access to the nation's land, both public and private, especially for the poor, women, and other marginalized groups. The Government will review and reform land policy and law, and develop comprehensive national land use surveying and mapping.

- Promoting security of land tenure and the rule of law with respect to landholding and dealings in land. The Government will review customary land tenure and existing local government institutions, and will recognize and protect rights of use and ownership of land and other resources by local communities. It will undertake an adjudication process to determine current claims to land, review mechanisms for land dispute resolution under statutory and customary law and propose, if appropriate, alternative dispute resolution mechanisms, and develop procedures for equitable and fair enforcement of laws pertaining to land and other property. The Government will also review the process of issuing public land sale deeds by the Office of the President.

- Promoting effective land administration and management. The Government will secure and conserve deeds and other records related to rights in land. It will clarify the roles of, and build the capacity within, the Ministry of Lands, Mines \& Energy (specifically the surveys unit), the Ministry of Agriculture, and the Forest Development Authority. By building capacity, it expects to be able to undertake a land cadastre in coming years to determine claims to land. However, during the PRS period, the Government will pilot a land registration system.

- Promoting investment in and development of the nation's land resources. The Government will review and revise laws pertaining to land and real estate taxation, with the view to discouraging large undeveloped land holdings. Policies and programs will also be developed that enable smallholders to move to more profitable and sustainable livelihoods, and develop national zoning regulations.

${ }^{48}$ Because of the critical nature of land in Liberia, the Government will address the issue in a comprehensive manner by establishing a Land Commission. The Land Commission will further identify, guide, and facilitate reforms in land policy, law, and programs. It will aim to facilitate land tenure arrangements that are conducive to sound land use and appropriate farming, forestry, and mining systems that are supportive of inclusive growth and sustainable natural resource management. It will help devise means that balance competing demands on land use, e.g., forest versus farm land, agrarian structure (smallholders versus plantations), and agricultural production (food crops versus export crops). The Governance Commission is working to help establish the Commission by July 2008.

${ }^{49}$ To address issues of climate change and the adverse effects of a changing environment, the 
Government will also consider revitalizing the National Disaster Relief Commission and its secretariat to educate the public about disaster risk reduction and to coordinate the Government's response to disasters when they do occur. In addition, the Government will endeavor to develop an integrated coastal zone management plan, a wetlands management policy and a water resources management plan to govern the use of, and interaction with, these valuable natural resources.

\subsection{Stimulating Private Sector Investment and Development in Downstream Production, Manufacturing, Trade, and Services}

${ }^{50}$ Although Liberia is endowed with rich natural resources that can help spur growth during the next several years, to sustain growth over the medium-to-long term it will aim to diversify the economy and encourage private sector investment in manufacturing, trade, and services. Liberia has the potential for economic activity in a variety of non-traditional products, including downstream processed products and other manufactures and services such as agro-processing, furniture and other downstream wood products, and downstream rubber products. Investment in such labor-intensive activities can create significant numbers of jobs, encourage MSME growth, stimulate exports, and provide the basis for sustained growth in productivity, skill levels, wages, and income over time. They can create important new economic opportunities for women, young adult workers, persons with disabilities, and unskilled and semi-skilled workers. As such they can be a vital ingredient to generating more inclusive and sustainable growth for all Liberians.

${ }^{51}$ However, development of these industries remains in its infancy due to the poor condition of infrastructure, cumbersome procedures, high administrative costs, a largely unskilled labor force and difficulties in firms moving from informal to formal status. Making the transition will take time and a significant improvement in Liberia's international competitiveness. During the PRS period the Government will aim to lay the foundation for diversification of the economy over the medium-to-long term, and will consider how and when to move forward with steps to achieving accession to the World Trade Organization.

${ }^{52}$ The key challenges and constraints to stimulating private sector trade and investment in non-traditional activities include the following:

- Weak infrastructure, especially roads, power, and telecommunications (see Chapter Nine for further details).

- Poor road conditions add to production costs and create delays, and significantly undermine linkages to markets for rural enterprises.

- Electricity is expensive and most micro and small enterprises have little or no access. With public energy generation and grid supplies only beginning to re-emerge in Monrovia, most energy will continue to be supplied by private generators. Restoring generation capacity and the grid network to ensure effective distribution of regular electrical power supply is critical.

- Telecommunications infrastructure remains weak, and the market needs modernized laws and regulations, with a clear separation of policy and regulatory and licensing functions.

- Cumbersome procedures and high administrative and regulatory costs. The World Bank Group's 2008 Doing Business survey ranked Liberia's business environment in the bottom 25 of 178 countries worldwide. There are a host of administrative and regulatory issues and barriers that severely limit the ability of businesses to operate effectively, including excessive inspections of businesses by public officials, cumbersome business start-up, work permit and other business-related bureaucratic procedures, visa difficulties, unclear investment procedures, informal taxes, and cumbersome customs procedures and charges. Notwithstanding some recent improvements, these costs are a particular burden to small and medium-sized enterprises, as well as to female entrepreneurs.

- Large Informal Sector. Liberia has an exceptionally large informal sector, currently generating as much as four times more employment than the formal sector. Many women, young adults and persons 
with disabilities work in the informal sector. While cushioning the impact of the economic collapse, informality has significant economic costs. Informal enterprises also have limited access to capital and business development services which results in their growing more slowly and generating fewer jobs than do formal firms. For those businesses not yet ready for formalization, the challenge for the Government is to implement programs and policies that help improve productivity and working conditions in the informal sector. In addition the Government will need to correct credit market failures in order to enhance access to capital for both the informal sector and those newly formalized, likely fragile businesses. Women and youth face particularly large obstacles in gaining employment and starting businesses and will benefit most from these reforms.

- Largely unskilled labor force. Many workers have insufficient basic skills, including functional literacy, necessary for productive employment.

- Limited access to finance. Many firms do not have access to the capital necessary to begin to expand their businesses. This is due to a combination of informality (which makes it difficult to obtain credit), a lack of business skills, and weaknesses in the financial sector as described in the next section. Women in particular face significant barriers to obtaining credit.

- Relatively small trade linkages with the region and the world. Few firms outside the traditional natural resource sectors export within the region or beyond. Strong integration with global markets is critical for expanding local markets, improving efficiency and obtaining new technologies.

- Lack of confidence among the general public in the sustainability of reforms. The past disruptions have diminished the public's ability and willingness to take the risks needed to expand productive enterprises. Overcoming this extreme risk aversion will require a stable, coherent policy setting in which the Government makes modest commitments to improve national welfare and delivers on them.

${ }^{53}$ The central goal in the area of private sector investment is to create a strong enabling environment for investment and exports in non-traditional activities by rebuilding infrastructure, reducing unnecessary business costs, streamlining administrative procedures and facilitating trade.

${ }^{54}$ The Government's main approach will be to focus on reducing unnecessary costs of doing business. It is committed to regulatory reform to improve the country's investment climate and ease administrative and regulatory burdens on private businesses. This approach will create new economic opportunities for small and medium-sized enterprises, and will begin to break down the barriers facing women and other marginalized groups.

${ }^{55}$ Specifically, the Government will take the following steps during the PRS period:

- First, it will rebuild infrastructure around the country, as described in more detail in Chapter Nine. The long-term competitiveness and sustainability of dynamic private investment in Liberia, as well as ensuring that enterprises can develop throughout the country, depend on building adequate and reliable infrastructure.

- Second, it will take steps to reduce or eliminate unnecessary regulations and administrative requirements that add to business costs. The Government has already appointed a cabinet-level committee to address the high costs and administrative and regulatory barriers related to doing business, and to take specific steps to implement administrative reforms to reduce these burdens. The committee will initially focus on administrative barriers associated with starting a business, licenses, registering property, and trading across borders. It will eliminate redundant and duplicate procedures, and streamline regulations and administrative steps wherever possible. These reforms will benefit all businesses, but will especially benefit MSMEs, female-headed and other informal enterprises where the monetary and time costs of doing business are more acutely felt. Among the initiatives already underway are the development of a streamlined business registration process and eventual computerized business registry, faster granting of permits for construction, the development of a one-stop shop for customs and 
- Third, it will take steps to strengthen the financial sector, as described in the next section, to encourage the development of credit markets and to improve access to finance by micro, small and mediumsized enterprises.

- Fourth, it will continue to improve tax policy and tax administration, working through the Legislature to reduce the corporate income tax rate to 30 percent and to reduce the personal income tax rate to 25 percent. The Government is also considering abolishing the turnover tax as a minimum tax and will progressively align its import tariffs with the ECOWAS Common External Tariff (CET). Over the medium term it will decrease its reliance on import duties and introduce a value-added tax, although the latter may not be feasible during the PRS period given capacity and other constraints.

- Fifth, it will work with partners to create training programs for women, young adult workers, persons with disabilities, and other marginalized groups to better enable them to take advantage of potential income-earning opportunities.

- Sixth, it will continue to improve the Investment Code. It is working to develop streamlined investment procedures and to level the playing field between domestic and foreign investors. As part of this strategy, it will take steps to create an appropriate environment for MSME development and to increase MSME participation in the economy.

- Seventh, it will consider developing one or more Special Economic Zones (SEZs) to promote investment, reduce production costs, generate employment, diversify production and better integrate Liberian firms with regional and global markets. Well-managed SEZs, export processing zones (EPZs), and other export platforms have been an integral part of the success of some countries in diversifying production and stimulating non-traditional labor-intensive exports. In particular, the Government will explore the development of an SEZ near Buchanan. In so doing the Government will fully consider the lessons from cross-country experiences in Africa and East Asia, and has requested support from its partners to that end.

- Eighth, it will work to strengthen cooperation with neighboring countries in both the Mano River Union and ECOWAS with an eye to increased trade and investment.

\subsection{Revitalizing Financial Services}

${ }^{56}$ An efficient financial sector is essential to poverty reduction, economic growth and social progress. The financial sector is dominated by the banking system, comprised of the Central Bank of Liberia (CBL) and five commercial banks with 13 branches, mainly in Monrovia (with branches in Margibi, Bong, Nimba and Grand Bassa counties). There are also non-bank financial institutions -20 insurance companies, 118 licensed foreign exchange bureaus, three money transfer/remittance entities and five microfinance institutions. The financial sector is narrow and underdeveloped, characterized by limited financial instruments, a low level of financial intermediation, and limited trust among the public. The cash-based payments system is outdated and inefficient. Liberia has a dual currency arrangement with the Liberian and US dollars as legal tender and a market-determined exchange rate.

${ }^{57}$ A number of systemic and institutional constraints have contributed to a low level of financial intermediation and availability of financing for productive investments, particularly to small and medium-sized enterprises, as well as rural-based agricultural industries. These include a high volume of non-performing loans, ineffective judicial procedures for loan recovery, high intermediation costs (especially in rural areas), inadequate credit risk management systems, few adequately trained personnel, and non-transparent corporate governance practices.

${ }^{58}$ The central goal for the Government's financial sector reform strategy is to promote a stable, sound and market-based financial system that supports efficient mobilization and allocation of resources to foster 
sustainable economic growth and poverty reduction throughout the country. The Government expects the financial sector to grow by 10 percent per year during the PRS period, roughly in line with aggregate economic growth.

${ }^{59}$ To achieve this goal the Government will focus on the following objectives:

- modernizing the payments system;

- ensuring that commercial banks are fully capitalized;

- exploring ways to address over time the issue of the capitalization of the Central Bank of Liberia;

- encouraging a sustainable, well-managed microfinance sector as a means of broadening and extending financial services, especially to rural areas;

- strengthening the legal framework to facilitate the collection of debt and enforcement of financial contracts;

- developing the necessary legal and regulatory environment to ensure that alternative frameworks for access to finance (such as leasing and equipment finance) can occur;

- laying the groundwork for developing markets for short-term securities and other money market instruments;

- improving transparency and efficiency in information-sharing among financial institutions on the creditworthiness of potential borrowers; and

- strengthening depositor protection and improving confidence in the financial system. ${ }^{43}$

${ }^{60}$ The Government's financial sector reform strategy focuses on promoting competition and efficiency ins the system to allow it to more effectively support development of the private sector, including in rural areas. This will call for, among other things, intensifying of supervision and regulation of commercial banks and non-bank financial institutions, strengthening prudential controls and improving the credit risk assessment capacity of commercial banks, rationalizing non-performing loans, and improving the existing legal framework for enforcement of financial contracts for the recovery of loans.

${ }^{61}$ Ongoing reforms spearheaded by the CBL focus on identifying deficiencies in individual banks and in the banking system as a whole, developing action plans for adequate capitalization and continued capital growth, enhancing corporate governance and risk management systems, developing partnerships with reputable outside banking investors, and promoting the development of microfinance.

${ }^{62}$ The strategy's key policies and actions include the following:

- promoting the use of checks and other payment instruments through consultation and information sessions with stakeholders;

- increasing the minimum capital requirement for entities to operate banking institutions;

- developing a national microfinance policy and modifying appropriate provisions of the Financial Institutions Act (FIA);

43 With respect to the issue of moribund financial institutions, e.g., ACDB and NHSB, over the PRS period, the Government will examine the issue of disposition of deposits. 
- reviewing and harmonizing existing financial legislation and regulations to make them consistent with the FIA, and preparing legislation to facilitate the collection of debt and enforcement of financial contracts, including the revision of the commercial code and the establishment of a commercial court or alternative dispute resolution mechanisms;

- preparing a framework for the issuance of short-term securities, possibly including Central Bank of Liberia $(\mathrm{CBL})$ liquidity management instruments;

- enhancing, in cooperation with commercial banks and business associations, the existing credit reference system in relation to the credit-worthiness of potential borrowers; and

- strengthening the CBL's supervisory capacity through the training of staff to perform bank examinations.

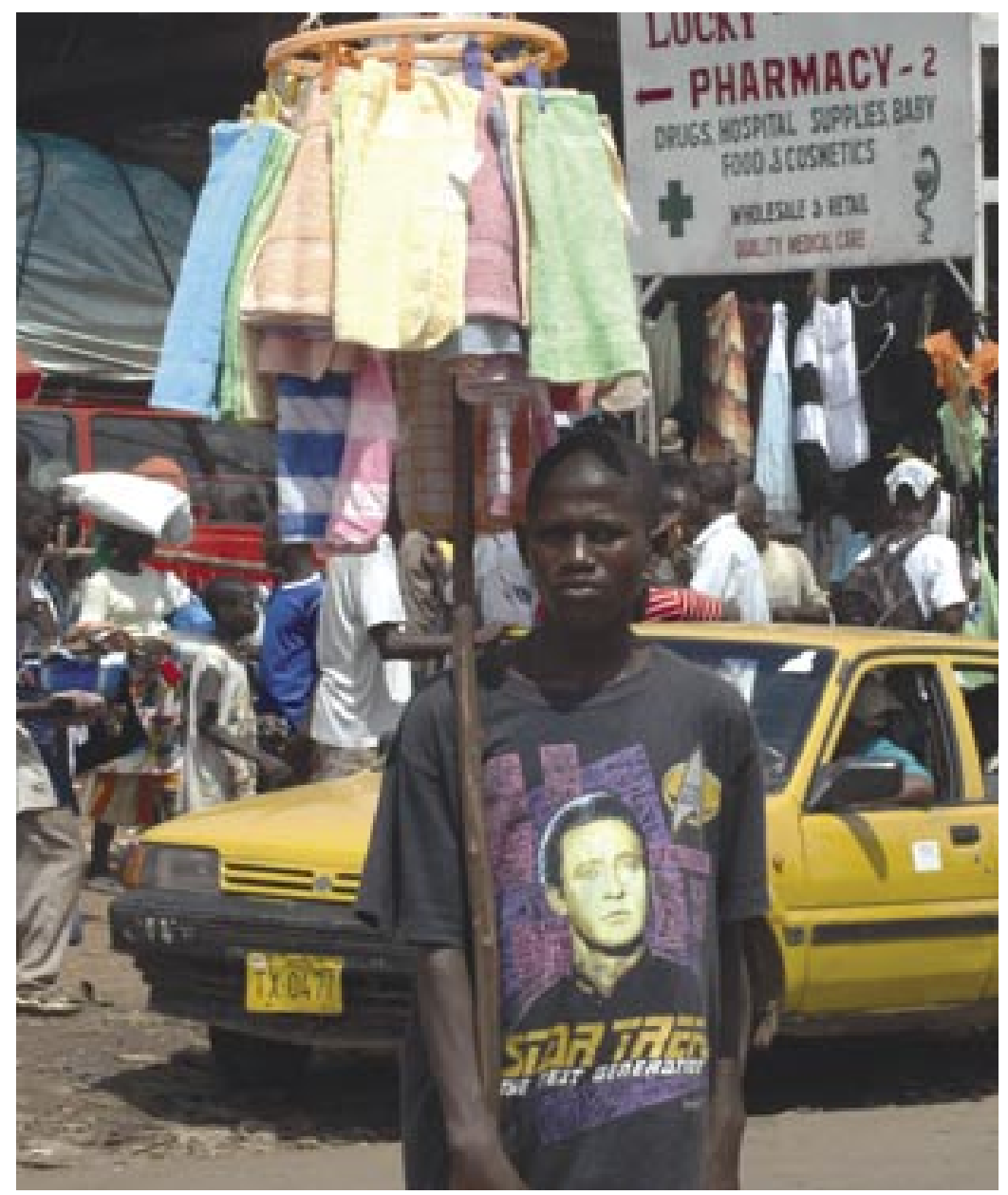

\subsection{Generating Productive Employment}

${ }^{63}$ One of the Government's most important goals during the PRS period is to promote the rapid creation of productive employment that will reduce poverty, ensure peace and stability, and enhance the overall wellbeing of the Liberian population.

${ }^{64}$ Rapid job creation is central to maintaining security (especially jobs aimed at the conflict-affected and youth), reducing poverty, and generating income for women, persons with disabilities, and other marginalized groups. Robust economic growth alone will not guarantee widespread job creation, especially to the extent that growth is concentrated in relatively capital-intensive sectors (such as mining). The challenge is to shape the revival of the growth process in a way that promotes to the fullest extent possible the creation of productive and remunerative employment. The major source of job growth will be private sector employment in agriculture, mining, forestry, and construction and other services. This will be complemented by emergency short-term measures that focus on labor-intensive infrastructure projects, urban sanitation and clean-up projects.

${ }^{65}$ The major challenges and constraints to increasing employment include the following:

- outdated labor laws, weak labor administration machinery and poor communication between employers and employees;

- lack of labor market information systems and labor market data including unemployment data;

- inadequate and inappropriate skills and knowledge in the labor force;

- weak linkages between education and labor market needs; 
- unequal and limited opportunities for women, youth, and persons with disabilities; and

- the impact of malaria, HIV and AIDS, and other diseases on the productive segments of the population.

${ }^{66}$ Many of the most important steps for expanding employment are described more fully in other sections on agriculture, forestry, mining, infrastructure and private sector investment. The Government plans to take additional action in three broad areas.

${ }^{67}$ First, it will strengthen overall labor policy and administration. The Government plans to introduce a new National Employment Policy. It will review and revise the Liberian Labor Code to make it more responsive to the needs of employees, employers and investors, while promoting fundamental human rights and other workplace standards appropriate for Liberia. The current labor administration machinery needs considerable strengthening, alongside institutional and human capacity building for the fledging employer and worker organizations to promote constructive social dialogue and maintain industrial harmony. In addition, the Government will conduct a National Labor Force Survey to collect more complete information on labor market characteristics and trends. This will include obtaining baseline information on unemployment in Liberia.

${ }^{68}$ Second, it will boost employment through labor-intensive public works projects using private contractors. It will complete the transformation of the Liberian Emergency Employment Program (LEEP) through considerable scaling up of pilot projects into the Liberian Employment Action Plan (LEAP). It will place particular focus on labor-intensive rural road projects linked to agricultural production and marketing, solid waste management programs in urban areas, and other essential public works.

${ }^{69}$ Third, it will introduce several targeted programs to address specific needs.

- Skills training. The Government will expand and modernize traditional apprenticeship and other short-term programs in the informal economy and MSMEs. It will strengthen curriculum, improve instructor training and expand vocational training centers across the counties.

- Opportunities for women. The Government will launch a Women's Entrepreneurship Program involving MSMEs that will aim to develop business skills, access to microfinance, and functional literacy.

- Opportunities for youth. The Government will develop and launch a Liberian National Youth Employment Action Plan in the context of the National Youth Policy. LEAP will monitor and facilitate the Action Plan through Key Initiative 2 on Youth and Skills Training, which is headed by the Minister of Youth and Sports, who in turn reports to the Chairman of the LEAP Inter-ministerial Working Committee, the Minister of Labor.

- HIV and AIDS. The Government in cooperation with the private sector will launch an HIV and AIDS at the Workplace Program which will address issues of prevention, treatment, and care with the goal of reducing the loss of workers and business costs associated with HIV and AIDS.

\subsection{Management of State-Owned Enterprises, Parastatals and Regulatory Agencies}

${ }^{70}$ Liberia's history of economic mismanagement and corruption was particularly evident with respect to state-owned enterprises (SOEs), regulatory agencies and parastatal enterprises. Inefficient and corrupt practices have restricted the production of goods and services, burdened the public treasury, and hindered economic growth.

${ }^{71}$ Liberia's approximately 15 SOEs, parastatals, and regulatory agencies must be rationalized and restructured. The process of SOE and parastatal reform is already underway. A number of SOEs and autonomous agencies have been provided with minimal budget allocations in anticipation of their dis- 
solution, including the Agriculture and Industrial Training Bureau, the Bureau of State Enterprises and the National Food Assistance Agency. Some others, notably the Liberia Petroleum Refining Corporation (LPRC), have been internally restructured and have dramatically improved their financial and operational performance. In several SOEs, parastatals and regulatory agencies, the GEMAP framework and other initiatives are improving financial and operational controls and practices. As confirmed in a recently signed MOU with key partners, the Government is committed to a build-operate-transfer (BOT) arrangement for the National Port Authority to facilitate needed investments and managerial improvements.

${ }^{72}$ The Government's objective for SOEs, parastatals and regulatory agencies is to aim for a more complete restructuring during the PRS period, in two parts. First, it will dissolve or privatize SOEs, parastatals and regulatory agencies that are moribund, unnecessary or more appropriate for private ownership. Second, it will continue improving efficiency and economic governance within those that remain. For each SOE, parastatal or regulatory agency it will consider the full range of options, including liquidation, full privatization, privatization with appropriate regulatory controls, public-private partnership to leverage private sector capital for investments, retaining public ownership with a private sector management contract, or retaining public ownership with mechanisms to ensure improved operational and financial performance.

${ }^{73}$ The first step will be to finalize the assessment criteria against which the performance and appropriate course of action for each SOE/parastatal/regulatory agency will be judged. These criteria would, inter alia, include the following:

- whether the core task of the enterprise is a core task of the Government;

- whether market failure exists that may be rectified by Government intervention, bearing in mind the potential for Government failure to outweigh market failure;

- whether marginalized groups within society would be denied access to basic goods or services under full private ownership;

- whether there are strategic reasons for Government involvement; and

- the extent of the opportunity and financial cost of Government involvement.

${ }^{74}$ Once the criteria are finalized by mid-2008, the Government will take the following steps:

- undertake assessments to determine the appropriate course of action for each SOE/parastatal/ agency, the timing within which any restructuring should occur, and the process by which restructuring operations will be implemented;

- draft the necessary legislation to effect the rationalization of relevant state-owned enterprises for liquidation, privatization, public-private partnership or appropriate regulatory controls, and then facilitate its enactment and implementation;

- design and implement restructuring plans for SOEs, parastatals and regulatory agencies that are not to be liquidated, privatized, or transformed into public-private partnerships, to strengthen their management and governance, enhance their efficiency, and improve their operational and financial performance, possibly through the use of performance contracts or regulatory mechanisms; and

- undertake periodic assessments as to whether the existing structures of remaining SOEs, parastatals and regulatory agencies continue to be consistent with the Government's objective of dissolving or privatizing those that are moribund, unnecessary or more appropriate for private ownership. 
Goal: To revitalize the food and agricultural sector to contribute to shared, inclusive, and sustainable economic growth and development; provide food security and nutrition; increase employment and income; and measurably reduce poverty.

Strategic objective 1: To develop more competitive, efficient, and sustainable food and agricultural value chains and linkages to markets

Agricultural supply chains have collapsed due to fragmented markets, weak rural demand, no value addition, and few incentives for cash crop production.
Support the replanting of smallholder tree crop farms by providing training on best practices (use of improved seed and stock varieties, etc.), improving technical services, and mandating out-grower schemes in agricultural concession agreements

Provide strategic farm inputs, e.g., fertilizer and high yield varieties of seeds and stocks, at affordable prices, carefully targeting the most needy on a time-limited basis so as to mitigate disruptions to input markets

Construct essential market infrastructure (drying and storage facilities, fish landing sites, farm to market roads, and local marketplace infrastructure) at the community level

Review and implement incentives for private sector investment (consistent with the investment code and tax and revenue laws)

Facilitate the provision of credit to smallholder farmers

\begin{tabular}{|c|c|}
\hline March 2011 & MoA \\
\hline March 2011 & MoA \\
\hline December 2010 & MoA \\
\hline December 2009 & MoA, MoF \\
\hline June 2011 & MoA, CBL \\
\hline
\end{tabular}

Strategic objective 2: To improve food security and nutrition, especially for vulnerable groups such as pregnant and lactating women and children under five

High levels of food insecurity and child malnutrition impede socioeconomic development and poverty reduction.

\begin{tabular}{|l|c|c|}
\hline $\begin{array}{l}\text { Rehabilitate previously established swamps to increase food } \\
\text { (particularly rice) production }\end{array}$ & March 2011 & MoA \\
\hline $\begin{array}{l}\text { Provide inputs such as seeds, tools, fertilizers, agro-chemi- } \\
\text { cals and agricultural processing equipment to vulnerable } \\
\text { groups such as women and smallholders }\end{array}$ & March 2011 & MoA \\
\hline $\begin{array}{l}\text { Restock small ruminants for onward distribution to farming } \\
\text { households }\end{array}$ & June 2010 & MoA \\
\hline $\begin{array}{l}\text { Rehabilitate previously established fish ponds in selected } \\
\text { communities }\end{array}$ & December 2010 & $\mathrm{MoA}$ \\
\hline $\begin{array}{l}\text { Establish a food security monitoring system to observe food } \\
\text { security and nutrition indicators and provide early warning of } \\
\text { potential emergencies }\end{array}$ & December 2009 & $\mathrm{MoA}, \mathrm{MoH}$ \\
\hline
\end{tabular}

Strategic objective 3: To strengthen human and institutional capacities to provide needed services, create a strong enabling environment, and reduce vulnerability

Agricultural institutions remain largely ineffective at delivering services such as regulation, policy and planning, and research and extension.
Strengthen the capacity of the Ministry of Agriculture and CARI by providing equipment and training to plan; develop policy; monitor food security and nutrition; enforce food, zoo, and phyto-sanitary standards; and transfer appropriate technology to farmers via research and extension

Review the mandates of existing agricultural parastatal institutions, redefining them where necessary and eliminating those that are moribund, unnecessary, or more appropriate for private ownership

Encourage, promote and strengthen 100 farmer-based organizations as the primary institution for farmer coordination, with particular emphasis on women and youth

Establish a national FBO forum and database and adopt an FBO focus in value chain development projects

\begin{tabular}{|c|c|}
\hline March 2010 & MoA \\
\hline December 2009 & MoA, CBL \\
\hline June 2010 & MoA \\
\hline December 2010 & MoA \\
\hline
\end{tabular}


Issue

Priority Interventions

Delivery Date

Lead Ministry I

Agency

Goal: To develop the forestry sector as a source of higher incomes for the rural population, ensuring that the benefits are shared equitable, and to put in place adequate environmental and other regulatory safeguards to ensure sustainability.

Strategic objective 1: To restart the commercial forest industry based on sustainable forest land use management practices and the rule of law

A lack of awareness and information, investment and employment, and compliance with the law in relation to commercial and other forestry.
Educate the Government, non-governmental partners and the general public on the new National Forest Reform Law and new FDA reforms

Work to allocate up to approximately 2.5 million hectares of forest into timber sales contracts, forest management contracts, and private use contracts

Grant and administer chain of custody contracts and establish a collaborative and participatory relationship with contractors, government agencies, and affected communities

\begin{tabular}{|c|c|}
\hline December 2010 & $\begin{array}{c}\text { FDA, MICAT, } \\
\text { MIA }\end{array}$ \\
\hline June 2011 & $\begin{array}{c}\text { FDA, MoF, MoJ, } \\
\text { PPCC, NIC }\end{array}$ \\
\hline June 2011 & FDA, MoF, MoJ \\
\hline
\end{tabular}

Strategic objective 2: To conserve Liberia's biodiversity and maintain resource benefits for local communities

The small area allocated for protection and a weak legal framework to govern wildlife management threaten biodiversity and conservation.

Strategic objective 3: To encourage local communities to sustainably manage their forests by creating rights, transferring control, and building local capacity for forest management within the communities

Currently no Wildlife Law is on the books, and thus the rights and responsibilities of communities with respect to forests are unclear.
Develop, update and implement polices and regulations on bushmeat, wood energy and other non-wood forest products

Empower local communities to establish their rights and responsibilities with respect to forests and create a framework for community forest management that allows communities to maximize their benefits from all potential uses

\begin{tabular}{|c|c|}
\hline April 2008 & FDA \\
\hline October 2008 & $\begin{array}{c}\text { FDA, } \\
\text { Legislature, MIA }\end{array}$ \\
\hline
\end{tabular}


Goal: To rapidly expand mining as an engine of economic growth and social development, to ensure that the benefits from mining activities are widely shared, to diversify the mining sector into new and downstream activities, and to improve support to local miners.

Strategic objective 1: To establish a guiding framework for the management of mineral resources

The mining sector lacks coherent regulation.
Review and amend the new Minerals and Mining Law

to be consistent with the National Mining Policy, Public

Procurement and Concession Act, the new Forestry Law,

the Extractive Industries Transparency Initiative (EITI),

Kimberly Process, and the Revenue Code

Conduct public awareness campaign to disseminate informa-

tion on the new National Mineral Policy

Strategic objective 2: To define clear terms and provisions for mining operations

There is a lack of consistent, fair and enforceable mineral agreements, contributing to high transaction costs.

\begin{tabular}{|l|c|c|}
\hline $\begin{array}{l}\text { Consolidate stakeholders' comments on a model Mineral } \\
\text { Development Agreement (MDA), including those of } \\
\text { Government ministries and agencies }\end{array}$ & May 2008 & MLME \\
\hline $\begin{array}{l}\text { Secure cabinet and Legislative approval for endorsement of } \\
\text { the Model MDA }\end{array}$ & June 2008 & $\begin{array}{c}\text { MLME, } \\
\text { Legislature }\end{array}$ \\
\hline $\begin{array}{l}\text { Enter into MDAs based on the Model MDA for the Western } \\
\text { Cluster, Bong Mines, Kitomo, Goe Fantro, and Amlib proj- } \\
\text { ects }\end{array}$ & June 2011 & MLME \\
\hline $\begin{array}{l}\text { Establish a protocol for regular reporting of all payments } \\
\text { made to, and revenues from, mining companies, per the } \\
\text { provisions of EITI, and share with industry actors }\end{array}$ & June 2011 & MLME \\
\hline
\end{tabular}

Strategic objective 3: To develop/obtain the tools for assigning title to mineral claims, and to resolve claim disputes

Titling processes are inconsistent, contributing to conflicts over land.

\begin{tabular}{|l|c|c|}
\hline $\begin{array}{l}\text { Review and approve the draft design of a Mining Cadastre } \\
\text { Information Management System (MCIMS) }\end{array}$ & June 2008 & MLME \\
\hline $\begin{array}{l}\text { Obtain physical location, trained staff and equipment neces- } \\
\text { sary to implement MCIMS }\end{array}$ & December 2008 & MLME \\
\hline Implement MCIMS & June 2009 & MLME \\
\hline
\end{tabular}

Strategic objective 4: To provide support to small scale mining with emphasis on improved techniques and better social and environmental practices

The recovery of minerals is inefficient, and environmental and social practices are generally poor.

\begin{tabular}{|l|c|c|}
\hline $\begin{array}{l}\text { Analyze impact of existing regulations on small-scale miners } \\
\text { and amend to facilitate small-scale mining and to ensure the } \\
\text { protection of human rights and the environment }\end{array}$ & October 2008 & MLME \\
\hline $\begin{array}{l}\text { Initiate sensitization and awareness campaigns to encour- } \\
\text { age use of cooperative schemes, human rights protection, } \\
\text { and environmentally sound practices }\end{array}$ & July 2008 & MLME \\
\hline $\begin{array}{l}\text { Provide training and equipment to small-scale miners to } \\
\text { improve efficiency and lessen the negative environmental } \\
\text { impacts }\end{array}$ & November 2008 & MLME \\
\hline To build capacity in the Ministry of Lands, Mines and Energy & August 2008 & MLME \\
\hline
\end{tabular}

Strategic objective 5: To build capacity in the Ministry of Lands, Mines and Energy

MLME lacks adequate Train staff to implement MCIMS

human resources. 
Goal: To develop a comprehensive national land tenure and land use system that will provide equitable access to land and security of tenure so as to facilitate inclusive, sustained growth and development, ensure peace and security, and provide sustainable management of the environment.

Strategic objective 1: To establish the Land Commission and enable it to address its mandate

The nonexistent and/or $\quad$ Establish a Land Commission by legislative enactment and $\quad$ July 2008 inadequate land policies and laws require comprehensive review by a Land Commission. secure funding to address land issues

Appoint and orient Commissioners and the Commission's Technical Secretariat

Support the Commission's work in conducting studies and consultations pertinent to its mandate

\begin{tabular}{c|c} 
July 2008 & $\begin{array}{c}\text { GC, Legislature, } \\
\text { President }\end{array}$ \\
\hline September 2008 & GC, President \\
\hline $2008-2011$ & LC
\end{tabular}

Strategic objective 2: To promote equitable and productive access and security of tenure to the nation's land, both public and private, especially for the poor, women, and other marginalized groups, and to promote the rule of law with respect to landholding and dealings in land

Inequities exist in access and utilization of land, favoring the wealthy and elites. Outdated and inadequate laws do not serve the country's development goals. Disputes are common and are not being equitably resolved.

\begin{abstract}
Review and reform public land policy and property laws to develop comprehensive and coherent policy and legal framework and to remove or revise outdated or outmoded provisions
\end{abstract}

Conduct a comprehensive national land use survey and mapping to identify current and future utilization of land

Review customary land tenure and existing local government institutions to identify best options for equitable and effective management of land and other natural resources

Recognize and protect rights of use and ownership of land and other resources by local communities

Review mechanisms for land dispute resolution under statutory and customary law and propose alternatives

Develop procedures for equitable and fair enforcement of laws pertaining to land and other property to minimize fraud and other illegal practices pertaining to land

\begin{tabular}{|c|c|c|}
\hline 2011 & LC \\
\hline 2011 & $\begin{array}{c}\text { LC, MLME, } \\
\text { MoA, FDA }\end{array}$ \\
\hline 2011 & LC, MIA \\
\hline 2011 & LC \\
\hline 2011 & LC, MoJ \\
\hline d & 2011 & LC, MoJ \\
\hline
\end{tabular}

\section{Strategic objective 3: To promote effective land administration and management}

\section{Outmoded systems of \\ Secure and conserve deeds and land records at one loca-} land administration and management encourage fraudulent behavior. Capacity in the ministries and agencies is limited. tion under the supervision of trained staff verify claims and expedite land transactions

Clarify roles, build capacity and equip the staff of MLME
Develop and implement records management system at the national and local level so that land records are available to (especially the survey unit), MoA and FDA

Pilot a land registration system in an area outside central Monrovia that is primarily held under fee simple

\begin{tabular}{|c|c|c|}
\hline 2009 & $\begin{array}{c}\text { LC, CNDRA, } \\
\text { MFA, EM }\end{array}$ \\
\hline 2009 & \begin{tabular}{c} 
LC, CNDRA \\
\hline
\end{tabular} & $\begin{array}{c}\text { LC, MLME, } \\
\text { MoA, FDA, UL }\end{array}$ \\
\hline 2011 & $\begin{array}{c}\text { LC, MLME, } \\
\text { CNDRA }\end{array}$ \\
\hline
\end{tabular}

\section{Strategic objective 4: To promote investment in and development of the nation's land resources}

Polices to promote investment and development are nonexistent or inadequate. Taxation and zoning rules are inadequate and/or outdated.

\begin{tabular}{|l|c|c|}
\hline $\begin{array}{l}\text { Review and/or develop policies on agricultural, forestry, and } \\
\text { mining concessions, including activities, provision of ser- } \\
\text { vices, taxation, etc. }\end{array}$ & 2010 & $\begin{array}{c}\text { LC, MoF, FDA, } \\
\text { MLME, MoA }\end{array}$ \\
\hline $\begin{array}{l}\text { Develop land policies and programs to provide security of } \\
\text { tenure and to enhance access in order for smallholders to } \\
\text { move to more profitable and sustainable livelihoods }\end{array}$ & 2009 & $\begin{array}{c}\text { LC, MLME, } \\
\text { MoA, FDA }\end{array}$ \\
\hline $\begin{array}{l}\text { Develop and implement national zoning regulations and } \\
\text { land taxation regulations that support and facilitate national } \\
\text { development objectives }\end{array}$ & 2009 & LC, MPW, MoF \\
\hline
\end{tabular}


Issue

Goal: To create a strong enabling environment for private sector investment and exports in non-traditional activities.

Strategic objective 1: To reduce or eliminate unnecessary business regulations and administrative requirements

Administrative and regulatory barriers severely limit the ability of businesses, especially MSMEs, to operate effectively and efficiently.

\section{Strategic objective 2: To improve the investment code}

Outdated provisions of the investment code create obstacles to domestic and foreign investment.

\begin{tabular}{|c|c|c|}
\hline $\begin{array}{l}\text { Implement agreed administrative reforms as identified by the } \\
\text { Business Reform Committee, with initial emphasis on those } \\
\text { associated with starting a business, licensing, registering } \\
\text { property, and trading across borders }\end{array}$ & April 2008 & $\begin{array}{l}\mathrm{NIC}, \mathrm{MoCl} \\
\mathrm{MoF}\end{array}$ \\
\hline $\begin{array}{l}\text { Develop and implement a streamlined business registration } \\
\text { process and a computerized business registry }\end{array}$ & June 2009 & $\mathrm{MoCl}$ \\
\hline Develop a "one-stop shop" for customs and port clearance & June 2008 & $\begin{array}{l}\text { MoF, NPA, } \\
\text { CBL }\end{array}$ \\
\hline
\end{tabular}

Submit legislation to streamline investment procedures and to level the playing field between domestic and foreign

May 2008

NIC, LRDC, Legislature investors

\section{Strategic objective 3: To build the capacity of the investment-promotion institution}

The capacity limitations of the NIC limit its effectiveness in promoting investment.
Reorient the function of the NIC from a regulatory role to an investment facilitation and attraction function and reorganize staff functions accordingly, to include capacity building for new functions

Establish an SME Business Support Unit

\begin{tabular}{l|l} 
January 2009 & NIC \\
\hline October 2008 & NIC
\end{tabular}

\section{Strategic objective 4: To facilitate the integration of Liberian firms with regional and global markets}

Lack of economic $\quad$ Investigate the feasibility of developing an SEZ near

diversification limits the potential for sustained growth in productivity, skill levels, wages, and income over time. Buchanan and other locations over the medium term Convene major investment forums
Ongoing

NIC, MFA MoP, MLME

April-December $\quad$ NIC 2008

\section{PRS Priority Action Matrix - Financial Sector Issues}

\section{Issue}

Lead

Delivery Date

Ministry /

Agency

Goal: To promote a stable, sound and market-based financial system that supports efficient mobilization and allocation of resources to foster sustainable economic growth and poverty reduction.

\section{Strategic objective 1: To modernize the payments system}

The majority of payments are made in cash, which undermines security and flexibility of finances and credit.
Undertake consultation with stakeholders to promote the use of checks and other payment instruments, including credit cards

Prepare and initiate the issuance of CBL liquidity management instruments

\section{Strategic objective 2: To ensure that commercial banks are fully capitalized}

There is a high risk of $\quad$ Increase minimum capital requirement for entities to operate bank default and low confidence in the financial system.

\section{banking institutions from the present $\$ 2,000,000$}

CBL 
Strategic objective 3: To broaden and extend financial services to MSMEs through microfinance and other financing mechanisms

Financing for productive investments for the poor and for MSMEs is limited.

\begin{tabular}{|l|c|c|}
\hline Develop a national microfinance policy & December 2008 & $\begin{array}{c}\text { CBL, } \\
\text { Legislature }\end{array}$ \\
\hline $\begin{array}{l}\text { Modify appropriate provisions of the Financial Institution Act } \\
\text { to make it applicable to microfinance and other non-deposit } \\
\text { taking financial institutions }\end{array}$ & December 2008 & $\begin{array}{c}\text { CBL, } \\
\text { Legislature }\end{array}$ \\
\hline $\begin{array}{l}\text { Review, modify or develop appropriate legislation or other } \\
\text { instruments to ensure that alternative frameworks for } \\
\text { access to finance such as leasing can occur }\end{array}$ & June 2011 & CBL, MoJ \\
\hline
\end{tabular}

Strategic objective 4: To strengthen the legal framework to facilitate the collection of debts and enforcement of financial contracts

Fragmented legislation and sluggish judicial procedures hamper loan recovery.

Review and harmonize existing financial legislation and regulations to make them consistent with the Financial Institution Act and, where necessary, propose new legislation to strengthen the stability and soundness of the financial system

Prepare legislation to facilitate the collection of debts and enforcement of financial contracts, including the establishment of a commercial code and a commercial court, and explore alternative dispute resolution methods

\begin{tabular}{|c|c|}
\hline June 2011 & CBL, MoJ \\
\hline June 2009 & CBL \\
\hline
\end{tabular}

Strategic objective 5: To begin to lay the groundwork for developing markets for short term securities and other money market instruments

\begin{tabular}{|l|l|c|c|}
\hline $\begin{array}{l}\text { Access to financial and } \\
\text { money market instru- } \\
\text { ments is limited. }\end{array}$ & $\begin{array}{l}\text { Prepare a framework for the issuance of short term securi- } \\
\text { ties, possibly including CBL liquidity management instru- } \\
\text { ments }\end{array}$ & June 2010 & CBL \\
\hline
\end{tabular}

Strategic objective 6: To improve the transparency and efficiency in information sharing among financial institutions on the credit-worthiness of borrowers

There is a high volume Establish, in cooperation with the commercial banks and of non-performing loans and credit risk management systems are inadequate. business associations, a credit information center on the credit-worthiness of potential borrowers

Strategic objective 7: To strengthen depositor protection and improve confidence in the financial system Corporate governance practices are opaque.

\begin{tabular}{|l|c|c|}
\hline $\begin{array}{l}\text { Conduct training of staff to perform banking examinations to } \\
\text { strengthen the CBL's supervision capacity }\end{array}$ & Ongoing & CBL \\
\hline Publish a list of banks licensed to operate in Liberia & $\begin{array}{c}\text { June 2008, 2009, } \\
2010\end{array}$ & CBL \\
\hline $\begin{array}{l}\text { Establish a system of off-site inspection by requiring } \\
\text { quarterly submission of prescribed data by all banks, and } \\
\text { submit the first written reports to the Banking Compliance } \\
\text { Committee }\end{array}$ & June 2010 & $\mathrm{CBL}$ \\
\hline
\end{tabular}


Goal: To promote productive employment that will reduce poverty, ensure peace and stability, and enhance the overall wellbeing of the Liberian population.

\section{Strategic objective 1: To strengthen overall labor policy and administration}

Labor laws are outdated, labor administration is weak, and communication between employees and employers is poor.

\begin{tabular}{|l|c|c|}
\hline $\begin{array}{l}\text { Formulate a National Employment Policy (NEP) and submit } \\
\text { for enactment }\end{array}$ & December 2009 & MoL \\
\hline $\begin{array}{l}\text { Establish NEP implementation, monitoring, and evaluation } \\
\text { responsibilities at MOL }\end{array}$ & December 2009 & MoL \\
\hline $\begin{array}{l}\text { Organize a national labor conference to review and reform } \\
\text { existing labor laws }\end{array}$ & March 2008 & MoL, SP \\
\hline Formulate a draft labor code and submit for enactment & April 2008 & MoL \\
\hline $\begin{array}{l}\text { Strengthen the participation of the National Tripartite } \\
\text { Committee (Employer, Employee and Government) by train- } \\
\text { ing and providing equipment to committee members }\end{array}$ & December 2011 & MoL, SP \\
\hline $\begin{array}{l}\text { Conduct sensitization and awareness campaigns on labor } \\
\text { code }\end{array}$ & June 2008 & MoL \\
\hline $\begin{array}{l}\text { Review and set a national minimum wage } \\
\text { Train labor commissioners, inspectors and staff of MoL divi- } \\
\text { sions }\end{array}$ & December 2008 & June 2011 \\
\hline $\begin{array}{l}\text { Develop a labor market information system for planning } \\
\text { and decision making (which will include the conducting of a } \\
\text { National Labor Force and Manpower Survey) }\end{array}$ & June 2011 & MoL \\
\hline
\end{tabular}

\section{Strategic objective 2: To create more and better jobs for Liberian men, women and youth}

Current labor administration programs have limited impact and lack coordination.

\begin{tabular}{|c|c|c|c|}
\hline \multirow{9}{*}{$\begin{array}{l}\text { Current labor adminis- } \\
\text { tration programs have } \\
\text { limited impact and lack } \\
\text { coordination. }\end{array}$} & $\begin{array}{l}\text { Establish an institutional framework for the Liberia } \\
\text { Employment Action Program (LEAP) }\end{array}$ & July 2008 & MoL \\
\hline & Decentralize LEAP activities and train regional office staff & November 2009 & MoL \\
\hline & $\begin{array}{l}\text { Promote community-based job creation through labor-inten- } \\
\text { sive public works projects }\end{array}$ & $\begin{array}{l}\text { Ongoing, } \\
\text { June } 2011\end{array}$ & MoL \\
\hline & $\begin{array}{l}\text { Establish agricultural and MSME programs such as manage- } \\
\text { ment training and skills development to create employment } \\
\text { opportunities for youth, women and the vulnerable }\end{array}$ & $\begin{array}{l}\text { Ongoing, } \\
\text { June } 2011\end{array}$ & $\begin{array}{l}\text { MoL, MoYS, } \\
\text { MoA }\end{array}$ \\
\hline & $\begin{array}{l}\text { Provide skills training for MSMEs to promote the transition } \\
\text { from the informal to the formal economy }\end{array}$ & $\begin{array}{l}\text { Ongoing, } \\
\text { June } 2011\end{array}$ & $\begin{array}{l}\text { MoL, MoYS, } \\
\text { MoE }\end{array}$ \\
\hline & $\begin{array}{l}\text { Develop vocational training opportunities for youth linked to } \\
\text { labor market projections and other youth livelihood schemes. }\end{array}$ & $\begin{array}{l}\text { Ongoing, } \\
\text { June } 2011\end{array}$ & MoYS \\
\hline & $\begin{array}{l}\text { Formulate a National Workplace Policy on HIV and AIDS and } \\
\text { conduct sensitization campaigns }\end{array}$ & December 2009 & MoL \\
\hline & $\begin{array}{l}\text { Conduct } 30 \text { workshops ( } 2 \text { in each county) on HIV and AIDS } \\
\text { in the workplace }\end{array}$ & June 2011 & MoL \\
\hline & $\begin{array}{l}\text { Train peer educators and tripartite constituents on HIV and } \\
\text { AIDS in the workplace }\end{array}$ & June 2011 & MoL \\
\hline \multicolumn{4}{|c|}{ Strategic objective 3: To develop a National Labor Market Information System } \\
\hline \multirow{6}{*}{$\begin{array}{l}\text { Limited availability of } \\
\text { labor market data and } \\
\text { capacity to generate } \\
\text { and manage data }\end{array}$} & Conduct training for SPSS and CSPro software & September 2009 & MoL \\
\hline & $\begin{array}{l}\text { Establish a data repository system for labor market informa- } \\
\text { tion }\end{array}$ & September 2008 & MoL \\
\hline & Provide computers and accessories for Statistical Bureau & December 2008 & MoL \\
\hline & Conduct labor force survey & September 2008 & MoL \\
\hline & Conduct manpower survey & September 2010 & MoL \\
\hline & Conduct occupational injury survey & June 2011 & MoL \\
\hline
\end{tabular}


Goal: To dissolve or privatize SOEs, parastatals and regulatory agencies that are moribund, unnecessary, or more appropriate for private ownership, and continue to improve efficiency and economic governance within remaining SOEs.

Strategic objective 1: To dissolve or privatize SOEs, parastatals and regulatory agencies that are moribund, unnecessary, or more appropriate for private ownership

Many SOEs/parastatals are inefficient and corrupt and their roles could be better performed by the private sector.

\begin{tabular}{|l|c|c|}
\hline $\begin{array}{l}\text { Establish an ad hoc committee to finalize the assessment } \\
\text { criteria for SOEs and to conduct SOE assessments }\end{array}$ & April 2008 & $\begin{array}{c}\text { LRDC } \\
\text { Secretariat, NIC, } \\
\text { MoCl, MoF, MoJ }\end{array}$ \\
\hline $\begin{array}{l}\text { Finalize assessment criteria to determine the appropriate } \\
\text { course of action for each SOE/parastatal/agency, the tim- } \\
\text { ing within which restructuring should occur, and the pro- } \\
\text { cess by which restructuring will be implemented }\end{array}$ & May 2008 & $\begin{array}{c}\text { Ad Hoc } \\
\text { Committee }\end{array}$ \\
\hline $\begin{array}{l}\text { Assess all SOEs, parastatals and regulatory agencies } \\
\text { Make recommendations and develop concrete plans for } \\
\text { each SOE/parastatal/agency }\end{array}$ & $\begin{array}{c}\text { June 2008 - } \\
\text { August 2008 }\end{array}$ & $\begin{array}{c}\text { Ad Hoc } \\
\text { Committee }\end{array}$ \\
\hline $\begin{array}{l}\text { Draft and pass legislation to effect rationalization, dissolu- } 2008 \\
\text { tion, privatization, or other needed regulatory controls for } \\
\text { each SOE/parastatal/agency }\end{array}$ & $\begin{array}{c}\text { October } 2008- \\
\text { January } 2009\end{array}$ & $\begin{array}{c}\text { Ad Hoc } \\
\text { Committee }\end{array}$ \\
\hline Implement plans and legislation & $\begin{array}{c}\text { Ad Hoc } \\
\text { Legislature }\end{array}$ \\
\hline
\end{tabular}

Strategic objective 2: To continue to improve efficiency and economic governance within remaining SOEs, parastatals and regulatory agencies

Certain SOEs/ parastatals provide goods or services that the Government will continue to provide; however inefficiencies and corruption limit their effectiveness.

\begin{tabular}{|c|c|c|}
\hline $\begin{array}{l}\text { Finalize restructuring plans for SOEs, parastatals and } \\
\text { regulatory agencies that are not being dissolved or priva- } \\
\text { tized }\end{array}$ & $\begin{array}{l}\text { October } 2008 \text { - } \\
\text { December } 2008\end{array}$ & $\begin{array}{c}\text { Ad Hoc } \\
\text { Committee }\end{array}$ \\
\hline Implement restructuring plans & January 2009 & SOEs \\
\hline $\begin{array}{l}\text { Undertake periodic assessments to determine the extent } \\
\text { to which remaining SOEs, parastatals and regula- } \\
\text { tory agencies perform in a manner consistent with the } \\
\text { Government's central goal }\end{array}$ & Ongoing & $\mathrm{NIC}, \mathrm{MoCl}, \mathrm{MoF}$ \\
\hline
\end{tabular}




\section{Strengthening Governance and the Rule of Law}

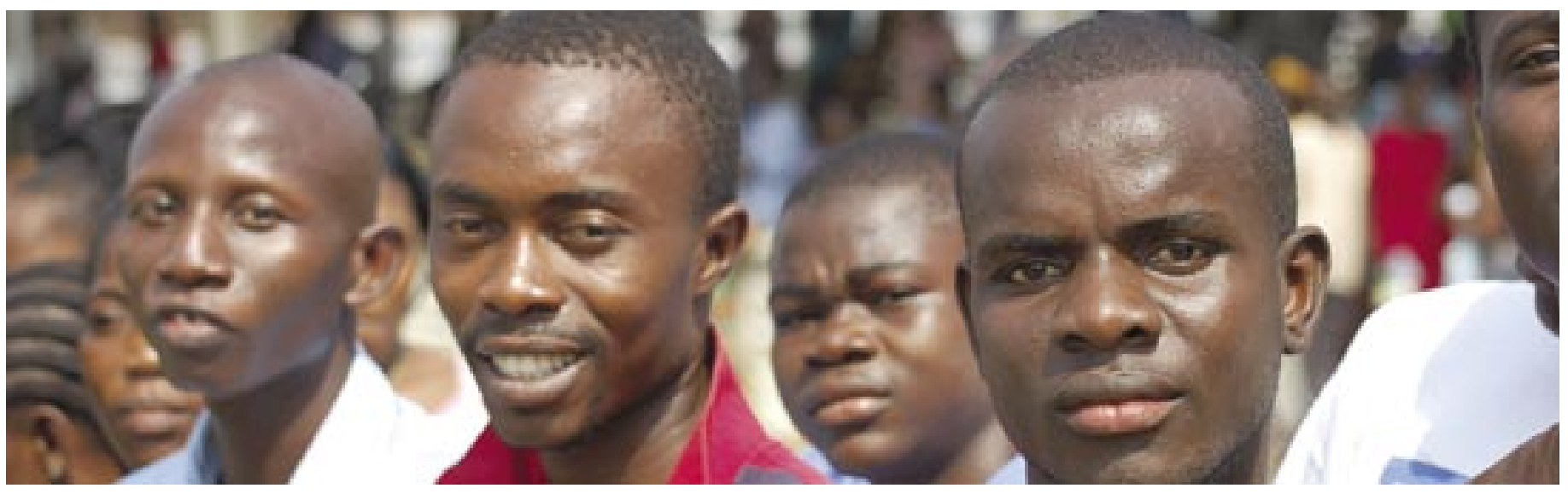

\subsection{Introduction}

The series of crises that besieged the Liberian nation over the last quarter century - from war and mismanagement to human rights abuses and deepening poverty - can be blamed largely on poor governance and disrespect for the rule of law. The situation has improved markedly since the end of the war, but Liberia continues to suffer from weak public institutions, corruption, limited justice and a lack of human capacity to quickly remedy these deficiencies. In recognition of these challenges, the Government will move forward resolutely to address the weaknesses of the state that have driven poverty, instability and conflict.

${ }^{2}$ The Government made important progress in addressing some of these issues under the iPRS. It established the Governance Commission to review policies, laws and government institutions and to address the many significant structural problems that contribute to poor governance. It has submitted legislation to establish an Anti-Corruption Commission, which will have the power to investigate and prosecute officials engaged in corrupt acts, Liberia has recently become a candidate country under the LEITI in an effort to bring transparency and accountability to the extractive industries that were previously the main source of funding for warlords and corrupt officials. The Government has taken initial steps towards establishing a Land Commission to address issues surrounding land use and ownership, which is cited by citizens as potential cause of conflict (see Chapter Seven). These initial steps will be further advanced during the PRS period.

${ }^{3}$ Improving governance necessarily entails transforming the relationship between the state and its citizens, focusing especially on those who are underrepresented or disadvantaged. Women, children and persons with disabilities suffer disproportionately from violence and abuse, and have been unable to participate fully in Liberia's new democratic environment. Youth have been deprived of education, health care and the benefits of a stable environment during their formative years. The Government will make special efforts to ensure that its institutions, policies and processes afford these groups consideration and equal representation. It is aiming build a culture of inclusive and participatory governance.

${ }^{4}$ Strengthening the effectiveness and integrity of legal and judicial institutions, expanding access to justice and protecting and promoting human rights are critical to peacebuilding and underpin many other objectives across the PRS. An effective court system is vital to dealing with Liberia's most significant current security threat, the growth in crime, and it is also essential to economic revitalization in providing a framework for resolving contractual and property disputes, thereby increasing commercial certainty and promoting private sector growth. The effort to defeat corruption depends on effective action through the courts, and providing more equal access to justice will contribute to eliminating the marginalization of some groups, which helped fuel the conflict. 
${ }^{5}$ Through the PRS, the Government will be guided by a set of principles central to democratic rule and good governance, including:

- providing for meaningful inclusion and participation of Liberians across every region and class in government processes;

- empowering all Liberians to participate in and take ownership of decision-making and development;

- building consensus around national priorities; ensuring responsiveness by government to the concerns expressed by Liberians;

- increasing transparency and accountability of government decisions and actions; and

- applying rules fairly and impartially and creating opportunities for all Liberians.

${ }^{6}$ Adhering to these principles will contribute significantly to the expansion of peace and poverty reduction by responding to the deficiencies of past governments and establishing an environment of productive engagement between the state and citizens. The media, civil society organizations, the private sector and academia have an important role to play in ensuring the Government upholds these principles.

${ }^{7}$ The Government's goal with respect to governance and rule of law is to work in partnership with all citizens to build and operate effective institutions and systems that will strengthen peace and promote and uphold democratic governance, accountability, and justice for all. Its efforts will be guided by four strategic objectives:

- enhancing citizen participation in and ownership of government policy formulation and implementation;

- building effective and efficient public institutions;

- strengthening and enhancing the integrity of legal and judicial institutions; and

- expanding access to justice, and enhancing the protection and promotion of human rights.

\subsection{Enhancing Participation in and Ownership of Government}

${ }^{8}$ During the PRS period, the Government will work to increase and enhance citizen participation in, and ownership of, government policy formulation and implementation. The lack of equity and participation in government processes was a significant contributing factor to the civil conflict. To address these issues successfully, both the structure of government and the culture of citizen participation must be reformed.

${ }^{9}$ The Government will take initial steps to shift the locus of power to the sub-national level through decentralization, bringing government decisions and programs closer to the people. It will improve governance and public integrity by supporting participation of civil society, including full involvement by women and the media, to bring accountability to public institutions and leaders. It also will identify and prosecute officials that partake in corrupt activities. A culture of participation by all citizens and partnership with government is critical to increasing transparency and accountability, reducing corruption and improving governance.

\subsubsection{Decentralizing Political Governance and Social Responsibilities}

${ }^{10}$ The Government of Liberia is committed to delivering to the Liberian people an improved system of governance that is more localized and more responsive to the needs and aspirations of all citizens 
throughout the country. Decentralization of power, decision-making and government authority will improve governance over time, increase transparency of government processes, enhance accountability and ultimately result in better delivery of services and the fulfillment of the Government's responsibilities to serve the Liberian people, promote democracy and reduce poverty. This process will take years, possibly decades, to complete, but the national effort begins in earnest during the PRS period.

${ }^{11}$ The development and implementation of the decentralization policy will be guided by several important principles. First, to be sustained through future changes in the country's leadership, the process and outcomes must be owned by the people of Liberia. Second, a successful strategy will build upon the experiences of other post-conflict countries and include carefully sequenced steps towards greater subnational autonomy. Third, leadership on the part of the central Government and Legislature is needed throughout the process to maintain commitment to the transformation of the governance culture and shift in the locus of power, and to remain flexible and responsive to changing circumstances in Liberia.

${ }^{12}$ The Governance Commission, Ministry of Internal Affairs and Ministry of Planning and Economic Affairs are working together to lead a national visioning exercise to inform a comprehensive decentralization policy, to be completed in mid-2009. The Liberian people must be prime contributors to the architecture of the new governance system to ensure legitimacy, sustainability, understanding and ownership. During the next year, the Government will undertake the diagnostic and other preparatory work to enable it to best design a fiscal, administrative, legal and political framework appropriate to Liberian circumstances and capacities. It will articulate the details of how, when and the extent to which decentralization will take place in policy and implementation plan documents, including steps to harmonize national, local community-based and traditional structures of governance. The Government will specifically encourage equal participation of women in defining the decentralization process.

${ }^{13}$ Through the PRS period, the Government will be focused on establishing and investing in the fundamental building blocks of successful decentralization and guided by a carefully sequenced series of activities and benchmarks to ensure that accountability increases and governance improves. In the early stages, it will pilot multiple approaches to ensure the adoption of the most effective mechanisms and methods to increase capacity and reduce poverty. At the county level, it will focus on developing management and administrative capacity, including financial management and planning skills. At the local level, it will focus on community-driven development, economic empowerment and strengthening participatory processes. It will take time to put in place the constitutional amendments, laws and regulations, and to build the capacity needed to advance to full decentralization. While these issues are reviewed, the Government will push forward with those aspects of decentralization that empower the Liberian people, contribute to poverty reduction and increase participation in Government activities.

${ }^{14}$ During the PRS period, additional steps will be taken to support democratization. The Government will strengthen the capacity of the National Election Commission to support sub-national elections. It will work to clarify administrative borders within Liberia and the jurisdictions of sub-national administrative areas, which is essential to preparing for expanded democratic governance. Towards this end, the National Boundary Harmonization Project, which clarifies internal boundaries through consultative processes, will complete its work and its decisions will be implemented. The Government will also establish a national biometric identification card system to register all Liberian citizens, which will also one day serve as the foundation for improved voter registration systems.

${ }^{15}$ Unprecedented population and unplanned urbanization are key challenges for poverty reduction in urban centers, particularly Monrovia. Large numbers of people flocked to urban areas during the conflict, putting significant pressures on the delivery of urban services. The lack of urban planning programs led to unguided development and settlement. At the national level, the Ministries of Internal Affairs, Public Works and the National Housing Authority have responsibilities for city, town, and regional planning, and the Government aims to strengthen their capacities and support urban planning in select cities. As part of the process of decentralization, the Government will aim to strengthen urban charters to more clearly delineate responsibilities of the national, county and city governments, including their respective authority for revenue generation and spending. It will also reform the Monrovia City Corporation to meet the challenges of providing services and managing over-population in the nation's capital. 
${ }^{16}$ Liberia is poised to establish a system of government that can sustain peace and set the country on the path toward equity and prosperity. In the design of the decentralization policy and programs, the Government will strive to create an economic and social environment that provides new and better opportunities for citizens, including women and persons with disabilities, and a system that empowers the Liberian people to determine their futures.

\subsubsection{Building a System of National Integrity}

${ }^{17}$ As in most post-conflict countries, corruption has eaten away at the fabric of Liberian society and has been a major contributor to poverty. It has been endemic, taking various forms including cronyism, misuse of public property and the improper awarding of public contracts and concessions. Economic pillage through resource extraction financed the conflict, and Liberian citizens still express concern about the manner in which their resources will be extracted in the future. In the past, Governments encouraged and participated in corrupt activities rather than combat them. This, in turn, incited conflict and undermined economic development and political legitimacy.

${ }^{18}$ Consistent with county feedback, the Government is strongly committed to tackling corruption in all of its forms and to increasing transparency in the public domain. It has already taken several important steps to reduce corruption. As explained in Chapter One, the Government has developed and adopted a strong national anti-corruption policy and strategic framework. The strategy consists of time-bound specific actions to be taken by Government and other stakeholders, including the establishment of an Anti-Corruption Commission with prosecutorial powers, a bill for which has been submitted to the Legislature.

${ }^{19}$ These efforts are yielding steady and positive results, as seen in the rapid increases in revenue, increased accountability and transparency, and enhanced public financial management. In the most recent edition of the World Bank Institute's Worldwide Governance Indicators, Liberia showed the world's second-largest rate of improvement in the 2006 index of "Control of Corruption."

${ }^{20}$ This progress must be consolidated and built upon. Many of the reforms described elsewhere in the PRS are designed to target corruption and build a system of national integrity, including strengthening public financial management, reforming pay and other aspects of the civil service, training and capacity building measures, strengthening of the Judiciary, and introducing policies to better manage natural resource sectors. The Government will work with the Legislature to enact and implement these reforms during the PRS period. In further pursuit of reducing corruption, other national institutions of integrity will also be reformed or strengthened, including the Public Procurement and Concessions Commission, and the General Auditing Commission.

${ }^{21}$ The Government has also drafted an Act amending certain provisions of the Penal Law to establish as criminal offenses all acts of corruption and related offenses and to provide appropriate punishment. It will push to enact a Freedom of Information Law and Whistleblower Statute. And the Governance Commission is launching sensitization and public awareness campaigns to inform and educate the entire Liberian citizenry about adverse effects of corruption.

${ }^{22}$ Combating corruption is essential to restoring public confidence in Government. A culture of transparency supported by increased participation by civil society will complement the rigorous efforts of Government to identify and bring corrupt individuals to justice.

\subsubsection{Strengthening Civil Society Participation in Governance}

${ }^{23}$ Governance is a collective endeavor and not just the domain of government. The predatory and corrupt practices of past governments were perpetrated in the context of a marginalized civil society, especially disadvantaged groups. In pursuit of strengthening peace, the environment for civic engagement must be open to all citizens and empower those who have been deprived of voice and representation in the past. The Government of Liberia will therefore continue to engage citizens, Liberian organizations, and other partners in its development planning and strive to increase the participation of civil society in pub- 
${ }^{24}$ The Governance Commission will ensure that opportunities are created for civic engagement in discussions around various reform processes. It will hold regular meetings with civil society actors and the media to provide updates on the reform agenda, and work closely with interested civil society actors in developing policies and procedures for various sectors. Opportunities will also be created for increased civil society engagement at the county and district administrative levels to ensure full participation of citizens in local governance processes.

${ }^{25}$ Children and youth, including those with disabilities, should be able to participate in government processes and civic dialogue through the full range of their education and development. To that end, the Government will develop a Children's Act to provide for the particular needs of children, as well as undertake a national consultation exercise with children and youth to promote and institutionalize the participation of these groups. Based on the outcomes of the exercise, the Government will develop mechanisms for the participation of children and youth in schools and Parent-Teacher Associations, in communities through youth centers and junior councils, and in the Legislature, with clear processes of interaction with the equivalent institutions for adults. Participation of youth in regional structures such as the Mano River Union also will be strengthened.

${ }^{26}$ The Government will strive to strengthen standardized human rights training, monitoring, reporting and advocacy through civil society networks, the educational system and within government structures in order to strengthen a human rights-based approach to development. Particular attention will be directed toward empowering disadvantaged groups, including persons living with disabilities. The legislation creating the National Commission on Disabilities will be reviewed to ensure that persons with disabilities are adequately represented and served by Government.

${ }^{27}$ Finally, the media will play a critical role in promoting accountability, transparency and sharing information with citizens across Liberia. The public must be equipped with accurate information to make informed judgments about their Government and its activities. Media repression during the decades of political, military and civil strife was severe, and the Liberian media now requires an extended period of revitalization and professional development. Both the quality and integrity of the media sector needs to be improved if it is to contribute effectively to strengthening governance and reducing poverty. Reforms will therefore be undertaken to support the development of a professional and vigorous media sector that will increase awareness and knowledge; facilitate monitoring and evaluation of government by civil society and other interested stakeholders; act as a check on corruption and the abuse of public office; and promote peace. Towards these ends, the Government will submit several important pieces of legislation to strengthen the public's access to information and to support reform within the media sector, including the Freedom of Information Act, Broadcasting Regulations, and the National Public Broadcasting Service Act.

${ }^{28}$ The Government will make special efforts to support community media development, particularly radio. Because of high illiteracy rates among rural populations, community radio can serve as an important forum to discuss and disseminate information about human rights, legal rights and community development, bring pressure for accountability of government officials, provide a vehicle for women's participation in debates, and strengthen the voices of underrepresented groups.

\subsubsection{Addressing Gender Inequities}

${ }^{29}$ The Government of Liberia is strongly committed to gender equality as a means of maintaining peace, reducing poverty, enhancing justice and promoting development in the country. To assure equal opportunities and participation in management and decision-making at all levels of society, women's and men's different experiences, needs, concerns, vulnerabilities, capacities, visions and contributions must be systematically taken into account in the reconstruction of Liberia. The Government is developing a gender policy and an implementation strategy, including the creation of a national gender forum, to guide it and other stakeholders on gender initiatives. 
${ }^{30}$ The Government already has put in place many initiatives to address issues affecting women. It has developed a National Gender Based Violence Plan of Action, and established a GBV secretariat within the Ministry of Gender and Development (See box on GBV in Chapter Seven). It has committed itself to fulfilling its obligations under ratified and signed international treaties, and established a secretariat to monitor and report on the steps taken to meet these obligations. Liberia passed a Rape Law in 2005 which explicitly specifies that rape is a criminal act. The Inheritance Act was also passed to govern the devolution of estates and establish rights of inheritance for spouses of both statutory and customary marriages. The MoGD established a National Secretariat of Women's NGOs to coordinate the work of local women's organizations, including support to capacity building, and the Ministry of Foreign Affairs is leading a process to facilitate and enhance women's involvement in conflict reduction, prevention, and consolidation of peace.

${ }^{31}$ Despite considerable progress, gender continues to play a decisive role in accessing resources and services. Women bear the brunt of the consequences of the conflict. A large number of women and girls have suffered sexual abuse, gender-based violence, forced sex in exchange for food and survival, forced and early marriage, or unwanted pregnancy. Women's participation in leadership and decision making remains low, with only 14 percent representation in the Legislature. Women continue to have limited access to education, health and judicial services, which has severely curtailed their participation in the formal economy. Lack of qualified women is often cited as the main reason for the limited representation of women in various sectors including the security sector.

${ }^{32}$ Since gender issues cut across all sectors, many important specific initiatives are discussed in other chapters of the PRS. With respect to governance and the rule of law, a central goal is to fully guarantee women and men equity in the enjoyment of their human rights. While further consultation is to be undertaken, the Government is considering or taking steps to ensure that:

- all public institutions establish an environment conducive to meaningful participation and advancement of women by adopting policies and procedures to eradicate gender inequalities within the public sector, including relevant provisions in the draft Civil Service Code of Conduct;

- all public institutions have a 'Gender Focal Point' who will be in charge of monitoring and advising on gender initiatives;

- constitutional reforms protect fundamental freedoms and rights including property, reproductive, economic and security rights;

- a local governance system that promotes gender equality and balance is established;

- local women's organizations and networks are strengthened to bring out the voices and perspectives of women into local governance and local decision making bodies;

- a minimum of 30 percent of all staff members, including in the managerial and senior management level, in the legal sector and law enforcement agencies are women;

- the legal sectors elaborate strategies to increase the number of female staff, lawyers and legal aids as well as ensure their retention; and

- procedures and mechanisms are put in place to support and protect through appropriate case management and referral systems all citizens who seek the support and services of a state/community governed by law, particularly survivors of GBV.

\subsection{Building Effective and Efficient Institutions}

${ }^{33}$ During the PRS period, the Government will review and revise government policies, laws and the Constitution to establish rational frameworks for better governance to strengthen and enhance the 
effectiveness and efficiency of public institutions and functionaries. Many of the legal, constitutional and institutional mandates that remain on the books today provide for sub-optimal and sometimes contradictory guidelines for government institutions and policies. The first step in building effective institutions is identifying and correcting deficiencies, inconsistencies and overlaps in the documents that define the Government's structure.

${ }^{34}$ As institutional frameworks are evaluated and foundational constraints are addressed, the Government will focus its efforts on reforming the public service and civil service. (See Chapter Twelve.) After years of neglect, improving management arrangements, operational guidelines and staffing of public institutions is essential to restoring integrity to the public sector.

\subsubsection{Reviewing Laws and the Constitution}

${ }^{35}$ Many years of mismanagement resulted in a proliferation of ill-conceived statutes that contribute to inefficiency in Government, inhibit investment and economic growth, and lead to confusion and controversy over numerous issues that are addressed by multiple laws. Some problems extend beyond statutes to the Constitution.

${ }^{36}$ The Government will propose legislation to establish the Law Reform Commission to review and recommend reform of the legal and regulatory framework to promote the rule of law throughout Liberia. Through this process, conflicting statutes will be identified and amendments will be proposed to the Legislature to rectify the problems. Antiquated laws will be repealed or updated to conform to international standards.

${ }^{37}$ The findings of the proposed Law Reform Commission will also be important in relation to future Constitutional review and reform processes. Some of the problems that characterize Liberia's government and contribute to poor governance are established by the Constitution. It is widely recognized that issues such as citizenship, length of tenure of elected officials, and the structure of government require reconsideration for Liberia to further democratize, decentralize, and meet its obligations to serve all Liberians.

\subsubsection{Public Sector Reform}

${ }^{38}$ The overarching goal in relation to public sector reform is to improve the effectiveness and efficiency of public institutions, to ensure their affordability and sustainability over time, to raise the quality of public services delivered to the citizenry and to enhance capacity to carry out core government functions. Years of war and mismanagement have undermined the basic principles of good management and service delivery and eroded the public's confidence in their Government's commitment and ability to serve them. Successful reform will address both institutional and human capacity deficiencies that hinder performance and productivity in public institutions. An important objective of public sector reform will be to reduce the role of public institutions in producing goods or delivering services that the private sector can produce or deliver at a socially acceptable cost, as described in Chapter Seven.

${ }^{39}$ By making public institutions more effective and efficient, the Government will make better use of resources, taxpayers will get better value for their money, services will be targeted and relevant to the citizens, and public institutions will be held accountable to the Government of Liberia and to the people. Specifically, the strategic objectives of the public sector reform program include ensuring that:

- all public sector and donor-funded activities are consistent with and supportive of Government priorities;

- all public sector reform activities are properly planned and sequenced, carried out in a timely manner, in harmony with overall reform objectives and make best use of available resources;

- reform objectives and activities are fully understood and supported by all key stakeholders in government, the public service, the general public and development partners; 
- institutional incentives for the ministries, agencies and counties enable reforms rather than hinder them;

- planning, budgeting and management processes in ministries and agencies are results-oriented; and

- all reform processes promote justice and equality for all citizens, including women and persons with disabilities, as core values of the public sector, and institutionalize processes to provide equal access and protection services for all.

${ }^{40}$ To further these objectives, the Government will develop a strategy document and action framework to articulate the steps and responsibilities and guide the actions of public institutions involved in the reform process. It will also undertake a restructuring of SOEs, regulatory agencies and parastatal enterprises during the PRS period as set out in Chapter Seven.

\subsubsection{Civil Service Reform}

${ }^{41}$ As part of public sector reform, the Government will work to strengthen and enhance the effectiveness and efficiency of public institutions and civil servants through a comprehensive civil service reform strategy, now under development. The strategy will guide and direct the Government's efforts aimed at reinventing the service from its current state of low productivity into a responsive, effective, and performance-oriented service with improved delivery capacity and ability to achieve the Government's development goals. The civil service reform process is described in greater detail in Chapter Twelve.

\subsection{Strengthening and Enhancing the Effectiveness and Integrity of Legal and Judicial Institutions}

${ }^{42}$ The justice system currently suffers from chronic capacity constraints. The lack of human, material and financial resources has severely hampered the administration and delivery of justice. In order for justice to be served, those who administer justice must be properly trained, equipped and resourced.

${ }^{43}$ The Government aims to improve the administration of justice by identifying key gaps in personnel and skills across all legal and judicial institutions, and devising a strategy to remedy these gaps. The strategy will include review and reform of recruitment, pay and incentives to attract and retain highly qualified and competent staff and ongoing training and support. It will be developed in the context of cross-government initiatives on civil service reform, and will make use as appropriate of existing programs such as the SES and TOKTEN (see Chapter Twelve) to fill critical positions to lead change in this sector. It will address all parts of the legal system, including the Judiciary, justice ministry, prosecutors, public defenders, and corrections officers, and will be closely coordinated with capacity building programs for the LNP and other agencies outlined in Chapter Six. It will give particular attention to developing internal systems to uphold the highest standards of integrity within those institutions, and to promote gender justice and equality as one of the core values of the Justice System.

${ }^{44}$ The Government will establish a judicial training institute to address the capacity building needs of the Judiciary. The Institute will support newly appointed magistrates and judges, as well as provide ongoing training and capacity building throughout judicial careers, in line with priorities identified by the Judiciary.

${ }^{45}$ The Government recognizes the need to improve the connections between the various parts of the criminal justice system. It will develop a strategy for improved management of cases between different elements of the system, to ensure higher quality gathering and preservation of evidence, appropriate prosecutorial decisions, timely scheduling of trials, and reducing lengthy pre-trial detentions.

${ }^{46}$ The Government also recognizes the need to improve the rehabilitative and preventive aspects of the justice system, and will establish a national policy for crime prevention, with an emphasis on com- 
munity responsibility and a particular focus on diversion programs for youth. It will implement specific measures to boost the focus on rehabilitation within the corrections system. Judges and lawyers will be trained to conduct hearings and adjudication for juvenile delinquents and juvenile status offenders, and in methods of effective diversion. Separate secure treatment facilities will also be created for youth. All of these together will enhance juvenile due process.

${ }_{47}$ The Government will develop and implement measures to ensure protection of vulnerable groups within the justice system, in particular during detention, including addressing the particular needs of children and young people, women, the elderly, and persons with disabilities.

The Government recognizes the role that traditional practices can play in providing accessible justice and alternative dispute resolution mechanisms. However, some traditional practices are widely acknowledged to contravene human rights. A national framework will be developed for the exercise of informal and customary justice to ensure that it conforms to human rights standards including gender equality, upholds the rule of law, and complements the formal justice sector. It will include measures to inform the community and law enforcement agencies of harmful traditional practices and their contravention of Liberian law, particularly those are harmful to women and marginalized groups.

\subsection{Expanding Access to Justice and Enhancing the Protection and Promotion of Human Rights}

${ }^{48}$ To ensure effective access to justice, individuals must also have knowledge of their rights and be able to access both the administrators of justice and associated facilities. Feedback from the districts and counties during PRS consultations indicated that people's major concerns regarding rule of law included corruption, a lack of legal aid, limited knowledge of laws (particularly laws regarding rape) and the protection of the rights of women and children.

\subsubsection{Strengthening the Provision of Legal Aid and Access to Justice}

${ }^{49}$ There is a role for a range of actors in providing legal assistance and encouraging equal access to justice. The Government will continue to strengthen the provision of Public Defenders in criminal cases, and will undertake a feasibility study into the provision of Government legal aid in civil cases. It will also provide a framework to encourage the provision of legal assistance by civil society and legal professionals in civil cases, as well as support to victims of crime. In all these areas, the priority focus will be on the poorest and most vulnerable.

\subsubsection{Improving Public Awareness}

${ }^{50}$ The Government will work with all actors, including traditional leaders, to take steps to educate the public with respect to individuals' rights and obligations under the law, particularly the rape law. Together with the strengthening of legal and judicial institutions, public education initiatives will also seek to increase people's knowledge of the justice system and reduce the number of mob justice incidents. It will also take specific measures at the local level to improve dialogue between citizens and the justice sector, to improve accessibility and understanding and to increase the accountability of justice sector institutions. Measures will also be undertaken to educate the public on laws relating to the environment.

\subsubsection{Enhancing the Protection and Promotion of Human Rights}

${ }^{51}$ Promoting and protecting human rights is the responsibility of all branches of government. The Government will provide resources and otherwise enable the Independent National Commission on Human Rights (INCHR) to fulfill its mandate to ensure protection of human rights throughout Liberia. The Government will support the Truth and Reconciliation Commission (TRC) to conclude its operations and submit its final report. INCHR is mandated to ensure implementation of its recommendations so as to bring Liberian society together in a process of healing, reconciliation and reunification. 
Issue

Priority Interventions

Goal: To build and operate efficient and effective institutions and systems, in partnership with the citizens, that will promote and uphold democratic governance, accountability, justice for all, and that will strengthen peace.

Strategic objective 1: To increase and enhance citizen participation in and ownership of government policy formulation and implementation

Given the current constitutional provisions, political and economic decision-making have taken a top-down approach for a long time, with local leaders and actors playing a limited role in the processes that impact their lives. This has led to widespread poverty and unaccountability in the use of public resources.
Strategic objective 2: To strengthen and enhance the effectiveness and efficiency of public institutions and functionaries

Public institutions, for the most part, have been bloated, disorganized, weak and supportive of corrupt practices.
Complete the review of the mandates and functions of government ministries, agencies and commissions in line with the expected leaner role of government, including the rationalization and restructuring of ministries, and new service and management orientation

Complete a comprehensive civil service reform strategy

\begin{tabular}{|l|c|}
\hline June 2009 & CSA, GC \\
\hline June 2008 & CSA \\
\hline
\end{tabular}

Develop and endorse a national decentralization policy and strategic operational agenda

Develop and begin to execute a strategic implementation plan for decentralization, based on the strategic operational agenda, create the necessary capacity and harmonize national and local government structures, including statutory and traditional structures and administrative boundaries

Design, endorse and roll-out a national biometric identification card system linked to a national database drawn from 2008 census data, and issue identity cards to all eligible Liberian citizens

Design and begin implementation of a comprehensive, gendersensitive capacity development strategy for local government and officials at county, district, chiefdom and clan levels

Develop a Children's Act and establish national and communitybased mechanisms to enhance children and youth participation

Initiate district development programs in at least 15 districts, building on community-driven processes with coordinated inputs from line ministries

Review and reform the mandate of the Monrovia City

Corporation to improve service delivery and to manage urban growth

Develop and implement action plan to increase the capacity of the National Elections Commission to manage sub-national elections

Develop a Strategic Framework defining various scenarios that could emerge during the national vision period (through 2027) and an action plan to implement the vision

Enact and begin implementation of the Freedom of Information Act and Whistle blower Statute, Broadcasting Regulations, and National Public Broadcasting Service Act

Develop and install a vigorous and professional communication strategy and program that shall enhance community-based M\&E of public and private performance and public awareness and knowledge of public programs

Define, establish, and put into effect a framework to ensure active civil society capacity development and shared ownership of the process inputs, and outcomes of national, regional and county development agendas

\begin{tabular}{|c|c|}
\hline June 2008 & $\begin{array}{l}\text { GC, MIA, } \\
\text { MPEA }\end{array}$ \\
\hline June 2009 & MIA, MPEA \\
\hline $\begin{array}{c}\text { January } \\
2009\end{array}$ & MIA, LISGIS \\
\hline $\begin{array}{c}\text { October } \\
2009\end{array}$ & MIA \\
\hline June 2010 & MoYS \\
\hline June 2011 & MIA \\
\hline June 2008 & GC, MCC \\
\hline $\begin{array}{c}\text { December } \\
2010\end{array}$ & NEC \\
\hline July 2009 & MPEA \\
\hline $\begin{array}{c}\text { January } \\
2009\end{array}$ & MICAT \\
\hline $\begin{array}{c}\text { December } \\
2010\end{array}$ & MICAT \\
\hline July 2009 & MPEA, MIA \\
\hline
\end{tabular}


Public institutions, for the most part, have been bloated, disorganized, weak and supportive of corrupt practices.
Complete the review of the mandates and functions of government ministries, agencies and commissions in line with the expected leaner role of government, including the rationalization and restructuring of ministries, and new service and management orientation

Complete a comprehensive civil service reform strategy

Develop and begin the implementation of a Redirected Workers

Program to ensure that government workers who are laid off or pensioned will benefit from a process of retraining, psychological preparation, and business start up support to pursue an alternative productive life after government service

Formulate, approve and commence implementation of policy guidelines and an operational framework to effectively guide the recruitment, placement, training, management and retirement of public servants and functionaries in a gender equitable manner

Enact and begin implementation of a Code of Conduct for public servants promulgated by the National Legislature and adopted as guiding principles for the public service

Design and install a biometric identification system to ensure greater transparency and accountability in the allocation and utilization of public servants and Government officials and link the system to the Integrated Financial Management System (IFMIS) at the Ministry of Finance

Install automated human resources records system at the Civil Service Agency and establish framework for linking it to other ministries and agencies

Analyze existing practices and prepare and endorse a welldefined national job classification system with a corresponding salary and benefits scale to adequately compensate public servants and officials

Develop and implement a program for building and sustaining strong professional and managerial leadership that is not only able to establish a modern and well-functioning civil service but also dedicated to realizing the development aims and objectives goals of government, including the sustainability of SES and TOKTEN candidates, training programs for enhancing civil service capacity in an on-going manner

Develop and introduce a performance management program in order to make the Civil Service more performance and resultsoriented

Mainstream gender issues into civil service operations, management and development including a sexual harassment policy for the civil service and an affirmative action program to ensure gender equity in senior levels of the civil service.

Establish at least three regional offices of the Civil Service Outreach Program to ensure better service delivery to civil servants working in the rural areas

Complete pension reform policy and begin implementation, including transfer of pension administration function to the National Social Security and Welfare Corporation (NASSCORP)

Review business processes and operations of independent agencies, bureaus and state-owned enterprises and suggest and endorse measures to streamline and harmonize them so as to improve performance and effectiveness and enact appropriate legislation to have them institutionalized

Finalize the structure and mandate of, and establish by legislation, the Anti-Corruption Commission adequately resourced with capacities to monitor and ensure greater transparency and accountability in the prudent use of national assets and resources and address corruption effectively

\begin{tabular}{|c|c|}
\hline June 2009 & CSA, GC \\
\hline $\begin{array}{c}\text { January } \\
2009\end{array}$ & CSA \\
\hline $\begin{array}{c}\text { November } \\
2008\end{array}$ & CSA, Cabinet \\
\hline $\begin{array}{c}\text { December } \\
2008\end{array}$ & Legislature \\
\hline $\begin{array}{c}\text { December } \\
2008\end{array}$ & CSA \\
\hline $\begin{array}{c}\text { June 2008 } \\
2010\end{array}$ & GC \\
\hline $\begin{array}{c}\text { July 2009 } \\
2009\end{array}$ & CSA \\
\hline $\begin{array}{c}\text { June } 2010 \\
\text { Septem }\end{array}$ & CSA \\
\hline $\begin{array}{c}\text { January } \\
\text { CSA }\end{array}$ & CSA, Cabinet \\
\hline
\end{tabular}


Legal and judicial institutions have a shortage of qualified personnel and weak capacity to contribute to improved security and prosperity, and to provide equitable access to justice for the poor.
Identify critical staffing and skills gaps within all legal and justice institutions, and develop a prioritised strategy for remedying these that is gender sensitive, in particular focusing on recruitment standards, in-service training, pay and incentives, appropriateness of pre-employment legal education, and full use of wider national programmes for enhancing civil service capacity, e.g., SES/TOKTEN

Establish a Judicial Training Institute to address ongoing training needs identified through judicially-led assessment of existing magistrates and judges, and other judicial personnel, as well as initial training for newly appointed judges and strengthen the institutional capacity of the University of Liberia Louis Grimes school of law

Identify a prioritised list of outstanding infrastructure and operational equipment requirements for all legal and judicial institutions, focused on: ensuring effective and equal delivery of justice in all counties and districts; tackling serious crime and disorder; and enabling the rapid resolution of commercial and property disputes

Strengthen the juvenile justice system with a particular focus on diversion programmes for youth

Establish a national policy for crime prevention, with an emphasis on community participation

Develop a national framework for the practice of informal, customary system of justice to ensure that it conforms to human rights standards including gender equality, upholds the rule of law, and complements the formal justice sector

Devise and implement effective national and county-level case management systems to ensure effective transfer of cases and evidence between the different criminal justice institutions, improve the basis for prosecutorial decisions, increase the speed at which cases are brought to a conclusion

Establish a Law Reform Commission that will review and make recommendations to revise civil, criminal and commercial laws

Identify and implement specific measures to boost the focus on March 2009 rehabilitation within the corrections system
March 2009 MoJ, Judiciary

\begin{tabular}{|c|c|}
\hline July 2009 & Judiciary \\
\hline March 2009 & MoJ, Judiciary \\
\hline March 2009 & MoJ, MoYS \\
\hline $\begin{array}{c}\text { September } \\
2008\end{array}$ & MoJ \\
\hline $\begin{array}{l}\text { August } \\
2010\end{array}$ & $\begin{array}{l}\text { MoJ, Judiciary, } \\
\text { MIA }\end{array}$ \\
\hline July 2009 & MoJ, Judiciary \\
\hline Dec. 2008 & $\begin{array}{c}\text { MoJ, } \\
\text { Legislature }\end{array}$ \\
\hline March 2009 & MoJ, MoYS \\
\hline
\end{tabular}




\section{Strategic objective 4: To expand Access to Justice, and enhance the protection and promotion of human rights}

under the Laws of Liberia

There are significant shortcomings in the protection and promotion of human rights, a lack of equal access to the justice system, and limited public understanding of citizens' rights under the law.
Establish and begin implementation of a framework to significantly reduce the length of pre-trial detention

Develop and implement measures to ensure protection of vulnerable groups within the justice system, in particular during detention, including addressing the particular needs of children and young people, women, the elderly, and persons with disabilities

Develop and support implementation of a national enabling framework for the provision of legal aid, particularly for the poorest and most vulnerable members of society, including through bolstering the public defender system, conducting a feasibility study into government provision of legal aid in civil cases, and enhancing the role of civil society in supporting access to justice

Develop simple public information materials about citizens' rights within the legal and judicial process, how to access justice and the content of key laws, and use the material as the basis for nationwide education and awareness campaigns Institute mechanisms at the local level for open dialogue with representatives of the legal and judicial institutions to ensure mutual understanding of issues of concern and institutional accountability of the legal and judicial sector

Establish a policy and operational framework to ensure gender justice and equality are core values with the legal and judicial system

Upon promulgation of pending legislation, commence operations of the Independent Human Rights Commission, and support the fulfilment of its mandate, including monitoring government compliance with human rights standards, as well as developing a framework for implementation of the recommendations of the Truth and Reconciliation Commission

\begin{tabular}{|c|c|c|}
\hline July 2009 & MoJ, Judiciary \\
\hline July 2009 & $\begin{array}{c}\text { MoJ, MoGD, } \\
\text { Judiciary }\end{array}$ \\
\hline $\begin{array}{c}\text { August } \\
2010\end{array}$ & MoJ, Judiciary \\
\hline $\begin{array}{c}\text { July } 2009 \\
\text { MoJ, MICAT } \\
2009\end{array}$ & $\begin{array}{c}\text { MoJ, Judiciary, } \\
\text { MIA }\end{array}$ \\
\hline $\begin{array}{c}\text { December } \\
2008\end{array}$ & $\begin{array}{c}\text { MoJ, MoGD, } \\
2008 \\
\text { December } \\
\text { HR Commission, } \\
\text { Leglature }\end{array}$ \\
\hline
\end{tabular}




\section{Rehabilitating Infrastructure and Delivering Basic}

\section{Social Services}

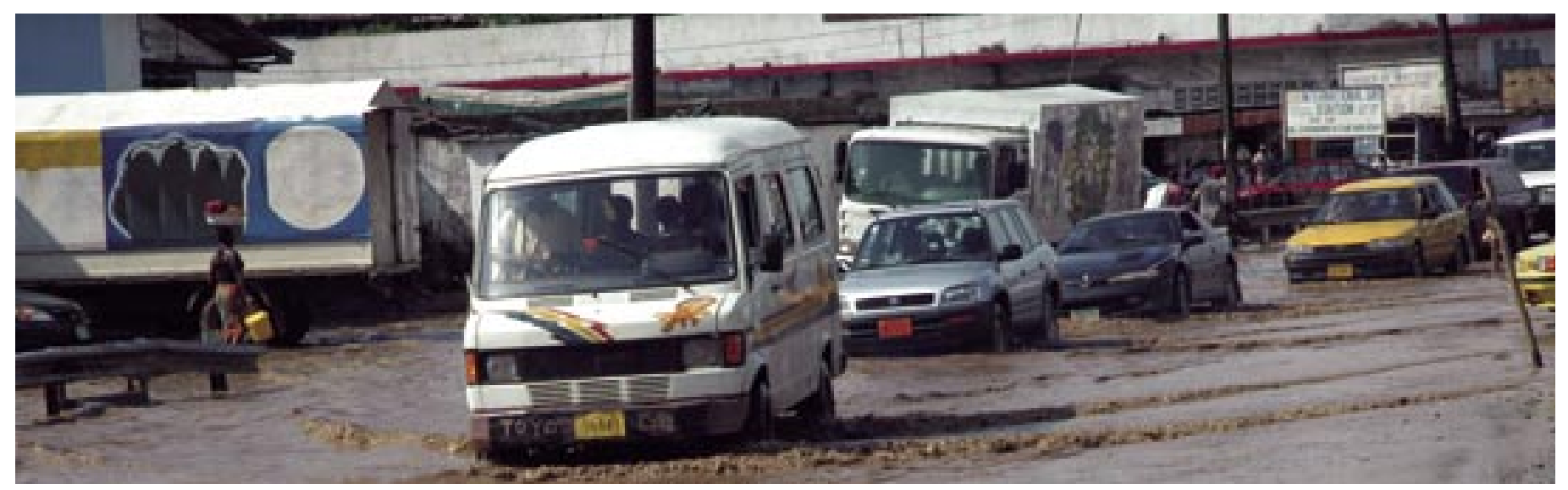

\subsection{Introduction}

1 Upon coming to power in January 2006, the Government inherited infrastructure that was in a state of total disrepair as a result of the war and years of neglect. Roads and bridges, telecommunications, power, transportation, water and sanitation systems, schools, and health facilities were almost all either destroyed or in need of significant repair. But this was by no means confined to the physical structures or architecture; national and local institutions that previously organized and supervised each of these essential sub-sectors had also deteriorated. Policies and regulations for efficiently delivering these systems and services were either outdated or were no longer in existence or enforceable. Managerial, planning and technical capacities were severely weakened and depleted.

${ }^{2}$ One of the Government's foremost objectives was therefore to quickly embark upon the rehabilitation of infrastructure and the rebuilding of systems to deliver basic services in order to create the conditions and linkages needed to achieve broad-based growth and poverty reduction. Rebuilding roads, in particular, is central to achieving all of the Government's other major objectives, including consolidating peace and security, facilitating inclusion, revitalizing growth throughout the country, building strong systems for local governance, promoting physical access to security and legal institutions, and making public and other services accessible to all Liberians. Without adequate infrastructure, the ability to create jobs, expand the rule of law and reduce poverty will be severely constrained, increasing the likelihood of a return to conflict. During the Government's county consultations and in survey results including the CWIQ and the PPA, Liberians frequently stated that roads are their number one priority. They also listed education and health as high priorities. ${ }^{44}$ Delivery of health, education, and other services must have special regard to youth, women, and persons with disabilities, who are too often marginalized from such services. Increasing school enrolments, offering more and higher quality training opportunities, and facilitating more recreation and sports activities, help build social capital, train Liberia's next generation of leaders, and lay the foundation for growth and poverty reduction. Much of the initial leg work on this agenda, especially on the physical side, was initiated under the 150-Day Action Plan and significantly progressed during the iPRS period.

\footnotetext{
44 These results were confirmed by the subsequent release of a 2007 Gallup Poll, which asked Liberians to pick the most important issue for the Government to address over the next 12 months. Almost three-quarters of respondents ( 74 percent) chose infrastructure and basic services-related issues, being the road system (33 percent), education (24 percent), water (10 percent), and electricity (7 percent). See Magali Rheault, Liberians Give High Marks to Their Government, February 21, 2008 at http://www.gallup.com/poll/104491/Liberians-Give-High-Marks-Their-Government.aspx.
} 
${ }^{3}$ But while some progress has been made, major challenges remain. Over the PRS period and beyond, a key Government goal will be to sustain and deepen the provision of basic physical infrastructure and the delivery of basic services. In that connection, and in order to move forward in an efficient and costeffective manner, the Government must consider a number of sector-specific policies and wider environmental issues, building on the progress under the iPRS. In so doing, it must address the fundamental issue of the role of the state in the delivery of growthenhancing infrastructure and basic services. It must determine:

- the extent to which the cost of providing basic infrastructure and services, including operations and maintenance expenditures) should be directly recoverable by fees or levies on users or beneficiaries; and how much could be explicitly supported through the budget;

- the appropriate regulatory and oversight institutions to organize and coordinate the delivery of these services, and the extent to which the necessary institutional capacity could be developed;

- the degree of private/public engagement in the actual delivery of those services, and the criteria that should influence their relative roles;

- the extent and sequencing of the decentralization of service delivery; and

- the appropriate frameworks for the maintenance and sustainability of infrastructure assets.

${ }^{4}$ In undertaking these determinations, the Government will ensure that decisions, policy, planning, and program implementation are inclusive in terms of geography, ethnicity, and gender. It will also be attentive to issues of accessibility for persons with disabilities, and sensitive to environmental issues.

${ }^{5}$ These issues have already emerged in the Government's initial responses for virtually all types of infrastructure and basic services, but must be addressed more comprehensively and conclusively during the course of the PRS. Although much progress has been made in relation to the rebuilding of infrastructure and the provision of basic services, a failure to consolidate and build on this progress in a timely manner will significantly undermine the effective and sustainable delivery of goods and services, while reducing their impact on poverty reduction.

\section{Liberia Reconstruction Trust Fund}

The extent of infrastructure needs in Liberia (as set out in detail in this chapter and in Chapter Eleven) has prompted a new multi-donor, pooled fund approach to infrastructure rehabilitation.

The World Bank-administered Liberia Reconstruction Trust Fund (LRTF) was developed during 2007 to mobilize critical funding for national priorities as defined in the PRS, with a particular focus on infrastructure. LRTF projects will also seek to accomplish two additional objectives: employment creation and capacity development. The projects will be executed by the Government through the Special Implementation Unit (SIU) in the Ministry of Public Works and the Public Financial Management Unit (PFMU) in the Ministry of Finance.

The LRTF provides partners with a mechanism through which to contribute to Liberia's reconstruction and development efforts without having to establish a ground presence in Liberia. The creation of a multi-donor fund will also simplify the management, monitoring and evaluation of aid flows, and thereby facilitate Government ownership of the reconstruction process. Already, the LRTF has received contributions from the World Bank (\$3 million) and from the German Government (\$12 million) with additional contributions from new donors expected soon. 


\subsection{Roads and Bridges}

${ }^{6}$ Nearly all roads and bridges were either seriously damaged or destroyed during the war, yet they are the pivotal links for the most critical development initiatives at this stage of the recovery process. Liberia's road network totals 6,162 miles. Only 456 miles of this is paved, and much of the pavement has grossly deteriorated. Primary and secondary laterite roads connect the 15 political sub-divisions of Liberia including the county capitals, district and chieftaincy headquarters. However, most of these laterite roads are not pliable during the six months of intense rainy season and have to be regraveled annually. Primary roads also link Liberia with its neighbors. An additional 1,500 miles of feeder roads were originally privately constructed, mainly by logging and mining companies, and partially by farmers to bring products to market, most of which are not now pliable.

\section{Figure 9.1: Status of Roads and Bridges in Liberia as of December 2007}

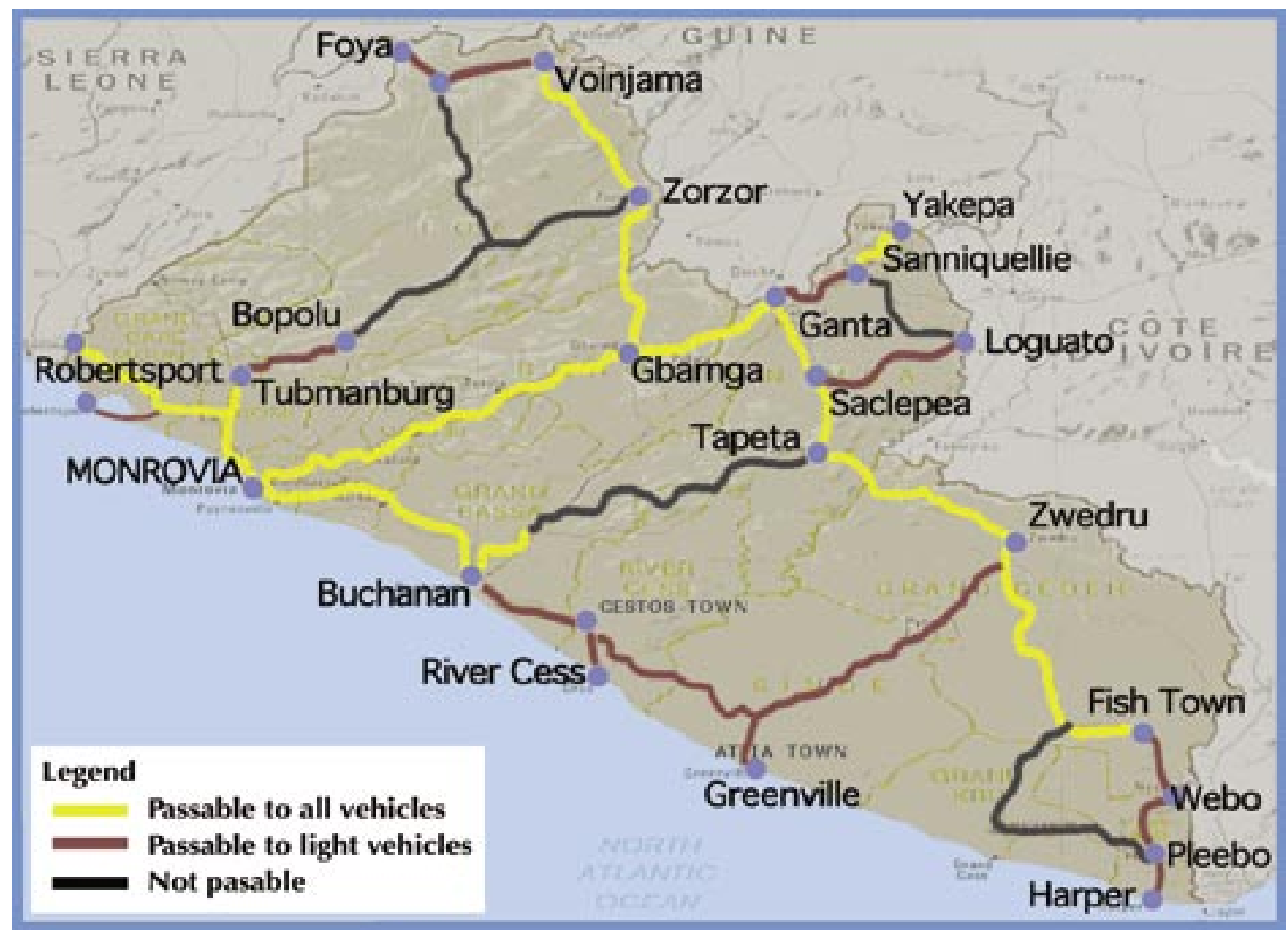

Source: Ministry of Public Works

${ }^{7}$ Going forward, the private sector will play a major role in road construction. The Government will own and develop the key strategic transport infrastructure, pursuing potential public-private partnership (PPP) initiatives.

${ }^{8}$ Under the iPRS, the Government began to rehabilitate and reconstruct 430 miles of primary and secondary roads. While it did not progress as far as it had hoped due to financing and capacity constraints, it made significant initial progress. It also initiated efforts to beef up the limited capacity for maintenance, and to acquire equipment to bolster the internal capability of the Ministry of Public Works (MPW). UNMIL continues to make significant contributions to maintaining the roads with the financial support of other partners.

${ }^{9}$ Over the PRS period, the Government will focus on four strategic objectives with regard to roads and bridges: 
- Ensure that all primary roads are pliable year-round, while aggressively opening secondary/feeder roads around the country. During the PRS period, the Government will build or reconstruct 1,187 miles of primary roads of which 1,075 miles will be paved (surface dressing) and 300 miles of allweather secondary roads around the country to connect the headquarters of the fifteen counties and other cities, with priority roadways determined largely by the size of the population and the economic potential of the areas reached. In addition, it will rehabilitate or construct 400 miles of feeder roads nationwide, with priority feeder roads determined in consultation with communities. Wherever possible, the Government will encourage labor-intensive construction methods and techniques, and adopt environmentally-sensitive practices. A total of 33 bridges are earmarked to be installed around the country during this period.

- Work in partnership with mining, logging and agricultural companies to undertake the rehabilitation of certain feeder roads as part of concession agreements and encourage the construction of these roads at minimum MPW standards. These feeder roads are critical for improving economic activities throughout the country, especially with respect to agriculture, thereby creating more inclusive economic opportunities for groups that are involved in such activities, including those marginalized from Liberia's past economic growth such as women and youth. These roads will also provide access for security institutions to maintain stability and law and order.

- Rehabilitate roads in the communities in Monrovia and the headquarters of the 15 counties. The Government will pave 62 miles of streets and neighborhood roads in Monrovia, and 150 miles laterite roads in the county seats within the next three years, which will include side brushing programs and the installation of road safety signs. This will greatly improve the mobility of the public at large, and enhance accessibility for persons with disabilities. It will also create jobs for young men and women in the communities and improve road safety.

- Rebuild the capacity for sustained construction and maintenance of roads and bridges. Many Liberian engineers lost significant opportunities for training and experience during the war. The MPW will therefore as a matter of priority begin to rebuild its own maintenance and other capacities by recruiting engineers and others with specialized skills through the Senior Executive Service

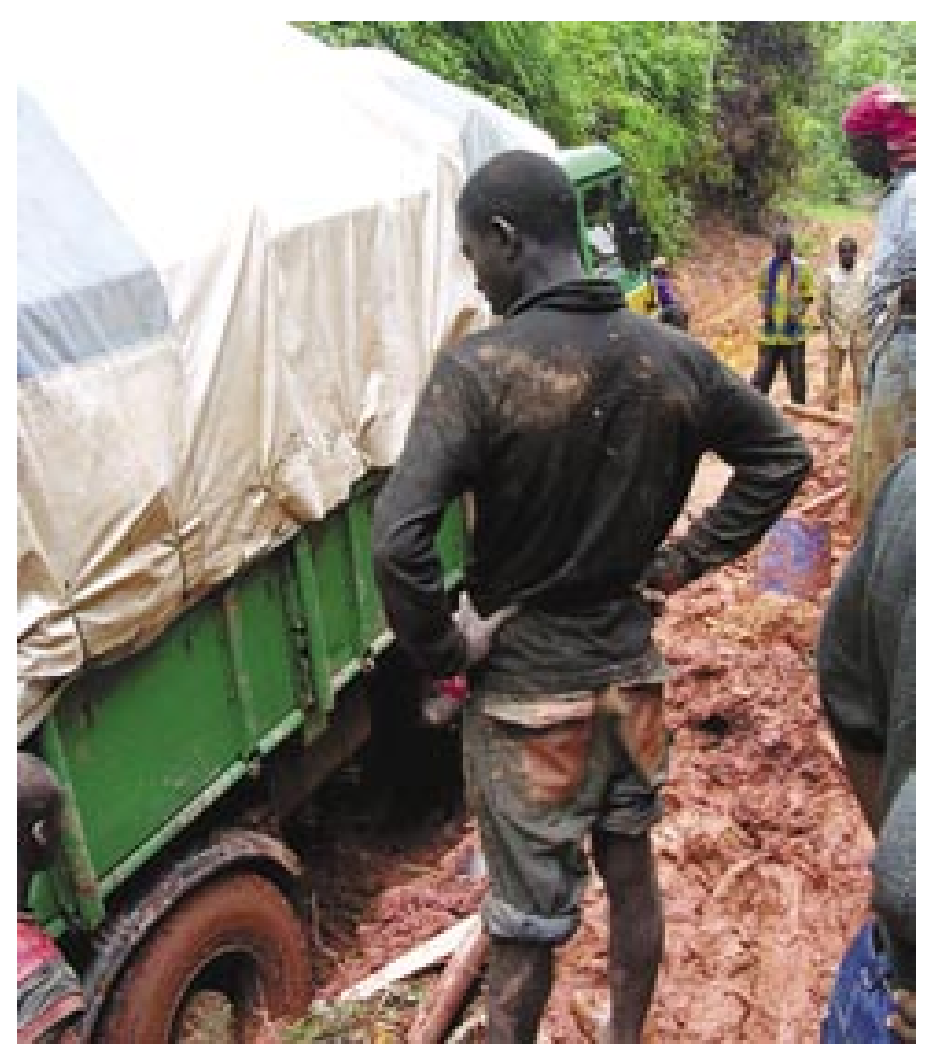
(SES) and Transfer of Knowledge through

Expatriate Nationals (TOKTEN) programs described in Chapter Twelve. Additionally, the Ministry will begin to renovate the Road Maintenance and Training Center (RMTC) to meet the capacity development needs of the sector in the short-to-medium term, while the Ministry transitions to a largely supervisory and policy coordination role. The Government will aim to create training opportunities and scholarships (especially for women) in engineering and related fields to rebuild the human capacity necessary for a strong infrastructure network. The MPW will also work with local private sector companies to boost their capacity to compete for road building contracts, as well as improving job creation and on-the-job training at the local level.

- Rebuild the financing, planning, and management systems necessary to ensure the capacities are in place to fund road construction and maintenance over time. Learning from international best practices, the Government will consider introducing a fuel tax to generate financial resources that 
could be used for this purpose. Although as a general policy the Government will not earmark taxes for specific purposes, revenue from a fuel tax would help ensure that road users pay for road maintenance. It will, however, be important to guard against introducing rigidities into the Government budget in doing so. The Government considered the establishment of a toll road system, but given issues in the complexity of execution and management, it has decided not to pursue this option at this time. In general, in the short-to-medium term, the MPW will endeavor to outsource an evergreater portion of road maintenance to local private firms. Over time, and as firms build greater capacity nationally, the Ministry intends to outsource its road maintenance function completely.

\subsection{Transportation}

${ }^{10}$ Prior to the civil war, the transport sub-sector in Liberia included road and railway networks, civil aviation, and several ports. Today, the railway network is not operational, civil aviation is limited to Monrovia with only UN flights operating upcountry, and the Port of Monrovia is the only fully operational port in the country with the Buchanan and Harper ports only partially operational and the Port of Greenville not at all. The Government is formulating a National Transport Policy, recognizing that achieving the growth, development and poverty reduction objectives of the PRS hinges on the availability of adequate and reliable transport. Enhancement of transport infrastructure should accelerate the development of other productive sectors, ensuring food security, efficient exploitation of natural resources and manufacturing.

\subsubsection{Land Transport}

${ }^{11}$ The Government's overriding objective for land transportation is to improve the supply of largely private sector-led transportation services, without compromising customer accessibility, safety and comfort. In Monrovia the situation is particularly acute. The Monrovia Transit Authority (MTA) is under-capitalized, with unclear legal status and authority and insufficient finance. Steps will be taken to engage the private sector in the provision of reliable and sustainable transportation services.

${ }^{12}$ During the iPRS period the MTA received 25 used buses donated by the Spanish Government. Nine of these buses have been rehabilitated and are now in service on a pilot basis, thus providing much needed public transport for the residents of Monrovia and its environs.

${ }^{13}$ During the PRS period, the Government will implement the provisions of an Act to create a National Transit Authority (NTA). The Act is with the Legislature and passage is expected shortly. The Act provides a framework for effective, efficient, integrated and affordable national transit services, and for the establishment of a National Public Bus Transport System. The Government will also begin to develop a National Transport Master Plan to support infrastructure in the transport sector, including roads, bus stop signs, bus shelters, and bus terminals across Liberia.

${ }^{14}$ In order to meet the demand in both urban and rural areas for accessibility, customer safety, comfort and adequacy, the envisaged National Transport Master Plan will aim to:

- increase private sector participation and public-private partnerships in the provision of transport and alternative transport services;

- develop and operate modes of transport in urban and rural centers on the basis of economic savings on fuel use, efficiency including traffic congestion, and environmental protection and safety;

- examine the current technologies available with a view to adopting the most ideal modes for urban and rural transport;

- segregate the flow of public transport and in particular bus transport, which should be confined to selected routes to speed up traffic flow; 
- facilitate a strong operator union and other fora for effective transport services;

- encourage the use of non-motorized transport and mass passenger transport as alternatives to ever growing vehicle traffic; and

- streamline regulatory functions for the oversight and monitoring of the above activities and, in particular, the business of private operators in the country.

${ }^{15}$ In addition, the MTA plans to introduce new routes and new bus stations to facilitate mass movement of commuters in areas of Monrovia not currently served by private operators. ${ }^{45}$ Further, MTA plans to introduce a fleet of small buses to take commuters from the main routes to various communities.

\subsubsection{Air Transport}

${ }^{16}$ Liberia's air transport system is a shell of its former self. Roberts International Airport (RIA) can support only limited international flights, and is in need of major repairs. Only 5 of 43 smaller domestic airfields have been partially repaired after the conflict, and are serviced only by UNMIL flights. Prior to the war, the Liberia Domestic Airports Agency (LDAA) served as a hub for domestic and sub-regional air traffic. LDAA faces the effects of the destruction of most of its infrastructure and the encroachment of squatters on LDAA land during the conflict.

${ }^{17}$ During the last two years, the Government commenced work on the installation of a refurbished system of ground and navigational equipment at RIA, acquired and installed rescue and firefighting equipment, and began to renovate passenger terminals and expand the runway.

${ }^{18}$ During the PRS period, a key goal for the Government is to upgrade RIA's capacity to international standards. It plans to introduce an Act to confer on RIA defined legal status and to transform the RIA into a National Airport Authority (NAA). Other specific plans under consideration include:

- construction of a new International Terminal building;

- installation of pipe-borne water, sewage, apron and taxiways to handle forecast passenger traffic of 350,000 per year from 2010 to 2020 ;

- construction of a new runway with updated navigational equipment and lights (pending determination of commercial feasibility);

- construction of a cargo terminal to service the West African hub; and

- reacquisition of illegally occupied LDAA property and submitting an Act aimed at creating LDAA's autonomous status. With the passage of the NAA, the role of the LDAA will be rationalized, with it likely to retain responsibility for operations of domestic flights within a wider NAA framework.

\subsubsection{Maritime and Inland Waterway Transport}

${ }^{19}$ All of Liberia's seaports are in a serious state of disrepair owing to structural damage and the lack of maintenance during the conflict. Yet nearly all of Liberia's supply of fuel, food and essential imports are handled by the National Port Authority (NPA). The rehabilitation and development of the NPA's capacity is essential for development and overall peace and security in Liberia.

${ }^{20}$ Under the iPRS, steps have been taken to address major physical weaknesses and operational inef-

45 These include areas such as UN Drive around South Beach, where the MPW, GSA, and MCC compounds are located; the University of Liberia Fendell Campus in Brewerville, and the Baptist Seminary on the Robertsfield Highway. 
ficiencies in the NPA. The Government has completed assessments of the requirements for rehabilitating the marginal wharf on an emergency basis, and has completed dredging of the port to a new and more acceptable level of almost 11 meters. It has also just completed a downsizing of NPA staff. Discussions are underway with respect to legal issues around the warehouses within the Freeport, a number of which have been sub-leased at exorbitant prices in relation to those paid under the original NPA leases. With support from the GEMAP, progress is being made in the installation of stronger systems of financial control and management in the operations of the port. An MOU was agreed with the Government, NPA and donor partners on a port sector reform program, encompassing funding of major emergency repairs for the NPA, as well as a public-private partnership to facilitate longer-term investments through a Build Operate Transfer (BOT) arrangement.

${ }^{21}$ During the PRS period, the NPA and the Government will build on these developments by:

- finalizing the BOT concession covering private management of the NPA and the outsourcing of operational functions, including container handling;

- rehabilitating the marginal wharf of the Port of Monrovia;

- acquiring adequate cargo handling equipment for efficient port operations;

- providing navigational aids for 24-hour berthing and unberthing of vessels;

- removing the wrecks within the harbor basin;

- acquiring basic marine craft (tugs, pilot boats, launches, etc.);

- refurbishing the oil jetty and the provision of a firefighting system;

- providing basic equipment for and initiating dredging of the ports outside Monrovia;

- acquiring sea-water firefighting capacity in the NPA yard/Freeport of Monrovia; and

- developing a Master Plan for the Freeport of Monrovia and other ports in the country.

\subsection{Energy}

${ }^{22}$ The conflict resulted in collateral damage, looting and vandalism of all energy infrastructure, including power plants, substation transmission lines, petrol storage tanks and depots. Today less than 2 percent of rural residents and 10 percent of urban residents have access to electricity produced mainly from private generators at prohibitive costs. More than 90 percent of Liberia's population depends on unreliable and inferior sources of energy such as firewood, charcoal, candles, kerosene and palm oil. The lack of reliable energy sources has put serious strain on Liberia's forest resources and restricted growth of enterprise. Prior to the war, the total electricity installed capacity of the Liberia Electricity Corporation (LEC) was approximately $191 \mathrm{MW}$, while that of concessionaires was $212 \mathrm{MW}$. By mid2008, electricity installed capacity will be a mere $12 \mathrm{MW}$.

${ }^{23}$ During the iPRS implementation period, the Government made important initial progress, including provision of approximately $2.65 \mathrm{MW}$ of power to some parts of Monrovia under the Emergency Power Program 1 (EPP1); installation of additional generators and network rehabilitation under EPP 2; requesting and receiving Expressions of Interest for the Monrovia Power Concession; awarding the contract for the feasibility studies for the rehabilitation of the Mt. Coffee Hydroelectric Facility; and entering an MOU with the West African Power Pool for the connection of 18 Liberian communities with electricity from Cote d'Ivoire. 
${ }^{24}$ During the PRS period, the Government will pursue four key strategic objectives:

- Complete and publish the national energy policy and master plan. The Government will complete its overall energy policy and strategy, and complete and publish the relevant legislation. The strategy will describe plans for liberalizing the electricity sub-sector, which could involve either "unbundling" the LEC and privatizing one or more generation, transmission and distribution units; introducing a management contract; or other arrangements. It will propose the establishment of an independent regulatory agency responsible for approving tariffs, system reliability, quality standards, and dispute resolution. It will also restructure the MLME and build its capacity to meet the emerging challenges in the energy sector.

- Further expand the Monrovia grid, and begin to expand the grid to other cities. The Government is planning a concession for an additional 30 to $50 \mathrm{MW}$ for Monrovia, which in addition to the generation under EPP 1 and EPP 2 will be adequate to meet the demand of Monrovia and its environs through the medium term. Policy decisions have to be made on whether the concession will be vertically integrated and on its duration in light of cost recovery implications and the potential for quickly installing capacity fueled by renewable sources such as biomass. The Government will also begin to extend grid electricity to other cities and localities, beginning with the eleven LEC Outstation Posts, most of which are in county Headquarters. It will also work to implement the cross-border electricity connection project with Cote d'Ivoire.

- Begin to develop new hydropower generation capacity and assess other energy sources. Upon completion of a Mt. Coffee feasibility study in September 2008, the Government will consider various financing options for the rehabilitation and expansion work, which is expected to last 5-6 years. (See box, Chapter Eleven.) It will assess the potential for other renewable energy resources such as hydropower, solar, wind and biomass, and begin to construct small hydropower, biomass, and other renewable energy systems as appropriate.

- Further develop the upstream and downstream petroleum sectors. The Government will review and determine the most appropriate structures (public or private) and functions of the National Oil Company of Liberia and the Liberia Petroleum Refining Corporation. It will institute measures to increase the product quality and profitability of the downstream petroleum sub-sector and expand and improve the petroleum product delivery service to rural Liberia. The Government will also institute measures to attract major investments to the upstream sub-sector. The Government has signed several production sharing contracts to conduct offshore petroleum exploration, and is in discussions with a view to signing several more, on the basis of the amended fiscal regime to be submitted for legislative approval. It will intensify efforts to explore for petroleum offshore by allocating several additional blocks for exploration.

\subsection{Post \& Telecommunications}

${ }^{25}$ Postal and telecommunication services play a critical role in the exchange of information and communication throughout the country. These services are crucial to support investment and to accelerate the delivery of basic social services. However, postal services are currently limited, with only 8 operational post offices outside Monrovia and nearly 90 percent of staff untrained. Further, there is insufficient basic equipment and services, including mail vans, computers and internet access. Similarly, telecommunications services are unreliable and coverage is limited. A lack of a workable policy agenda for both sectors has also impeded progress.

${ }^{26}$ The central goal of the post and telecommunications sector is to make progress toward the provision of universal services and to operate in accordance with the rules and standards of the Universal Postal Union (UPU) and the International Telecommunication Union (ITU). To do so will require improvements in infrastructure, institutions and human capacity across each of the sectors. 


\subsubsection{Postal Services}

${ }^{27}$ During the iPRS implementation period, the Government completed the rehabilitation of fifteen post offices in eight counties, and made stamps and mail boxes available in the main post office in Monrovia. Further progress is inhibited by the lack of an overarching postal policy (now under development), weak infrastructure, poor road networks, weak capacity, and inadequate vehicles and supplies.

${ }^{28}$ Over the PRS period, the postal sector will endeavor to provide reliable and effective universal service consistent with international standards to at least 70 percent of Liberians, including major towns or villages with a population of 10,000 or more.

${ }^{29}$ To do so, the Government will undertake the following:

- construct and rehabilitate additional postal structures throughout the 15 county headquarters and dwellings of 10,000 or more inhabitants, with work covering the furnishing of structures with the necessary logistical and other equipment, and the procurement of adequate mail vans, motorcycles and bicycles;

- develop a comprehensive postal policy;

- hire and train competent staff for all postal positions;

- initiate financial and electronic services such as money orders, bill payments, wireless transfers, hybrid mail and other internet-related services; and

- increase awareness of postal services through a national promotional campaign.

\subsubsection{Telecommunications}

${ }^{30}$ Under the iPRS a major achievement was the passage of a new Telecommunications Act that lays out the regulatory and operational architecture for the sub-sector (standardization of licensing fees and concession agreements, and assessment of the value of frequencies/spectrum and other national resources). The Government also established the Liberian Telecommunications Authority (LTA). In addition, it made initial progress in laying the foundation toward the reinstallation of a national fixed line network by the Liberia Telecommunication Company (LTC), and concluded the payment of salary arrears to redundant LTC staff. It took initial steps toward the formulation of a national ICT policy through robust stakeholder consultations.

${ }^{31}$ Four mobile phone companies now provide services and competition in the sector is high. But the sector faces several key challenges, including weak infrastructure, lack of accessibility, and issues of affordability, especially for the rural poor.

${ }^{32}$ Over the PRS period, the telecommunications sector will develop a national Information Technology (IT) infrastructure and a nationwide communication backbone that will ensure a secure communications network for the Government and people of Liberia. In particular, the following actions will be undertaken:

- Ministry of Post and Telecommunications (MoPT) will finalize and begin implementing the telecommunication and ICT policy initiated under the iPRS;

- LTA will complete the standardization of licensing and fee regimes and the setting of procedures for the implementation of Universal Access based on the telecommunication and ICT policies;

- LTA will make substantial progress in development of a telecom network (50 percent local, 25 percent rural) and significantly increase the subscriber base, reaching as many of the major areas of 
the country as possible;

- The Ministry and LTA will consider options to create Universal Access regimes using innovative public private partnership arrangements to provide connectivity outside of Monrovia; and

- LTC will put in place a competent management team and workforce, and settle all relevant and justifiable issues concerning back pay and retrenchment of some 50 percent of former employees.

\subsection{Water and Sanitation}

${ }^{33}$ Poor access to safe drinking water and sanitation services are major causes of illness and poverty. The impact of inadequate drinking water and sanitation services is greatest on the poor, who are badly served by the formal sector. Many people, particularly women and children, fetch water from long distances or pay high prices from vendors. In addition, water and sanitation-related sicknesses put severe burdens on health services, keep children out of school, and undermine investment in agriculture and other economic sectors. The war significantly undermined the delivery of water and sanitation services. Access to safe drinking water and adequate sanitation facilities fell from 37 percent and 27 percent of the population in 1990, respectively, to 17 percent and 7 percent respectively in 2003. Monrovia's water supply fell from 18 million gallons daily to just 1 million gallons.

${ }^{34}$ While significant progress has been made since the end of the war, still only 25 percent of Liberians have access to safe drinking water and just 14 percent have access to human waste collection and disposal facilities. ${ }^{46}$

${ }^{35}$ Regarding solid waste management, the Government has also begun to introduce improved management practices in Monrovia with the establishment of 120 collection points with waste skips and pad in place. Weekly haulage of solid waste in Monrovia increased from $980 \mathrm{~m}^{3}$ in March 2007 to 2,125 $\mathrm{m}^{3}$ in November 2007. Under this arrangement the secondary collection of solid waste from communal dumpsites has been outsourced to private service provid-

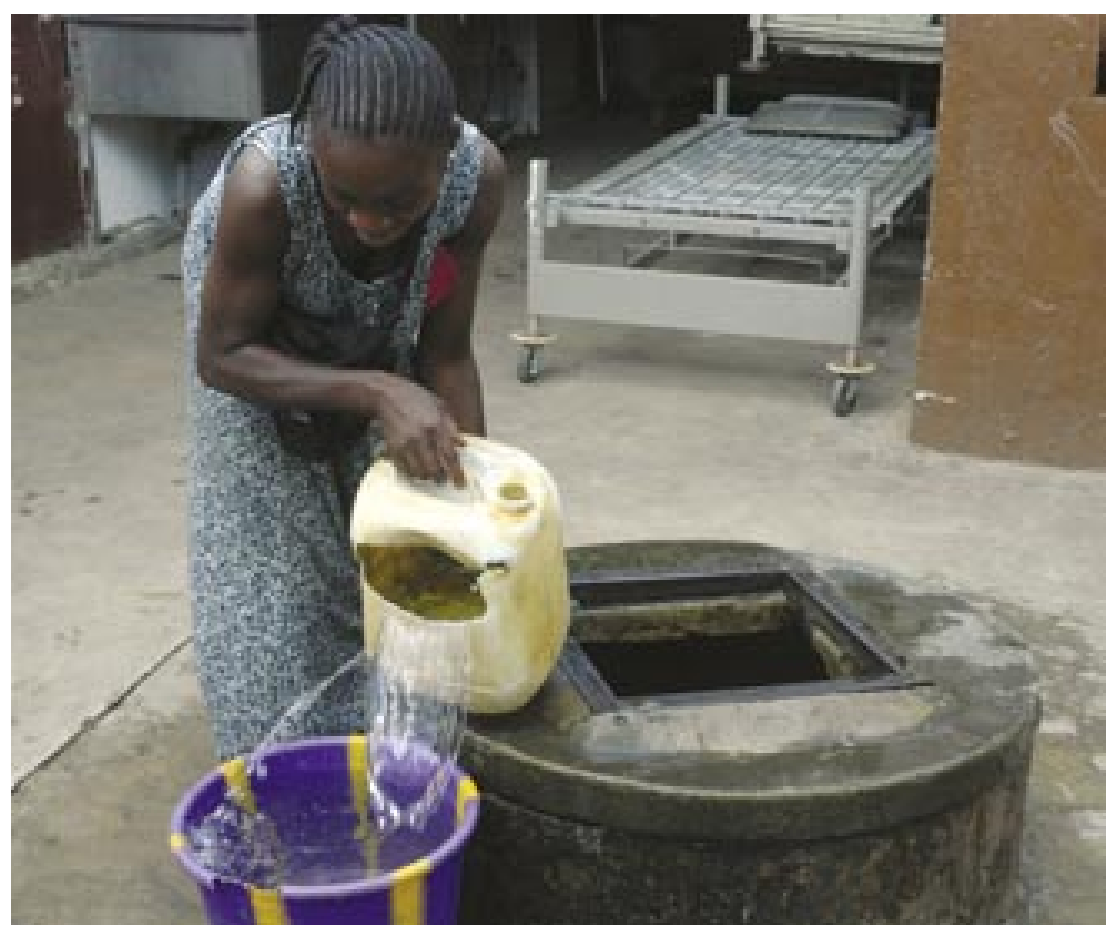
ers to collect the backlog and current daily generation of $700 \mathrm{~m}^{3}$. The Monrovia City Corporation (MCC), which previously provided this service, has now assumed the role of a facilitator responsible for providing guidelines and monitoring adherence to them. In addition to this arrangement, primary collection of waste from households and other sources to communal dumpsites is being undertaken by community-based enterprises and other groups. This has provided jobs in solid waste management, while also reducing environmental and health hazards and enhancing the appearance of communities. There remains, however, no reliable landfill site in Monrovia and its environs. Appropriate waste treatment and disposal system and facilities are needed urgently. The Government must also make plans as to how to sustain these services as they are currently donor-funded.

\footnotetext{
46 These figures were extrapolated by the joint Government-NGO working group on Water and Sanitation using a 2004 baseline and accounting for the water and sanitation projects undertaken nationally by the Government and partners since that time. They are used as the baseline indicators for the Government's strategic objectives in Water and Sanitation, including the MDGs.
} 
${ }^{36}$ The basic goal of the Government with respect to water and sanitation is to reduce the water and sanitation-related disease burden in Liberia.

${ }^{37}$ To achieve this goal, the Government will address three strategic objectives:

- increase access to safe drinking water (from 25 percent to 50 percent by 2011 , including to 45 percent of the rural population);

- increase access to human waste collection and disposal facilities (from 15 percent to 40 percent, including to 35 percent of the rural population); and

- ensure the sustainability of 90 percent of water and sanitation facilities in the country

${ }^{38}$ In working toward these objectives, the Government will undertake the following actions:

- rehabilitate damaged water and waste collection/disposal facilities, and construct new facilities as needed;

- establish water quality testing facilities nationwide with trained staff and necessary equipment;

- scale-up hygiene promotion in schools and communities in all fifteen counties, including establishing or supporting existing water, sanitation, and hygiene (WASH) committees at the community level and engaging them in sensitization/training events;

- carry out standardization and quality control for all equipment and facilities;

- establish a theft control mechanism for water and sanitation assets;

- develop or procure improved hydro-geological information systems;

- develop a national solid waste management policy, strategy and regulations to ensure effective co-ordination and sustainability of efforts in the disposal of domestic refuse, clinical waste and toxic waste, and which will create the necessary enabling conditions for private sector investment and public engagement in waste management; and

- undertake plans and an EIA for the Mount Barclay landfill facility in Monrovia and closure of the Fiamah dump site.

\subsection{Public Buildings and Housing}

${ }^{39}$ Public buildings were badly damaged or destroyed during the conflict, and the lack of maintenance has led to further deterioration. The clearest example was the major fire in the Executive Mansion in July 2006 caused by faulty and outdated wiring. The poor state of government buildings significantly undermines the capacity of government institutions at all levels of government. With respect to housing, about 80 percent of the pre-war housing stock and related infrastructure were destroyed and/or remain in a state of disrepair. This has worsened an already bad situation with grave inadequacies in both stock and quality of housing and other infrastructure and services. The housing crisis in Liberia could be fully addressed by a dual approach of tackling basic shelter and related infrastructure and services, and capacity building for effective housing delivery, land management and appropriate finance and construction technology.

${ }^{40}$ During the iPRS period, the Government rehabilitated market buildings and public toilets in Monrovia, outsourced toilets to community-based groups for local management, and rehabilitated or constructed administration buildings in each of the 15 county capitals. The Government selected eight communities 
and neighborhoods for the upgrade and development of children's playgrounds, and four areas within Monrovia to establish community resource centers to serve as clearing houses and information dissemination points. The National Housing Authority has completed valuation of the various housing units at three public housing estates and has transformed its rental program by instituting a system of home purchase of the units for permanent ownership by long-standing tenants. Estate residents have been encouraged to organize community groups for the management of infrastructure and services such as internal roads, landscaping, etc.

${ }^{41}$ During the PRS period, the Government will sustain the process of rebuilding and rehabilitating public buildings and related community and household level infrastructure. In the administrative districts, the Ministry of Internal Affairs will construct and rehabilitate administration buildings and palava huts. The Government will also strengthen the capacity of the General Services Administration (GSA) to oversee public facilities, including developing a GSA business plan. The rebuilding and rehabilitation of public buildings will facilitate the relocation of public institutions from private buildings leading to significant long-term cost savings. It will also strengthen the capacity of the GSA to oversee public facilities, including the implementation and update of the GSA business plan. Some of the planned rehabilitation actions are:

- rehabilitating the GSA Road Facility and strengthening site security and lighting;

- rehabilitating the GSA Road Refueling Station and setting up filling stations in the counties; and

- assessing and rehabilitating 25 public buildings, including the executive and centennial pavilions, municipal and administrative buildings, civil compounds, local mansions and guest houses, etc through collaboration and partnership between GSA and MPW under a mutually agreed work program.

${ }^{42}$ Following the collapse of the National Housing and Savings Bank, 47 the Government will consider options for the introduction of other means of increasing access to finance for the development of housing. In addition to microcredit, it will explore the development of mortgage finance. This would require reform of the foreclosure laws and practices by making them non-judicial, consistent with international best practice. Other steps in this direction will include:

- creation of a nationwide property registration process;

- establishment of a reference system for information on the credit-worthiness of potential borrowers, in cooperation with the commercial banks;

- introduction of laws and practices that inhibit land speculation; and

- formulation of a National Housing Policy and Shelter Implementation Strategy.

${ }^{43}$ The Government will also progressively work with its partners to establish and equip multi-purpose youth centers in 13 counties, and multi-purpose children's resource centers in 58 districts. These centers are intended to provide the safe space for children and youth to meet and develop their own programs, as advocated by girls during county consultations. Such centers will also provide opportunities for alternative learning in vocational skills, literacy, environmental management, life skills and sexual and reproductive health; for sports and recreation, which are key to character development; for livelihoods programs including social entrepreneurship; and for enabling the participation of children and youth in governance. 


\subsection{Health}

${ }^{44}$ Liberia's health sector is transitioning from an emergency phase to a development phase. However, a large percentage of the population-especially the rural and urban poor-continues to have limited access to health and social welfare services. The 2007 CWIQ survey found a national average of 43 percent of respondents had been sick in the past month. Malaria remains the leading cause of morbidity and mortality, followed by diarrhea and acute respiratory infections. The national HIV prevalence rate is approximately 1.5 percent, based on the recent DHS.48 Almost forty percent of Liberian children are growth-stunted from poor nutrition, about one third of under-fives are severely underweight, and recent estimates indicate that one in five deaths in children under-five is attributable to malnutrition. 49 According to the $2007 \mathrm{DHS}$, the unmet need for family planning is over 60 percent, 48 percent of Liberian women become pregnant by the age of 18 , and less than half of all births are delivered by a health professional.

${ }^{45}$ Notwithstanding these figures, Liberia has made important progress over the last few years with significant reductions in infant and child mortality rates, a reduction in the fertility rate, and greatly expanded access to HIV and AIDS care and treatment services. The Government developed a comprehensive National Health Policy and Strategic Plan, and initiated a National Two-Year Transition Plan in 2006 as a short-term emergency intervention to prevent the potential crisis that was developing as a result of the departure of humanitarian NGOs. The Government and NGOs secured increased donor funding for NGOs to implement the transition plan, and they continue to operate over 80 percent of existing health facilities nationwide.

${ }^{46}$ Although the recent progress has been welcome, Liberia's health challenges remain immense. Many of the most critical issues cannot be properly tackled until the foundations of a functioning health sector are properly laid down.

${ }^{47}$ The overall goal of the health sector is to expand access to basic health care of acceptable quality and establish the building blocks of an equitable, effective, efficient, responsive, and sustainable health care delivery system across Liberia. Specifically, the Government is aiming to ensure that 70 percent of health facilities in each county are providing the Basic Package of Health Services (BPHS) by December 2010. The Government is aiming to further reduce the child mortality rate by ten to fifteen percent and the maternal mortality rate by five to ten percent over the same period. ${ }^{50}$ To achieve these goals, the Government will aim to address six strategic priority areas:

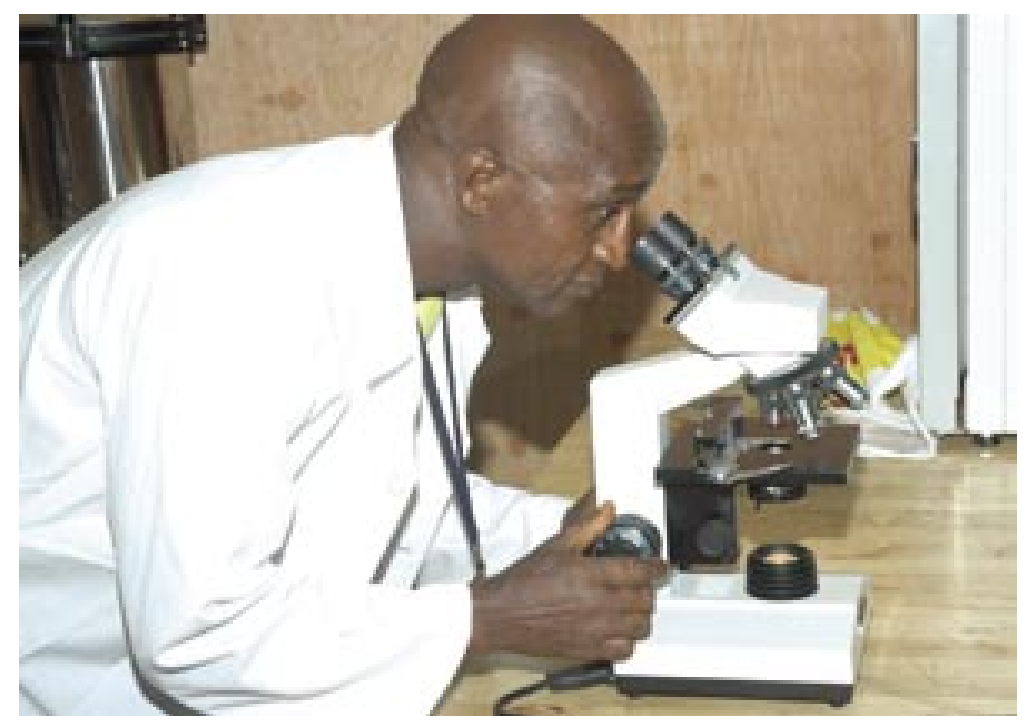

${ }^{48}$ Build Human Resources: Liberia's ratios of physicians, nurses and midwives are extremely low at $0.03,0.18$, and 0.12 , per 1,000 persons. The Ministry of Health is committed to identifying, training and retaining qualified health personnel and to increase the number of health workers to approximately $6,000-8,000$ over the PRS period, essentially doubling the existing workforce of 3,966 . The Government will suspend tuition and fees and revitalize the three rural health training institutions, strengthen the medical school, provide scholarships for specialized clinical and managerial health

\footnotetext{
48 As discussed in Chapter Three, a 2006 MoHSW antenatal care survey found the national prevalence to be much higher, at 5.7 percent.

49 MoHSW/AED/World Food Program, Nutrition Policy Analysis using PROFILES: Investing in Nutrition to Reduce Poverty, December 2007.

50 This is a critical issue for the Government of Liberia and requires cross-sector partnerships to exceed these targets. The Health Sector Working Group will continue to review and update these targets during the PRS period.
} 
workers, and train 500 Certified Midwives and 5,000 traditionally trained midwives in Life Saving Skills. Along with developing a National Human Resource Policy and Plan, it will institute incentive schemes, retention programs, and performance measurement systems to maintain a force of qualified health workers.

- Expand access to the Basic Package of Health Services (BPHS): The BPHS focuses on six national health priorities: maternal and newborn care, child health, reproductive and adolescent health, communicable disease control (including HIV and AIDS), mental health, and emergency care. The Government will maintain the suspension of fees until the socio-economic situation improves and financial management systems perform at a level that ensures an even more povertyfocused utilization of revenues. The Government will strategically implement the BPHS within each county to provide effective and affordable health services to the largest number of beneficiaries to meet its goal that 70 percent of health facilities in each county be providing the BPHS by December 2010. To reach this target, birth registration centers, basic Emergency Obstetric Care Centers, drug depots, and ambulance services will be established across the country. In addition, expanding access to disease prevention and control programs (such as Antiretroviral Therapy for the treatment of HIV infection and DOTS for the treatment of Tuberculosis) will continue to be a key focus throughout Liberia.

- Rehabilitate Health Infrastructure: Liberia needs 500-550 health facilities to reach the target of a quality facility within $10 \mathrm{~km}$ of every community. This represents a significant increase from the number of 354 facilities currently functional. Over the PRS period, the Government intends to rebuild and renovate 205 health facilities, and construct rehabilitation facilities for mental health and youth. Consistent with the Government's decentralization policies, communities will work with health providers to determine the location of health facilities to be renovated and constructed and to constitute local management structures to guarantee community contribution.

- Strengthen Social Welfare Programs: Social welfare systems were seriously damaged by the conflict, and yet the war itself significantly increased the number of people in need of social services. There is a serious shortage of trained social workers, counselors, and practitioners, and a lack of facilities to support those most vulnerable, including orphans and vulnerable children (OVC). The Government will therefore develop a National Social Welfare Policy and Plan to provide the vision and direction for the social welfare sector to address the needs of the vulnerable and excluded segments of the Liberian population. It will aim to strengthen mental health/trauma healing services under the Policy and Plan to help break the cycle of conflict.

- Further Develop Support Systems: The Government will introduce a computerized Health Management Information System (HMIS) by 2009, consisting of supply chain and logistics management systems that forecast demand, facilitate the procurement of medical supplies, and coordinate with county level systems. The HMIS will also include databases and electronic systems for human resources, infrastructure, and finances. The MoHSW will continue to promote the new culture of transparency and accountability in its decision-making and operations. It will also decentralize certain management responsibilities: local governments will be responsible for primary health services, while the central Government will focus on policies, aggregated planning, and standardization. The central Government will aim to progressively expand the responsibilities of the county authorities as they become equipped to assume them. The MoHSW will distribute a standard supplies and equipment list to all levels to facilitate procurement, installation, use, and maintenance, and will create a national reference laboratory and blood bank in Monrovia by December 2010.

- Strengthen Health Financing: With over $60 \%$ of the population estimated to be living in poverty, ${ }^{51}$ many individuals have limited financial capacity to pay for health care and the demand for alternative financing is high. In 2007, public health expenditure per capita was about US\$5, compared to the projected need of US\$34 to meet the MDGs. The Government will not be able to independently

${ }^{51}$ CWIQ, 2007 
fund the health sector without sustained donor support and private provider participation for at least the next 10 years. The MoHSW will collaborate with its partners to develop a national health financing strategy that considers a range of financing mechanisms. In the interim, the Government is working to establish a pooled fund mechanism as a short-term intervention for partners to co-finance and better coordinate their support to the public health sector.

\subsection{Education}

${ }^{49}$ Liberia's education system was seriously undermined by the war. More than 30 percent of public and 24 percent of community schools were totally destroyed, and a further 16 percent of public and community schools experienced major damage. ${ }^{52}$ Desks, chairs, and other basic supplies disappeared. Enrolment rates plummeted as a whole generation of children missed the opportunity to go to school. Almost 35 percent of the population has never attended school, including nearly 44 percent of females. Further, about 56 percent of Liberians are considered functionally illiterate,

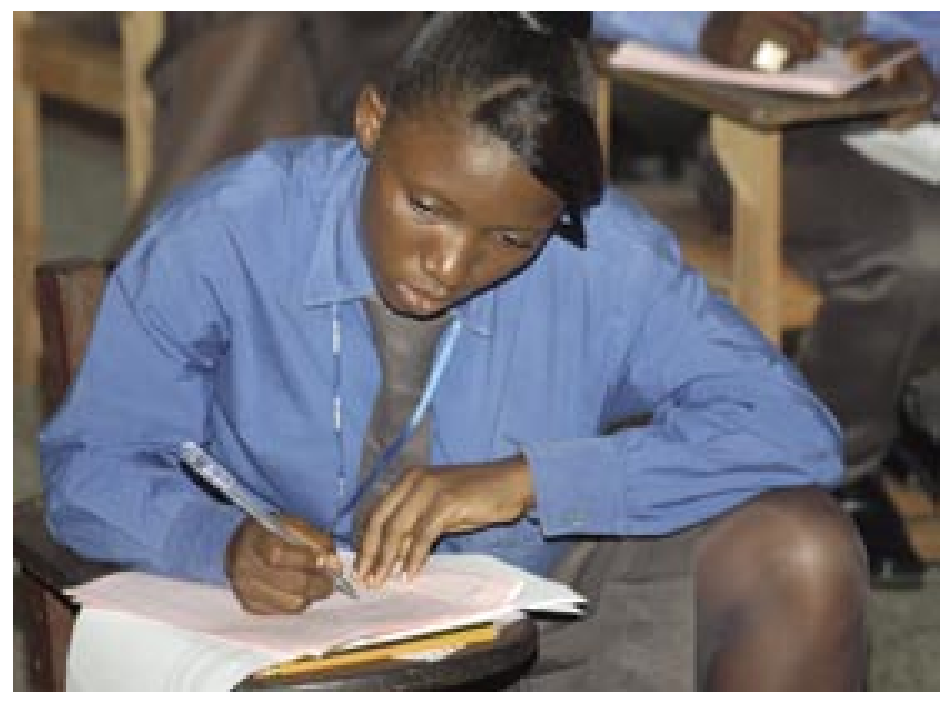
including a staggering 59 percent of females. ${ }^{53}$

${ }^{50}$ Today only 45 percent of classrooms in the public sector are in good condition. ${ }^{54}$ Only 22 percent of public and community schools have seats, and only one-third of public and community schools have functioning pit latrines or flush toilets. Textbooks are scarce - there is just one for every 27 students. Teacher salaries are low, making retention difficult, and only 24 percent of primary teachers in the public school system possess the minimum primary school teaching certificate.

${ }^{51}$ The education sector currently faces several key challenges, including the following:

- inadequate and undefined sources of finance that will enable the sector to keep pace with the ever increasing demand for quality and relevant education;

- weak capacity for management and governance from central to the local level;

- an outdated curriculum and inadequate textbooks, chairs, desks, and school supplies;

- insufficient school access that limits the ability of every child, including girls and persons with disabilities, to exercise his/her right to quality education;

- insufficient numbers of well trained, qualified, and motivated teachers;

- an understaffed and over-crowded public university; and

- poor quality programs being offered at some institutions of higher learning.

${ }^{52}$ Education made strong initial progress during the iPRS period. The Government introduced the Free and Compulsory Education Policy, which abolished tuition fees in public primary schools and signifi-

\footnotetext{
52 Data in section 9.9 is drawn from the EMIS School Census of 2005-2006, unless otherwise noted.

53 CWIQ, 2007

54 As a result, the ratio of public and community school students to classrooms in good condition is more than 300:1.
} 
cantly reduced them for public secondary schools. It introduced the Accelerated Learning Program (ALP), a parallel primary intervention designed to address the basic education needs of young adults who missed out on primary education. It sought to improve enrolment, attendance and retention through its school feeding program. Overall, enrolments in public primary schools increased by 82 percent between $2005 / 06$ and 2007/2008, or from 597,316 to 1,087,257. Enrolment in secondary schools increased by 16 percent over the same period, from 132,224 to 153,467.55 The Government introduced adult literacy programs in certain counties, and took initial steps to reduce dropouts, especially among girls. It made initial progress in increasing funding for the University of Liberia and other accredited universities, rehabilitating Regional Teacher Training Institutes, recommencing teaching training programs, and establishing and accrediting institutions of higher learning.

${ }^{53}$ Liberia's Education Law establishes the relative priorities afforded to different levels of education, with primary education the highest priority, followed by secondary and then tertiary education. It should be noted however, the achievement of primary and secondary level goals are not possible without input from the tertiary level in the form of training for teachers and administrators, provision of expertise for curriculum development and textbook writing, and other areas.

${ }^{54}$ During the PRS period, the Government's overall goal for education is to improve access to and the quality of relevant education at all levels, emphasizing the availability of Universal Primary Education and recognizing the needs of the disadvantaged, especially girls. To achieve this goal, it will aim to achieve seven strategic objectives:

- Strengthen the curriculum. Curriculum reform is an essential part of the education reform initiative. The Government is planning to develop and introduce a compulsory core curriculum (language and arts, mathematics, science and social studies ${ }^{56}$ ) that will be implemented nationwide, together with an optional/complementary curriculum with regional variations. The new curriculum will be adopted by September 2011.

- Improve access to quality, safe, and hygienic schools. The Government will respond to county feedback and build 240 new primary classrooms (40 primary schools) and 54 new secondary classrooms (4 schools), rebuild or repair 200 existing primary classrooms (33 primary schools) and 72 secondary classrooms ( 6 secondary schools), provide 14,150 chairs, build 82 latrines and install 82 wells and hand pumps.

- Recruit and train qualified teachers. During the PRS period the Government will re-open three Regional Teacher Training Institutes to train between 650 and 1000 new teachers annually. It will extend the field-based in service training to five counties in 2008/2009, nine counties in 2009/2010 and fifteen counties in 2010/2011, and will construct 105 teacher houses in hardship locations.

- Improve learning achievement and school completion rates. Although enrolment rates have increased, they remain low, especially for girls. But enrolment rates are only a start. Many children drop out of school, and only a small number successfully transition from primary to secondary schools. Increasing the number of classroom and school supplies, revising the curriculum, expanding the number of qualified teachers and providing school feeding programs should all help improve enrolment and retention rates. During the PRS period, the Government aims to increase the primary school net enrolment rate from 37.3 to 44.8 percent as an initial step toward achieving Universal Primary Education by 2015. It will aim to improve the ratio of girls to boys in primary school from 0.96 to 0.98 , and in secondary schools from 0.78 to 0.83 , with the ultimate target of achieving the relevant MDGs by 2015. It will purchase and facilitate the publication of textbooks to improve the learner/textbook ratio in four core subjects and across all public schools to 2:1. Most importantly, the Government will provide feeding for at least 600,000 students and take-home rations for 30,000

\footnotetext{
${ }^{55}$ However, preliminary data from the current school census shows a decline in enrollments at community high schools, and an increase in enrolments at private high schools. Any such decline in public secondary enrollment that is validated in the final report will be studied to determine possible causes and potential remedies.

56 The social studies curriculum will include material on peacebuilding, human rights, HIV and AIDS, civic education and GBV.
} 
adolescent girls, using locally produced food where feasible.

- Strengthen the quality and accessibility of skills and vocational training. The Government will work to improve the quality and accessibility of skills training and adult education to provide for the large number of unskilled and unemployed youths nationwide, including young women. Specifically, it will:

- refurbish and equip four existing multi-lateral high schools, and the two existing vocational and technical institutions (Booker Washington Institute and LSVTC) so that they can offer skills training;

- lend support to literacy and skills training in youth centers, including the training of young people as literacy and skills teachers in their communities; and

- increase the number of skills training center graduates each year by 50 starting from 2010 .

- Improve the quality of tertiary education while carrying out a limited and phased expansion and decentralization. Specifically, the Government will aim to ensure that:

- all institutions of higher learning review and revise their curricula under the leadership of the $\mathrm{MoE}$ and the National Commission for Higher Education (NCHE);

- a revised national accreditation scheme is operational and being enforced by a strengthened NCHE;

- qualified and experienced faculty and administrators are trained and recruited; and

- arrangements are initiated for the establishment of at least one new institution of higher learning outside of Monrovia.

- Strengthen the overall governance, management, and financial basis of the education system. Apart from completing a National Education Policy now under preparation, the MoE is continuing its efforts to upgrade the quality of the staff in planning, procurement, and financial management. One key action will be the continued reduction of "ghost" names on the sector's payroll and the establishing of a teacher database. Other actions to be undertaken include:

- reviewing and amending the Education Act;

- reviewing and revising the organizational structure, reporting lines and positions, responsibilities and functions of officials of the Ministry of Education;

- reviewing the salaries of teachers and introducing salary scales based on qualification, experience, performance, position/responsibility, teaching subject, place of teaching;

- producing and training relevant staff on the use of an M\&E framework and evaluation sheets;

- revising and upgrading the qualifications and experience needed by quality assurance officers (County Education Officers, District Education Officers and supervising authorities at MoE headquarters);

- resourcing and otherwise better enabling CEOs and DEOs to fulfill their roles and responsibilities; and

- commencing annual pre-notified inspection of schools and publishing reports for public consumption every 2 years. 
Issue

Priority Interventions

Delivery Date

Goal: To ensure that all roads are pliable year round, to refurbish select public buildings, and to build the capacity necessary for a sustained road maintenance program.

Strategic objective 1: To rehabilitate, reconstruct and construct primary/secondary, feeder and neighborhood roads

The country's road network is in a state of near-total deterioration.
Build or reconstruct 1,187 miles of primary roads, (1,075 miles paved, surface dressing) and 300 miles of all-weather secondary roads (year one: 450 miles, year two: 520 miles, and year three: 517 miles) Install a total of 33 bridges around the country

Reconstruct and rehabilitate 300 miles of all-weather secondary roads: 100 miles per year

Rehabilitate and construct 150 miles of neighborhood roads in Monrovia and the county seats

Ensure that environmental impact studies are conducted and that sound environmental practices are followed in all of these projects

Design and implement a road safety initiative including side brushing, and fabricate and install road safety signs on city streets

\begin{tabular}{|c|c|c|}
\hline June 2011 & MPW \\
\hline June 2011 & MPW \\
\hline June 2011 & MPW \\
\hline June 2011 & MPW \\
\hline June 2011 & MPW \\
\hline June 2011 & MPW \\
\hline
\end{tabular}

\section{Strategic objective 2: To build human resource capacity}

\section{The capacity of} maintenance workforce and management is limited.

Renovate the RMTC and develop a long term strategy for capacity building

Provide scholarships for study in subjects relevant to Roads and Bridges infrastructure at local universities and abroad, on a gender equity basis 
Issue

Priority Interventions

Delivery Date

Goal: To improve the Liberian transport sector through policy, systems and infrastructure development that create access to reliable, affordable and efficient services.

Strategic objective 1: To improve the transport sector through effective systems and infrastructure for quality service provision

The transport sector suffers from a lack of coherent policy guidance, inadequate coordination, and a lack of data for planning purposes.

\begin{tabular}{l} 
Formulate and launch a National Transport Policy \\
\hline Formulate and launch a National Transport Master Plan \\
\hline $\begin{array}{l}\text { Harmonize national meteorological and hydrological services } \\
\text { within the appropriate legal framework in line with WMO stan- } \\
\text { dards }\end{array}$ \\
\hline $\begin{array}{l}\text { Conduct training for MoT staff in transport management, eco- } \\
\text { nomics, research, and meteorology }\end{array}$
\end{tabular}

\begin{tabular}{|c|c|}
\hline February 2008 & MoT \\
\hline December 2008 & MoT \\
\hline December 2008 & MoT \\
\hline August 2008 & MoT \\
\hline
\end{tabular}

Strategic objective 2: To improve urban transit in Monrovia and its environs

Monrovia and sur- $\quad$ Rehabilitate and repair 25 buses donated by the Spanish

rounding areas lack a Government to service main bus routes

mass transit system.

Purchase 15 mini-buses to take commuters from main routes

to various communities

Develop Urban Transport Policy of MTA

Construct three bus stops at ELWA, Fendell and Brewersville-

Moulton junctions and post signs along bus routes

Develop a three-year Business Plan for restructuring MTA, diversifying investment including a private equity partnership

Rehabilitate and upgrade maintenance facilities and inventory systems for mass transit

\begin{tabular}{|c|c|}
\hline 2008,2009 & MTA \\
\hline 2008,2009 & MTA \\
\hline 2008,2009 & MTA \\
\hline 2008,2010 & MTA, IPA \\
\hline 2008,2009 & $\begin{array}{c}\text { MTA, MoF, } \\
\text { MCC }\end{array}$ \\
\hline 2009,2011 & MTA \\
\hline
\end{tabular}

Strategic objective 3: To restore and expand national air capacity as quickly as possible to international standards

Airport infrastructure is generally poor and the sector lacks adequate institutional frameworks.
Conduct a feasibility study on reconstruction of airport infrastructure

Pending economic feasibility study, rehabilitate Roberts International Airport and the Liberia Domestic Airport Agency, including terminal buildings and runways; fire rescue and ground handling facilities, control towers, security and ramp equipment, and navigational aids

Reacquire land encroached upon by squatters at the LDAA

Resurvey and fence the LDAA to ensure safety and control of airport facilities

Rehabilitate at least five airfields located in Foya, Harper, Vionjama, Greenville and Zwedru

Formulate and implement a Master Plan for RIA

Integrate RIA and LDAA's operations under National Airport

Authority through legislation

\begin{tabular}{|c|c|}
\hline December 2009 & RIA \\
\hline 2010 & $\begin{array}{c}\text { MoT, RIA, } \\
\text { LDAA }\end{array}$ \\
\hline March 2008 & LDAA \\
\hline July 2008 & RIA \\
\hline November 2009 & MoT \\
\hline July 2008 & MoT \\
\hline July 2008 & $\begin{array}{c}\text { RIA, } \\
\text { Legislature }\end{array}$ \\
\hline
\end{tabular}

Strategic objective 4: To restore viable, self-sustaining activities at physically more robust national ports

Ports infrastructure is generally poor and the ports lack adequate institutional frameworks.
Rehabilitate facilities of NPA including small ports for improved operating efficiency

Improve operational performance of NPA by privatizing management of operations

Structure and implement the National Port Master Plan

\begin{tabular}{|c|c|}
\hline December 2009 & NPA \\
\hline August 2008 & NPA \\
\hline 2009 & NPA \\
\hline
\end{tabular}


Issue

Priority Interventions

Delivery Date

Lead

Ministry

Agency

Goal: To provide reliable, sustainable and affordable energy services to all Liberians in an environmentally sound manner.

Strategic objective 1: To extend grid electricity throughout Monrovia and its environs

Presently only 2.65MW of power

is available in

Monrovia, while

demand hovers

between 30 and

$50 \mathrm{MW}$.

\begin{tabular}{|l|c|c|}
\hline Rehabilitate electricity infrastructure such as HV, MV and LV Lines & December 2009 & $\begin{array}{c}\text { MLME, } \\
\text { LEC }\end{array}$ \\
\hline Increase electricity generation & December 2010 & $\begin{array}{c}\text { MLME, } \\
\text { LEC }\end{array}$ \\
\end{tabular}

\section{Strategic objective 2: To develop hydro capacity and other renewable energy sources}

As diesel prices rise, hydropower and other renewable sources will be required for the provision of affordable and reliable electricity.
Rehabilitate the Mt. Coffee hydro-electric facility

Assess other hydropower potential and construct several mini hydropower facilities across the country

Assess solar, wind and biomass potential to harness these resources

\begin{tabular}{|c|c|}
\hline December 2011 & $\begin{array}{c}\text { MLME, } \\
\text { LEC }\end{array}$ \\
\hline December 2010 & $\begin{array}{c}\text { MLME, } \\
\text { LEC }\end{array}$ \\
\hline July 2009 & $\begin{array}{c}\text { MLME, } \\
\text { LEC }\end{array}$ \\
\hline
\end{tabular}

\section{Strategic objective 3: To expand grid electricity to other urban areas and some rural areas}

Grid electricity is non-existent outside Monrovia.
Extend grid electricity to county headquarters and other areas,
beginning with the eleven LEC outstations

Connect 18 communities along the border with Cote d'Ivoire through the West Africa Power Pool

\begin{tabular}{|c|c|} 
December 2011 & $\begin{array}{c}\text { MLME, } \\
\text { LEC }\end{array}$ \\
\hline December 2010 & $\begin{array}{c}\text { MLME, } \\
\text { LEC }\end{array}$
\end{tabular}

\section{Strategic objective 4: To improve legal, institutional and regulatory frameworks in the energy sector}

The sector lacks a comprehensive national policy, strategic plan and investment-friendly legislation.

\begin{tabular}{|c|c|c|c|}
\hline \multirow{3}{*}{$\begin{array}{l}\text { The sector lacks } \\
\text { a comprehensive } \\
\text { national policy, } \\
\text { strategic plan and } \\
\text { investment-friendly } \\
\text { legislation. }\end{array}$} & Complete and publish the National Energy Policy & June 2008 & $\begin{array}{l}\text { MLME, } \\
\text { LRDC }\end{array}$ \\
\hline & Prepare a strategic plan for the energy sector & December 2008 & $\begin{array}{l}\text { MLME, } \\
\text { LRDC }\end{array}$ \\
\hline & $\begin{array}{l}\text { Draft relevant energy bills to attract private capital and improve gov- } \\
\text { ernance in the sector }\end{array}$ & December 2009 & $\begin{array}{l}\text { MLME, } \\
\text { LRDC }\end{array}$ \\
\hline \multicolumn{4}{|c|}{ Strategic objective 5: To develop the upstream and downstream petroleum sectors } \\
\hline \multirow{3}{*}{$\begin{array}{l}\text { Liberia potential for } \\
\text { offshore petroleum } \\
\text { discovery. There } \\
\text { is also a need to } \\
\text { improve the profit- } \\
\text { ability of the down- } \\
\text { stream petroleum } \\
\text { sector. }\end{array}$} & Attract major oil companies to conduct petroleum exploration & December 2010 & $\begin{array}{c}\text { MLME, } \\
\text { NOCAL, } \\
\text { LPRC }\end{array}$ \\
\hline & Merge LPRC and NOCAL & December 2008 & $\begin{array}{c}\text { MLME, } \\
\text { NOCAL, } \\
\text { LPRC }\end{array}$ \\
\hline & $\begin{array}{l}\text { Expand and improve petroleum delivery services to all parts of } \\
\text { Liberia }\end{array}$ & December 2010 & $\begin{array}{c}\text { MLME, } \\
\text { NOCAL, } \\
\text { LPRC }\end{array}$ \\
\hline
\end{tabular}


Goal: To progress towards the provision of universal services as defined by the Universal Postal Union (UPU) and the International Telecommunication Union (ITU).

\section{Strategic objective 1: To build postal and telecom infrastructure, equipment and systems}

Most citizens lack access to postal, telecommunications and ITC services due to weak or nonexistent infrastructure.
Construct or rehabilitate 150 postal structures across the 15 county headquarters and population centers of 10,000 or more, and furnish the structures with the necessary logistical and other equipment

Complete a feasibility study on a nationwide block/house numbering system

Create a nationwide database for effective and accurate delivery

Conduct a national promotional campaign to raise awareness of postal and telecom services

Obtain vehicles to deliver mail to and from regional centers and land borders

Obtain equipment and develop systems to enable Government to pay salaries and pension and other benefits through the Post

Obtain equipment and develop systems to enable all residents to have easy access to remittance services

Implement the Universal Access Program through the public provision of telecommunications services to areas not serviced by private providers

Obtain infrastructure, equipment and technical support to ensure the sustainable operational efficiency of the LTC

Introduce financial and electronic services such as money orders, bill payments, wireless transfers, hybrid mail and other internet-related services

\begin{tabular}{|c|c|}
\hline June 2011 & MPT,UPU \\
\hline December 2008 & MPT \\
\hline December 2008 & MPT \\
\hline December 2009 & MPT \\
\hline December 2008 & MPT \\
\hline December 2009 & MPT \\
\hline December 2009 & MPT, MoF \\
\hline December 2010 & LTA \\
\hline December 2009 & LTC \\
\hline
\end{tabular}

\section{Strategic objective 2: To develop national postal and telecom policies and improve institutions}

\section{Both sectors are lack-} ing transparent and coherent policies.
Develop a comprehensive Postal Policy to govern national postal operations, which will include consultative meetings in each of the five regional centers

Formulate and implement a modern and comprehensive Telecom and ICT Policy to facilitate Universal Access, transparency, and reliable, low-cost provision of services nationwide

Expand the mandate of the Liberia Telecommunications Corporation (LTC) to offer other ICT Services apart from traditional telephone services

Complete the standardization of licensing and fee regimes and the setting of procedures for the implementation of Universal Access based on the telecommunication and ICT policies

\begin{tabular}{|c|c|}
\hline December 2009 & MPT \\
\hline July 2008 & MPT \\
\hline December 2011 & LTC \\
\hline December 2011 & LTA \\
\hline
\end{tabular}

\section{Strategic objective 3: To develop human resources}

Few MoPT staff are trained.
Develop training curricula for all functions and staff levels up to Director, utilizing the experience of other African Postal Training Institutions and the Universal Postal Union (UPU)

Hire and train a competent LTC management team and workforce, and settle all relevant and justifiable issues concerning back pay and retrenchment of some 50 percent of former employees.

Conduct capacity building activities for LTA and MPT policy and regulatory staff in telecommunication

\begin{tabular}{|c|c|c|}
\hline February 2010 & MPT,UPU \\
\hline g- & December 2011 & LTC \\
\hline$d$ & 2011 & LTA, MPT \\
\hline
\end{tabular}


Issue

Priority Interventions

Delivery Date

Lead

Ministry

Agency

Goal: To reduce the water and sanitation-related disease burden in Liberia

Strategic objective 1: To increase access to safe drinking water from 25 percent to 50 percent by 2012, including 45 percent of the rural population

Only about 42 per- $\quad$ Conduct a sector assessment and publish a strategic sector plan

2008

LWSC, MPW

cent of the Liberian population has access to improved drinking water.

Rehabilitate 7 rural city water outstations

Rehabilitate 90 percent of existing water points in rural communities, schools and health centers

Construct three groundwater-fed systems (Monrovia)

Construct 700 boreholes fitted with hand pumps (rural)

December 2010 LWSC, MPW

Construct 800 hand-dug wells fitted with hand pumps (rural)

December 2010 LWSC, MPW

Construct 100 spring catchment-fed systems in rural hill towns

Construct 2,000 bio-sand filters in inaccessible rural communities

Establish water quality testing facilities nationwide with trained staff

and necessary equipment

December 2010 LWSC, MPW

December 2010 LWSC, MPW

December 2010 LWSC, MPW

December 2010 LWSC, MPW

December 2010 LWSC, MPW

September 2009 MLME,

LWSC

Strategic Objective 2: To increase access to human waste collection and disposal facilities from 15 percent to 40 percent, including 35 percent of the rural population

Only about 39 per- Rehabilitate 100 percent of the Monrovia sewerage system

cent of the population has adequate means of human waste collection.

Rehabilitate 3,000 existing communal latrines in schools, hospitals and clinics

Assist families in the construction of 50,000 household latrines in rural communities

Construct 10,000 communal and institutional latrines in schools, health centers and public buildings

Establish 15 SanPlat latrine slab fabrication centers and produce 50,000 slabs

Scale up hygiene promotion efforts in all fifteen counties

\begin{tabular}{|l|c|}
\hline December 2010 & $\begin{array}{c}\text { LWSC, MoH, } \\
\text { MPW }\end{array}$ \\
\hline December 2010 & $\begin{array}{c}\text { LWSC, } \\
\text { MPW, MoH }\end{array}$ \\
\hline December 2010 & LWSC, MPW \\
\hline December 2010 & LWSC, MPW \\
\hline December 2010 & LWSC, MPW \\
\hline
\end{tabular}

Strategic Objective 3: To ensure the sustainability of 90 percent of water and sanitation facilities in the country

Operation of water and sanitation facilities is currently unsustainable. There is a lack of a comprehensive national policy on solid waste disposal, and many hazardous materials enter the waste stream. Solid waste dump sites in Monrovia are inadequate.
Invest in the procurement of spare parts for standard hand pumps and establish 200 hand pump spare part depots, in all fifteen counties

Carry out standardization and quality control for all equipment and facilities and establish a theft control mechanism

Develop and enact a national Solid Waste Management policy, strategy and regulations

\begin{tabular}{|c|c|}
\hline December 2010 & $\begin{array}{l}\text { LWSC, } \\
\text { MPW }\end{array}$ \\
\hline December 2010 & $\begin{array}{l}\text { LWSC, } \\
\text { MPW }\end{array}$ \\
\hline May 2008 & $\begin{array}{l}\text { MCC, MPW, } \\
\text { Legislature }\end{array}$ \\
\hline March 2008 & MCC, MPW \\
\hline June 2008 & MCC, MPW \\
\hline December 2010 & MLME \\
\hline December 2010 & $\begin{array}{c}\text { LWSC, } \\
\text { MoH, MPW }\end{array}$ \\
\hline
\end{tabular}


Issue

Priority Interventions

Delivery Date

Lead

Ministry I

Agency

Goal: To rebuild and rehabilitate public buildings and related community and household-level infrastructure.

Strategic objective 1: To strengthen urban infrastructure and city planning

Liberia's urban infra- Rehabilitate City Hall or primary civic buildings in county structure is destroyed and in disarray and city planning is poor.

\section{seats of all 15 counties}

Construct or rehabilitate district administration buildings in

45 of 126 districts and palava huts in 126 districts

Assess and rehabilitate 25 public buildings

Build new cemetery to service Monrovia area

Construct or rehabilitate 5 playgrounds, including transform-

ing Fiamah landfill into playground, in selected communities and 3 green/open spaces

Rehabilitate four community resource centers in West Point, Clara Town, Slipway and Soniwen for municipal community outreach, information dissemination and clearing

Conduct feasibility study for establishment or rehabilitation of playgrounds and municipal outreach centers in 15 County Capitals and implement pilot in 5 capitals

Produce a zoning map of Monrovia and for 5 major urban centers

Draft a National Zoning Act
2008, $2011 \quad$ MPW, MIA

2008, $2011 \quad$ MPW, MIA

2008, 2011 MPW, MIA

2008, 2011 MCC, MPW

2008, 2011 MCC, MPW

2008, 2011 MCC, MPW

2008, 2011 MCC, MPW

2008, 2011 MCC, MPW

2008, $2011 \quad$ MPW, MoJ

\section{Strategic objective 2: To facilitate access to low-income housing}

Stock of low-income $\quad$ Negotiate and acquire 300 acres of land in each county housing is inadequate to meet demand. for housing, including 750 acres around Montserrrado to absorb some of the demand from Monrovia

Construct 300 low-income housing units in Montserrado, Margibi and Bomi

Conduct feasibility study to upgrade five slums in Monrovia: West Point, Soniwen, Clara Town, Logan Town and Randall Street/South Beach

Create Urban Housing Policy for low-income housing

\begin{tabular}{|c|c|}
\hline 2008,2011 & NHA, MIA, \\
\hline 2008,2011 & MPW, NHA \\
\hline 2009,2010 & NHA \\
\hline 2008,2011 & NHA \\
\hline
\end{tabular}

Strategic objective 3: To build capacity and train employees of GSA, MCC, NHA and MPW in urban infrastructurerelated issues

Government lacks capacity to carry out urban and other infrastructure work.

Conduct technical and managerial skills training workshops for 500 employees of MCC, MPW, NHA, and GSA
2008,2011

MCC, MPW, NHA, GSA

Strategic objective 4: To provide safe public spaces for children and youth

Rural children and youth and especially girls have few safe spaces to meet and participate in sports and alternative education activities.
Establish and equip multi-purpose youth centers in 13 counties, and multi-purpose children's resource centers in 58 districts
2008, 2011

MPW, MoYS 
Issue

Priority Interventions

Delivery Date

Lead

Ministry I

Agency

Goal: To expand access to basic health care of acceptable quality and establish the building blocks of an equitable, effective, efficient, responsive and sustainable health care delivery system.

\section{Strategic objective 1: To build human resources}

Liberia has a health workforce ratio of only 0.18 per 100,000 people.

No formal training, retention, deployment or gender equity programs are in place.
Establish pre-service nursing and midwifery program in Zwedru, Grand Gedeh County

Re-establish the laboratory technician program at TNIMA

Develop and implement National Health Leadership and Management Program

Train 500 certified midwives in Life Saving Skills (LSS)

Train 5,000 traditionally trained midwives in Home-Based LSS

Develop guidelines and conduct study on gender to guide all human resources decisions

Establish Human Resource Unit in the Ministry and decentralize HR functions to county level

Develop and finalize National Human Resource policy, plan, and SOPs

Upgrade national scholarship program to train health workers in specific professional fields

Place 6,000 health workers on the standardized incentive package

Train and deploy midwives, physician assistants, and laboratory technicians in health facilities

\begin{tabular}{|c|c|}
\hline December 2009 & $\mathrm{MoH}$ \\
\hline December 2009 & $\mathrm{MoH}$ \\
\hline June 2009 & $\mathrm{MoH}$ \\
\hline October 2010 & $\mathrm{MoH}$ \\
\hline December 2008 & $\mathrm{MoH}$ \\
\hline December 2010 & $\mathrm{MoH}$ \\
\hline July 2009 & $\mathrm{MoH}$ \\
\hline December 2010 & $\mathrm{MoH}$ \\
\hline December 2010 & $\mathrm{MOH}$ \\
\hline December 2010 & $\mathrm{MoH}$ \\
\hline
\end{tabular}

\section{Strategic objective 2: To expand access to the Basic Package of Health Services (BPHS)}

\section{Access to health} services is estimated to be 41 percent.

\section{Limited supply} chains and population tracking systems are worsening the health situation.
Develop curriculum and training modules and train 4000 health workers on the BPHS

Implement the BPHS in 70 percent of existing functional health facilities

Establish gender sensitive medical care services in all BPHS facilities nationwide

Restore ambulance and communication services to strengthen the referral system in 15 county hospitals

Create drug depots in the 15 counties and ensure sustained delivery of drugs and medical supplies

Establish birth registration centers in all health facilities and 300 communities nationwide

Establish 50 basic Emergency Obstetric Care Centers and strengthen comprehensive Emergency Obstetric Care services in 15 hospitals

Expand access to disease prevention and control programs (particularly for HIV and AIDS and tuberculosis)

\begin{tabular}{|l|c|}
\hline December 2010 & $\mathrm{MoH}$ \\
\hline December 2010 & $\mathrm{MoH}$ \\
\hline October 2010 & $\mathrm{MoH}$ \\
\hline December 2010 & $\mathrm{MoH}$ \\
\hline December 2010 & $\mathrm{MoH}$ \\
\hline December 2010 & $\mathrm{MoH}$ \\
\hline December 2010 & $\mathrm{MoH}$ \\
\hline
\end{tabular}

\section{Strategic objective 3: To rehabilitate health infrastructure}

Many of the current facilities are not equipped or designed for an optimal level of service delivery.

\begin{tabular}{|l|c|c|}
\hline Rebuild and renovate 205 health facilities nationwide & December 2010 & $\mathrm{MoH}$ \\
\hline $\begin{array}{l}\text { Restore health training program in Bong, and re-construct two } \\
\text { midwifery schools in Grand Gedeh and Lofa }\end{array}$ & May 2010 & $\mathrm{MoH}$ \\
\hline $\begin{array}{l}\text { Rebuild one national mental rehabilitation center and rehabilitate } \\
\text { two mental health facilities }\end{array}$ & February 2010 & $\mathrm{MoH}$ \\
\hline $\begin{array}{l}\text { Develop and institute architectural standards for health infrastruc- } \\
\text { ture }\end{array}$ & July 2008 & $\mathrm{MoH}$ \\
\hline Rebuild one rehabilitation facility for youth in contact with the law & December 2010 & $\mathrm{MoH}$ \\
\hline
\end{tabular}




\section{Strategic objective 4: To strengthen social welfare programs}

\begin{tabular}{|c|c|c|c|}
\hline \multirow{6}{*}{$\begin{array}{l}\text { Family and com- } \\
\text { munity support net- } \\
\text { works were eroded } \\
\text { during the war. }\end{array}$} & $\begin{array}{l}\text { Develop a National Social Welfare Policy and Plan, with a focus } \\
\text { on gender, internationalization, war-affected youth, mental health, } \\
\text { HIV and AIDS, and disabilities }\end{array}$ & July 2008 & $\mathrm{MoH}$ \\
\hline & $\begin{array}{l}\text { Execute implementation of Policy \& Plan, and develop its M\&E } \\
\text { systems }\end{array}$ & July 2009 & \\
\hline & $\begin{array}{l}\text { Develop incentive, scholarship, and training programs for } 1,500 \\
\text { new social workers and other line workers. }\end{array}$ & December 2010 & $\mathrm{MoH}$ \\
\hline & $\begin{array}{l}\text { Develop a strict accreditation process for welfare institutions and } \\
\text { standards for licensing social workers. }\end{array}$ & February 2009 & $\mathrm{MoH}$ \\
\hline & $\begin{array}{l}\text { Create counseling, psychosocial, and alternative care services; } \\
\text { and develop inter-agency collaborations to focus on the most vul- } \\
\text { nerable populations }\end{array}$ & December 2010 & $\mathrm{MoH}$ \\
\hline & $\begin{array}{l}\text { Provide a safety net for poor households affected by AIDS, includ- } \\
\text { ing AIDS orphans }\end{array}$ & December 2010 & $\mathrm{MoH}$ \\
\hline \multicolumn{4}{|c|}{ Strategic objective 5: To further develop support systems } \\
\hline \multirow{4}{*}{$\begin{array}{l}\text { No functional } \\
\text { reporting tool, } \\
\text { standards for } \\
\text { medical donations, } \\
\text { or central lab. }\end{array}$} & Establish a Health Management Information System (HMIS) Unit & December 2008 & $\mathrm{MoH}$ \\
\hline & Develop and Implement HMIS Programs & December 2010 & $\mathrm{MoH}$ \\
\hline & Standardize medical equipment in all BPHS facilities & December 2010 & $\mathrm{MoH}$ \\
\hline & Establish a national reference laboratory and blood bank & December 2010 & $\mathrm{MoH}$ \\
\hline \multicolumn{4}{|c|}{ Strategic objective 6: To strengthen health financing } \\
\hline \multirow{3}{*}{$\begin{array}{l}\text { Services unafford- } \\
\text { able for majority of } \\
\text { population. }\end{array}$} & $\begin{array}{l}\text { Conduct and disseminate three policy research studies on issues } \\
\text { related to health financing }\end{array}$ & June 2009 & $\mathrm{MoH}$ \\
\hline & $\begin{array}{l}\text { Establish a funding mechanism with donors and set up an exter- } \\
\text { nal aid coordination unit }\end{array}$ & December 2008 & $\mathrm{MoH}$ \\
\hline & Develop a National Health Financing Policy and Strategic Plan & December 2009 & $\mathrm{MoH}$ \\
\hline
\end{tabular}


Issue

Goal: To provide access to quality and relevant educational opportunities at all levels and to all, in support of the social and economic development of the nation

\section{Strategic objective 1: To strengthen the curriculum}

School curricula are weak and outdated.

Develop new primary and secondary school curricula and have

100 percent of schools adopt

\begin{tabular}{c|c}
$\substack{\text { September } \\
2011}$ & MoE \\
\hline
\end{tabular}

Strategic objective 2: To expand access to quality, safe, and hygienic schools

Access is severely lim- $\quad$ Build 240 primary classrooms (40 schools) and 54 secondited due to insufficient facilities and supplies, while the available facilities are disproportionately located out of reach for some regions. ary classrooms (4 schools); repair 200 primary classrooms (33 schools), and 72 secondary classrooms (6 schools); construct 14,150 chairs and 82 water wells with hand pumps

Facilitate purchasing and publishing of approved textbooks

\begin{tabular}{|c|c}
\hline 2011 & MoE \\
\hline $\begin{array}{c}\text { September } \\
2010\end{array}$ & MoE \\
\hline
\end{tabular}

\section{Strategic objective 3 : To recruit and train qualified teachers}

Only one third of primary teachers in public schools have been trained, and only $9 \%$ have received some ALP training.
Extend field-based in-service training to all fifteen counties

Scrutinize and harmonize the MoE payroll and establish a teacher database

Rehabilitate three Regional Teacher Training Institutes to train between 650-1000 new teachers annually

Review and revise of the salaries of teachers and introduce salary scales based on qualification, experience, performance, position/responsibility, teaching subject, and place of teaching Construct teacher 35 houses per year (105 over 3 years)

\begin{tabular}{|c|c|}
\hline 2011 & MoE \\
\hline June 2008 & MoE \\
\hline July 2008 & MoE \\
\hline & MoE \\
\hline
\end{tabular}

\section{Strategic objective 4: To improve learning achievement and school completion rates}

Enrolment rates remain Provide feeding for at least 600,000 students and take-home low, especially for girls. Only a small number successfully make the transition from primary to secondary education. rations for 30,000 adolescent girls, and encourage girls' enrolment through special scholarship program.

\begin{tabular}{|c|c|}
\hline Ongoing & MoE \\
\hline & \\
\hline $\begin{array}{c}\text { September } \\
2009\end{array}$ & MoE \\
\hline $\begin{array}{c}\text { September } \\
2009\end{array}$ & MoE \\
\hline $\begin{array}{c}\text { Starting from } \\
2010\end{array}$ & MoE \\
\hline
\end{tabular}

Strategic objective 5: To strengthen the quality and accessibility of vocational training

\section{Large number of} unskilled and unemployed youths nationwide.

\begin{tabular}{|l|c|c|}
$\begin{array}{l}\text { Refurbish and equip the six existing multi-lateral high schools to } \\
\text { reactivate skill training and increase the production of skill train- } \\
\text { ing graduates }\end{array}$ & $\begin{array}{c}\text { September } \\
2009\end{array}$ & MoE \\
\hline $\begin{array}{l}\text { Establish a skills training center to serve three counties that never } \\
\text { previously had any government provisions. }\end{array}$ & $\begin{array}{c}\text { September } \\
2009\end{array}$ & MoE \\
\hline $\begin{array}{l}\text { Increase the production of skills training center graduates by } 50 \\
\text { annually }\end{array}$ & $\begin{array}{c}\text { Starting from } \\
2010\end{array}$ & MoE \\
\hline
\end{tabular}

Strategic objective 6: To improve the quality and standard of tertiary education and to implement a phased expansion of the higher education system

Outdated accreditation scheme, outdated curricula, and a lack of qualified staff. Sector unable to meet the national demand.

\begin{tabular}{|l|c|c|}
\hline $\begin{array}{l}\text { All institutions of higher learning review and revise their curricula } \\
\text { under the leadership of the MOE and NCHE }\end{array}$ & 2009 & $\begin{array}{c}\mathrm{MoE}, \\
\mathrm{NCHE}\end{array}$ \\
\hline $\begin{array}{l}\text { Address the situation of poor staffing University of Liberia through } \\
\text { new appointments }\end{array}$ & Ongoing & $\mathrm{MoE}$ \\
\hline $\begin{array}{l}\text { Commence arrangements for the establishment of at least one } \\
\text { new institution of higher learning outside of Monrovia }\end{array}$ & $\begin{array}{c}\text { September } \\
2009\end{array}$ & $\mathrm{MoE}$ \\
\hline $\begin{array}{l}\text { Revise and upgrade the needed qualifications and experience } \\
\text { of the quality assurance officers (CEOs, DEOs and supervising } \\
\text { authorities at MoE), and resource and capacitate them to better } \\
\text { play their role }\end{array}$ & December 2009 & MoE \\
\hline
\end{tabular}


Strategic objective 7: To strengthen the overall governance, management and financial wellbeing of education

Inadequate and

undefined sources of

finance, weak capac-

ity for management

and governance, weak

regulatory framework.

\begin{tabular}{|l|c|c|}
\hline Review and amend the Education Act & December 2010 & $\begin{array}{c}\text { MoE, } \\
\text { Legislature }\end{array}$ \\
\hline $\begin{array}{l}\text { Produce a National Education Policy of Liberia and revise all } \\
\text { existing contributing policies }\end{array}$ & December 2009 & MoE \\
\hline $\begin{array}{l}\text { Produce M\&E framework and evaluation sheet and commence } \\
\text { training of staff on their use }\end{array}$ & June 2008 & MoE \\
\hline $\begin{array}{l}\text { Commence annual pre-notified inspection of schools, publishing } \\
\text { reports for public consumption every 2 years }\end{array}$ & December 2009 & MoE \\
\hline
\end{tabular}




\section{The Macroeconomic Policy Framework}

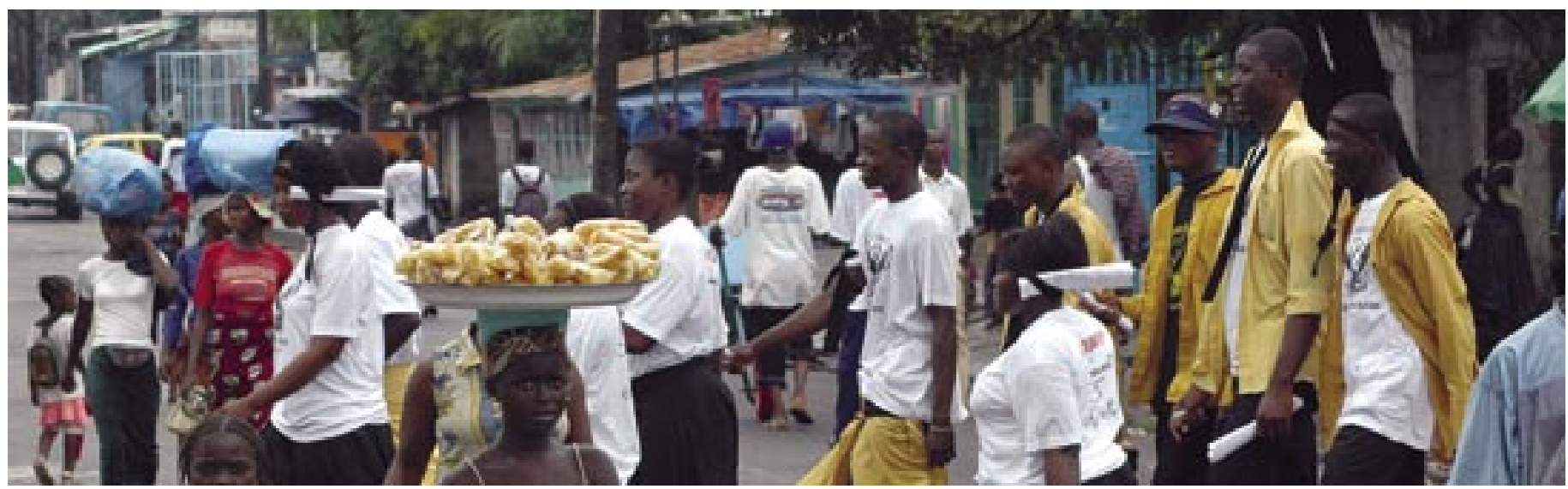

\subsection{Introduction}

A stable macroeconomic environment is critical to the achievement of rapid, inclusive and sustainable economic growth. Without macroeconomic stability, it will be difficult to attract investment, create jobs, generate revenues and reduce poverty. The Government's main macroeconomic goals therefore are to implement sound fiscal, monetary, trade and exchange rate policies that foster competition, maintain price stability, create employment opportunities, and encourage private sector investment in order to provide the foundation for rapid, inclusive, and sustainable growth. Specifically, it will aim to reduce consumer price inflation to 7.0 percent by 2011 , increase Government revenues to 27 percent of GDP, 57 and maintain broad stability in the exchange rate. It also will aim to complete the HIPC debt relief process during the PRS period, resulting in the cancellation of the majority of Liberia's external debts.

${ }^{2}$ To achieve these goals, the Government will launch a medium-term strategy for strengthening and ensuring transparent public financial management (PFM) anchored on a new PFM law. It will continue to pursue its comprehensive tax policy and administration reforms aimed at broadening the tax base with minimal tax burden on the very poor, and will allocate expenditure to the highest priority needs. Transparent and accountable financial management, coupled with fiscal policy in part aimed at ensuring that the benefits from growth are widely-shared through effective basic services, will be critical components of Liberia's drive to break from the past and generate inclusive development.

${ }^{3}$ However, during the PRS period, Liberia's financial sector and revenue base will not be able to develop at the pace required to mobilize adequate domestic savings. Liberia will therefore continue to require large amounts of external financing in the form of grants and private capital inflows to achieve rapid, inclusive and sustainable growth. With limited debt service capacity, the Government will continue to forgo new external borrowing, although it will review this policy once it has adequately addressed its immense domestic and external debt overhang, created the necessary debt management capacity, and prepared a comprehensive national debt management strategy. Thus the Government will rely primarily on high levels of grants to supplement its capacity to mobilize domestic resources, and will promote an environment conducive to increased private capital inflows to meet the external financing needs necessary for economic growth.

57 The relatively high revenue/GDP ratio in part reflects a likely underestimation of GDP in the absence of official and complete national accounts statistics. 


\begin{tabular}{|l|c|c|c|c|c|}
\hline & 2007 & 2008 & 2009 & 2010 & 2011 \\
\hline Consumer prices (annual average) & 11.4 & 10.6 & 9.0 & 8.0 & 7.0 \\
\hline Consumer prices (end of period) & 11.7 & 9.5 & 8.5 & 7.5 & 6.5 \\
\hline & \multicolumn{4}{|c|}{ In percent of GDP, unless otherwise indicated } \\
\hline Broad money (M2, percent change) & 40.1 & 23.2 & 20.4 & 25.0 & 23.3 \\
\hline Broad money & 26.2 & 26.5 & 26.6 & 26.6 & 26.6 \\
\hline Net domestic credit (\% change) & 11.0 & 10.2 & 8.2 & -69.8 & 11.0 \\
\hline Net claims on government (\% change) & 9.6 & 10.7 & 7.4 & -77.3 & 6.1 \\
\hline Claims on private sector (\% change) & 46.2 & 21.5 & 20.0 & 25.2 & 23.0 \\
\hline Overall fiscal balance (cash basis) & 3.8 & -0.4 & -12.1 & -10.3 & -10.4 \\
\hline Current account balance & -66.5 & -94.5 & -87.6 & -62.6 & -40.9 \\
\hline Trade balance & -35.6 & -62.4 & -53.0 & -31.0 & -17.3 \\
\hline Exports, f.o.b. & 31.0 & 40.7 & 54.3 & 70.2 & 81.0 \\
\hline Imports, f.o.b. & -66.6 & -103.2 & -107.3 & -101.1 & -98.3 \\
\hline Donor transfers (net, US\$ millions) & 229.5 & 236.7 & 215.0 & 222.7 & 235.9 \\
\hline Public sector external debt outstanding & 611.9 & 509.4 & 453.6 & 12.5 & 6.7 \\
\hline Gross official reserves (US\$ millions) & 85.1 & 91.6 & 119.8 & 147.5 & 170.7 \\
\hline (in months of imports of goods and & & & & & \\
\hline services) & 1.5 & 1.0 & 1.1 & 1.2 & 1.2 \\
\hline Memo items: & & & & & \\
\hline Population (millions) & 3.8 & 3.9 & 4.1 & 4.3 & 4.5 \\
\hline
\end{tabular}

Source: Government of Liberia and IMF staff estimates

\subsection{Public Financial Management}

${ }^{4}$ The Government began to implement wide-ranging PFM reforms in 2006 , and will continue to broaden and deepen the process during the PRS period. Stronger financial management is essential for reducing corruption and holding the Government accountable for appropriate use of public funds for the greater good. The Government has improved the budget preparation process and successfully implemented an interim commitment control system that prevents the accumulation of domestic arrears, introduced regular fiscal reporting, implemented a new procurement law, and with the help of international partners, introduced better financial controls in key state-owned enterprises. Deeper reforms are necessary to improve the effectiveness of the budget through better preparation, execution, reporting, and auditing. Further strengthening of budget systems also will facilitate direct donor support for the PRS through the budget, and for Liberia's exit from the Governance and Economic Management Assistance Program (GEMAP).

${ }^{5}$ The Government has already begun to take steps in the above direction. It has introduced legislation for the merger of the Bureau of the Budget into the Ministry of Finance to facilitate greater efficiency in the budget process, and the legislature has just approved its proposal to set strict limits on budget transfers to foster better budget preparation, execution and discipline. Building on this step, the Government intends to introduce comprehensive PFM legislation by mid-2008 that will modernize, consolidate, and better clarify the roles, functions, and accountabilities of the executive, the Legislature, the auditor-general, and other key stakeholders in the budget cycle.

${ }^{6}$ The Government will also pursue comprehensive civil service reforms aimed at improving the efficiency of delivery and quality of public services, improving payroll management through enhanced automation and regular auditing, and creating further fiscal space for PRS priorities. As a short-term measure 
to address the chronic mid-level capacity weaknesses, the Government will continue to improve the design and accelerate the implementation of the Senior Executive Service program, as discussed in more detail in Chapter Twelve.

${ }^{7}$ Measures will be taken to speed the pace of non-wage spending, which reflect both poor procurement planning and weak capacity of ministries to plan and implement program operations, as well as continued weaknesses in the expenditure management system. While there has been improvement in budget execution, non-wage spending has been hampered by challenges in meeting the strict standards of the new procurement legislation. In response, the Government will intensify training and capacity-building in the procurement units of line ministries and agencies, and make revisions to the procurement law that better balance the requirements of rapid post-conflict reconstruction and the need for transparency safeguards at all levels of government in the use of public resources.

${ }^{8}$ To modernize budget execution and improve cash management, the Government plans to implement a customized integrated financial management information system. As these improvements take hold, the Government will also streamline and ultimately wind down the activities of the cash management committee, with the view to setting up a system consistent with best practices. It also intends to improve financial safeguards through stronger internal audit mechanisms, update and formulate as necessary clear standard operating guidelines, as well as seek to improve its systems and procedures in line with recommendations from regular external audits by the General Auditing Commission (GAC). It will also continue publishing and improving quarterly reports of the budget outcome, with specific focus on improving disclosure of the results of expenditures of key social service ministries such as the number of schools built.

${ }^{9}$ To better coordinate and direct resources to the PRS priorities for accelerating growth and reducing poverty, the Government intends to implement a comprehensive system of tracking donor aid flows, and to include the flows in the budget where possible during the PRS period. It will institute administrative measures to enforce financial reporting by line ministries and agencies that receive donor assistance by ensuring the required skills and resources are within the ministries and agencies. Greater cooperation of donors will be needed in promoting more transparent planning and reporting of donor assistance to the country, and an increased use of the national systems in channeling their support.

${ }^{10}$ To ensure that the budget adequately reflects the needs of the counties and the rural population, the Government will pursue more systematic consultations at the county level. It will also work toward providing more information in the budget on the geographical dimensions of budget allocations where relevant and feasible. The revised chart of accounts and revisions of budget codes currently being developed should help facilitate this objective. Moreover, as part of the decentralization process and the Government's financial support for county development, it will aim to build the skills and capacity at the county and district level to appropriately manage and oversee public sector finances.

\subsection{Fiscal Policy}

${ }^{11}$ Sound fiscal policy is central to achieving macroeconomic stability and ensuring that the benefits of growth are widely shared. The Government is committed to maintaining a balanced cash-based budget for most of the PRS period in order to maintain macroeconomic stability and to maximize the fiscal space necessary for implementing the PRS, drawing on domestic revenues and resources provided by donors through the budget. On the revenue side, the Government will continue its efforts to broaden the tax base through tax policy reforms and modernization of domestic tax and customs administration. On the expenditure side, the Government will seek to improve the efficiency, quality and transparency of delivery of public services through fundamental reforms of the public financial management system. This will include new PFM legislation, improvements in the processes of national budget preparation, execution, reporting and auditing, improvements in procurement planning and procedures, formulation of administrative regulations to govern the procurement law and its possible amendment, implementation of the Liberia Extractive Industry Transparency Initiative, and stronger accountability safeguards based on regular audits. 


\subsubsection{Tax Policy Reform and Modernization of Revenue Administration}

${ }^{12}$ Several short-to-medium term reforms are already underway or being proposed in the areas of the goods and services tax (GST), excises, income tax, tax incentives and the Investment Code. These reforms are generally intended to lower rates to improve Liberia's competitiveness and promote private sector growth, broaden the tax base (inter alia by progressively increasing the share of consumption-based taxes), and remove ineffective and inequitable taxes, while at the same time improving transparency, accountability and efficiency in the use of public funds. Key reforms include:

- amending the Liberia Revenue Code (LRC) to eliminate discretionary tax exemptions for investors, reducing corporate and personal income tax rates, streamlining taxes to support formalization of small businesses, and reducing tax rates on the very poor (e.g. by introducing a threshold for income taxes);

- harmonizing Liberian import tariffs with the ECOWAS common external tariff;

- revising the investment code and aligning it with the LRC;

- bringing the mineral and petroleum taxation regime in line with worldwide best practices;

- completing the modernization and automation of domestic revenue administration;

- modernizing and automating customs and excise through a temporary outsourcing;

- transitioning over the medium term from the GST toward a value-added tax, consistent with international best practice; and

- implementing the Liberia Extractive Industry Transparency Initiative to ensure full public disclosure of all revenues from the mining, petroleum, and forestry sectors.

\subsubsection{Revenue Projections}

${ }_{13}$ When the Government took office in January 2006 , annual revenues were just over US $\$ 80$ million. In two years, the Government has more than doubled that figure, with revenues for FY 2007/2008 projected at US $\$ 185$ million. Revenues should continue to grow during the PRS period to US $\$ 329.8$ million in 2010/2011, mainly through continued buoyant economic growth (and the resulting increases in trade and income taxes) and receipts for new mining concessions, forestry fees, telecommunications license fees and continuing gains from tax administration improvements. As a result, revenues as a share of GDP are expected to increase by nearly 3 percentage points.

${ }^{14}$ The Government expects that donor support for the PRS through the budget will be forthcoming to supplement its own revenue mobilization efforts. In the absence of firm donor commitments, the current macroeconomic framework assumes that donor support through the budget will start at around US $\$ 10$ million in FY 2008/2009, and remain at around 1 percent of GDP over the PRS period. Overall, net donor inflows are expected to remain at around the currently estimated level of US\$230 million in 2007 through 2011. The scaling down of UNMIL operations and further decline in emergency post-conflict humanitarian assistance is expected to be offset by higher levels of donor support for reconstruction. Currently most projected donor support falls outside of the budget and has been subject to little coordination. However, the Government expects that as it strengthens its budgetary procedures, its internal and external audit processes, and its capacity to effectively and transparently allocate financial resources and deliver public services, more donor support will be channeled through the budget. Greater budget support is an effective mechanism for donor contributions in support of the implementation of Liberia's PRS.

${ }^{15}$ The Government also recognizes that the financing required for sustained economic growth and poverty reduction will not be met by domestic savings and donor grant support. For this reason, it is firmly committed to ensuring that the environment is attractive for higher levels of foreign direct investment, which 
has been rapidly increasing over the past two years. It will continue to encourage investment, with a focus on those that will further the Government's goal of rapid, inclusive and sustainable growth.

\section{Table 10.2: Revenue Projections FY 2006/2007-FY 2010/2011, US\$ millions}

\begin{tabular}{|c|c|c|c|c|c|}
\hline & $\begin{array}{c}2006 / 7 \\
\text { Act. }\end{array}$ & $\begin{array}{l}2007 / 8 \\
\text { Budget }\end{array}$ & $\begin{array}{l}\text { 2008/9 } \\
\text { Proj. }\end{array}$ & $\begin{array}{c}\text { 2009/10 } \\
\text { Proj. }\end{array}$ & $\begin{array}{c}\text { 2010/11 } \\
\text { Proj. }\end{array}$ \\
\hline Total revenue and grants & 148.3 & 185.7 & 240.0 & 272.9 & 329.8 \\
\hline Total domestic revenue & 146.8 & 185.7 & 240.0 & 261.1 & 315.9 \\
\hline Tax revenue & 140.0 & 149.5 & 176.2 & 222.2 & 260.9 \\
\hline Taxes on international trade and transactions & 69.9 & 70.1 & 81.6 & 111.1 & 132.3 \\
\hline Taxes on income & 42.5 & 48.6 & 55.1 & 66.0 & 77.6 \\
\hline Taxes on goods and services & 26.1 & 26.9 & 37.5 & 41.9 & 47.4 \\
\hline Of which: maritime revenues & 11.8 & 13.0 & 20.0 & 17.2 & 18.9 \\
\hline Other & 1.4 & 3.8 & 2.0 & 3.1 & 3.7 \\
\hline Nontax revenue & 6.9 & 36.2 & 63.8 & 38.9 & 55.0 \\
\hline \multirow[t]{2}{*}{ Grants } & 1.5 & 0.0 & 0.00 & 11.8 & 13.9 \\
\hline & \multicolumn{5}{|c|}{ In percent of nominal GDP } \\
\hline Total revenue and grants & 22.1 & 24.0 & 25.6 & 27.3 & 28.1 \\
\hline Total domestic revenue & 21.9 & 24.0 & 24.4 & 26.1 & 26.9 \\
\hline Tax revenue & 20.8 & 19.3 & 21.4 & 22.2 & 22.2 \\
\hline Taxes on international trade and transactions & 10.4 & 9.0 & 10.5 & 11.1 & 11.3 \\
\hline Taxes on income & 6.3 & 6.3 & 6.4 & 6.6 & 6.6 \\
\hline Taxes on goods and services & 3.9 & 3.5 & 4.3 & 4.2 & 4.0 \\
\hline Of which: maritime revenues & 1.8 & 1.7 & 1.8 & 1.7 & 1.6 \\
\hline Other & 0.2 & 0.5 & 0.2 & 0.3 & 0.3 \\
\hline Nontax revenue & 1.0 & 4.7 & 3.0 & 3.9 & 4.7 \\
\hline Grants & 0.2 & 0.0 & 1.2 & 1.2 & 1.2 \\
\hline \multicolumn{6}{|l|}{ Memo item: } \\
\hline Estimated fiscal year GDP* & 671.9 & 775.2 & 867.5 & 999.7 & $1,175.3$ \\
\hline
\end{tabular}

* See box below for the methodology used to estimate GDP.

Source: Government of Liberia and IMF staff estimates

\subsubsection{Expenditure Patterns and Projections}

${ }^{16}$ As a result of the rapid increase in revenues, the Government has been able to increase spending in critical areas during the last two years to support its initial efforts in reconstruction and equitable development, and should be able to make further increases during the PRS period. When the current Government took office, its US $\$ 80$ million budget allowed per capita public spending of less than US $\$ 25$ per person per year, one of the lowest levels in the world. It has already raised that figure to US\$50 per person in the FY 2007/2008 budget, and projects that it will be able to increase it further to over US\$70 per person in the 2010/2011 budget.

${ }^{17}$ But raising revenue and increasing total spending is not enough. Equally important is improving the allocation, internal control and effectiveness of expenditure. Section 10.2 described some of the steps the Government is taking in PFM to assure that the funds go to their intended purposes and are not subject to misuse. In terms of allocation, the Government used the additional funds to begin to revitalize agriculture, rebuild economic and social infrastructure, raise civil service salaries, and increase support for county development.

${ }^{18}$ The Government cannot project the allocation of future spending with certainty since the budget is subject 


\section{Real GDP Growth Assumptions}

In the absence of official national income statistics, the real GDP growth forecasts in the PRS are based largely on projections in the main productive sectors, as drawn from sectoral discussions. The weights of the various sectors are based on the last official real GDP estimates available in 1996. Real GDP was compiled in US dollars at constant 1992 prices. Production projections were used for agricultural commodities including rubber, forestry, mining (using plans by ArcelorMittal), and cement (using expansion plans by Cemenco). Excluding rubber, growth in agriculture production including rice, cocoa, cassava, and oil palm is expected to average around 5 percent per year. For rubber, a 2 percent decline per year is expected over the period 2008-2011 owing to the aged trees and the ongoing replanting program. The key services sectors are projected to grow rapidly in line with the productive sectors. Thus, sharp recovery is expected to continue in construction, electricity, wholesale and retail trade, financial services, and government services. Nominal GDP was compiled in US dollars using world commodity prices for some subsectors and domestic inflation forecasts for the rest, with the latter being impacted by the exchange rate assumption. As a key indicator of external competitiveness during the PRS period, a constant real exchange rate is assumed between the Liberian and US dollar.

Real GDP growth in 2008-2010 will be driven by the resumption of diamond, timber, and iron ore production. The lifting of UN sanctions cleared the way for resumption of diamond production in 2007 and timber exports in 2008. Iron ore mining is expected to commence in 2009 and also expand quickly. Throughout the period, the services sector is expected to make a significant contribution to real GDP growth. By 2013, timber, iron ore, and diamond production are projected to reach long-run sustainable output, and the annual growth rate of real GDP is assumed to revert to a long-run average of about $3 \frac{3}{4}$ percent.

Liberia's economic recovery is projected to be faster than average for conflict-affected non-oilproducing sub-Saharan African (SSA) countries. The average growth rate of its real GDP in the first five post-conflict years is projected at 7 percent, compared to the SSA average of 5 percent. Nevertheless, it is expected that Liberia's output will reach pre-conflict levels only after six years; the SSA average is four years. The longer recovery period reflects the severity of war damage, which is matched only in neighboring Sierra Leone.

Liberia: Sectoral Contribution to Real GDP Growth, 2002-10

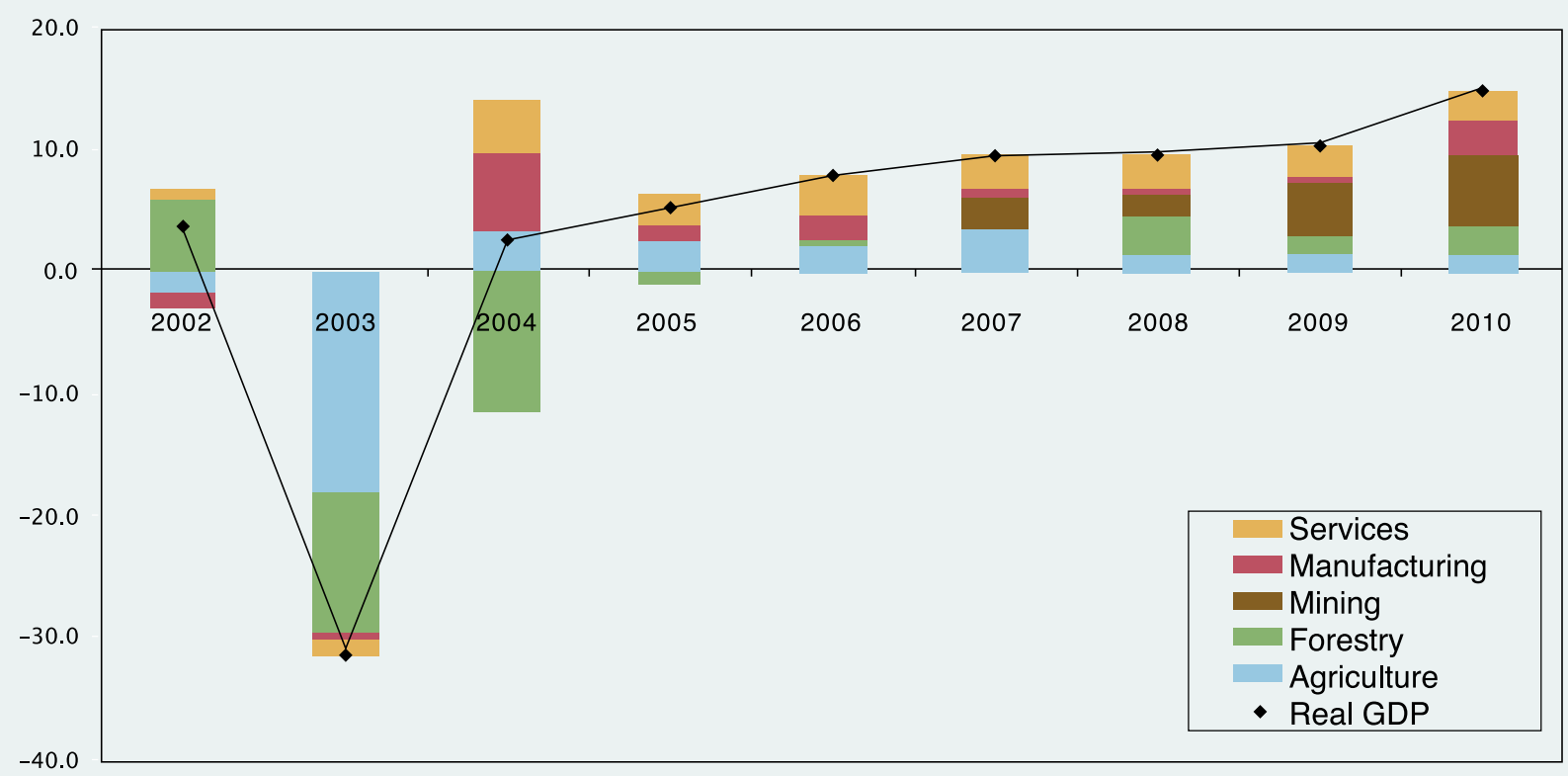

Sources: Government and IMF staff projections 
to Legislative approval. However, it plans to increasingly align the budget with PRS priorities and the goal of rapid, inclusive, and sustainable growth. It aims to continue to increase allocations for basic health and education, infrastructure construction and repair, agricultural activities, and other key priorities. Through the decentralization process, it expects to allocate progressively larger funding to counties and districts so that the benefits from increased revenues from concession agreements and other sources can be widely shared to benefit the entire Liberian population. As mentioned previously, it will be critical to build financial management capacity at the county level to facilitate such increases which will be calibrated accordingly.

\subsubsection{Domestic Debt Management}

${ }^{19}$ The Government finalized its domestic debt resolution strategy in January 2007 after an independent vetting of the stock of debt by an internationally-recruited auditing firm. Of the total outstanding claims of approximately US $\$ 914$ million, US $\$ 304$ million was deemed valid, with the remainder classified as either rejected or contestable. The Government has engaged the external auditors to further vet the "contestable" claims and additional rental claims that have since surfaced by the end of fiscal year 2007-2008.

${ }^{20}$ The domestic debt resolution strategy provides for burden-sharing by creditors, with valid vendor claims discounted by increasing percentages depending on their amount; thus claims above US $\$ 1$ million will be discounted by about 88 percent. Given the fragility of the banking system, the strategy gave special treatment to debt owed the CBL and other financial institutions.

${ }^{21}$ The Government began to make small claimant and vendor payments in FY 2006/2007, with payments reaching US\$2.8 million, and will effect additional payments before the end of FY 2007/2008. It also made payments to CBL and private banks in fiscal year 2007/2008 based on long-term restructuring arrangements. The strategy provides for the establishment of a domestic debt trust fund to finance the strategy over the long term, and the Government plans to submit legislation to that effect before the end of fiscal year 2007/2008. The Government will also act to strengthen the debt management unit within the Ministry of Finance.

\subsubsection{External Debt Management}

${ }^{22}$ At the time of its inauguration in January 2006, the Government inherited one of the largest external debt burdens in the world, with total debt amounting to US $\$ 4.8$ billion, equivalent to (in net present value terms as at June 2006) over 2,000 percent of the value of 2007 exports. Significant progress has been made since then to begin to relieve the debt burden, but there is still far to go.

${ }^{23}$ The Government welcomes the generous support of the international community in embracing a comprehensive solution to Liberia's huge external debt burden under the Heavily Indebted Poor Country (HIPC) Initiative. In the first key steps, in December 2007 Liberia's debts to the World Bank and the African Development Bank were reduced by US $\$ 400$ million and US $\$ 240$ million, respectively, and Liberia returned to good standing with both organizations. In November 2007 the shareholders of the IMF agreed to a financing package that will allow for the eventual reduction of Liberia's debts to the IMF in the context of the HIPC program. In March 2008 Liberia cleared its arrears to the IMF, obtained IMF Board approval for a new three-year Poverty Reduction and Growth Facility (PRGF) supported program, and reached its HIPC Decision Point, meaning that its major creditors formally agreed to deliver deep interim relief to reduce Liberia's debt burden to within the HIPC sustainability threshold (most of the actual debt reduction will come at the time of the HIPC Completion Point, which could occur as early as the middle or latter part of 2009). The Government has requested the Paris Club group of bilateral creditors to provide debt relief as part of the HIPC process, and initial Paris Club treatment is planned for mid-April 2008. It has continued good-faith discussions and negotiations with its commercial creditors in mid-2007 aimed at reaching a settlement on comparable terms with other creditors.

${ }^{24}$ All told, based on its HIPC Preliminary Document, Liberia anticipates total debt reduction of approximately 97 percent in net present value terms from all creditors on a fair burden basis through the HIPC process. ${ }^{58}$

\footnotetext{
58 The Government anticipates 67 percent reduction from traditional "Naples" terms, augmented by a further 91 percent reduction on the residual amount as determined by Liberia's HIPC "common reduction factor" jointly calculated by the IMF and World Bank.
} 
As a result, Liberia's debt (in net present value terms) is expected to decline from US $\$ 4,739$ million to US $\$ 240$ million under the Initiative. Going beyond HIPC, the Government especially welcomes the decision by many bilateral creditors and the stated intention of the IMF, World Bank, and African Development Bank to top-up debt relief and provide 100 percent debt forgiveness.

${ }^{25}$ During the HIPC interim period, the Government is committed to ensuring that the required fiscal space for economic and social reconstruction is not constrained by burdensome debt payments following normalization of our external financial relationships with creditors. To this end, the Government aims to secure additional debt relief and or rescheduling agreements from non-Paris Club bilateral creditors, small multilaterals, and commercial creditors. Debt service will therefore remain limited during the PRS period at less than one percent of GDP.

${ }^{26}$ With limited debt service capacity, the Government will continue to forgo external borrowing, although as noted above it will review this policy in terms of highly concessional borrowing once it has adequately addressed its immense domestic and external debt overhang, created the necessary debt management capacity, and prepared a comprehensive national debt management strategy.

\subsection{Monetary and Exchange Rate Policy}

${ }^{27}$ As a key element of maintaining a stable macroeconomic environment, the Central Bank of Liberia will implement monetary policies aimed at reducing inflationary pressures, since inflation undermines investment and is particularly deleterious to the poor. To bolster the monetary policy framework, the CBL will continue to strengthen the policy tools available to manage liquidity, improve coordination between the fiscal and monetary authorities, and consider the policy options in the current dual currency arrangement. The Government will also continue to focus on strengthening the banking sector to improve private sector access to credit, and to develop a modern national payments system, as described in Chapter Seven.

${ }^{28}$ The CBL will continue to use the exchange rate as the main indicator of domestic monetary conditions, given the limited scope for monetary policy in the current dual currency and dollarized environment. The Government recognizes the strong transmission role played by the exchange rate on price inflation in the Liberian context. The CBL will therefore manage Liberian dollar liquidity with the aim of maintaining broad exchange rate stability as a means of managing consumer price inflation.

${ }^{29}$ The Government aims to reduce consumer price inflation to 7 percent by 2011 . It will slow the annual growth of broad money (M2) to around 23 percent by the end of the PRS period. The ratio of M2 to GDP will increase marginally from 26 percent in 2007 to 27 percent in 2011, compared with the 2007 average of 30 percent in other low income Sub-Saharan African countries. In recognition of the need to facilitate adequate financial savings to sustain the higher private sector credit necessary for economic growth, the Government will continue to place strict limits on its overall domestic borrowing requirement, while targeting an accumulation of international reserves consistent with the need to cushion the economy against unpredictable external shocks. The CBL will continue to use foreign exchange auctions to smooth out fluctuations in the exchange rate, and to respond to imbalances in the domestic money market.

\subsection{External Trade and Balance of Payments}

${ }^{30}$ Liberia expects its external trade deficit to narrow over the next three years on the basis of strong exportled growth in the key productive sectors. Export growth will be led by revival in mining of iron ore, gold, and diamonds; timber harvesting, as well as agricultural exports such as cocoa and oil palm. The Government hopes to facilitate the eventual process of diversification into non-traditional exports, as described in Chapter Seven, by rebuilding infrastructure, strategically targeting promotional opportunities such as the US Government's African Growth and Opportunity Act (AGOA), and identifying new potential markets. Import demand will, however, remain very high as investment projects depend on large initial capital and raw material imports. To further enhance trade facilitation, the Government is reengineering administrative pro- 
cedures, reducing unnecessary business costs and improving service quality.

${ }^{31}$ Based on these developments and the expected sharp reduction in debt service payments after HIPC debt relief, the Government expects the external current account deficit, excluding grants, to improve from 66 percent of GDP in 2007 to 41 percent of GDP in 2011.59 Nevertheless, to meet its external financing needs, Liberia will continue to require large amounts of grant financing for the implementation of its PRS and to ensure stability in the external accounts. In the absence of firm commitments, the current macroeconomic framework assumes a gradual tapering off of grants in GDP terms from around 31 percent of GDP in 2007 to 19 percent in 2011.

${ }^{32}$ The Government recognizes that donor financing may not be adequate for its large reconstruction needs, and is therefore targeting private sector financing in infrastructure or activities of state owned enterprise that can be privatized. The Government aims to create an attractive environment for foreign investment through its open trade and investment regime and low business costs. These policies are crucial to enhancing Liberia's external competitiveness, to attracting and retaining investments in Liberia, and to serve as a buffer against external shocks in the context of low levels of international reserves. These policies will, however, be buttressed by efforts to maintain net international reserves at the modest level of around 1.2 months of imports of goods and services.

Table 10.3: External Trade and Balance of Payment Indicators 2007-2011, US\$ millions

\begin{tabular}{|c|c|c|c|c|c|}
\hline & $\begin{array}{c}2007 \\
\text { Est. }\end{array}$ & $\begin{array}{l}2008 \\
\text { Proj. }\end{array}$ & $\begin{array}{l}2009 \\
\text { Proj. }\end{array}$ & $\begin{array}{l}2010 \\
\text { Proj. }\end{array}$ & $\begin{array}{l}2011 \\
\text { Proj. }\end{array}$ \\
\hline Trade balance & -260.5 & -510.9 & -486.2 & -335.1 & -219.4 \\
\hline Exports, f.o.b. & 227.0 & 333.4 & 497.6 & 759.8 & $1,027.1$ \\
\hline Imports, f.o.b & -487.5 & -844.2 & -983.8 & $-1,094.9$ & $-1,246.4$ \\
\hline Current transfers (net) & 290.6 & 298.4 & 277.3 & 285.6 & 299.4 \\
\hline Current account balance & -257.0 & -536.3 & -588.5 & -454.9 & -283.3 \\
\hline Current account balance (excluding grants) & -486.6 & -773.0 & -803.5 & -677.5 & -519.2 \\
\hline Capital and financial account & 99.9 & 442.1 & 486.2 & 343.2 & 305.3 \\
\hline Official financing & -5.0 & -9.0 & -9.8 & -22.1 & 2.2 \\
\hline Disbursements & 0.0 & 0.0 & 0.0 & 0.0 & 7.2 \\
\hline Private financing & 104.9 & 451.1 & 495.9 & 365.3 & 303.1 \\
\hline Foreign direct investment & 120.0 & 396.6 & 406.6 & 339.3 & 339.3 \\
\hline Other investment (including errors and omissions) & -15.1 & 54.5 & 89.3 & 26.0 & -36.2 \\
\hline Overall balance & -157.1 & -94.1 & -102.4 & -66.6 & 22.0 \\
\hline Financing & 157.1 & 15.0 & 33.9 & 66.6 & -22.0 \\
\hline Change in net international reserves (increase -) & -10.4 & -12.4 & -14.5 & -19.0 & -22.0 \\
\hline Arrears (accrual +) & -497.5 & $-3,646.3$ & 0.0 & 0.0 & 0.0 \\
\hline Prospective debt relief and rescheduling & 665.0 & $3,673.7$ & 48.4 & 85.6 & 0.0 \\
\hline Financing gap & 0.0 & -79.1 & -68.5 & 0.0 & 0.0 \\
\hline \multicolumn{6}{|l|}{ Memorandum items: } \\
\hline Public Debt outstanding (including arrears) & $4,480.3$ & $4,168.2$ & $4,158.2$ & 135.0 & 26.5 \\
\hline (percent of exports of goods and services) & $1,430.1$ & 906.0 & 605.5 & 12.9 & 7.9 \\
\hline (percent of GDP) & 611.9 & 509.4 & 453.6 & 12.5 & 6.7 \\
\hline Debt service charges & 1.3 & 3.9 & 3.9 & 3.9 & 14.9 \\
\hline (percent of GDP) & 0.2 & 0.5 & 0.4 & 0.4 & 1.2 \\
\hline Gross official reserves & 85.1 & 91.6 & 119.8 & 147.5 & 170.7 \\
\hline Gross official reserves (months of imports of goods and services) & 1.5 & 1.0 & 1.1 & 1.2 & 1.2 \\
\hline GDP at current prices & 732.2 & 818.2 & 916.8 & $1,082.6$ & $1,268.0$ \\
\hline
\end{tabular}

Source: Government of Liberia and IMF staff estimates

59 The ratios may be overstated as a result of the likely underestimation of GDP in the absence of complete national accounts data. 
Goal: To implement sound fiscal, monetary, trade and exchange rate policies that foster competition, maintain price stability, create employment opportunities, and encourage private sector investment in order to provide the foundation for equitable, inclusive, and sustainable growth.

Strategic objective 1: To create a new framework for public financial management

Fragmented and incomplete legislation, unclear rules, and lack of coordination create opportunities for abuse and corruption.
Submit to the Legislature new comprehensive PFM laws that address weaknesses in budget preparation, budget execution and cash planning, GoL banking arrangement, GFSM 2001-compatible accounting and reporting, debt and guarantee management Develop a medium-term macrofiscal framework for the purpose of preparing the budget
June 2008

MoF, President

December 2008

MoF

Strategic objective 2: To improve PFM using an integrated financial management system

The accounting system is handicapped by a single-entry system, weak purchase order and accounts payable systems, and weak coordination between HR and Payroll and between MoF, $\mathrm{BoB}$, and $\mathrm{CBL}$.

\begin{tabular}{|l|c|c|}
\hline $\begin{array}{l}\text { Improve the manual accounting system with revised } \\
\text { templates, accounting manuals and procedures, and } \\
\text { train employees on their use }\end{array}$ & 2009 & $\begin{array}{c}\text { MoF, BoB, } \\
\text { CSA }\end{array}$ \\
\hline Implement IFMIS & 2009 & MoF, BoB \\
\end{tabular}

Strategic objective 3: To improve revenue collection by implementing tax administration reforms and automation

Outdated laws, overlapping procedures, weak organizational structures and limited automation have resulted in inefficient revenue administration.

\begin{tabular}{|l|c|c|}
\hline $\begin{array}{l}\text { Amend the LRC with respect to corporate and per- } \\
\text { sonal tax reduction and tax elimination }\end{array}$ & December 2008 & MoF \\
\hline Eliminate the hut tax & December 2008 & MoF \\
\hline $\begin{array}{l}\text { Eliminate the power to grant discretionary tax and } \\
\text { import duty exemption }\end{array}$ & December 2008 & MoF \\
\hline $\begin{array}{l}\text { Make the investment code consistent with the LRC, } \\
\text { harmonize Liberian Tariff with ECOWAS CET }\end{array}$ & December 2008 & MoF \\
\hline $\begin{array}{l}\text { Revise the policies and procedures for mineral and } \\
\text { forestry taxation }\end{array}$ & December 2008 & MoF \\
\hline Move from GST to VAT & December 2010 & MoF \\
\hline $\begin{array}{l}\text { Outsource the functions of Customs and Excise for } \\
\text { a limited period }\end{array}$ & December 2009 & MoF \\
\hline \begin{tabular}{l} 
Implement a Tax Automation System (TAS) \\
\hline
\end{tabular} & December 2009 & MoF \\
\hline
\end{tabular}

Strategic objective 4: To develop a comprehensive national debt management strategy and improve debt management capacity

No national debt management policy and limited debt management capacity risk return to debt overhang.
Develop national debt management strategy that is consistent with the PFM legal framework

Install debt management software to support data storage, analysis, reporting and interfaces with $\mathrm{CBL}$ and $\mathrm{BoB}$, and train staff on its use

\section{Strategic objective 5: To modernize customs operations}

Poor integrity, weak internal controls, and long delays in customs clearance result in poor investment climate, revenue leakage.
Comprehensively overhaul the Bureau of Customs and Excise with respect to structures, staffing, procedures, processes, and practices.

Revise existing laws and introduce new laws to improve investment climate, maximize revenue and facilitate trade

Implement a customs automation system

\begin{tabular}{|c|c|}
\hline December 2009 & $\begin{array}{c}\text { MoF, } \\
\text { Cabinet }\end{array}$ \\
\hline 2009 & MoF \\
\hline
\end{tabular}

MoF, abine

\begin{tabular}{|c|c|}
\hline 2010 & MoF \\
\hline 2010 & $\begin{array}{c}\text { MoF } \\
\text { Legislature }\end{array}$ \\
\hline 2010 & MoF \\
\hline
\end{tabular}




\section{Costing of the Poverty Reduction Strategy}

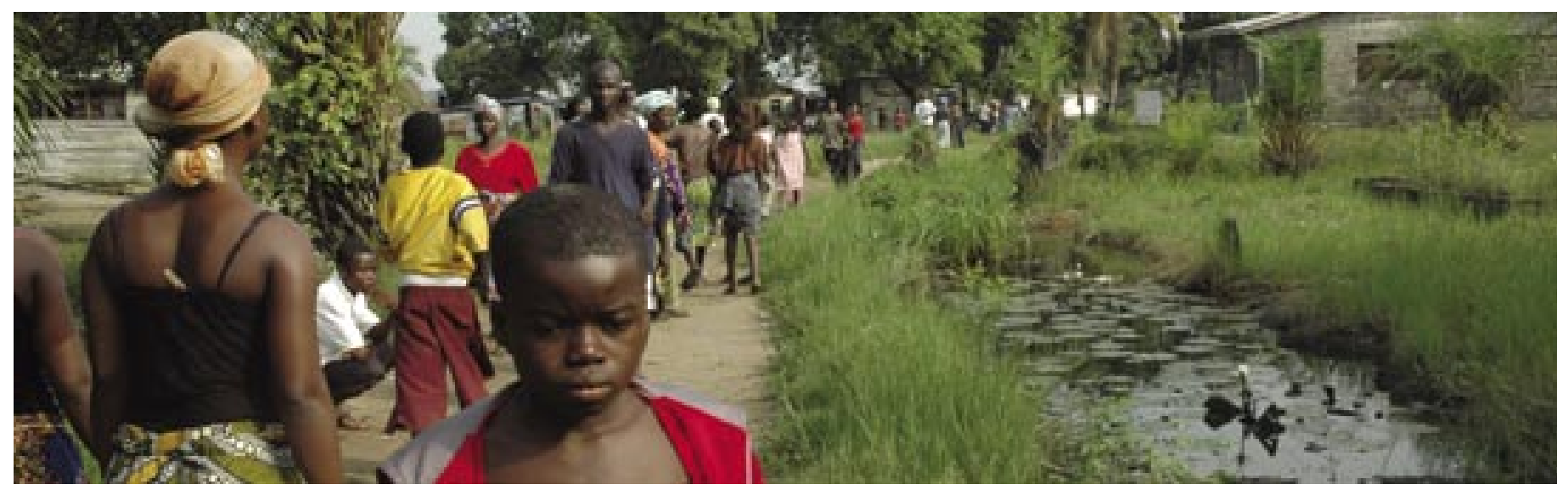

\subsection{Introduction}

Previous chapters have identified the key activities in each of the Pillars and cross-cutting areas required to meet the Government's goal of promoting rapid, inclusive, and sustainable growth and development over the PRS period. This chapter estimates the financial costs of these activities, and compares them against the potential availability of the funds to finance them.

${ }^{2}$ The cost estimates were derived through a bottom-up approach. Each PRS Working Group estimated the cost of implementing their top three priorities that contribute to the strategic objectives of the four Pillars and cross-cutting areas over the period 2008-2011.60 Based on this analysis, the estimated total costs for fully implementing the PRS over the next three years will be US\$1.61 billion. On the financing side, the Government estimates that it will be able to generate approximately $\$ 510$ million in revenues that can be dedicated to PRS-related activities, leaving a gross financing gap of approximately US $\$ 1.1$ billion over the PRS period (about US $\$ 400$ million per year), before taking into account financing from development partners or the private sector. A significant portion of this gross financing gap will be filled by funds already committed by development partners to finance ongoing activities, but the size of current commitments cannot be estimated precisely due to a paucity of complete data. Nevertheless, the gross financing gap clearly exceeds current commitments.

${ }^{3}$ This remaining financing gap after current partner commitments must be closed through some combination of additional government revenue, additional support from the international community, financing from the private sector (domestic and foreign) through public-private partnerships, and scaling back or re-phasing of proposed PRS activities. The chapter identifies some of the key broad areas that remain unfunded (or under-funded) that would be scaled back in the event that additional financing is not available.

${ }^{4}$ Although financing is the focus of the discussion in this chapter, the Government fully understands that financing alone will not determine the success of the PRS. Achieving the PRS goals will require strong Government commitment, policy reforms, concerted efforts to build capacity, vibrant citizen participation, and effective and efficient supporting arrangements with partners, alongside appropriate levels of financing. Thus the analysis of financing constraints described in this chapter should be considered in conjunction with the policy commitments and other changes described earlier in the PRS and the analysis of capacity constraints and risks described in the next two chapters.

\footnotetext{
60 As a result, the strategy document does contain some items for which there are no associated costs indicated. The total cost expressed in this chapter is best described as the cost for the PRS' highest priorities, not every action articulated.
} 


\subsection{Cost Estimates}

${ }^{5}$ Two basic approaches have shaped the costing exercise. First, the estimated cost of each activity has been derived using techniques that are fully consistent with established budgeting principles. This enables the PRS to be integrated as seamlessly as possible into the Government's existing budgeting processes. Second, the approach to the costing and budgeting exercise is iterative; the cost of each activity is based on the best readily available estimates with the expectation that they will be updated regularly as experience accumulates and new information emerges.

${ }^{6}$ The initial cost estimates included here for each activity are based on analysis conducted by each of the twenty four PRS Working Groups. Some Working Groups and Pillars had difficulty obtaining the data to fully cost their activities over the PRS period; however, the vast majority was able to locate data and worked to justify the assumptions made in calculating costs.

${ }^{7}$ Table 11.1 presents the detailed costs. The data are arranged by year and grouped by Pillar, including costs associated with relevant cross-cutting activities. Not surprisingly, the bulk of the identified costs are concentrated in Pillar 4, Infrastructure and Basic Services. These costs relate to health, education, roads and bridges, energy, and water and sanitation. These five sub-categories together account for more than $60 \%$ of the total cost of fully implementing the PRS. Many of the activities relate to repair, reconstruction, rehabilitation, new construction, and human capacity building.

${ }^{8}$ Several specific items warrant further discussion. One of the central themes of Liberia's PRS is that rebuilding the nation's road network is central to achieving almost all of the key goals of the PRS. Although the rates of return are high on building roads, roads are expensive to build and repair, especially since the road network was so badly damaged and neglected during the conflict. Similarly, the costs of rebuilding the electricity network are significant. The energy costs in the table do not include the costs associated with rehabilitating the Mt. Coffee hydroelectric facility, a potentially important project which is discussed in a text box below. As noted in Chapter Nine, the Government is explicitly seeking to encourage private sector investment in energy expansion, particularly through PPPs.

${ }^{9}$ The costs associated with rebuilding the education and health sectors are also significant. A substantial component of the education budget is directed towards the reconstruction of education facilities and the training of teachers and education administrators. The health sector requires a major commitment to the rehabilitation and restocking of health care facilities and the training of health professionals in order to expand and sustain the delivery of the BPHS throughout the country. 


\begin{tabular}{|c|c|c|c|c|c|}
\hline & FY 2008/2009 & FY $2009 / 2010$ & FY 2010/2011 & Total & $\begin{array}{l}\% \text { of PRS } \\
\text { Cost }\end{array}$ \\
\hline \multicolumn{6}{|l|}{ Pillar I : Peace and security } \\
\hline Subtotal & 106.6 & 75.1 & 70.7 & 252.4 & $15.66 \%$ \\
\hline \multicolumn{6}{|l|}{ Pillar II : Economic revitalization } \\
\hline Growth and Macro Framework & 11.8 & 9.8 & 6.9 & 28.5 & \\
\hline Poverty Diagnostics & 3.2 & 2.9 & 4.1 & 10.3 & \\
\hline Financial Services & 0.8 & 0.5 & 0.4 & 1.7 & \\
\hline Food and Agriculture & 13.4 & 13.6 & 11.7 & 38.7 & \\
\hline $\begin{array}{l}\text { Investment and State-Owned } \\
\text { Enterprises }\end{array}$ & 0.9 & 1.0 & 0.2 & 2.1 & \\
\hline Labor and Employment & 7.5 & 10.6 & 10.2 & 28.3 & \\
\hline $\begin{array}{l}\text { Trade, Export Promotion, and } \\
\text { Industrial Policy }\end{array}$ & 2.4 & 1.6 & 1.4 & 5.3 & \\
\hline Relevant Cross-Cutting & 8.2 & 9.1 & 9.0 & 26.3 & \\
\hline Subtotal & 48.2 & 48.9 & 44.0 & 141.1 & $8.75 \%$ \\
\hline \multicolumn{6}{|l|}{ Pillar III : Governance and rule of law } \\
\hline Reforms (ACC, LC, etc) & 2.6 & 1.0 & 1.4 & 4.9 & \\
\hline $\begin{array}{l}\text { Rule of Law - Infrastructure (courts, } \\
\text { offices, etc) }\end{array}$ & 22.0 & 11.8 & 13.1 & 46.9 & \\
\hline Rule of Law - Other & 22.1 & 22.7 & 18.1 & 62.9 & \\
\hline Civil Service Reform & 7.9 & 17.1 & 12.2 & 37.1 & \\
\hline Audits & 5.6 & 5.8 & 5.9 & 17.3 & \\
\hline $\begin{array}{l}\text { Decentralization - County and Local } \\
\text { Development }\end{array}$ & 6.7 & 12.3 & 15.6 & 34.6 & \\
\hline Relevant Cross-Cuttting & 7.7 & 6.1 & 6.6 & 20.1 & \\
\hline Subtotal & 74.6 & 76.7 & 72.8 & 224.1 & $13.90 \%$ \\
\hline \multicolumn{6}{|c|}{ Pillar IV : Infrastructure and basic services } \\
\hline Roads and Bridges & 86.3 & 142.2 & 129.4 & 357.9 & \\
\hline Education & 59.7 & 48.8 & 48.2 & 156.6 & \\
\hline Health & 39.9 & 39.9 & 39.9 & 119.6 & \\
\hline Water and Sanitation & 37.0 & 44.7 & 61.8 & 143.5 & \\
\hline Energy & 80.0 & 38.3 & 38.3 & 156.6 & \\
\hline Posts and Telecommunications & 5.2 & 6.1 & 6.8 & 18.0 & \\
\hline Transport & 7.1 & 7.1 & 7.1 & 21.2 & \\
\hline Other Infrastructure & 2.5 & 3.1 & 3.8 & 9.4 & \\
\hline Relevant Cross-Cutting & 3.2 & 4.9 & 3.4 & 11.5 & \\
\hline Subtotal & 320.8 & 335.1 & 338.5 & 994.5 & $61.69 \%$ \\
\hline TOTAL PRS COSTS & 550.2 & 535.8 & 526.0 & 1612.0 & $100.00 \%$ \\
\hline
\end{tabular}

61 Pillar I does not include costs associated with the UN peacekeeping force. The financial sector does not include costs associated with the recapitalization of the Central Bank of Liberia; the Government will explore ways to address this issue over time. This sector also does not include costs associated with the reimbursements of deposits from moribund financial institutions (e.g. ACDB, NHSB), although work will be done to examine this issue over the PRS period. 
${ }^{10}$ In Pillar II, the Growth and Macroeconomic Framework section includes significant expenditures to reform and modernize the Government's financial management and revenue systems and for modernization and temporary outsourcing of customs. Under Labor and Employment, a high priority is to establish several emergency employment programs to create jobs for ex-combatants, unemployed youth, and young women.

${ }^{11}$ In order to mainstream cross-cutting issues, it was important to ensure that the various Pillar agencies appropriately incorporated into their activities issues related to gender equity, environment, HIV and AIDS, peacebuilding, children and youth, and monitoring and evaluation, and that they remain committed to these issues to ensure regular monitoring and advocacy. Therefore the costs associated with cross-cutting issues are integrated into the relevant pillars, either directly into pillar activities (e.g. environmental safeguards for roads as part of roads \& bridges) or as cross-cutting costs under the pillar.

\section{Mt. Coffee Hydroelectric Facility}

Costing for energy needs does not include the cost of rehabilitating the Mt. Coffee hydroelectric facility. The potential electricity generating capacity of Liberia's St. Paul River including the Mt. Coffee dam, is estimated at $1000 \mathrm{MW}$. To develop this potential, the Government is considering establishing a St. Paul River Authority (SPRA) to greatly spur economic growth. SPRA will be a public-private partnership (PPP) fully managed by private sector participants as a national economic engine to produce power.

Prior to the civil conflict, Liberia had a total installed capacity of over $400 \mathrm{MW}$, a little over half of which was produced by private concessionaires. With the ongoing resumption of mining, the demand for power is already on the upswing, starting with ArcelorMittal's announced requirement of $185 \mathrm{MW}$. Therefore there is significant demand for a renewable and reliable hydropower source. Excess power from the project will also have an outlet for export earnings through the West Africa Power Pool (WAPP) to the growing markets of Nigeria, Ghana and Ivory Coast.

The liberalization of the power sector is happening simultaneously with the strategy formulation for hydropower development. In cooperation with the right private sector partners, Liberia can become the prime producer of environmentally friendly hydropower in the ECOWAS region.

\subsection{Government Financing}

${ }^{12}$ The second part of the costing framework is to derive the aggregate resource envelope. The first step is to estimate total revenues for the PRS period, which was done in Chapter Ten (Table 10.2), and is shown in Table 11.2. Although the Government is fully committed to achieving these revenue goals, they are based on the twin assumptions of robust economic growth and an increase in revenue as a share of GDP to 27 percent. ${ }^{62}$ Thus, they should be seen as an upper-end projection.

${ }^{13}$ Since the Government is presently committed to a cash budget, the revenue estimates are taken as the maximum levels of domestic expenditure. Some of the Government's expenditures are already directed towards PRS activities. However, some expenditure by the Legislature, the President's Office, the Ministry of Foreign Affairs, and certain other essential operations are not directly financing PRS activities. The financing scenario outlined here assumes that an increasing share of government revenues will go towards the Poverty Reduction Strategy in each fiscal year of implementation, building

62 The high revenue/GDP ratio may, however, also reflect an underestimation of GDP in the absence of complete national accounts data. See the text box on Real GDP Growth Assumptions in Chapter 10 for more information on the method of GDP calculation. 
from the current projection of just over $55 \%$ of GoL revenues going towards poverty reduction. ${ }^{63}$ Based on this calculus, government financing available for PRS activities is estimated to be US $\$ 510$ million for the three-year period.

Table 11.2: GoL Revenues for PRS, FY 2008/2009 through 2010/2011 (US\$ millions)

\begin{tabular}{|l|c|c|c|c|}
\hline & FY 2008/2009 & FY 2009/2010 & FY 2010/2011 & Total \\
\hline Total GoL Revenue & 240 & 272.9 & 329.8 & 824.7 \\
\hline \% of GoL Revenue for PRS & $55 \%$ & $60 \%$ & $65 \%$ & \\
\hline Government PRS Financing & 132 & 163.7 & 214.4 & $\mathbf{5 1 0 . 1}$ \\
\hline
\end{tabular}

Source: PRS Chapter 10; PRS Costing Team estimates

\subsection{Aggregate Costs and the Gross Financing Gap}

${ }^{14}$ Table 11.3 summarizes the costs and government resources available for PRS activities. The table indicates that after financing from the Government, there is a remaining gap of approximately US\$1.1 billion (about $70 \%$ of the total). A significant portion of this gap will be financed through existing donor commitments for ongoing activities. Unfortunately no comprehensive firm numbers of current partner commitments exist at this stage ${ }^{64}$ so a net financing gap cannot be calculated precisely. Nevertheless, current commitments clearly are less than the total financing gap, so additional resources - over and above currently committed funds - will be necessary to fully finance implementation of this poverty reduction strategy.

\section{Table 11.3: PRS Gross Financing Gap, FY 2008/2009 through 2010/2011 (US\$ millions)}

\begin{tabular}{|l|c|c|c|c|c|}
\hline & FY 2008/2009 & FY 2009/2010 & FY 2010/2011 & Total & \% of PRS Cost \\
\hline Total PRS Costs & 550.2 & 535.8 & 526 & 1,612 & $100 \%$ \\
\hline Government PRS Financing & 132 & 163.7 & 214.4 & 510.1 & $32 \%$ \\
\hline Gross PRS Gap & 418.2 & 372 & 311.6 & $\mathbf{1 , 1 0 1 . 9 0}$ & $68 \%$ \\
\hline
\end{tabular}

Source: Ministry of Finance, PRS Costing Exercise. Government financing are drawn from Table 11.2.

${ }^{15}$ Ultimately the financing gap must be closed, either through additional financing or by scaling back or re-phasing proposed PRS activities. On the financing side, one possibility could be further increases in Government revenue. However, as mentioned previously, the current revenue projections are based on the twin assumptions of rapid economic growth and a significant increase in the revenue/GDP ratio, meaning that a substantial additional increase in Government revenues is unlikely. A second option is financing from the private sector through PPPs, concession agreements to finance certain infrastructure, or other arrangements. The Government will be pursuing these options in appropriate PRS activities, but they are likely to be limited in scope during the three-year implementation period. A third option is increased support from the international community from current or new partners, either as budget

\footnotetext{
63 The estimate for current GoL financing towards the PRS is based on figures drawn from functional classifications in the FY 2007/2008 budget, and should be seen as extremely rough estimates. As GoL moves towards program budgeting, it will become increasingly easier to track the share of revenue going towards PRS implementation.

64 The Government will compile additional data and information from its partners in preparation for the partners' forum on the PRS around particular sectors (such as infrastructure) in order to get a fuller picture of the net gap (including already committed funds) and potential financing options.
} 
support or to finance specific projects and programs.

${ }^{16}$ The gross financing gap of approximately US $\$ 367$ million per year, to be financed through partner contributions and new private financing (including activities undertaken by private enterprises, such as concessionaires, in implementing projects in Liberia), exceeds the sums described in the macroeconomic framework in Chapter 10. Total grant financing from partners was estimated at US $\$ 230$ million in 2007; as such, a significant increase in partner and private sector financing is necessary to fully close the gap and ensure full implementation of the PRS.

${ }^{17}$ If additional financing is not found, then the Government will scale back some of the proposed activities. Some of the most important potentially unfunded (or under-funded) activities include:

- construction or repair of roads and bridges;

- emergency employment programs for ex-combatants, young adults, and women;

- extending the delivery of the basic package of health services (BPHS) throughout the country;

- rebuilding the education system;

- provision of water and sewage services;

- hiring and training police officers and building police stations; and

- construction of youth centers as safe spaces for rural youth to meet and learn.

${ }^{18}$ The Government hopes to secure additional funding for these critical activities in the coming months to ensure smooth and effective implementation of the PRS.

\subsection{Moving Forward}

${ }^{19}$ Since the Pillar Groups have carefully recorded the assumptions and references from which their estimates were derived, there is now a rich database with which to monitor the activities as they are implemented and to update the cost estimates as new information emerges. There is also now a core group of staff who understand the policy dimensions of the various Pillar and cross-cutting activities. At a broader level, the costing exercise has highlighted the importance of deeper institutional coordination among government agencies to make PRS costing a routine operation in preparation of the national budget.

${ }^{20}$ With the PRS now completed, the Government looks forward to discussing with its development partners how they will modify and adjust their strategies to ensure that they are fully aligned with PRS priorities. It also urges current and new partners to consider increased resource mobilization to ensure the PRS is fully implemented and achieves its important goals. 



\section{Part 3: \\ PRS Implementation}

\section{Chapter Twelve}

\section{Building Capacity}

\subsection{Introduction}

$T_{c}^{\mathrm{te}}$

he low capacity of Liberia's public and private institutions continues to be a constraint on

Government effectiveness and the economy as a whole. The combination over many years of political patronage and conflict has left Liberia with high numbers of unskilled workers with little technical or professional capacity to produce goods and deliver services. The human resource challenges faced by public institutions and private industry present both serious challenges to development and considerable opportunities for improvement in productivity over the PRS period.

${ }^{2}$ Liberia's ability to expand and develop the economy is hampered by limitations in the number of educated and skilled workers. Over the PRS period, natural resource-based sectors will drive growth, but their continued development will require a more robust, capable work force. As security conditions and basic services improve, members of the Diaspora may return and inject significant capacity within certain sectors, but the Government must proactively take steps to increase capacity through strategic interventions, including vocational training and adult education. Investments in primary, secondary and tertiary education will underpin medium-to-long-term capacity development as the next generation is equipped to participate in the global economy.

${ }^{3}$ Within the public sector, the Government made some advances to mitigate the effects of low capacity during the iPRS period through the Transfer of Knowledge through Expatriate Nationals (TOKTEN) program and other employment programs and through significant amounts of technical assistance, especially in the health sector. While these inputs and programs have assisted in meeting pressing needs, they are only part of the solution to the problem of building Liberia's capacity to independently deliver effective government administration and services.

${ }^{4}$ The first hurdle in dealing with this national lack of capacity is identifying personnel that are capable of addressing the problems. The Civil Service Agency (CSA) and other institutions which are trying to close the human capacity gap face the same capacity constraints and challenges as other ministries and agencies. To be successful, qualified Liberians from across the Government must be recruited to engage in and lead the process and maximize transfer of knowledge and skills through on-the-job training. Donor and civil society assistance has and will continue to play a central role in supporting this process. Reforming the civil service and building human capacity across public institutions are components of a broader public sector reform process, which will address structural and institutional inefficiencies. 
${ }^{5}$ As with any process in development, building broad-based capacity is a long-term endeavor. There are no quick fixes. The Government will develop a 10-year capacity building plan to organize national efforts and leverage support for Liberia's capacity development programs. This plan, to be completed in 2009, will articulate well-sequenced, strategic interventions to stimulate capacity development within the private and public sectors and to reform the civil service.

\subsection{Civil Service Reform}

${ }^{6}$ The civil service suffers from a particular lack of capacity, with current pay structures and other incentives not conducive to a productive and efficient civil service. The Government also faces an acute lack of human capacity with respect to analyzing, implementing and managing public sector policies and programs.

${ }^{7}$ In tandem with the broader efforts to reform Liberia's public sector, the Government is currently in the process of formulating a comprehensive civil service reform strategy to commence during the PRS period. The framework will guide and direct the Government's efforts aimed at reinventing the service from its current low productive status to a responsive, effective, and performance-oriented service needed to deliver improved services to people and achieve the Government's development goals. As described in Chapter Eight, the Government will seek to establish an environment conducive to high achievement and the participation and advancement of persons across different religions, ethnicities, and genders. The key components of this civil service reform strategy include:

- Right-sizing and restructuring the Civil Service: The Government is committed to establishing a leaner and more efficient and effective civil service and to removing duplications and overlaps in the organization of ministries and agencies. It will establish new organizational structures for ministries and agencies to better synchronize ministry mandates, functions and organizational design to improve work flow, coordination and productivity (See Chapter Eight.). It will rationalize staffing numbers to fit with the new functions and mandates of each ministry or agency, and develop descriptions of the functions of work units, specifications of key staff positions and job descriptions. The Government will consider complementary programs such as retraining and redeployment schemes, to facilitate the departure of surplus employees. One of the Government's key reform objectives is to depoliticize the civil service by reducing the layers of political appointees in ministries and agencies.

- Pay reform: Civil servant salaries are low, even after accounting for allowances and in-kind benefits, and are insufficient to attract, motivate, and retain experienced professionals. The low pay has served as an obstacle to properly disciplining employees, to maintaining work ethics and achieving appropriate levels of productivity. The Government will undertake comprehensive pay reform, taking into consideration issues such as external and internal equity, internal equity, private sector pay rates, and attracting and retaining persons whose market value is higher than public sector salary structures allow. It will consolidate allowances and salaries and monetize other in-kind benefits into salaries, both to benefit employees and treat them equitably, as well as to establish a more transparent compensation system and improve administrative efficiency.

- Pension reform: Pension reform is linked to and stands to benefit from pay reform. Low pension benefits are a disincentive to retirement from the civil service. Many employees remain in the service well past their productive years, adding to the already bloated staff levels. The Government will undertake reform of the pension system to ensure its sustainability, yet make it more attractive for retirees to vacate positions that can then be filled with more capable employees. It will streamline and rationalize the administration of pensions as part of the public sector pay reforms, and better define the roles of the Ministry of Finance, the National Social Security and Welfare Corporations, and the CSA to enhance pension administration. Moreover, it will develop the relevant structures and operational guidelines to ensure that retired civil servants are paid what is due to them in a decent, regular manner.

- Development of a human resources management information system: The Government will reform 
the human resources management information system in order to facilitate informed decisionmaking about personnel. The system will be robust, computerized and flexible, and designed to provide adequate information on all persons working in the service at any point in time. It will deploy a biometric personnel identification system for all public servants and officials and link it with the Integrated Financial Management Information System (IFMIS) at the Ministry of Finance to harmonize personnel information with payroll. Through this system, efforts will be made to remove any remaining "ghost workers" from the payroll and to establish the actual number of civil servants working for the Government.

\section{- Decentralization of government services:}

Decentralization is a long term process, and the civil service will move forward according to the timelines established in the national decentralization policy. Ultimately, ministries will function primarily as policy making and regulatory institutions, while sub-national government entities will be responsible for program implementation and decisions regarding employment of public servants. Capacity development strategies will consider the changing demands and responsibilities of public servants in Monrovia and the counties. During the PRS period, the Government will aim to begin to strengthen the capacities of county and district workers, and will consider providing incentives and improved benefits to attract and retain rural workers.

\section{- Performance management: The Government} will develop and commence a performance management system in order to make the civil service more performance- and results-oriented. It will support the installation of performance management systems to guide agencies, departments, work units and the employees that staff them. Establishing recognition and reward schemes will be an integral part of making these systems effective.

- Building Sustainable Human Capacity: Many Government employees lack the necessary skills to carry out their jobs, at least partially because of lack of training opportunities, lack of innovations in public sector management, and inadequate access to modern technologies. While short term programs such as the Senior Executive Service (SES, see below) are targeted at redressing the issue of low capacity in the civil service, it is essential to give serious attention to improving the skills and competencies of civil servants and

\section{The Liberian Diaspora}

The decades of conflict and economic collapse caused many skilled and educated Liberians to leave the country in search of a better life abroad. The resulting capacity deficit is a major impediment to the successful reform of public and private institutions. The Government is committed to developing incentives and creating the conditions for Diaspora Liberians to return home and contribute to the country's transformation.

The Diaspora has swelled to an estimated 450,000 persons, or nearly 12 percent of the Liberian population. Since the inauguration of President Ellen Johnson Sirleaf in 2006, some have returned home, and today play a critical role in reconstruction and development efforts in private enterprise, civil society, and public service.

This process has been facilitated in part through the Transfer of Knowledge through Expatriate Nationals (TOKTEN) and Senior Executive Service (SES) programs, which aim to bring skilled Liberians from home and abroad into government service. In a country where only 14.4 percent of public sector employees hold graduate degrees, the focus is to recruit doctors, engineers, scientists, economists, environmentalists, business executives and other highly skilled professionals. Over 50 professionals have already been recruited through these programs.

Dr. Robert Dennis, Chief Medical Officer at Monrovia's John F. Kennedy Memorial Hospital, provides a prime example of the strong contributions to capacity made by the Diaspora. Dr. Dennis left a position as Chief of Plastic Surgery and Vice Chair of the Surgery Department at Harvard University Hospital, and now applies his considerable expertise to leading all clinical operations at the nation's main Government hospital.

Expanding the efforts to infuse Liberia's institutions with skills and talent from the returning Diaspora is a key feature of the Government's reconstruction and development strategy during the PRS period. 
8 to infuse the civil service with more productive employees. To address this problem, the Government will establish training programs to increase the skills of workers.

The Government will also strengthen the Liberia Institute of Public Administration (LIPA) such that it can provide in-service training to the civil service. Efforts are underway to improve LIPA's capacity to meet the training challenges in the civil service, but more financial support will be required to enable LIPA to develop appropriate courses and recruit skilled trainers. It will also support the University of Liberia to develop programs that can adequately train a new generation of technical and managerial personnel to fill entry level positions.

\subsection{Building Capacity in Senior Management: SES and TOKTEN}

To fill gaps in capacity at the senior levels of the civil service in the near-term, the Government will continue to implement its Senior Executive Service (SES) program. This scheme aims to develop a new generation of public service leadership for change and will be aligned with and supportive of other ${ }^{10}$ national capacity building efforts.

Specifically, the SES aims to:

- attract and retain qualified professionals with requisite technical and managerial skills for strategic decision making and improved service delivery;

- inject into the civil service the "surge" capacity needed to build momentum and sustain the Government's reform and development agenda; and

- provide a platform for transforming the civil service into a more professional, effective and accountable institution of democratic governance.

The SES will consist of senior Liberian civil servants drawn from both the current service and from outside it, either in the private sector or from the Diaspora, merged into a unified group of managers demonstrating a set of core competencies and subject to high standards of performance. The SES Program is managed by the Civil Service Agency, which is responsible for all aspects of the Government's civil service reform agenda. It is overseen by a Project Implementation Committee that includes key imple-

${ }^{12}$ menting Ministries and principal donors.

Likewise, the Transfer of Knowledge through Expatriate Nationals (TOKTEN) program will continue to attract Liberians for short and medium-term technical assistance activities. TOKTEN facilitates the recruitment of professional expatriate nationals, as well as those locally available, to serve in key capacities in the Government and national institutions to ensure effectiveness and efficiency in public sector operations. In the short term, the program aims to repatriate Liberian nationals to support nation building through the revitalization of government institutions. In the long term, TOKTEN endeavors to ensure the sustainability of government operations through the availability of required human capacity in key institutions.

\section{${ }_{13} 12.4$ Building Capacity in the Education Sector}

Liberia's education sector is essential to building the human capital required to transform and develop the nation. However, the education sector faces many challenges: there are insufficient numbers of trained, qualified and motivated teachers and faculty; enrolment, attendance and completion rates are low, particularly among girls; facilities and basic equipment are in poor condition or scarce supply; and the sector suffers from weak management and governance. These challenges are significant, but must be overcome to provide broad-based and sustainable improvements in the capacity of the Liberian

${ }^{14}$ people, both of current and future generations.

To address capacity issues during the PRS period, the Government will take measures to improve 
access to and the quality of schools and universities, with a particular emphasis on promoting Universal Primary Education. In addition to targeting these traditional education systems, the Government will ${ }^{15}$ also address the needs of the current working-age population through vocational training programs.

As described in Chapter Nine, the Government's reform agenda with respect to education will focus on the following broad objectives:

- strengthening school curricula;

- improving access to quality, safe and hygienic schools;

- recruiting and training qualified teachers;

- improving learning achievement and school completion rates;

- strengthening the quality and accessibility of skills and vocational training;

- improving the quality of tertiary education; and

${ }^{16}$ - strengthening the overall governance, management and financial basis of the education system.

Strengthening Liberia's primary, secondary, and tertiary education systems is crucial to building the capacity of Liberia's workforce and governance structures over the long term. To complement these efforts, it is critical to also strengthen vocational and skills training to build capacity and enhance the skills of Liberian workers over the short and medium terms. Building workers' skills is also important for diversification and the realization of Liberia's growth potential as described in Chapters Four and Seven. Towards this end, the Government plans to refurbish and equip four existing multi-lateral high schools and two existing vocational and technical institutions. The focus of programs at these high schools and institutions will be training for fields for which there is demand for workers, including such fields as plumbing, auto mechanics, and construction and computer services.

\section{Building Capacity in the Health Sector}

Improving health underpins all aspects of development. A healthy population is capable of engaging in productive activities within the public and private domains, driving economic growth and contributing to the transformation of the nation. As in the education sector, capacity constraints plague the health system. Bolstering the capacity of health workers and managers is central to improving health service delivery in Liberia. As part of the National Health Plan's human resources strategy, the Government plans to:

- Develop personnel who are competent to respond appropriately to care needs, through efficient education and training programs. The Government aims to enhance the ability of health professionals to deliver approved health service packages at various levels of health care, and to better coordinate health personnel education programs. The head of the human resource unit of the Ministry of Health will establish a coordinating education committee including representatives of universities, Nursing Colleges, the Ministry of Education, health service providers, nongovernmental organizations and the public. Health care training and education programs will include the planning, implementation, monitoring, evaluation, review, and coordination of all health personnel education programs.

- Develop and strengthen curricula for in-service and pre-service training: The Government will restructure primary health care training curricula to reflect community needs more accurately. Teaching will place greater emphasis on community empowerment and intervention programs that are results-driven. 
- Promote equitable distribution of health personnel: The Government will aim to fill new and vacant posts at all health service delivery levels, targeting core cadres. Counties will be responsible for recruiting and placing health workers at the appropriate facility level within the county. The Government will reallocate budgets and personnel to under-utilized and underserved areas to address geographic and skills imbalances, and will develop a policy to guide mobility of personnel between positions in the district, county and national health services.

- Initiate a rapid hire plan (RHP): The Government is interested in implementing a rapid hire plan as an alternative for improving equity in worker distribution. Such a plan is a fast-track stop-gap measure that seeks to mobilize and bring on board additional health workers to combat such priority diseases as malaria, diarrheal diseases, HIV and AIDS, and TB. The Government will explore options, including the SES program, to attract qualified health workers from the Diaspora. It will also explore options to streamline the hiring process to facilitate rapid hiring and placement. 


\section{Monitoring and Evaluation}

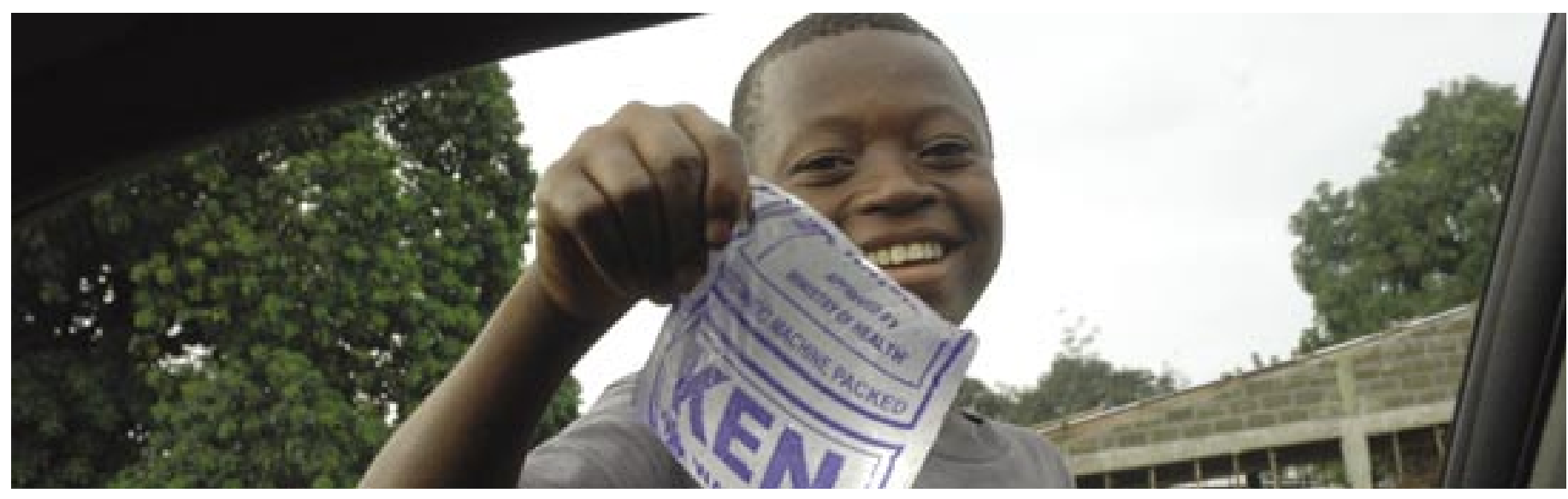

\subsection{Introduction}

${ }^{1}$ The primary objective of the Monitoring and Evaluation (M\&E) Framework is to provide a picture of Liberia's progress toward PRS goals by tracking key outcome and output indicators. In addition, the more frequent monitoring of PRS deliverables will enable the Government and its partners, through the Cabinet and LRDC Steering Committee, to act swiftly to make adjustments to programs and activities as needed. This type of robust monitoring will help to assess and ensure the inclusive and sustainable achievement of the goals and strategic objectives for poverty reduction in this PRS.

${ }^{2}$ This chapter provides a framework to monitor Liberia's progress towards its key goals of establishing a stable and secure environment and generating rapid, inclusive, and sustainable growth and development. This will be accomplished by tracking progress in a number of key areas, as outlined in the PRS indicator matrix below. The framework focuses on outcomes and impact, and is complementary to other monitoring activities, such as the tracking by each Pillar on the progress of the deliverables articulated in their action matrices and reporting of partner actions, inputs, and funding.

${ }^{3}$ PRS indicators were selected through the participation of PRS working groups, taking into account the limited statistical and information base and capacity constraints. An M\&E collection and reporting architecture was then developed to allow for efficient collection of these data. The capacity for more efficient collection will be built over the PRS period. The Secretariat of the Liberia Reconstruction and Development Committee (LRDC) will have overall responsibility for monitoring PRS implementation, while the Liberian Institute for Statistics and Geolnformation Services (LISGIS) will play the central data collection and vetting role crucial to the PRS. Both these institutions will aim to strengthen and expand their capacity for effective monitoring of progress during the PRS implementation period.

${ }^{4}$ While the primary goal of the M\&E framework articulated in this chapter is to monitor the impact of the PRS, PRS deliverables will also be tracked to ensure implementation is proceeding smoothly. In addition, LRDC will monitor financial flows from the Government of Liberia and its development partners in an effort to get a better overall picture of how the Government's inputs and external support are being used. Efforts will also be undertaken to improve the quality of county-level data over the next three years.

\subsection{Context}

${ }^{5}$ The effective tracking of progress under the PRS is crucial for its successful implementation. Building the capacity, systems, and databases necessary for effective tracking represents a substantial chal- 
lenge given Liberia's recent history. During the war, Liberia's statistical system all but ceased to function. The population census was more than 20 years out of date, economic statistics were extremely limited and restricted to Monrovia, and routine data systems in service delivery were virtually nonexistent. Hence, there were very little data available to inform the drafting of the iPRS.

${ }^{6}$ From this disadvantaged starting position, the Government moved into the 2006-2007 iPRS period by beginning to redevelop the country's statistical system in part to prepare the poverty diagnostics to serve as the basis for this full PRS (see Chapter Three). All statistical series, ranging from health to education and economic data, required resuscitation. One significant source of assistance in this effort was the fact that there were a number of data collection operations being conducted by humanitarian agencies; most extensively by the OCHA Humanitarian Information Centre (HIC), which has since transitioned into the UNDP/GoL National Information Management Center (NIMAC) project.

${ }^{7}$ A number of important surveys were conducted by LISGIS and other line ministries and agencies with the support of development partners during the iPRS implementation period, much improving the overall data picture:

- the Core Welfare Indicators Questionnaire (CWIQ) survey, which provided benchmark data for the PRS on income/consumption poverty, public access to basic services, and living conditions;

- the Demographic and Health Survey (DHS);

- the Comprehensive Food Security and Nutrition Survey (CFNS), which provided consumption data for rural households;

- a Participatory Poverty Assessment (PPA), which provided information on the perceptions of poverty in Liberia and helped to define where the poor are physically concentrated and the factors that perpetuate their conditions.

${ }^{8}$ Additionally, Liberia is now conducting its first national census in over 20 years. This will create new sets of validated multi-sectoral data and statistical series.

${ }^{9}$ Despite these recent efforts, substantial challenges remain in developing a national M\&E system. In particular, the capacity of the statistics system needs to be greatly strengthened, alongside the capacity of the LRDC to manage the process and conduct the analyses necessary to monitor PRS progress. Staff from ministries and agencies at the national and county levels will face vastly increased responsibilities in collecting, gathering and analyzing data and managing the delivery of key outcomes and outputs. The scope for collecting data on a regular basis remains extremely limited, with significant capacity constraints and, in many critical areas, poor or absent baseline indicators. These challenges underscore the importance of selecting a limited number of key indicators for monitoring the impact of the PRS.

\subsection{Indicators}

${ }^{10}$ The PRS M\&E system will focus on tracking impact as well as a variety of outputs from each Pillar. The framework described here will be complementary to other reporting mechanisms, such as the county-based reporting system supporting periodic reporting by Pillar Groups of their progress on specific actions and deliverables (or outputs, as they are referred to in this chapter) and the system being developed by the LRDC Secretariat for regular reporting of partner activities, inputs, and financing.

${ }^{11}$ For example, extreme poverty now stands at $48 \%$, and at the end of the PRS period, the Government targets a drop of nearly $10 \%$, to $44 \%$. The Government currently scores a 2.1 (of 10) on Transparency International's perception of corruption index and the target is a score of 4.0 at the end of the PRS period. Child mortality targets a drop of $15 \%$ (to 94/1000), and maternal mortality a $10 \%$ reduction (to 895/100,000). The various ministries and agencies have been assigned responsibility for providing the 
${ }^{12}$ Indicator selection was made through a process of stakeholder consultations led by the M\&E working group chaired by LISGIS and the LRDC Secretariat. Line ministries and agencies, civil society representatives and partners worked through their respective Pillar structures to develop Pillar Indicator Matrices.

${ }^{13}$ Baseline data have been generated for most PRS indicators, drawing where possible on existing data sources such as the recently completed CWIQ and DHS. In some instances, baseline data are not yet available, but the responsible agencies are committed to ensuring that the baselines are established as soon as possible.

${ }^{14}$ The main source of quantitative data will be line ministries and agencies. The CWIQ and the DHS will be the main sources of statistical data for PRS M\&E. The two surveys will be conducted by LISGIS over a three-year cycle. A simple version of the CWIQ may be conducted on a yearly basis, depending on resource and capacity availability. Other data sources will be socio-economic statistics compiled from regular administrative records in line ministries and agencies such as macroeconomic aggregates from the Central Bank, national accounts, education and labor statistics. Other line ministry surveys will also provide valuable information to complement the CWIQ and DHS. The National Population and Housing Census will also serve as a key source of data.

${ }^{15}$ All national statistics will be fed into the Liberialnfo database, and capacity will be developed to publish this online. Qualitative data will be obtained through further Participatory Poverty Assessments (PPAs), which solicit the views of communities through focus group discussions on the implementation of community projects and programs.

\subsection{Institutional Framework for Monitoring Impact}

${ }^{16}$ The LRDC Secretariat will be the key institution responsible for reporting on M\&E. This will involve consolidating the M\&E outputs and outcomes at the national level in close collaboration with LISGIS to ensure the quality and consistency of the data and statistics. The LRDC Secretariat, working in tandem with LISGIS, will produce annual reports on progress towards each of the indicators for review by the Pillars, the Cabinet, and the LRDC Steering Committee. This information will be published as part of an Annual National PRS Progress Report for public dissemination and discussion. To the maximum extent possible, these reports will detail indicators by gender, age, and county, extracting the relevant information from the reports generated by line ministries and agencies. There will be a mid-term evaluation of the PRS as well as a full evaluation of the strategy in 2011 at the conclusion of the implementation period.

${ }^{17}$ National surveys will be coordinated and in some cases conducted by LISGIS in line with its mandate. To complement these surveys, individual line ministries and agencies will provide other PRS relevant data. Some information will flow from the counties and will be aggregated at the national level. Survey reports by international organizations such as Transparency International will be used to supplement the national data collection effort.

${ }^{18}$ Most data will originate within a given line ministry at either the local or national level (see Figure 13.1 below). LISGIS will then be responsible for ensuring the quality of the data and will eventually forward vetted national data to the LRDC Secretariat. The LRDC Secretariat will share data with the relevant Pillars and produce a National PRS Progress Report annually, which will be broadly distributed throughout Liberia and made available on the internet through a dedicated GoL website.

${ }^{19}$ As Liberia moves towards decentralizing political authority, it is becoming increasingly important for county officials to have quality data at their disposal. This will begin during the PRS period through the generation of county-by-county reports based on county-disaggregated data emerging from line ministries and LISGIS survey instruments. This will be a collaborative effort of the LRDC Secretariat and LISGIS, with support from the UN's county-based Information Management Offices (IMOs), which will eventually evolve into County Statistics Units (CSUs). 
Figure 13.1: Flow of M\&E Data

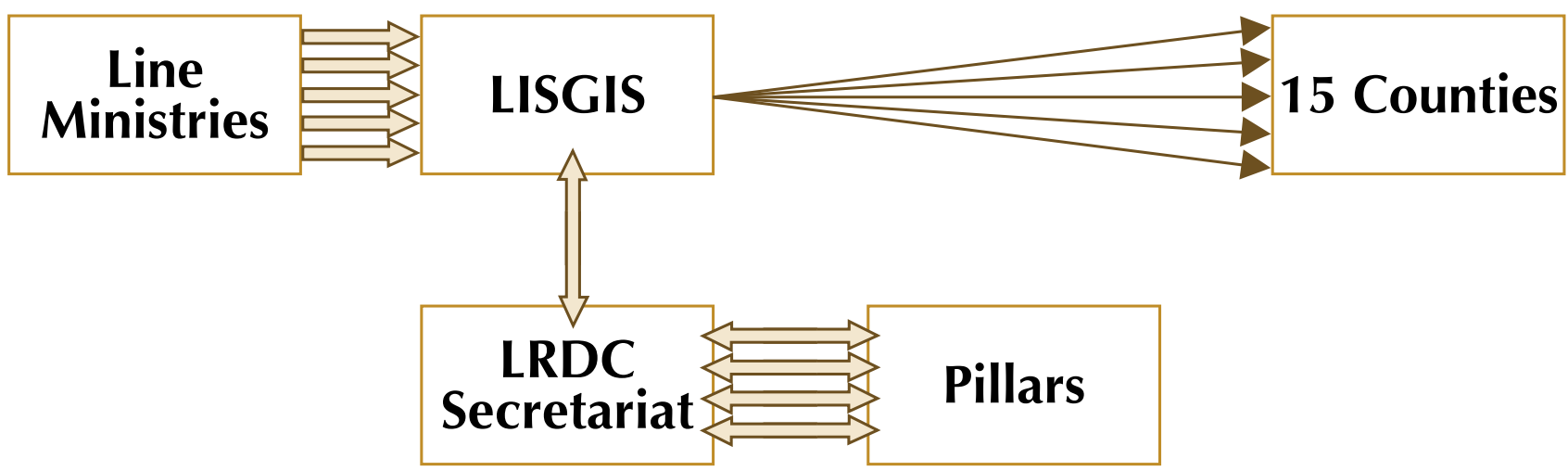

$\longrightarrow=$ National data

$\longrightarrow=$ County disaggregated data

\subsection{Monitoring Deliverables}

${ }^{21}$ Sections 13.3 and 13.4 described the indicators and institutional framework that will be used to monitor the impact of the PRS. This section explains an additional type of monitoring that will be employed during the three year period: regular reports on PRS deliverables that will allow the Government and its partners through the Cabinet and LRDC Steering Committee to act swiftly to make adjustments to programs and activities when necessary.

\subsubsection{Purpose}

${ }^{22}$ Frequent reporting on deliverables - in contrast to monitoring the broader impact of the PRS - will provide key government decision-makers the opportunity to monitor the progress of programs on a far more regular basis. Such reports will focus on the challenges of implementation of key national deliverables. This category of reporting is necessary to ensure a more frequent feedback loop to allow for the modification of programs or removal of bottlenecks throughout the implementation period.

\subsubsection{Reporting Structure for Monitoring Deliverables}

${ }^{23}$ The method of reporting on deliverables will vary depending on the nature of the action being monitored. For actions that occur at the national level - such as the implementation of a new National Investment Policy - reports on deliverables will be channeled through the national Pillar structure. Pillars will report on implementation challenges, as necessary, to the LRDC Steering Committee.

${ }^{24}$ At the county level, program- and project-level M\&E reporting will originate principally from line ministry officers (see Figure 13.2 below). Line ministries at the county level will share their reports on project deliverables with the Office of the County Superintendent, in addition to their existing reporting relationship within their respective ministries. The County Superintendent's Office will share information at county level Pillar meetings, where progress will be tracked and any actions required for implementation will be discussed and reported, as necessary, to the County Development Steering Committee (CDSC). The CDSC will review progress across all pillars and forward required actions for implementation to the LRDC Secretariat. The county-level structures mentioned here are discussed further in Section 13.7. 


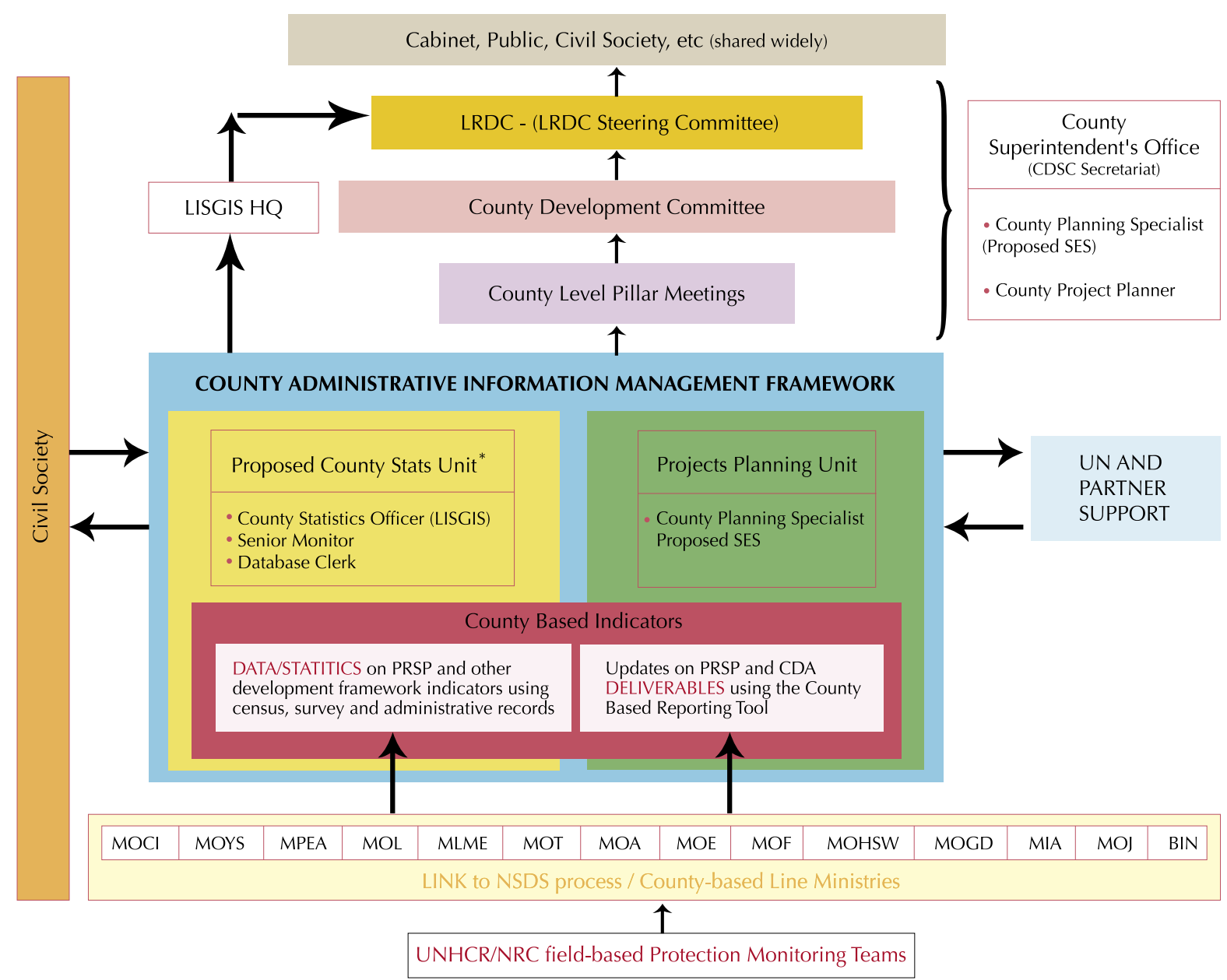

25 *Although just two County Statistics Units (CSUs) have been established to date (currently known as Information Management Offices or IMOs), the Field Supervisors, Senior Monitors and Database Clerks who will comprise these offices are already working in similar capacities in their respective counties. Field Supervisors are currently serving as data collection supervisors for UNHCR and the Norwegian Refugee Council (NRC) in each county. LISGIS will soon deploy County Statistics Officers to these Units in coordination with UNHCR/NRC and UNDP/NIMAC. Arrangements are being made between LISGIS and these partners to have the Senior Monitor and the Database Clerk (both NRC staff in the IMOs) to transition into LISGIS and to be an integral part of the data collection and management team within the county. Also, the Field Supervisor (currently in the IMO) will transition into supporting the Project Planning Unit within the County Superintendent's Office. This is envisaged to happen as soon as the infrastructure for these CSUs is ready. Section 13.7 discusses these issues in greater detail.

\subsection{Strengthening the Foundation for Future Analyses}

\subsubsection{LRDC}

${ }^{26}$ To successfully monitor Liberia's progress towards its key PRS goals, the M\&E capacity of the LRDC Secretariat must be significantly strengthened. Currently, the Secretariat manages the process of information flow between the four Pillars and the Steering Committee. The Secretariat is now in the process of building systems to better report on partner activities and inputs. It will require additional staffing and other assistance to build the necessary capacity to compile key information, analyze data, and generate the critical annual reports needed to monitor PRS progress. 


\section{The National Strategy for the Development of Statistics (NSDS)}

The National Strategy for the Development of Statistics (NSDS) establishes a plan to create a coordinated and efficient statistical system in Liberia by 2012. The draft of this soon-to-be-completed document presents five long-term strategic objectives:

1) Make statistics relevant to national and local development;

2) Develop an efficient capacity building plan for the Liberia national statistical system;

3) Develop a coordinated, harmonized and effective national statistical system;

4) Ensure adoption and consistent use of relevant statistical methods and standards; and

5) Develop and manage an efficient information sharing system.

The NSDS is a framework for collecting, managing, and coordinating the dissemination of accurate and relevant statistics across all sectors toward the implementation of the PRS. Implementation of the NSDS is expected during 2008-2012.

Within the objectives of the NSDS, an extensive list of concrete actions is proposed to respond to the current challenges within the Liberian statistical system. This includes sector specific actions such as plans to conduct quarterly nationwide surveys on transportation and developing a legal framework for agriculture sector statistical activities. There are proposals to upgrade the human capacity of the statistics system through measures such as upgrading the statistics program at the University of Liberia and short and long term training opportunities for LISGIS staff. The strategy also plans outreach efforts including meetings with the Legislature and a broader statistical awareness and education campaign.

\subsubsection{LISGIS}

${ }^{27}$ Current LISGIS capacity for the required collection, analysis, and standardization of data is limited. Strengthening LISGIS will enable the organization to fulfill its critical mandate of data collection, analysis and dissemination, and ensure that a strong statistical system will be in place as Liberia's development partners begin to phase out their role. To address the capacity challenges of LISGIS, the UNDP/ NIMAC project is presently implementing an exit strategy in which it will transition functions, staff, resources and assets into LISGIS in a coordinated and sustainable manner. The successful completion of this process will see LISGIS' capacity strengthened in a relatively short period. In addition, a UNHCR/NRC Protection monitoring team, which has provided data collection support to the recently completed Establishment Census, PPA and Population Census, will be available as a resource during the PRS period. Finally, a National Strategy for the Development of Statistics (NSDS) is being finalized to provide a comprehensive framework for the collection, processing and standardization of statistical data for the Liberia National Statistical System (See below.).

\subsubsection{Line Ministries}

${ }^{28}$ The accurate and timely collection of data by line ministries is crucial to the success of the monitoring and evaluation of the PRS, and has historically been a weakness of the statistical system. Significant training and capacity building of the line ministry staff in data collection, collation, analysis and standardization at national and sub-national levels will be undertaken to strengthen reporting. The strengthened institutional links between GOL ministries and LISGIS are expected to contribute positively to the functioning of the M\&E system by ensuring that data are collected consistently, and are credible, accessible, and published in a timely manner. 
${ }^{29}$ Much of this has been articulated in the NSDS, which is expected to systematize and bring greater coherence to the design, collection and production of statistics in the country.

\subsection{Building County-Level M\&E Structures}

${ }^{30}$ Over the PRS period, there will be an effort to expand and strengthen the county-level M\&E institutional framework. The County Administrative Information Management Framework - comprised of County Statistics Units (CSUs) and Project Planning Units, which will be equipped with IT equipment (computers, printers, etc.) and internet access - will be crucial in assisting County governance structures with compiling and sharing information. As of the completion of this document, CSUs (currently known as Information Management Offices or IMOs) are fully functioning in two counties. Seven more are scheduled to be fully operational by June 2008 and all 15 counties are slated to have CSUs by the end of 2008. The infrastructure for these CSUs, including offices, computers, and staffing has funding through December 2008. Hence, for 2009 and beyond, it will be necessary to identify funding for IMO implementation to ensure the continued operation of the CSUs. LISGIS has planned a two-phased decentralization strategy. Initially it will move into seven existing IMOs and later transition into the remaining eight counties. NIMAC, in coordination with UNHCR and LISGIS, is finalising a funding strategy to support the staffing component of the initial seven CSUs in 2009.

${ }^{31}$ County Development Steering Committees (CDSCs) will serve as the LRDC Steering Committee on the County level, tracking local PRS implementation and reporting significant issues back to the LRDC Steering Committee. CDSCs are in the process of being established and there will be a need to expand information management capacity at this level. UNDP has committed to assisting on several fronts such as with the development of reporting templates for CDSC use. Additionally, UNDP will be offering capacity support to the Project Planner and more general administrative support to Superintendents' offices.

\section{PRS Priority Action Matrix - Monitoring and Evaluation}

Issue

Priority Interventions

Delivery Date

Lead Ministry

I Agency

Goal: To effectively monitor the implementation of the PRS and regularly present progress reports that can lay the basis for planning decisions.

Strategic objective 1: Ensure that data are collected to track the selected outcome and output indicators

CWIQ, DHS and PPA $\quad$ Conduct annual CWIQs (household module) if adequate provided baseline data. Follow-up evaluations will be needed to measure progress.

\begin{tabular}{|l|c|c|}
\hline $\begin{array}{l}\text { Conduct annual CWIQs (household module) if adequate } \\
\text { resources are mobilized }\end{array}$ & $\begin{array}{c}\text { June 2009, 2010, } \\
2011\end{array}$ & LISGIS \\
\hline $\begin{array}{l}\text { Conduct a full DHS and household expenditure review } \\
\text { after } 3 \text { years. }\end{array}$ & June 2011 & LISGIS \\
\hline $\begin{array}{l}\text { Conduct periodic Participatory Poverty Assessments } \\
\text { (PPA). }\end{array}$ & Periodic & LISGIS \\
\hline $\begin{array}{l}\text { Collate and compile other socio-economic statistics from } \\
\text { administrative records. }\end{array}$ & Periodic \\
\hline $\begin{array}{l}\text { Conduct surveys on other relevant socio-economic indica- } \\
\text { tors. }\end{array}$ & Line Ministries \\
\hline $\begin{array}{l}\text { Work closely with line ministries to ensure coordination of } \\
\text { data collection for selected PRS outcome indicators. }\end{array}$ & $\begin{array}{c}\text { June 2009, 2010, } \\
2011\end{array}$ & LISGIS, LRDC \\
\hline
\end{tabular}




\section{Strategic objective 2: Establish a national M\&E structure}

Currently, line ministries report on an ad hoc basis, data collection is not systematic, and national indicators are not standardized.
Conduct workshops to clarify county based and national reporting responsibilities of Line Ministries, LRDC and LISGIS, in a written and signed output document agreed to by all Line Ministries, LRDC and LISGIS.

Ensure PRS monitoring is periodically addressed during LRDC pillar meetings, and reflection of the discussion in the minutes.

Equip and strengthen the staffing levels within the M\&E Secretariat in LRDC

Begin producing quarterly and annual national PRS progress reports on deliverables, selected indicators and statistics (including updating of Liberialnfo).

Ensure that the recommendations of the National Statistical Development Strategy for Liberia are mainstreamed into the PRS implementation.

Strategic objective 3: Regularly report on the implementation of national deliverables at the county level and make adjustments to programs and activities when necessary

County M\&E structures are weak, and data from the line ministries is not shared regularly with county authorities. Only 2 out of 15 counties have functioning CSUs.
Establish policy framework for information sharing by Line Ministries at county level.

Establish and equip County Stats Units (CSUs) with a LISGIS County Statistics Officer in place in 7 Counties initially and in the rest of the counties within the first half of the PRS period.

Finalize County-Based Reporting template for tracking of deliverables at the county level.

Conduct Training in all 15 counties to roll out the CountyBased Reporting system among all relevant county authorities.

Institute pillar structure at county level and establish regular county-level pillar meetings.

Begin producing and disseminating quarterly progress reports in all counties.

Ensure county deliverables are discussed at LRDC

Steering Committee and Cabinet meetings

\begin{tabular}{c|c|}
\hline August 2008 & LRDC, LISGIS \\
\hline July 2008 & LRDC \\
\hline September 2008 & LRDC \\
\hline June 2008 & $\begin{array}{c}\text { LRDC, M\&E } \\
\text { Secretariat }\end{array}$ \\
\hline July 2008 & LISGIS, MPEA \\
\hline
\end{tabular}

\begin{tabular}{|c|c|}
\hline July 2008 & LISGIS, LRDC \\
\hline July 2008 & MIA, LISGIS \\
\hline April 2008 & $\begin{array}{l}\text { LRDC, } \\
\text { LISGIS, MIA }\end{array}$ \\
\hline April-June 2008 & $\begin{array}{l}\text { LRDC, } \\
\text { LISGIS, MIA }\end{array}$ \\
\hline May 2008 & LRDC, MIA \\
\hline July 2009 & MIA \\
\hline July 2008 & LRDC \\
\hline
\end{tabular}

\section{Strategic objective 4: Build human capacity within statistics and M\&E}

Current government capacity for statistical data compilation and processing is low. Less than $10 \%$ of staff in statistical agencies has statistics training.
Develop an in-service statistical training program for junior- and mid-level statistical staff within LISGIS and Line Ministries and train at least 100 staff over 3 years.

Conduct annual trainings for county officials and countybased ministry staff on data collection and analysis (train at least 10 people per county, and conduct refresher trainings on an annual basis).

Develop a statistics degree program at University Liberia in order to begin training a new generation of professional statisticians.

\begin{tabular}{|c|c|c|} 
& Progressive & LISGIS, UL \\
\hline September 2008, & LISGIS, UL \\
2009,2010 & \\
\hline al & July 2009 & LISGIS, UL \\
\hline
\end{tabular}


Note: with reference to the indicators below marked To Be Determined (TBD), though no data currently exist to establish either a baseline and/or target for these indicators, the aim is to begin to collect this data during the PRS period. Once available, a baseline will be entered into an updated M\&E indicators matrix and a target will be identified in collaboration with the relevant Working Group and Pillar.

"End of PRS Period" connotes June 2011 unless otherwise indicated.

\begin{tabular}{|c|c|c|c|c|c|c|c|}
\hline Indicator & Type & Baseline & Target & $\begin{array}{l}\text { Target } \\
\text { Date65 }\end{array}$ & $\begin{array}{l}\text { Source of } \\
\text { Verification }\end{array}$ & $\begin{array}{l}\text { Lead } \\
\text { Ministryl } \\
\text { Agency }\end{array}$ & $\begin{array}{c}\text { MDG } \\
\text { Related? }\end{array}$ \\
\hline \multicolumn{8}{|c|}{ Pillar I: Security } \\
\hline $\begin{array}{l}\text { Annual NSSRL- } \\
\text { IM benchmarks } \\
\text { achieved }\end{array}$ & Outcome & $\begin{array}{l}\text { National } \\
\text { Security } \\
\text { Threat } \\
\text { Assessment }\end{array}$ & $\begin{array}{l}\text { Achieve all bench- } \\
\text { marks annually }\end{array}$ & Annual & $\begin{array}{l}\text { NSSRLAnnual } \\
\text { Validation } \\
\text { Report }\end{array}$ & MoD & - \\
\hline $\begin{array}{l}\text { Percent of the popu- } \\
\text { lation that perceives } \\
\text { the security situation } \\
\text { to be better than in } \\
\text { the previous year66 }\end{array}$ & Outcome & $50 \%$ & $60 \%$ each year & Annual & CWIQ & MoD, MoJ & - \\
\hline $\begin{array}{l}\text { Police:population } \\
\text { ratio67 (Population } \\
\text { assumed at } \\
\text { CWIQ estimate of } \\
2,705,385 \text { ) }\end{array}$ & Output & $1: 775$ & $1: 700$ & $\begin{array}{l}\text { End of } \\
\text { PRS } \\
\text { Period }\end{array}$ & $\begin{array}{l}\text { LNP Quarterly/ } \\
\text { Annual Report }\end{array}$ & LNP & - \\
\hline $\begin{array}{l}\text { Ratio of arrests } \\
\text { to reported major/ } \\
\text { violent crime }\end{array}$ & Outcome & $1: 1.79$ & $1: 1$ & $\begin{array}{l}\text { End of } \\
\text { PRS } \\
\text { Period }\end{array}$ & $\begin{array}{l}\text { LNP Quarterly/ } \\
\text { Annual Report }\end{array}$ & LNP & - \\
\hline $\begin{array}{l}\text { Number of fully } \\
\text { staffed BIN key bor- } \\
\text { der posts }\end{array}$ & Output & 18 & 36 & $\begin{array}{l}\text { End of } \\
\text { PRS } \\
\text { Period }\end{array}$ & $\begin{array}{l}\text { NSSRL- } \\
\text { IM Annual } \\
\text { Validation } \\
\text { Report }\end{array}$ & BIN & - \\
\hline \multicolumn{8}{|c|}{ Pillar II: Economic Revitalization } \\
\hline \multicolumn{8}{|l|}{ Poverty } \\
\hline $\begin{array}{l}\text { Percent of popula- } \\
\text { tion below national } \\
\text { poverty line } 68\end{array}$ & Outcome & $64 \%$ & $60 \%$ & $\begin{array}{l}\text { End of } \\
\text { PRS } \\
\text { Period }\end{array}$ & CWIQ & LISGIS & MDG 1 \\
\hline $\begin{array}{l}\text { Incidence of extreme } \\
\text { poverty69 }\end{array}$ & Outcome & $48 \%$ & $44 \%$ & $\begin{array}{l}\text { End of } \\
\text { PRS } \\
\text { Period }\end{array}$ & CWIQ & LISGIS & MDG 1 \\
\hline \multicolumn{8}{|c|}{ Growth and Macroeconomic Framework } \\
\hline Real GDP (USD) & Outcome & 195.2 & $\begin{array}{l}\text { 2008: } 775.2 \\
\text { 2009: } 867.5 \\
\text { 2010: } 999.7 \\
\text { 2011: } 1175.3\end{array}$ & Annual & $\begin{array}{l}\text { Surveys } \\
\text { ("National } \\
\text { Accounts" in } \\
\text { the future) }\end{array}$ & CBL & MDG 8 \\
\hline $\begin{array}{l}\text { Export of goods, } \\
\text { f.o.b. (Millions of } \\
\text { USD) }\end{array}$ & Output & 2007: 227 & $\begin{array}{l}\text { 2008: } 333 \\
\text { 2009: } 498 \\
\text { 2010: } 760 \\
\text { 2011: } 1027 \\
\end{array}$ & Annual & $\begin{array}{l}\text { Balance of } \\
\text { Payments }\end{array}$ & CBL & MDG 8 \\
\hline $\begin{array}{l}\text { Foreign Direct } \\
\text { Investment (Millions } \\
\text { of USD) }\end{array}$ & Output & 2007: 120 & $\begin{array}{l}\text { 2008: } 397 \\
\text { 2009: } 407 \\
\text { 2010: } 339 \\
\text { 2011: } 339\end{array}$ & Annual & $\begin{array}{l}\text { Balance of } \\
\text { Payments }\end{array}$ & $\mathrm{CBL}$ & - \\
\hline
\end{tabular}

\footnotetext{
65 Anticipated date for achievement of target.

66 This indicator will also be tracked on a disaggregated basis by sex.

67 This indicator will also be tracked on a disaggregated basis by county and number of female officers.

68 This indicator will also be tracked on a disaggregated basis by age of the individual, female/male head of household, and urban/rural.

69 This indicator will also be tracked on a disaggregated basis by age of the individual, female/male head of household, and urban/rural.
} 


\begin{tabular}{|c|c|c|c|c|c|c|c|}
\hline $\begin{array}{l}\text { Consumer Price } \\
\text { Index (\% change) }\end{array}$ & Outcome & $9 \%$ & $\begin{array}{l}\text { 2008: } 10.6 \% \\
\text { 2009: } 9.0 \% \\
\text { 2010: } 8.0 \% \\
\text { 2011: } 7.0 \%\end{array}$ & Annual & $\begin{array}{l}\text { Harmonized } \\
\text { Consumer } \\
\text { Price Index } \\
\text { (HCPI) } \\
\end{array}$ & CBL & - \\
\hline \multicolumn{8}{|l|}{ Agriculture } \\
\hline $\begin{array}{l}\text { Volume of agricul- } \\
\text { tural production } \\
\text { (\% growth), disag- } \\
\text { gregated by food } \\
\text { and non-food crops, } \\
\text { number of acres } \\
\text { of land cultivation } \\
\text { (commercial/private } \\
\text { farms) }\end{array}$ & Output & $7 \%$ & $\begin{array}{l}\text { 2008: } 3.6 \% \\
\text { 2009: } 3.7 \% \\
\text { 2010: } 3.8 \% \\
\text { 2011: } 3.8 \%\end{array}$ & Annual & MoA & $\mathrm{MoA}$ & - \\
\hline \multicolumn{8}{|l|}{ Forestry } \\
\hline $\begin{array}{l}\text { Volume of timber } \\
\text { products [categories } \\
\text { to be specified by } \\
\text { FDA] produced (in } \\
\text { '000 cubic meters) }\end{array}$ & Output & 0 & $\begin{array}{l}\text { FY 08/09: } 536 \\
\text { FY 09/10: } 903 \\
\text { FY 10/11: } 1327\end{array}$ & Annual & FDA & FDA & - \\
\hline \multicolumn{8}{|l|}{ Mining } \\
\hline $\begin{array}{l}\text { Volume of iron ore } \\
\text { produced }\end{array}$ & Output & 0 & 3 million tons & \begin{tabular}{|l|} 
End of \\
PRS \\
Period \\
\end{tabular} & MLME & MLME & - \\
\hline \multicolumn{8}{|c|}{ Land and Environment } \\
\hline $\begin{array}{l}\text { Review and reform } \\
\text { by Land Commission } \\
\text { of all aspects of } \\
\text { land policy, law, and } \\
\text { administration }\end{array}$ & Output & $\mathrm{N} / \mathrm{A}$ & $\begin{array}{l}\text { Completed reform of } \\
\text { land policy, law, and } \\
\text { administration }\end{array}$ & $\begin{array}{l}\text { End of } \\
\text { PRS } \\
\text { Period }\end{array}$ & $\begin{array}{l}\text { Land } \\
\text { Commission } \\
\text { annual report }\end{array}$ & $\begin{array}{l}\text { GC, LC } \\
\text { (when } \\
\text { estab- } \\
\text { lished) }\end{array}$ & - \\
\hline \multicolumn{8}{|c|}{ Private Sector Investment } \\
\hline $\begin{array}{l}\text { Number of new busi- } \\
\text { nesses registered70 }\end{array}$ & Output & $\begin{array}{l}\text { 2007: } 1047, \\
172\end{array}$ & $\begin{array}{l}\text { (Increase of } 15 \% \text { per } \\
\text { year) } \\
\text { 2008: } 1204,197 \\
\text { 2009: } 1227,226 \\
\text { 2010: } 1411,260 \\
\text { 2011: } 1622,299\end{array}$ & Annual & $\begin{array}{l}\text { MoCl Annual } \\
\text { Report }\end{array}$ & $\mathrm{MoCl}, \mathrm{NIC}$ & - \\
\hline \multicolumn{8}{|l|}{ Financial Sector } \\
\hline $\begin{array}{l}\text { Banking system } \\
\text { deposits/GDP (\%) }\end{array}$ & Output & $21.4 \%$ & $30.0 \%$ & \begin{tabular}{|l|} 
End of \\
PRS \\
Period \\
\end{tabular} & CBL & CBL & - \\
\hline $\begin{array}{l}\text { Non-performing } \\
\text { loans as a percent } \\
\text { of total assets of the } \\
\text { banking system }(\%)\end{array}$ & Output & $31.0 \%$ & $15.0 \%$ & $\begin{array}{l}\text { End of } \\
\text { PRS } \\
\text { Period }\end{array}$ & CBL & CBL & - \\
\hline \multicolumn{8}{|l|}{ Employment } \\
\hline $\begin{array}{l}\text { Employment rate (\% } \\
\text { above the baseline } \\
\text { as determined by } \\
\text { MoL } 2008 / 2009 \text { labor } \\
\text { market survey) }{ }^{71}\end{array}$ & Outcome & TBD & TBD & Annual & $\begin{array}{l}\text { MoL labor } \\
\text { market survey }\end{array}$ & MoL & - \\
\hline $\begin{array}{l}\text { Wage employment in } \\
\text { the non-agricultural } \\
\text { sector (\% of total } \\
\text { employment) }\end{array}$ & Outcome & TBD & TBD & Annual & $\begin{array}{l}\text { MoL labor } \\
\text { market survey }\end{array}$ & MoL & - \\
\hline \multicolumn{8}{|c|}{ State Owned Enterprises } \\
\hline $\begin{array}{l}\text { Net total transfers } \\
\text { to SOEs/parastatals } \\
\text { as \% of Government } \\
\text { revenue }\end{array}$ & Output & $2.4 \%$ & $1 \%$ & Annual & $\begin{array}{l}\text { National } \\
\text { Budget }\end{array}$ & MoF, BoB & - \\
\hline
\end{tabular}

70 This indicator will also be tracked on a disaggregated basis by Liberian/foreign-owned.

71 This indicator will also be tracked on a disaggregated basis by sex and age 


\begin{tabular}{|c|c|c|c|c|c|c|c|}
\hline \multicolumn{8}{|c|}{ Pillar III: Governance and Rule of Law } \\
\hline \multicolumn{8}{|l|}{ Governance Reform } \\
\hline $\begin{array}{l}\% \text { of public expen- } \\
\text { diture transferred to } \\
\text { local authorities } 72\end{array}$ & Outcome & $6.1 \%$ & $\begin{array}{l}\text { 2009: } 6.6 \% \\
\text { 2010: } 7.1 \% \\
\text { 2011: } 7.7 \%\end{array}$ & Annual & \begin{tabular}{|l|} 
National \\
Budget
\end{tabular} & MIA & - \\
\hline $\begin{array}{l}\text { Percent of the popu- } \\
\text { lation that perceives } \\
\text { the Government of } \\
\text { Liberia to be per- } \\
\text { forming better than in } \\
\text { the previous year }\end{array}$ & Outcome & TBD & $60 \%$ Annually & Annual & $\begin{array}{l}\text { Question will } \\
\text { be added to } \\
\text { future CWIQ } \\
\text { surveys }\end{array}$ & CSA & - \\
\hline $\begin{array}{l}\text { Number of minis- } \\
\text { tries, agencies and } \\
\text { SOEs/parastatals } \\
\text { restructured based } \\
\text { on revised, published } \\
\text { and adopted man- } \\
\text { dates }\end{array}$ & Output & 0 & TBD & $\begin{array}{l}\text { End of } \\
\text { PRS } \\
\text { Period }\end{array}$ & $\begin{array}{l}\text { GC status } \\
\text { report }\end{array}$ & GC, CSA & - \\
\hline $\begin{array}{l}\text { Score on } \\
\text { Transparency } \\
\text { International } \\
\text { Corruption } \\
\text { Perception Index }\end{array}$ & Outcome & 2.1 out of 10 & 4.0 out of 10 & $\begin{array}{l}\text { End of } \\
\text { PRS } \\
\text { Period }\end{array}$ & $\begin{array}{l}\text { Transparency } \\
\text { International } \\
\text { Corruption } \\
\text { Perception } \\
\text { Index }\end{array}$ & GC, ACC & - \\
\hline \multicolumn{8}{|l|}{ Rule of Law } \\
\hline $\begin{array}{l}\text { Number of benefi- } \\
\text { ciaries of legal aid } \\
\text { (civil/criminal) }\end{array}$ & Output & TBD & TBD & Annual & TBD & MoJ & - \\
\hline $\begin{array}{l}\text { Number of Circuit } \\
\text { Courts and } \\
\text { Magisterial Courts } \\
\text { rehabilitated/ } \\
\text { constructed and } \\
\text { functioning (judged } \\
\text { by whether a legal } \\
\text { proceeding has been } \\
\text { completed in that } \\
\text { court) }\end{array}$ & Output & $\begin{array}{l}\text { Circuit } \\
\text { Courts: } 7 \text { of } \\
15 \\
\\
\text { Magisterial } \\
\text { Courts: } 5 \text { of } \\
124\end{array}$ & $\begin{array}{l}\text { Circuit Courts: } 13 \\
\text { of } 15 \\
\text { Magisterial Courts: } \\
43 \text { of } 124\end{array}$ & $\begin{array}{l}\text { End of } \\
\text { PRS } \\
\text { Period }\end{array}$ & $\begin{array}{l}\text { Judiciary } \\
\text { Quarterly } \\
\text { and Annual } \\
\text { Reports/GC } \\
\text { Status Reports }\end{array}$ & $\begin{array}{l}\text { Judiciary, } \\
\text { MoJ }\end{array}$ & - \\
\hline $\begin{array}{l}\text { Number of Judicial } \\
\text { Officers trained and } \\
\text { deployed at Circuit/ } \\
\text { Magisterial Courts } \\
\text { (disaggregated by } \\
\text { gender) }\end{array}$ & Output & $\begin{array}{l}336 \\
\text { Magistrates } \\
\text { 22 Justices } \\
\text { of the Peace }\end{array}$ & $\begin{array}{l}403 \text { Magistrates } \\
27 \text { Justices of the } \\
\text { Peace }\end{array}$ & $\begin{array}{l}\text { End of } \\
\text { PRS } \\
\text { Period }\end{array}$ & $\begin{array}{l}\text { Judiciary } \\
\text { Quarterly } \\
\text { and Annual } \\
\text { Reports/ } \\
\text { MoJ Annual } \\
\text { Reports } \\
\end{array}$ & $\begin{array}{l}\text { Judiciary, } \\
\text { MoJ }\end{array}$ & - \\
\hline $\begin{array}{l}\% \text { of Juvenile } \\
\text { Offenders with } \\
\text { access to rehabilita- } \\
\text { tion services }\end{array}$ & Output & TBD & TBD & $\begin{array}{l}\text { End of } \\
\text { PRS } \\
\text { Period }\end{array}$ & $\begin{array}{l}\text { Judiciary } \\
\text { Quarterly } \\
\text { and Annual } \\
\text { Reports/GC } \\
\text { Status Reports }\end{array}$ & $\begin{array}{l}\text { Judiciary, } \\
\text { MoJ }\end{array}$ & - \\
\hline $\begin{array}{l}\% \text { of cases success- } \\
\text { fully prosecuted }\end{array}$ & Output & $21 \%$ & $\begin{array}{l}32 \% \text { (Increase of } \\
50 \%)\end{array}$ & $\begin{array}{l}\text { End of } \\
\text { PRS } \\
\text { Period }\end{array}$ & $\begin{array}{l}\text { Judiciary } \\
\text { Quarterly } \\
\text { and Annual } \\
\text { Reports/GC } \\
\text { Status Reports }\end{array}$ & $\begin{array}{l}\text { Judiciary, } \\
\text { MoJ }\end{array}$ & - \\
\hline
\end{tabular}

72 This indicator will also be tracked on a disaggregated basis by county. 


\section{Roads and Bridges}

\begin{tabular}{|c|c|c|c|c|c|c|c|}
\hline $\begin{array}{l}\text { Number of new miles } \\
\text { of roads rehabilitated/ } \\
\text { reconstructed } 73\end{array}$ & Output & N/A & $\begin{array}{l}\text { Total primary: } 1,187 \\
\text { miles }(1,075 \text { to be } \\
\text { paved, surface dress- } \\
\text { ing) } \\
\text { All weather second- } \\
\text { ary roads: } 300 \text { miles } \\
\text { Feeder roads: } 400 \\
\text { miles } \\
\text { Neighborhood roads: } \\
212 \text { miles }\end{array}$ & $\begin{array}{l}\text { End of } \\
\text { PRS } \\
\text { Period }\end{array}$ & $\begin{array}{l}\text { MPW prog- } \\
\text { ress reports }\end{array}$ & MPW & - \\
\hline $\begin{array}{l}\text { Person-months of } \\
\text { roadwork employ- } \\
\text { ment created per } \\
\text { year }\end{array}$ & Output & $\begin{array}{l}24,120 \text { per- } \\
\text { son-months/ } \\
\text { year }\end{array}$ & $\begin{array}{l}45,288 \text { person- } \\
\text { months/year }\end{array}$ & Annual & MPW reports & MPW & - \\
\hline \multicolumn{8}{|l|}{ Transportation } \\
\hline $\begin{array}{l}\text { Number of buses } \\
\text { regularly operating in } \\
\text { Monrovia. }\end{array}$ & Output & 9 & 70 & $\begin{array}{l}\text { End of } \\
\text { PRS } \\
\text { Period }\end{array}$ & $\begin{array}{l}\text { MTAAnnual } \\
\text { Report }\end{array}$ & MTA & - \\
\hline $\begin{array}{l}\text { Number of vessels } \\
\text { entering and clearing } \\
\text { Freeport of Monrovia } \\
\text { per month }\end{array}$ & Output & 28 & 32 & $\begin{array}{l}\text { End of } \\
\text { PRS } \\
\text { Period }\end{array}$ & $\begin{array}{l}\text { NPA Monthly } \\
\text { Statistics on } \\
\text { Cargo and } \\
\text { Vessel Traffics }\end{array}$ & MoT, NPA & - \\
\hline \multicolumn{8}{|l|}{ Water and Sanitation } \\
\hline $\begin{array}{l}\text { Access to safe drink- } \\
\text { ing water }\end{array}$ & Outcome & $25 \%{ }^{74}$ & $\begin{array}{l}\text { Increase by } 25 \% \text { (to } \\
50 \% \text { ) }\end{array}$ & $\begin{array}{l}\text { End of } \\
\text { PRS } \\
\text { Period }\end{array}$ & $\begin{array}{l}\text { VPA, UNICEF, } \\
\text { CWIQ }\end{array}$ & MPW & MDG 7 \\
\hline $\begin{array}{l}\text { Access to improved } \\
\text { sanitation }\end{array}$ & Outcome & $15 \% 75$ & $\begin{array}{l}\text { Increase by } 25 \% \text { (to } \\
40 \% \text { ) }\end{array}$ & $\begin{array}{l}\text { End of } \\
\text { PRS } \\
\text { Period }\end{array}$ & VPA, UNICEF & MPW & MDG 7 \\
\hline \multicolumn{8}{|l|}{ Health } \\
\hline Child mortality rate & Outcome & 111 per 1000 & $\begin{array}{l}\text { Reduce by } 15 \% \text { (to } \\
94 / 1000 \text { ) }\end{array}$ & $\begin{array}{l}\text { End of } \\
\text { PRS } \\
\text { Period }\end{array}$ & DHS & MoHSW & MDG 4 \\
\hline $\begin{array}{l}\text { Maternal mortality } \\
\text { rate }\end{array}$ & Outcome & $\begin{array}{l}994 \text { per } \\
100,000 \text { live } \\
\text { births }\end{array}$ & $\begin{array}{l}\text { Reduce by } 10 \% \text { (to } \\
895 / 100,000 \text { ) }\end{array}$ & $\begin{array}{l}\text { End of } \\
\text { PRS } \\
\text { Period }\end{array}$ & DHS & MoHSW & MDG 5 \\
\hline $\begin{array}{l}\text { Child malnutrition (\% } \\
\text { of children under } 5 \text { ) } \\
\text { (stunting, wast- } \\
\text { ing, height for age, } \\
\text { weight for height, } \\
\text { weight for age) }\end{array}$ & Outcome & $\begin{array}{l}\text { Height for } \\
\text { age: } 39 \% \\
\text { Weight for } \\
\text { height: } 7 \% \\
\text { Weight for } \\
\text { age: } 19 \%\end{array}$ & $\begin{array}{l}\text { Improve weight for } \\
\text { age by } 15 \%\end{array}$ & $\begin{array}{l}\text { End of } \\
\text { PRS } \\
\text { Period }\end{array}$ & DHS & MoHSW & MDG 1 \\
\hline $\begin{array}{l}\text { Contraceptive preva- } \\
\text { lence rate (disag- } \\
\text { gregated by method: } \\
\text { any method, con- } \\
\text { dom, pills, etc.) }\end{array}$ & Output & $\begin{array}{l}\text { Any method: } \\
11 \% \\
\text { Condom: } \\
1.6 \%\end{array}$ & $15 \%$ (any method) & $\begin{array}{l}\text { End of } \\
\text { PRS } \\
\text { Period }\end{array}$ & DHS & MoHSW & MDG 6 \\
\hline $\begin{array}{l}\text { HIV prevalence rate } \\
\text { (disaggregated by } \\
\text { sex and age) }\end{array}$ & Outcome & $1.5 \%$ & $\begin{array}{l}\text { Contain rate (no } \\
\text { increase) }\end{array}$ & $\begin{array}{l}\text { End of } \\
\text { PRS } \\
\text { Period }\end{array}$ & DHS & MoHSW & MDG 6 \\
\hline $\begin{array}{l}\text { Doctors per } 1000 \\
\text { persons }\end{array}$ & Output & $0.03(2006)$ & 0.06 & $\begin{array}{l}\text { End of } \\
\text { PRS } \\
\text { Period }\end{array}$ & $\begin{array}{l}\text { MoHSW Rapid } \\
\text { Assessment }\end{array}$ & MoHSW & - \\
\hline
\end{tabular}

\footnotetext{
73 This indicator will also be tracked on a disaggregated basis by type: all-weather, feeder, neighborhood roads.

74 The CWIQ resulted in far higher figures for access to safe drinking water and improved sanitation than the 2004 Village Profile Assessment (VPA). Several 76 sources of data in this area exist and are not necessarily comparable. Baselines and targets for these indicators may be adjusted during the PRS implementation period.

75 Ibid
} 


\begin{tabular}{|c|c|c|c|c|c|c|c|}
\hline $\begin{array}{l}\text { Nurse per } 1000 \text { per- } \\
\text { sons }\end{array}$ & Output & $0.18(2006)$ & 0.36 & $\begin{array}{l}\text { End of } \\
\text { PRS } \\
\text { Period }\end{array}$ & $\begin{array}{l}\text { MoHSW Rapid } \\
\text { Assessment }\end{array}$ & MoHSW & - \\
\hline $\begin{array}{l}\text { Midwives per } 1000 \\
\text { persons }\end{array}$ & Output & $0.12(2006)$ & 0.24 & $\begin{array}{l}\text { End of } \\
\text { PRS } \\
\text { Period }\end{array}$ & $\begin{array}{l}\text { MoHSW Rapid } \\
\text { Assessment }\end{array}$ & MoHSW & - \\
\hline \multicolumn{8}{|l|}{ Education } \\
\hline $\begin{array}{l}\text { Net enrollment ratio } \\
\text { in primary education } \\
\text { (disaggregated by } \\
\text { gender) }\end{array}$ & Outcome & $\begin{array}{l}\text { Primary: } \\
37 \% \\
\text { Secondary: } \\
15 \%\end{array}$ & $\begin{array}{l}\text { Primary: } 44.8 \% \\
\text { Secondary: } 20 \%\end{array}$ & $\begin{array}{l}\text { End of } \\
\text { PRS } \\
\text { Period }\end{array}$ & CWIQ & $\begin{array}{l}\text { MoE/ } \\
\text { LISGIS }\end{array}$ & MDG 2 \\
\hline $\begin{array}{l}\text { Gender Parity Index } \\
\text { in primary enrollment }\end{array}$ & Outcome & $\begin{array}{l}43 \text { girls for } \\
\text { every } 100 \\
\text { boys }\end{array}$ & $\begin{array}{l}48 \text { girls for every } 100 \\
\text { boys }\end{array}$ & $\begin{array}{l}\text { End of } \\
\text { PRS } \\
\text { Period }\end{array}$ & $\begin{array}{l}2007-2008 \\
\text { School } \\
\text { Census }\end{array}$ & $\begin{array}{l}\text { MoE/ } \\
\text { LISGIS }\end{array}$ & MDG 3 \\
\hline $\begin{array}{l}\text { Teacher to student } \\
\text { ratio }\end{array}$ & Output & $1: 35$ & $1: 45^{76}$ & $\begin{array}{l}\text { End of } \\
\text { PRS } \\
\text { Period }\end{array}$ & $\begin{array}{l}2007-2008 \\
\text { School } \\
\text { Census }\end{array}$ & MoE & - \\
\hline Youth literacy rate & Outcome & $73 \%$ & $85 \%$ & $\begin{array}{l}\text { End of } \\
\text { PRS } \\
\text { Period }\end{array}$ & CWIQ & $\begin{array}{l}\text { MoE/ } \\
\text { LISGIS }\end{array}$ & - \\
\hline \multicolumn{8}{|l|}{ Energy } \\
\hline $\begin{array}{l}\text { Percentage of house- } \\
\text { holds with access to } \\
\text { electricity }\end{array}$ & Outcome & $0.6 \%$ & $10.0 \%$ & $\begin{array}{l}\text { End of } \\
\text { PRS } \\
\text { Period }\end{array}$ & $\begin{array}{l}\text { MLME/LEC } \\
\text { Annual Report }\end{array}$ & $\begin{array}{l}\text { MLME, } \\
\text { LEC }\end{array}$ & - \\
\hline $\begin{array}{l}\text { Total installed capac- } \\
\text { ity (MW) }\end{array}$ & Output & $2.6 \mathrm{MW}$ & $29.6 \mathrm{MW}$ & $\begin{array}{l}\text { End of } \\
\text { PRS } \\
\text { Period }\end{array}$ & $\begin{array}{l}\text { MLME/LEC } \\
\text { Annual Report }\end{array}$ & $\begin{array}{l}\text { MLME, } \\
\text { LEC }\end{array}$ & - \\
\hline $\begin{array}{l}\text { Percentage of rural } \\
\text { households with } \\
\text { access to electricity }\end{array}$ & Outcome & $0.0 \%$ & $2.0 \%$ & $\begin{array}{l}\text { End of } \\
\text { PRS } \\
\text { Period }\end{array}$ & $\begin{array}{l}\text { MLME/LEC } \\
\text { Annual Report }\end{array}$ & $\begin{array}{l}\text { MLME, } \\
\text { LEC }\end{array}$ & - \\
\hline $\begin{array}{l}\text { Regional or cross } \\
\text { border interconnec- } \\
\text { tivity (miles of cross } \\
\text { border transmission } \\
\text { lines) }\end{array}$ & Output & 0 miles & 150 miles & $\begin{array}{l}\text { End of } \\
\text { PRS } \\
\text { Period }\end{array}$ & $\begin{array}{l}\text { MLME/LEC } \\
\text { Annual Report }\end{array}$ & $\begin{array}{l}\text { MLME, } \\
\text { LEC }\end{array}$ & - \\
\hline \multicolumn{8}{|c|}{ Post and Telecommunications } \\
\hline $\begin{array}{l}\text { Universal Access } \\
\text { telecommunications } \\
\text { coverage throughout } \\
\text { Liberia }\end{array}$ & Outcome & $14.9 \%$ & $\begin{array}{l}\text { 2009: } 17.9 \% \\
\text { 2010: } 21.5 \% \\
\text { 2011: } 25.8 \%\end{array}$ & Annual & $\begin{array}{l}\text { AnnualBlycroft } \\
\text { Estimates } \\
\text { Report }\end{array}$ & LTC, LTA & - \\
\hline $\begin{array}{l}\% \text { of the population } \\
\text { with local access to } \\
\text { postal services }\end{array}$ & Outcome & $2 \%$ & $70 \%$ & $\begin{array}{l}\text { End of } \\
\text { PRS } \\
\text { Period }\end{array}$ & $\begin{array}{l}\text { MPT Annual } \\
\text { Report }\end{array}$ & MPT, UPU & - \\
\hline \multicolumn{8}{|c|}{ Urban and Other Infrastructure } \\
\hline $\begin{array}{l}\text { Additional units of } \\
\text { low-income housing } \\
\text { constructed }\end{array}$ & Output & 1,700 units & $\begin{array}{l}\text { Construct } 300 \text { units } \\
\text { to reach total of } \\
2,000\end{array}$ & $\begin{array}{l}\text { End of } \\
\text { PRS } \\
\text { Period }\end{array}$ & $\begin{array}{l}\text { NHA Annual } \\
\text { Report }\end{array}$ & $\mathrm{NHA}$ & - \\
\hline $\begin{array}{l}\text { Administration build- } \\
\text { ings and palava huts } \\
\text { constructed and } \\
\text { rehabilitated. }\end{array}$ & Output & TBD & $\begin{array}{l}\text { New or rehabilitated } \\
\text { administration build- } \\
\text { ings in } 45 \text { districts } \\
\text { and new or rehabili- } \\
\text { tated palava huts in } \\
126 \text { districts }\end{array}$ & $\begin{array}{l}\text { End of } \\
\text { PRS } \\
\text { Period }\end{array}$ & $\begin{array}{l}\text { Quarterly } \\
\text { count reports }\end{array}$ & MIA & - \\
\hline
\end{tabular}

76 The teacher-to-student ratio is projected to rise from 1:35 to 1:45 for two reasons: concerns about the accuracy of the baseline figure and the expected increase in enrolment over the next three years. 


\section{Managing Potential Risks and Constraints}

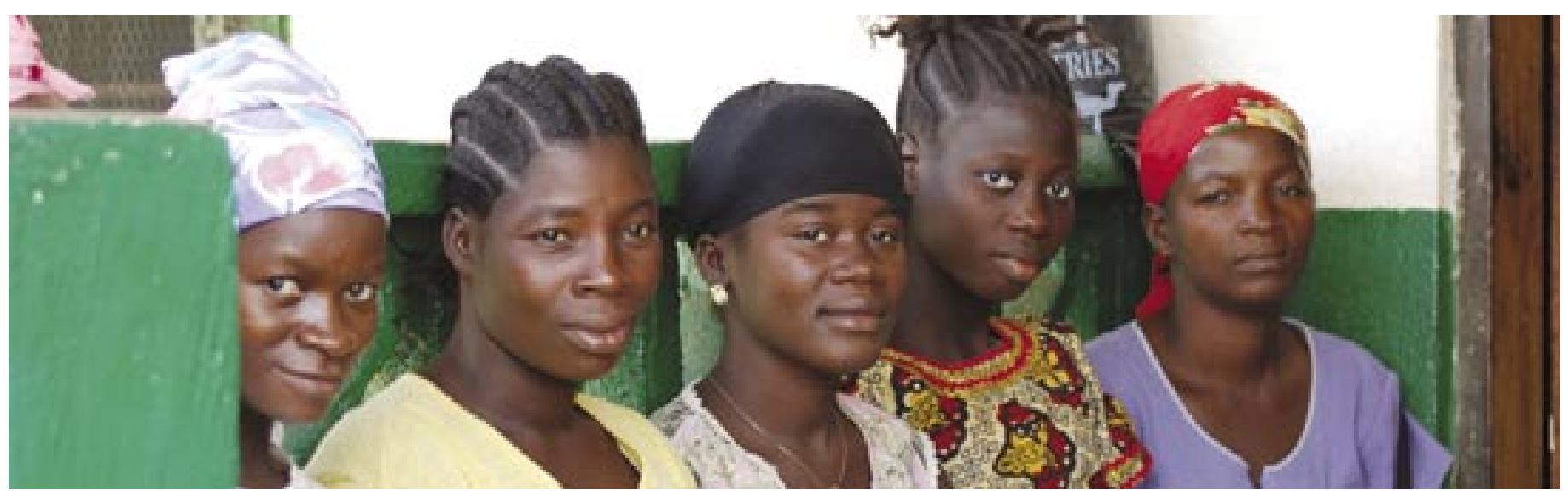

\subsection{Introduction}

${ }^{1}$ There are a number of risks and constraints that could derail the implementation of the PRS and frustrate the Government's commitment to generating rapid, inclusive and sustainable growth. The major ones include shortfalls in external financing, limited leadership as well as administrative and technical capacity, and external and internal instability. Although these risks and constraints are real, the potential consequences arising from them can be reduced through their identification and the implementation of mitigation strategies.

\subsection{Financing}

${ }^{2}$ A significant constraint to implementing the strategy is the timely availability and coordinated distribution of financing. A total of US\$ 1.6 billion will be needed to implement the priority actions over the PRS period. As detailed in Chapter Ten, Liberia's financial resources, after more than a quarter of a century of mismanagement and economic decline, are limited. Attracting and maintaining quality human capital, strengthening institutional capacity, facilitating employment-creating production, and otherwise implementing the policies and programs contained in the PRS will require a massive amount of external financial resources

${ }^{3}$ The Government, with the generous support of the international community, has taken significant steps toward drastically reducing its external debt burden which will in turn facilitate the mobilization of needed external resources. Other government advances, such as public financial management reform and the implementation of the anti-corruption strategy, are expected to further encourage donor partners to expand support to Liberia, and to increasingly channel a larger share through the budget. The Government will continue to implement reforms to increase confidence that funds will be managed in a prudent and effective manner. It will also implement a donor coordination and tracking mechanism to facilitate adequate, timely and coordinated donor support over the PRS period and beyond.

\subsection{Capacity}

${ }^{4}$ Another critical constraint to the successful implementation of the PRS is the limited leadership, as well as administrative and technical capacity, at various levels in the public and private sectors. The Government could have adequate financing and could still fail to fully implement the strategy if capacity constraints remain binding. 
${ }^{5}$ Although some progress can be made with respect to capacity, there remains the risk that such progress will be slower than desired. Even with SES, TOKTEN and other capacity building initiatives, generating the capacity to implement the PRS activities will take time and may be subject to setbacks and delays. Timely, successful implementation of the Civil Service reforms laid out in the PRS will be required to keep momentum, and any failure in this regard would likely have negative consequences for implementation of the overall PRS process. One of the key challenges in creating capacity will be in training personnel who can determine what needs to be done to move the PRS activities forward and in what order. This will require people with the capacity and confidence to make the hard choices needed to sort out the feasible from the desirable.

${ }^{6}$ A number of initiatives are being designed and implemented to build capacity and mitigate the risk of capacity constraints jeopardizing the full implementation of the PRS. A more detailed discussion is set out in Chapter Twelve.

\subsection{External Stability}

7 The history of conflict and other turmoil in the West African sub-region over the past two decades is well established, as is Liberia's own susceptibility to contagion. Yet, the extraordinary goodwill that Liberia continues to enjoy, both regionally and in the rest of the international community, together with the desire of the Liberian people for sustained peace should work to mitigate the risk that regional shocks will lead to Liberia relapsing into conflict or other forms of instability over the medium term. International goodwill, the attitude of the Liberian people and advancements in regional institutions will not, however, be taken for granted; rather they must and will continue to be consolidated and improved through prioritizing the maintenance of regional stability. This will include working with ECOWAS, and rebuilding political and economic links through the Mano River Union.

${ }^{8}$ In addition to the spread of regional conflict and other forms of instability, economic contagion is a potential risk, particularly given that Liberia's growth and development strategy is based in large part on the participation and rejuvenation of the private sector. As this PRS is being finalized, there exists significant uncertainty associated with the price of oil and with the United States' and other international financial markets. Support from
Tapping Dormant Human Capital: Changing Minds, Changing Attitudes

"In order to revitalize the economy, we ourselves have to transform our view of what government is." - Hon. Julia Duncan Cassell, Superintendent, Grand Bassa County

Much of Liberia's human capital sits idle as capable Liberians wait for someone - the Government, NGOs, or others - to improve their lives. A central thrust over the PRS period will be to encourage ordinary Liberians to trade their feelings of dependency for a commitment to hard work and self-reliance.

In March 2008, the President stated, "Government can strive to create an enabling environment, to create the avenues for success. But it is you who must seize these opportunities, you who must put in the hard work to make our collective dream a reality. You must not wait for the Government to make your life better, but rather work to better your own life."

Through labor-based public works, SME support programs, work ethics lessons in the primary school curriculum, and other means, the PRS implementation period will stress the need for active commitment and hard work to reduce poverty. Poverty will only be reduced if the people themselves play an active role in governance, and in laboring to improve their own lives. In this context, the Ministry of Information, Culture, and Tourism is pursuing an agenda it calls "Changing Minds, Changing Attitudes". Liberia will only be as strong as the hearts, minds, and working hands of its people. 
the international community will partially shelter Liberia from any adverse economic consequences resulting from an international economic downturn. Efforts to move towards a more diversified Liberian economy and to become more regionally integrated will also increase Liberia's ability to withstand external instability over the medium term. However, over the three-year PRS period, Liberia will remain vulnerable to international economic shocks, including to international prices of its exports.

\subsection{Internal Stability}

${ }^{9}$ A final challenge to the successful implementation of the PRS is the maintenance of internal stability. Threats continue to exist, with large numbers of uneducated, unemployed and marginalized youth susceptible to being recruited into conflict, limited police resources, and insufficient rule of law infrastructure. There are also many unresolved issues with respect to land. These threats are particularly salient given that UNMIL is expected to commence its drawdown during the PRS period which will potentially have security and economic implications.

${ }^{10}$ Other forms of political and economic instability also pose a threat to the successful implementation of the PRS. In particular, the depth of the proposed reform agenda is such that implementation of the PRS will require trust and cooperation on the part of the Legislature. This has been promoted through on-going dialogue and extensive consultations with the Legislature with respect to the content of the PRS (see Chapter Five for further detail). There is also the risk of popular dissatisfaction if improvements in living standards don't materialize quickly.

${ }^{11}$ The Peace and Security and Governance and Rule of Law Pillars have undertaken and continue to propose various initiatives to build peace and security capabilities and to reduce the risk of a return to conflict. These measures involve input from a wide range of Liberian and international stakeholders and are consistent with promoting democracy, good governance, rule of law and human security. In addition, the PRS is designed to generate growth that is more inclusive than in the past. The widespread public consultations and involvement of a broad range of stakeholders in the preparation of this PRS will further reduce the risk of exclusion as well as buy-in from the Legislature. The Government is aware that it must establish and maintain an effective communications strategy regarding implementation of the PRS, to report on the progress toward its objectives as well as to calibrate the strategy to evolving needs. Such an effort will be essential in reducing the risk of dissatisfaction and instability.

\subsection{Effects on Growth Projections}

${ }^{12}$ The economic growth rates projected over the PRS period and set out in Chapter Seven may be affected by the above risks and constraints. However, there are other risks and constraints that could affect growth, leading to reduced government revenues and the incomplete implementation of the Poverty Reduction Strategy agenda.

${ }^{13}$ The emphasis on rebuilding basic infrastructure as one of the three prongs of Liberia's growth and development strategy makes Liberia vulnerable to a variety of project implementation risks. In particular, Liberia has a limited window of opportunity during its dry season to undertake the vast majority of its building of roads and other infrastructure projects. If the country experiences a shortened dry season, or if projects are otherwise delayed such that their implementation cannot be completed during the dry season, then the quality and the completion of the projects will be compromised. This is turn would have flow-on effects to the other prongs of the growth strategy: the rejuvenation of the natural resources sectors and laying the foundation for a more diversified economy.

${ }^{14}$ As the people of Liberia now turn to the important task of implementing the Poverty Reduction Strategy, the Government is committed to vigilance in prevention of, and timely response to, the risks that are within its power to mitigate. 


\section{Annex 1}

\section{Cross-Cutting Issue Strategy Brief: Gender Equity}

\section{Introduction}

${ }^{1}$ This annex to the PRS expands on its content related to gender equity, a cross-cutting issue featured under all four Pillars. The Government of Liberia is strongly committed to gender equity as a means of maintaining peace, reducing poverty, enhancing justice and promoting development in the country. To assure equal opportunities and participation in management and decision-making of all levels of the society, women's and men's different experiences, needs, concerns, vulnerabilities, capacities, visions and contributions must be systematically taken into account.

\section{Context}

${ }^{2}$ Despite the progress since the end of civil war in many sectors of Liberian society, gender continues to play a decisive role in determining access to resources and services. Women and girls continue to have limited access to education, health services and judicial services, which has severely curtailed their participation in the formal economy.

${ }^{3}$ With some notable recent exceptions including the Presidency, women and girls have been missing out on opportunities and participation in management and decision-making at all levels of the society. In particular, gender segregation in the labor market constrains women's and girls' participation in the more profitable sectors and limits their opportunities for economic empowerment. 77 Though systemic data are unavailable, this trend has contributed to feminization of poverty in Liberia.

${ }^{4}$ The vast majority of Liberian women and girls have suffered GBV including sexual abuse. A culture of violence continues to permeate the society and rape continues to be featured

\section{The Concept of Gender}

The concept of gender is applied as a tool of analysis to investigate the differences and inequities between males and females, which are determined not by the biological diversities but rather the social differences between males and females dictated by culture and tradition. These social differences are learned and change over time.

Gender analysis examines the relationship between sexes, their roles in society, and their access to and control of resources. It can help diagnose and design a set of recommended policy actions, but those actions must always be sensitive to the risk of stigmatization and isolation of women and girls.

Gender analysis distinctly recognizes women, girls, men and boys as target groups. Gender is not just about "women's issues"; the efforts to modify behavior harmful to either gender must involve both men and women.

While this Annex mirrors most of the content of the PRS that specifically refers to issues of gender equity, the strategies and actions discussed here are not the only PRS interventions that relate to gender. To site but one example, the effort to create a businessconducive environment for MSMEs will have substantial benefits for women and girls, who are known to make up the majority of the entrepreneurial class in Liberia.

77 World Bank/MoGD, Liberia Gender Needs Assessment: Towards Women's Economic Empowerment, 2007 
among the most frequently reported crimes in Liberia. Domestic violence is endemic. The country has among the highest rates of teenage pregnancy in the world. Further, the alarming rate of GBV also exposes the risk of women, girls, boys and men to HIV and other STIs. Women and girls are doubly disadvantaged by HIV and AIDS: both as PWLHAs themselves and as caregivers of PLWHAs in their families and communities.

${ }^{5}$ With some notable exceptions including the Presidency, women's participation in political leadership and decision making remains low, with only 14 percent representation in the Legislature (2007). Destruction of institutions during the war affected all Liberians, but particularly limited women's and girls' access to education; today, the ratio of girls' to boys' enrolment is $95 / 100$ at the primary level, decreasing to $75 / 100$ in secondary schools, ${ }^{78}$ and twice as many women as men are illiterate.

${ }^{6}$ Despite statutory provisions recognizing the equality of the sexes, in many areas of the country customary laws and practices prevail, some of which are harmful to women and girls. Customary law infringes on women's and girls' rights, including the right to property. Women and girls who break traditional gender norms continue to experience violence intended to make them conform to traditional roles.

${ }^{7}$ The Government has already undertaken many initiatives to address issues affecting women and girls. It has developed a National Gender Based Violence Plan of Action, and established a GBV secretariat within the Ministry of Gender and Development. (See box on GBV in Chapter Seven.) It has committed to fulfilling its obligations under ratified and signed international treaties, and established a secretariat to monitor and report on the steps taken to meet these obligations. Liberia passed a Rape Law in 2005, which explicitly specifies that rape is a criminal act. The Inheritance Act was also passed to govern the devolution of estates and establish rights of inheritance for spouses of both statutory and customary marriages. The MoGD supported the establishment of the National Secretariat of Women's NGOs to build consensus on women's empowerment and coordinate the work of local women's organizations, including support to capacity building.

\section{Objectives}

${ }^{8}$ The PRS lays the groundwork for the achievement of gender equity and women's and girls' empowerment, promoting equitable access to resources and benefits. In the economic realm, the PRS incorporates gender equity considerations in the development and implementation of macro- and microeconomic policies, as well as programs underpinning the overall growth strategy, with the ultimate goal of promoting women's economic empowerment. To build a more effective, responsive, and supportive legal, social and political environment, including all aspects of protection and access to justice, health care, and education, the PRS further includes measures for the prevention of and response to GBV including addressing the root causes of the crime and the promotion of an increasing number of women in national security institutions. Toward the building of capacity, the PRS reinforces the institutional framework, capacity and mandate of the Ministry of Gender and Development (MoGD) to take the lead in implementing and monitoring the National Gender Policy, the PRS, and international conventions as well as to mainstream gender in legal, constitutional, and governance reforms. The Government is committed to ensuring that key PRS monitoring data collected are disaggregated by age and sex, where relevant, which will facilitate MDG monitoring and the development of internationally comparable data.

\section{Pillar I: National Security}

${ }^{9}$ Representation of women in the security sector remains limited, at only 4.7 percent of the AFL and about 20 percent in the LNP. Security sector agencies acknowledge that gender discrimination occurs in attitudes, incentive systems, operational structures, and in bureaucratic procedures of the institutions. Discrimination against women has a negative impact not only on females joining the institutions but also on the delivery and quality of services provided by the sector to the population at large and in affirming

\footnotetext{
78 UNESCO, 2007
} 
${ }^{10}$ The Government's security sector reforms are intended to establish mechanisms to protect the fundamental freedoms of Liberians. To that end, the AFL, BIN, LNP and Bureau of Corrections will champion human rights and gender equity. Institutional reform will ensure adoption of gender justice and equity as core values and allow for equal access and protection within the institutions and outreach services. The Government will improve the quality of security services provided to the population at large, and particularly to vulnerable sections including survivors of gender based violence (GBV) by adoption of a peoplecentered human security approach.

${ }^{11}$ Specific strategies include:

- designing and implementing innovative strategies to increase the number of women at all levels in security sector agencies, including in key decision making positions;

- developing and adopting policies on sexual harassment, gender-sensitive human resources, discrimination against people living with HIV and AIDS, and others;

- developing and adopting a Code of Conduct for security agencies with emphasis on domestic violence;

- developing and implementing procedures to address violations of the Code of Conduct, in order to provide a safe working environment for women;

- appointing a gender adviser in all security sector agencies for identifying and providing opportunities for capacity building and gender mainstreaming;

- implementing mechanisms to disaggregate data by sex and age, where applicable, in the case management system (particularly in LNP and BCR);

- developing and implementing gender-sensitive community policing, problem solving and crime prevention methods training (ongoing and in-service) as well as specialized training on GBV and HIV and AIDS; and

- designing and implementing specific capacity building programs for the Women and Children Protection unit of the LNP.

\section{Pillar II: Economic Revitalization}

${ }_{12}$ Women and girls play a pivotal role in Liberia's economy. They are the major players in the agricultural sector, where they constitute most small-holder producers and the majority of the agricultural labor force. They produce 60 percent of agricultural products and play a critical role in the production of food crops, as well as processing food and cash crops. They carry out 80 percent of trading activities in rural areas and play a vital role in linking rural and urban markets through their informal networks. In urban areas, women and girls predominate in small-scale trade, often in the informal sector. Only 2 percent of those in the formal sector in Liberia are women ${ }^{79}$.

${ }^{13}$ Despite women's and girls' important economic role, they have limited access to the inputs and services essential to carrying out their productive functions, and are absent from important economic sectors. Women have less access than men to productive inputs and services, including land, skills training, basic tools, and technology. This lack of access is notable in agricultural production, where most rural women and girls are employed; it limits women's economic advancement in rural areas. Similarly, lack of access to

79 World Bank/MoGD, Liberia Gender Needs Assessment: Towards Women’s Economic Empowerment, 2007 
training and to larger credit lines limits the ability of women to graduate to the formal sector in urban areas. Women also are severely handicapped in their access to formal labor markets due to lack of education.

${ }^{14}$ Expanding women's and girls' economic opportunities will contribute to economic revitalization and poverty reduction. Liberian women and girls are dynamic entrepreneurs, judging by the proportion of self-employed women (77 percent compared with 40 percent men) in urban areas. 80 Expanding economic opportunities for women will contribute to revitalizing the economy. Additionally, as Liberian women spend a higher proportion of their income than men on food and education, 81 expanded economic opportunities for them will have positive effects on family welfare, food security, and poverty reduction.

${ }^{15}$ The PRS aims to create the enabling environment to support and expand women's and girls' economic role, and in turn their contribution to the revitalization of the economy by focusing on four areas: increasing women's productivity and capacity; supporting and expanding women's role in the rural and urban value chain; increasing women's participation in non-traditional segments of the economy and the labor market; and strengthening Liberia's institutional capacity for gender and economic policy analysis and formulation.

${ }^{16}$ PRS interventions under Pillar II include:

- conducting an assessment and producing a strategy paper on the demand for marketable skills for men, boys, women and girls in traditional and non-traditional economic sectors to enhance employment;

- implementing skills training for 5,000 women and girls in areas with clear market demand, including in non-traditional sectors;

- piloting programs in urban and rural areas to ensure girls' safe transition from schools to work, and evaluating feasibility for replication and scaling up;

- reforming the Vocational Training System based on the assessment of marketable skills.

- addressing the needs of female producers in all rural programs designed to enhance access to key productive assets and services in the agricultural value chain (land, credit, information, training, social capital, etc);

- implementing a Rural Women's Empowerment Project which strengthens the institutional capacity of female producers' and entrepreneurs' organizations and provides support services including skills and business training, access to credit, technical assistance and business support services, market information;

- building the capacity of MoGD on gender and economic analysis;

- implementing a capacity building program for technical staff of LISGIS; and

- implementing a capacity building program for technical staff of the following ministries to conduct gender analysis of their sectors: MPEA, MoF, MoA, MoCl, MoL, MPW, and MLME.

\section{Pillar III: Governance and Rule of Law}

${ }^{17}$ With respect to governance and the rule of law, a central goal is to fully guarantee women and men equity in the enjoyment of their human rights. While further consultation is to be undertaken, the Government is considering or taking steps to ensure that:

80 Ministry of Planning and Economic Affairs/World Food Program. Comprehensive Food Security and Nutrition Survey, 2007
81 Ministry of Planning and Economic Affairs/World Food Program. Comprehensive Food Security and Nutrition Survey, 2007 
- all public institutions establish an environment conducive to meaningful participation and advancement of women by adopting policies and procedures to eradicate gender inequalities within the public sector, including relevant provisions in the draft Civil Service Code of Conduct;

- all public institutions have a 'Gender Focal Point' in charge of monitoring and advising on gender initiatives;

- constitutional reforms protect fundamental freedoms and rights including property, reproductive, economic and security rights;

- a local governance system is established that promotes gender equality and balance;

- local women's organizations and networks are strengthened to bring out the voices and perspectives of women into local governance and local decision making bodies;

- a minimum of 30 percent of all staff members, including in the managerial and senior management level in the legal sector and law enforcement agencies are women; and

- the legal sectors elaborate strategies to increase the number of female staff, lawyers and legal aids as well as ensure their retention.

${ }^{18}$ The aim of good governance is to enable full and equal access to all citizens. This is fundamental to the fight against inequity and thus poverty, as it allows for citizens participation in decisions on resource control, access and allocation. In Liberia, the gender imbalance in Governance is a clear manifestation of gender inequity. Women are represented in highly visible positions in the sector but the overall political representation of women is limited. As Liberia takes measures to reconstruct itself into equitable democratic nation, addressing issues of structural inequity and marginalization of women is critical. To encourage women's participation in governance processes, strategies include:

- developing and adopting policies in all public institutions and government agencies to address gender inequities, including Codes of Conduct, sexual harassment policies, human resources policies, domestic violence policies, and non-discrimination policies;

- establishing Gender Focal Points in all line ministries and public institutions and building their capacity;

- continuing the process of legal reform to ensure protection of fundamental freedoms and to promote equal rights including economic, property and reproductive rights, and security;

- enhancing participation of women and encouraging grassroots networks to bring out the voices and perspectives of women into local governance and local decision making bodies; and

- ensuring that land reforms adequately address issues of land access and ownership.

${ }^{19}$ The primary concern in the area of Rule of Law is to improve access to justice and the quality of service of legal institutions, including to survivors of GBV. Activities related to Rule of Law to be conducted during the PRS implementation period include:

- implementing the National GBV Plan of Action;

- developing and implementing gender-sensitive capacity building programs for officers in the legal sector and in law enforcement agencies;

- increasing the number of women staff at all levels of legal and law enforcement agencies;

- establishing legal aid mechanisms, including through civil society organizations, to provide legal ser- 
vices nation-wide particularly to vulnerable and indigent clients;

- establishing a referral and case management system disaggregated by sex and age for survivors of GBV;

- bolstering the Government's efforts to date to establish a clear, transparent and secure chain for GBV survivors from reporting the crime through the process of conviction and punishment; and

- developing a national framework on customary practices and raise the awareness of all legal and judicial actors.

\section{Pillar IV: Infrastructure and Basic Services}

${ }^{20}$ As the infrastructure development preferences of men and women are often different, women and men will be involved in the planning, programming and implementation processes of infrastructure projects. Women will also be represented in the ranks of those employed in the construction and rehabilitation of infrastructure.

${ }^{21}$ In the area of education, the Government is committed to providing universal primary education and implementing the National Action Plan 2004-2015: Education for All, and has prioritized girls' education through the National Girls Education Policy. Still only 29 percent of women are literate as opposed to 62 percent of men. The dropout rate for girls is particularly high across all counties. The gender imbalance among schoolteachers is an area of concern too; less than half of the teachers in primary school are female and in secondary school female teachers decrease to one third of the male teachers. ${ }^{82}$ In addition to the seven strategic objectives for education (See Section 9.9), which will be achieved to improve outcomes for all learners, other specific measures to encourage girls' access to education are being considered:

- review and revise the National Girls Education policy and Education for All policy;

- conduct and implement findings of an assessment study to analyze the causes of the wide gender gap in primary and secondary enrolment;

- promote gender balance of teaching-staff at all levels by developing strategies to improve retention of female school teachers and to encourage further training;

- revise curriculum to include GBV, Sexual Exploitation and Abuse, and Human Rights; and

- expand adult literacy programs taking special measures to increase female enrolment, retention and completion of program.

${ }^{22}$ The two decades of conflict devastated the health sector. Of the 325 health facilities before the war, about 95 percent were partially or wholly destroyed. Liberia has already developed a National Health Policy (2007), which provides for Basic Package of Services at all levels of health care. Though the National GBV Plan of Action lays out various systematic interventions for the prevention of GBV and care support for GBV survivors, the government will ensure that the implementation of National Health Policy is gender-sensitive and responds to the needs of GBV survivors through:

- developing and implementing guidelines for gender-sensitive health care, including training programs for health care staff, to foster attitudinal change and provide humanistic health care, with a particular emphasis on women and children in general and GBV victims in particular;

82 UNESCO, 2007 
- developing and implementing a gender-sensitive Social Welfare Policy with emphasis on specific services available to GBV survivors, PLWHA, orphans and other vulnerable women and children, including psycho-social support;

- developing gender-sensitive protocols and procedures to respond adequately to GBV cases: provision of post-exposure prophylaxis (PEP), other medical services, appropriate referral, and forensic evidence;

- training medical and auxiliary health care providers with respect to those protocols; and

- developing and integrating modules on gender and HIV and AIDS in the curricula in all colleges and institutions for health care workers. 


\section{Cross-Cutting Issue Strategy Brief: Peacebuilding}

\section{Introduction}

This annex to the PRS expands on the content related to peacebuilding, a cross-cutting issue featured under all four Pillars. While the PRS is an important mechanism through which peacebuilding can be integrated into poverty reduction, the PRS is itself an exercise in peacebuilding. The process of preparing the PRS through broad-based participation and consultation, reaching consensus, and transparent and accountable decision-making inspires confidence in the government and in peaceful coexistence. These principles, in guiding not only the preparation of the PRS, but more importantly the process of governing, are central to building trust and consolidating peace. The successful realization of this vision depends on whether the PRS reflects and addresses the complexities of a country recovering from violent conflict.

\section{Context}

${ }^{2}$ The origins of violent conflict in Liberia lie in deep-rooted structural cleavages, social divisions, marginalization and exclusion, perpetuated by the state and by those who controlled the state. Liberia remains a highly fragmented society, while the cumulative legacies from violence and impunity have deeply entrenched distrust between citizens and the state. The majority of Liberians lives under difficult conditions and are undoubtedly weary of war, but peace remains fragile and is not deeply entrenched in the minds and practices of society and politics.

${ }^{3}$ This post-conflict reality constrains Liberia's development efforts. Given that violent conflict often results from and exacerbates inequities, disproportionately affects the poor and increases the depth of poverty, then any efforts to reduce poverty must simultaneously address the effects of conflict. Strategies for development must be informed by an understanding of the residual potential for conflict, as well as the potential for peace consolidation.

\section{The Concept of Peacebuilding}

Peacebuilding is sometimes incorrectly perceived to be a distinct set of activities or specialist knowledge. Additionally, it is sometimes perceived to be an external concept imposed on national governments and local communities by the international community.

Peacebuilding is neither; instead it embodies a vision of a society that is peaceful, respects and protects the rights of citizens and ensures that disputes and tensions which are normal to any society are handled in a way that prevents their escalation into organized violence. Most societies comprise diverse communities and identities, while political competition and struggle for power are part of the routine functioning of the political system. Where Liberia differs is the absence or weakness of structures and practices for dealing with and managing its plurality and fragmentation that obviates the need to resort to violence.

Peacebuilding is not focused on resolving all conflicts which are normal to any society, but on the processes which transform such disputes into intractable, polarizing issues and on strengthening those structures and processes that minimize the possibility of escalation into violent conflict. Although there are activities that may have explicit peacebuilding objectives, integrating peacebuilding into the PRS does not necessarily change what is being done, rather it focuses on the "how". An integrated peacebuilding and conflict sensitive approach to poverty reduction implies that poverty reduction and development objectives need to be weighed against the peacebuilding objectives of whether such efforts aggravate conflict situations or help to strengthen the foundations for peace and a respect for human rights. 
${ }^{4}$ Going forward, Government policies and programs that do not consider the impact of activities on sources of tension in society can not only undermine poverty reduction and development but also risk aggravating those tensions, adding to distrust and perceptions of failed expectations and in essence prevent the consolidation of peace. The incorporation of peacebuilding principles and ideas into the PRS constitutes the initial step by Government towards conflict sensitive policies and programs. While current Government capacity to develop and implement conflict sensitive policies and programs is limited, special focus will be placed on developing the requisite knowledge and skill sets across Government ministries and agencies over the PRS period.

${ }^{5}$ Peacebuilding is a two-fold process requiring the dismantling of structures of violence and the construction of structures of peace. It is an evolving process whereby the conditions for sustainable peace are institutionalized in society. PRS policies, planning and program implementation are meant to:

- address the consequences and legacies of violent conflict;

- address the structural conditions, processes and attitudes that sustain social and political division and encourage the use of violence; and

- support those structures, institutions, practices and attitudes that strengthen the prospects for peaceful coexistence.

${ }^{6}$ While the causes of violent conflict in Liberia are multi-faceted, deep-rooted and complex, there are six key issue areas which remain problematic and cut across the pillar areas. They each require focused attention throughout all components of the PRS to mitigate their potential to mobilize groups for violent action.

- Land conflicts - Land disputes have become a manifestation of conflict over identity and citizenship issues. There is a proliferation of land disputes over tenure and ownership, the reintegration of refugees and ex-combatants into communities in relation to property, the property rights of women, and private concessions.

- Youth - Young men and women have been denied education, have had their transition from childhood to adulthood interrupted by war, have few skills and are often burdened with many of the responsibilities of adults, particularly as heads of households and income earners. Unmet expectations with this group could trigger significant social unrest, not only in Liberia, but across the region.

- Political polarization - Reaching political consensus on the rules of the game, supporting reconciliation rather than polarization, and de-linking political and economic power are essential for ensuring that the political system is a vehicle for peaceful political competition. In its absence, political actors are likely to resort to other means to achieve their ends, including intimidation and violence.

- Management of natural resources - Liberia's wealth of natural resources has not benefited society as a whole but has served to create inequalities and resentment. The Government has taken a number of important steps to redress this including the Forestry Reform Law and the Chain of Custody Act. It is important for the PRS to recognise the importance of balancing the needs of the poor with the needs for national development and revenue generation.

- The State and its citizens - The Liberian State historically has been more predatory in nature than protective of its citizens; it created and exacerbated social divisions by marginalizing and denigrating certain social groups, and consolidating the domination of elites. Political and economic power are linked, exacerbating urban-rural inequality.

- Weak and dysfunctional justice systems - The formal and customary justice systems do not provide justice and have created a system of impunity. 


\section{Objectives}

${ }^{7}$ Integrating peacebuilding into the PRS requires the government to adopt a new set of principles which are central to the process of democratization, of improving governance and of consolidating peace. The media, civil society organizations, the private sector and academia have an important role to play in ensuring the government upholds these principles:

- Meaningful Inclusion and Participation - Creating space for ordinary Liberians across every region and class to speak on the issues that concern them through sustainable processes of consultation is fundamental to peace. The process of designing and implementing the policies and programmatic activities outlined in the PRS must be broad-based and inclusive to all ethnic and identity groups such as women and girls, men and boys, ex-combatants, war-affected populations, political parties, and civil society organizations.

- Empowerment - In order for all Liberians to participate, disadvantaged, grassroots and rural groups need to be empowered by giving them the tools and capacities to participate and take ownership of decision-making processes.

- Consensus building - It is not enough to listen to different perspectives; somehow they must be translated into the public and national interest as a basis for collective action. Reaching consensus on difficult issues involves compromise and negotiation, which are some of the mechanisms for managing conflict.

- Responsiveness - If no action is taken by government in response to the concerns expressed by Liberians, then the exercise of consultation is futile. Decision-making, planning and implementation needs to demonstrate that the government is responding to public priorities by taking concrete action.

- Transparency and accountability - Government actions must be visible to the public to ensure they are taken in the interest of all Liberians and for the sake of any personal or group advancement. The mismanagement of the past, in which a small elite gained economic advantage over the majority, was a key factor in the conflict.

- Fairness and impartiality - Rules and opportunities must apply to all Liberians equally across society, regardless of status. The failure of the state in the past to be a fair and impartial mediator was another key source of conflict.

\section{Pillar I: National Security}

${ }^{8}$ Security and stability are the foundations for peace in Liberia. In the immediate post-war phase, national security was concerned with demobilization and the reintegration of ex-combatants. While this process is not yet complete, national security in Liberia has shifted to broader issues relating to a national security strategy, security organs, and building trust in security sector institutions. At the same time, other forms of violence threaten the law and order of the country including criminal violence, violence against women and adolescent girls, and the potential for social unrest.

9 The objective of a peacebuilding approach to the security pillar requires that during the three year period, the policies, structures, operational practices and attitudes of the security sector lead to functioning and responsible institutions that are focused on protecting the security of the Liberian people as a whole. These recommendations were adopted by the pillar:

- Ensure the national security policy is national and serves to protect all Liberians equally across the country. This policy and its implementation must actively transform the security sector into democratic, apolitical, impersonal, ethical and professional institutions that are based on national security considerations, merit and accountability. 
- Ensure that recruitment of security sector institutions represents all identity groups, at all levels including the officer corps and senior management. Anticipate and develop contingency plans for shortfalls in meeting recruitment targets, uncertain budgetary support to meet salary and force requirements, as well operational limitations in responding to potential security threats.

- Develop and enforce stronger measures to protect adolescent girls and women. Take the necessary steps to provide basic law and order in the country.

- Strengthen civilian oversight and democratic accountability of security institutions by training the political class and civil society groups to perform this monitoring role.

- Build trust and confidence in these institutions by instituting systems of accountability and enforcing transparent punitive measures in response to violations of conduct to prove that impunity will not be tolerated. It must be clear to the public that no member of the security or police forces is above the law.

- Plan and prepare for situations where there are rising tensions, whether social unrest, local conflicts, land conflicts, or ethnic clashes. The LNP and AFL will put a strategy in place for responding to such conflicts to prevent their escalation and to ensure the security forces do not aggravate the problem through their own actions.

- Create representative county- and eventually district-level committees to provide a forum in which security issues relating can be addressed locally. Such committees should be coordinated with decentralized local government, civil society and other stakeholders.

\section{Pillar II: Revitalizing the Economy}

${ }^{10}$ The revitalization of the economy is central to reducing poverty and for redressing the imbalances that fuelled conflict. However, economic revitalization alone is not enough to ensure peace will last in Liberia. Economic growth, increased production and structural reform can build the conditions for peace if they bring sustainable livelihoods throughout the country. However, unless structural inequities and deficiencies are addressed, they will be perpetuated and sustained even as development occurs. Political decisions regarding which sectors, which plantations, which concessions, and which regions receive significant inputs can impact negatively or positively on the factors that strengthen or weaken peace. The distortions created by the war economy, as well as structural inequalities between groups, need to be addressed.

${ }^{11}$ The Government will only be involved in that which the private sector cannot do or should not do. Thus the PRS gives a primary role to the private sector and to an extent, market forces. Notwithstanding the small scale and limitations of the private sector in Liberia, the business class has not been a neutral or impartial actor during Liberia's many crises. Safeguards, regulatory policies and political oversight will be put in place to ensure that the interests of national economic growth are balanced against the immediate needs of the poor.

${ }^{12}$ Given the historic economic discrimination against certain groups in Liberia and their related impoverishment, a peacebuilding approach to economic revitalization requires that the government's economic revitalization strategy be pro-poor and includes targeted measures to address inequities and grievances between groups. The implementation of the economic growth strategies, which have equitable growth at their core, will need to include consideration of:

- decisions about where investments are made and which sectors are prioritized. These will be based on competent analyses of the impact on the communities involved, and the nation as a whole, in order to create a society where economic opportunity is equally available to all Liberians irrespective of identity, class or region. These decisions will also be guided by the principle of separating economic opportunity from political power, where access to and control of the state no longer serve as the main avenues to economic wealth; 
- development of a formula for equitable revenue distribution through legislation and concrete actions. Equitable distribution does not occur automatically through market forces or through good intentions. The ad hoc approach of individual companies providing revenue to the national government and to local communities creates space for corrupt practices and prevents the development of reliable, sustainable and systematic budgeting practices;

- employment creation. Many jobs will be created over the PRS implementation period, but equal attention will be paid to the vast numbers who will remain unemployed;

- extension of economic benefits to rural areas. Policy and planning will recognize urban and rural needs, and thus take action to meet the priorities of each;

- ensuring that private sector development does not consolidate or contribute to socio-economic cleavages. The Government will enforce strong regulatory and monitoring frameworks to ensure the private sector upholds international labor and human rights laws; and

- targeting youth and women. Women are more likely to invest in food production, health and education, which directly consolidate peace.

\section{Pillar III: Governance and Rule of Law}

${ }^{13}$ Good governance and the rule of law are the prerequisites of a well-functioning state and therefore help to sustain peace both directly and indirectly. Liberia is a highly fragmented society and the system of governance is not yet able to deal with this fragmentation. Consensus on the rules of the game to ensure peaceful political competition is not yet apparent, while the practices of cooperation and compromise for the public interest are underdeveloped. The process through which conflicts in society are negotiated and resolved is at the very heart of governance.

${ }^{14}$ During the PRS implementation period, the Government will take the following steps toward strengthening governance and rule of law:

- Build trust in government institutions by taking more aggressive action on governance reform. Provide more resources to the Governance Commission and set deadlines for recommendations on key policy areas including security sector reform, land and decentralization.

- On the basis of the roadmap for the creation of the Liberian National Land Commission, implement measures to harmonize land ownership, access to land, and the enforcement of formal land titles. Institute dispute settlement mechanisms for the effective and conflict sensitive resolution of land conflicts. Establish a joint government and civil society monitoring and evaluation mechanism for handling land conflicts to reduce tensions.

- Build the capacity of the Truth and Reconciliation Commission, specifically the Healing and Reconciliation Section and its civil society partners, to enable them to bring Liberian society together in a process of healing, reconciliation and reunification.

- Provide sufficient resources to the Independent National Commission on Human Rights (INCHR) to enable it to lead efforts to integrate the protection of human rights throughout the work of the government and ensure that is realized in practice throughout Liberian society. Standardized human rights training, monitoring, reporting and advocacy need to be strengthened through civil society networks, the educational system and within government structures.

- Prioritize legal reform to set the stage for constitutional reform, and develop a strategy for responding to conflicts and tensions arising over these changes in order to prevent political paralysis. 
- Develop a coherent strategy to harmonize the statutory and customary justice systems and strengthen the credibility and legitimacy of justice institutions. Accelerate legal training and dissemination of legal codes, redress corruption and monitor community-based justice, while reforming archaic laws and laws that restrict the rights of women. Build capacity in alternative dispute resolution, conflict resolution mechanisms, and certain traditional means of resolving disputes that contribute to reconciliation.

- Institute a clear and coherent decentralization policy and strategy, while taking steps to harmonize formal and local community-based and traditional structures of governance. Integrate findings from the CDA consultations into the process of decentralization, and develop processes that institutionalize community consultation.

- Empower the Boundary Harmonization Committee which is mandated to redraw and streamline through consultative town hall meetings, the demarcation of municipalities and chieftaincies. Develop a strategy to resolve disputes that are emerging from the work of the committee.

\section{Pillar IV: Infrastructure and Basic Services}

${ }^{15}$ The scale and scope of the challenges to build and restore infrastructure and deliver basic services to the population are enormous, with for example 95 percent of health facilities and 65 percent of educational facilities damaged or destroyed during the war. Accessibility to basic services across the country is poor and unequal across regions, with many services provided by the UN or humanitarian agencies. These agencies are now in the process of withdrawing which could result in service gaps if the state is unable to assume responsibility over these facilities. Religious institutions have also played a significant role in providing education and health services in rural areas. Government regulation and oversight is needed to ensure consistency, quality, as well as monitoring their important role in civic education.

${ }^{16}$ The objective of a peacebuilding approach to the rehabilitation of infrastructure and delivery of basic services pillar is to ensure that decisions, policy, planning and program implementation are inclusive, fair, and equitable in terms of geography, ethnicity and gender. To that end, the Government will:

- ensure that the provision of basic services is more equitable across the country and that staff recruitment is more representative. Training will include awareness of human rights and conflict sensitivity. Civil service salaries must progressively be adjusted to a level that retains qualified staff and prevents corruption;

- end discriminatory practices that excluded children from school and led to the neglect of certain areas. In the past, education has been a means by which certain groups dominated Liberian society and sustained their domination. Build an inclusive education system that empowers Liberian children and youth and that establishes equal access to opportunity;

- ensure the national curriculum develops and includes an impartial and objective history of Liberia, as well as strong civic education teaching, with peace education and human rights components. The Government will develop accelerated adult and remedial education program specifically targeted at youth. Young adults cannot attend the same schools and program as children, even if their educational levels are equivalent, and thus tailored educational opportunities, in addition to vocational training, are urgently needed;

- ensure the health system at the policy, planning, and delivery levels focuses on equitable delivery of quality and reliable health services across the country; and

- balance the competition for access to scarce resources in a manner that is sensitive to the needs of those whose needs will be unmet. In selecting priorities in the rebuilding and maintenance of roads, housing and potable water systems, the Government will ensure that strategies for the extension of infrastructure around the country are fair, balanced and based on consultation with local communities. 


\section{Cross-Cutting Issue Strategy Brief: Environmental}

\section{Issues}

\section{Introduction}

${ }^{1}$ This annex to the PRS expands on the content related to environmental issues, a cross-cutting theme featured under all four Pillars. The people of Liberia and especially the poor are critically dependent on fertile soil, clean water and healthy ecosystems for their livelihoods and wellbeing. This reliance creates complex, dynamic interactions between environmental conditions, people's access to and control over environmental resources, and poverty. In addition to being vulnerable to environmental hazards, the poor are usually confronted by economic, technological and policy-related barriers in deriving full benefits from their environmental assets. Taking strategic actions based on knowledge of the poverty-environment relationship is a prerequisite for enduring success in the effort to reduce poverty. Investments in the productivity of environmental assets will generate large benefits for the poor and for the enhancement of overall growth.

${ }^{2}$ While this Annex mirrors most of the content of the PRS that specifically mentions environmental issues, the strategies and actions discussed here are not the only PRS interventions that relate to the environment. To site but one example, efforts in the transport sector to increase the number of bus riders and reduce the number of taxis plying the streets will have direct positive effects on air quality in urban areas.

\section{Context}

${ }^{3}$ Since 2003, significant and visible progress has been made in building Liberia's environmental governance framework and reforming natural resources management. Key achievements include:

- approval of the National Environmental Policy and adoption of two major environmental laws (Environment Protection and Management Law, and the Environmental Protection Agency Act), which came into effect in April 2003;

- development of a National Biodiversity Strategy and Action Plan;

- comprehensive assessment of Liberia's forest resources (Liberia Forest Reassessment) carried out by Fauna and Flora International in collaboration with government partners;

- active participation in multilateral environmental agreements, regional cooperation initiatives and implementation of projects supported by the Global Environment Facility;

- establishment of the Environmental Protection Agency (EPA) in 2003, which became fully functional with the formation of a Board of Directors and Policy Council in 2006;

- approval of the Forestry Reform Law in 2006;

- admission of Liberia into the Kimberly Process Certification Scheme and preparation of a draft Mining Law;

- publication of Liberia's first State of the Environment Report in June 2007, establishing a baseline for monitoring environmental conditions and trends; 
- development of EIA administrative procedures;

- preparation of a national action plan and strategy to address land based sources of marine pollution;

- deployment of environmental inspectors in seven counties by July 2007 ;

- establishment of a basic environmental laboratory facility at the EPA;

- certification of environmental consultants to conduct environmental impact assessments;

- establishment of environmental units in government ministries and agencies (currently underway);

- development of a National Adaptation Program of Action to Climate Change;

- preparation of a draft Integrated Water Resources Management Policy; and

- preparation of a draft National Energy Policy.

\section{Objectives}

${ }^{4}$ The PRS lays the foundation for sustainable protection and use of Liberia's natural environment for the sake of improving livelihoods and wellbeing. The "resource curse" that characterized Liberia's past was typified by mismanagement of the proceeds from extractive industries and their misuse that undermined national security, governance and rule of law; and channeled most of the benefits of economic growth to a small elite. Eliminating this curse requires the establishment or restoration of proper administration and management of natural resource uses. The PRS also works to bolster government efforts to protect against natural disasters and emergencies, including climate change risks.

\section{Pillar l: Security}

${ }^{5}$ The PRS calls for policy and legal frameworks for more robust and transparent oversight of natural resource extraction and ensuring a more equitable distribution of the proceeds, particularly at the community level. The laws pertaining to extractive industries will be written or modified to comply with international standards. The Government will also work to increase preparedness against natural disasters and emergencies, including climate change risks.

${ }^{6}$ To these ends, the Government will:

- train security and customs officers at international border crossings to combat illegal trade in commodities of environmental concern, particularly in endangered species, hazardous wastes and chemicals, invasive alien species and living modified organisms;

- consider viable options to prevent illegal mining, logging and wildlife poaching in protected areas, especially Sapo National Park, concentrating on alternative livelihood support projects for communities adjoining protected areas; and

- develop a national disaster management policy and plan and establish an inter-sectoral coordination mechanism to increase security against the priority threats of floods, coastal erosion, forest fires and chemical spills. 


\section{Pillar II: Economic Revitalization}

${ }^{7}$ Exploitation of Liberia's abundant natural resources will be the major driver of poverty alleviation in the PRS implementation period and beyond. Thus the need to arrest the following trends:

- rapid deforestation rates (estimated at two percent per annum) due to unsustainable agricultural practices, decreasing fallow periods, the cutting of trees for fuelwood and charcoal production that results in the degradation of habitats including soil erosion and water pollution, and the depletion of natural resources including wildlife;

- unsustainable patterns of production, consumption and waste disposal, which have proliferated due to the high rates of population growth, urbanization and the ongoing reconstruction drive;

- unsustainable use of natural resources including the coastal sand mining that leads to coastal erosion;

- uncontrolled and illegal exploitation of marine fish stocks, mostly by foreign enterprises;

- unsustainable and uncontrolled harvesting of wildlife for bushmeat; and

- conflicts of land use between extractive industry and subsistence farmers.

${ }^{8}$ To these ends, the PRS includes policies and programs to ensure that a significant percentage of the revenue generated from timber and mining concessions and rubber plantations reaches and benefits the poor and assists in poverty reduction; and for building effective management structures to ensure sustainable utilization of physical and biological natural resources. Specific priority actions include:

- land policies to create security of tenure;

- implementation of new FDA policies and strategies for commercial, community and conservation forestry;

- development of technical guidelines for the agriculture sector to ensure that agriculture policy, particularly for swamp reclamation, takes full account of the economic goods and services provided by wetlands to the poor;

- development of a social and environmental policy and strategy for the rubber sector;

- pilot projects on community forestry;

- development of a strategy for access to modern energy services by the poor;

- pilot projects for sustainable cultivation practices;

- development of an integrated coastal zone management plan;

- finalization of the integrated water resources management policy and development of an action plan;

- environmental awareness-raising campaigns;

- development and publishing of environmental quality standards, as required by the Environment Protection and Management Law. 


\section{Pillar III: Governance and Rule of Law}

${ }^{9}$ The poor governance, lawlessness and culture of impunity that characterized Liberia's past led to serious environmental problems such as illegal and unsustainable exploitation of the natural capital and the neglect of water quality and public health standards. Reckless exploitation of natural resources and pollution of the environment contributed to feelings of powerless, apathy, suspicion of the judicial system and disinterest in obeying the law.

${ }_{10}$ A new framework for adequate resource access and tenure by the poor, proper land use planning, and natural resource management of concessions and protected areas will help to minimize or avert conflicts over resource use. Important prerequisites for sound environmental governance are:

- strengthening of democratic processes at both the national and decentralized levels;

- building the confidence of the public in the judicial system;

- re-tooling the judicial officers for effective enforcement of environmental laws; and

- instituting workable systems of transparency and accountability at all levels of public management.

${ }^{11}$ An institutional coordination mechanism centered on a vibrant Environment Protection Agency (EPA) can enable key environmental stakeholders to act in concert towards the fulfillment of the objectives of the national environment policy and law. The new environmental governance regime will also be capable of engaging effectively in regional cooperation with neighboring countries in the management of trans-boundary environmental resources and in the enforcement of international conventions. Over the PRS implementation period, the Government will work to:

- ensure the strict application of Environmental Impact Assessment (EIA) requirements for all key infrastructure and industrial projects, and publish sector-specific EIA guidelines for infrastructure, forestry and mining;

- create security of rural land tenure;

- create conditions to encourage the private sector to provide waste management services through open and competitive tendering processes;

- review the Environmental Policy and the Environment Protection and Management Law (2002) to identify priority subsidiary regulations and/or guidelines for their implementation;

- promote transparency and accountability and raise public environmental awareness;

- conduct periodic workshops to inform and train staff from line ministries, agencies, the private sector and NGOs on their duties and responsibilities under national environmental laws;

- strengthen the capacity of NGOs and civil society to monitor the implementation of agreements between timber and mining concessions, the Government, and communities and ensure that funds are channeled towards poverty reduction;

- deploy EPA environmental inspectors in the remaining nine unstaffed counties;

- establish EPA county offices, and equip them to ensure proper functioning;

- establish Environment Units in line ministries; and 
- develop information materials to improve environmental awareness for both the government and general public.

\section{Pillar IV: Infrastructure and Basic Services}

${ }^{12}$ From an environmental perspective, perhaps the most important impact of the collapse of infrastructure during the war years has been the heightened dependency on biomass for fuel. Nearly the entire population of Liberia today relies, in part or in full, on charcoal and fuel wood to meet their energy needs, and the growth in demand for wood has significantly accentuated deforestation and biodiversity loss. Inadequate access to water, sanitation and waste management services have adversely affected public health and hygiene, especially for the poor and internally-displaced people in rural and peri-urban areas. The poor road network in the country is impairing market access and delaying the economic empowerment of the poor. While investments in the expansion of road networks and energy services are essential for the revitalization of household economies, such investments must avoid or minimize adverse environmental and social impacts, and must be preceded by impact assessments to protect the poor from disproportionately bearing the cost and risks of development.

${ }^{13}$ Priority actions for the environment under Pillar III include:

- extending grid electricity throughout Monrovia and its environs and to county headquarters and other areas

- developing hydro capacity and other renewable energy sources

- increasing access to human waste collection and disposal facilities from 15 percent to 40 percent, including 35 percent of the rural population

- strengthening capacity in urban master-planning and management.

- developing a national Solid Waste Management policy, strategy and regulations, to help ensure effective coordination and sustainability of present efforts in the disposal of domestic refuse, clinical waste and toxic waste.

- developing a waste management policy and enacting subsidiary regulations, as required by the Environment Protection and Management Law;

- including in the above a clinical waste policy and regulations;

- undertaking engineering designs and EIA for the Mount Barclay landfill facility in Monrovia;

- preparing a plan and technical specifications for the closure of the Fiamah dump site in Monrovia;

- developing an integrated water resources management strategy and road map, to include issues of water supply, sanitation and the control of water borne disease; and

- designing and implementing pilot projects for water purification, rainwater harvesting and shelter construction. 


\section{Introduction}

${ }^{1}$ This annex expands on the content related to HIV and AIDS, a cross-cutting issue featured under all four of the PRS Pillars. HIV and AIDS is a major challenge in Liberia's transition from the emergency phase to recovery and development. The national response to HIV and AIDS is factored into Liberia's development and poverty reduction plans because the epidemic has the potential to slow the progress of many initiatives meant to build much-needed human capital and revitalize the economy. Ensuring that this does not happen requires that the citizens be empowered with the appropriate skills to arrest the spread of HIV and to minimize the impact. Integrating HIV and AIDS into the national poverty reduction strategy, and across the Pillars, helps to create the necessary policy and planning environment for a comprehensive, multi-sectoral national response.

${ }^{2}$ While this Annex mirrors most of the content of the PRS that specifically refers to issues of HIV and AIDS, the strategies and actions discussed here are not the only PRS interventions that will help to arrest the epidemic. To site but one example, investments in better equipping and building the capacity of the Liberia Coast Guard and the Bureau of Immigration and Naturalization will help to mitigate human trafficking and illegal immigration, thus reducing any cross-border threat from STIs.

\section{Context}

${ }^{3}$ While further study is called for, two recent surveys provide insight on the burden of HIV in Liberia. The 2007 DHS is the first to use population-based testing to determine HIV prevalence. It sampled a total of over 7,000 households and estimates prevalence at 1.5 percent, or 1.8 percent for females and 1.2 percent for males. ${ }^{83}$ A previous estimate of 5.7 percent was based on the results of sentinel surveillance among pregnant women and girls attending ten antenatal care (ANC) clinics in urban areas. Because of their differing methodologies, the two surveys cannot be compared to show a trend over time, and the fact that the second is lower than the first does not in itself signal that the HIV level has decreased in Liberia.84 Future studies will seek to corroborate the ANC findings, especially in the light of the DHS finding of sero-positive HIV prevalence among the adult population of less than 2 percent.

${ }^{4}$ In any event, the prolonged civil war left most of the population of Liberia severely challenged in meeting their social, cultural and economic needs, thereby making them vulnerable to a sharp increase in HIV prevalence, the likely result of which would be a negative impact on development: increased child and adult morbidity and mortality, increased absenteeism at the workplace and in schools, and lower economic output, among other effects.

${ }^{5}$ HIV and AIDS-related vulnerability impacts a broad spectrum of the population, especially young people and females in particular, such that in Liberia as elsewhere, there is an increasing feminization of the epidemic. Already, evidence from the recent 2006 sentinel survey results indicate signs of increased HIV prevalence among young females aged 15-19 years (4.7 percent) and those aged 20-24 years (6.4 percent). 85 The burden of the epidemic reflects regional/county differentials, mirroring the relatively higher HIV prevalence of neighboring countries; both the DHS and ANC surveys found pockets of high prevalence along the eastern corridor bordering Cote d'Ivoire.

\footnotetext{
83 Population-based testing collects blood from a nationally representative sample of the population in their homes. This method provides direct information on HIV infection among adults.

${ }^{84}$ LISGIS. New National Survey Finds 2 Percent of Liberian Adults Have HIV; Fertility and Child Deaths Have Declined, July 13, 2007

85 NACP/MoHSW (Technical Assistance provided by WHO.), HIV Sentinel Survey among Antenatal Clients, 2006
} 
${ }^{6}$ The critical gap for the national response to HIV and AIDS can be summarized at three program levels:

- Understanding the epidemiology of the disease and designing interventions based on the evidence gathered. Policy actions will be directed to creating evidence-led and targeted delivery of HIV and AIDS prevention interventions and services when the new national strategic plan is developed. To date, no clear links between poverty and AIDS have been identified through local studies, and other potential factors driving the HIV epidemic in Liberia need to be fully understood. These relate to behavioral characteristics such as early age of sexual debut for young women; transactional sex fuelled by household food insecurity and precipitated by trends of poverty; sexual violence including coercion and rape; 86 low condom use; a high percentage of children not living with their parents; large numbers of youth out of school; an upsurge in drug and alcohol abuse; and socio-cultural factors such as uneven gender relationships, rapid urbanization and stigma.

- Institution-building including program development and coordination, and the lack of human capacity. In developing the national strategy, emphasis will be placed on targeted interventions and performance targets that increase accountability for policy makers, program implementers and development partners. The serious capacity constraints facing the NAC and NACP call for policy actions directed at strengthening the leadership and developing the partnerships necessary to develop the national strategy around shared goals such as the MDGs and universal access.

- Aligning the current response in Liberia with the UNAIDS-recommended Three Ones principles: one national HIV and AIDS authority, one national strategic framework and one national monitoring and evaluation framework. The recently re-constituted National AIDS Commission (NAC) will be strengthened to effectively manage the national response and to ensure that programs of its partners are well coordinated and aligned with national goals and priorities as enshrined in the Three Ones.

\section{Objectives}

${ }^{7}$ The program actions on HIV and AIDS in the PRS are intended to promote human development by reducing the impact of HIV and AIDS vulnerability, morbidity and mortality; enhance the management of the national response through support for the development and implementation of a new national multi-sectoral strategic framework led by the NAC; support efforts aimed at reducing new HIV infections through the provision of information to empower individuals to make informed decisions and avoid risky behaviors; and to scale up access to treatment and care services, mitigating the impact of the epidemic on those already infected and affected. In these efforts, the Government will harness the efficiency gains from partnerships with diverse stakeholders, ensuring programs are well-coordinated and aligned with national priorities.

\section{Pillar I: Security}

${ }^{8}$ The LNP, AFL, BIN and other security personnel are generally at higher risk of HIV than the population at large. It is therefore imperative during the PRS implementation period that they play a vital role in preventing and mitigating the impact of the epidemic. Each security arm will have a comprehensive HIV and AIDS program for all personnel and will support HIV prevention through sensitization programs that are promoted from the highest ranks to emphasize the importance of soldiers remaining HIV negative, and the serious impact that HIV and AIDS can have on national security. Security agencies will incorporate clauses in their codes of conduct that strictly forbid rape as an act of war or in any context, with severe punishments for soldiers who rape. Further, security agencies will continue to be trained in the prevention of GBV.

86 NAC and UNAIDS, Report on the Joint Review of the HIV and AIDS National Response in Liberia, September 2007. 


\section{Pillar II: Economic Revitalization}

${ }^{9}$ The epidemic has potential impacts on the economy at both the micro and macro levels. Thus, the Economic Revitalization Pillar of the PRS incorporates HIV prevention, treatment, care, and impact mitigation into economic growth plans. As seen in many other countries, AIDS has the potential to reduce the labor supply and productivity levels; contract the tax base; weaken demand; discourage investment; reduce enterprise profits; and cause stigmatization of and discrimination against workers living with the disease, all of which would have a negative impact on economic growth.

${ }_{10}$ The Government will develop and implement workplace policies and plans that respond to HIV and AIDS prevention and care programs in the public, private and informal sectors. Already the NAC and the NACP have recognized this, and with the Ministry of Labor and the ILO, begun consultations to develop a national policy framework with representatives of employers and workers.

\section{Pillar III: Governance and Rule of Law}

11 The PRS implementation period will see the adoption of legislation and key policy actions to support Pillar III efforts aimed at supporting a comprehensive, multi-sectoral HIV and AIDS response, including:

- strengthening the capacity of the courts and law enforcement to provide legal remedy under the law for GBV;

- integrating HIV prevention interventions within GBV program activities;

- establishing the appropriate legal and legislative framework for NAC to its full mandate as a public service institution;

- developing the National Social Welfare Policy and Plan, to include HIV and AIDS prevention efforts and counseling for at-risk populations;

- supporting recent progressive legislation to protect against rape and other forms of GBV to ensure their full implementation with appropriate structures and trained staff; and

- ensuring that the rights of citizens to public information and the protection of basic rights are protected and upheld. Among these are actions directed at ensuring adequate protection under the law for victims of rape and sexual violence, stigma and discrimination, and promoting confidentiality.

\section{Pillar IV: Infrastructure and Basic Services}

${ }^{12}$ The health sector naturally has the leading role in the national response to HIV and AIDS. The Government has scaled-up the number of PMTCT, VCT and ART services, which has resulted in a considerable increase in the number of people benefiting. But PMTCT, VCT and ART services are only part of the necessary response, which will also include innovative prevention methods, policy responses, economic impact mitigation and moves toward decentralization of response.

${ }_{13}$ During the PRS implementation period, the health sector will establish more uniform, governmentowned and structured strategic programming through:

- expanding and improving existing prevention interventions (ABC, VCT, PMTCT) at all levels;

- addressing the structural drivers of the epidemic (gender and income inequities, stigma, discrimination, and poverty) through evidence-informed approaches (community and family dialogues on sexuality and norms, male circumcision, etc.); 
- engaging youth and PLWHA as implementers;

- ensuring HIV and AIDS and tuberculosis service integration;

- taking steps to manage the lack of doctors, pharmacists and laboratory technicians; and

- strengthening the administrative and managerial capacity of the decentralized systems of the MoHSW including the NAC.

${ }^{14}$ The BPHS is the cornerstone of the National Health Plan ${ }^{87}$ and defines an integrated minimum package of standardized prevention and treatment services that includes HIV and AIDS prevention, treatment and care services covering such programs as VCT, PMTCT, ART delivery, and surveillance. The BPHS will be adapted for each level of the health system (community, health clinic, health center, county hospital, and tertiary hospital) and will be introduced incrementally to become functional in 70 percent of existing health facilities by the end of 2008. The BPHS ensures that adequate numbers of health workers are in place with the right skills.

${ }^{15}$ Within the context of expanding access to health care, the BPHS intends to increase geographic access to health services, especially the construction/upgrading of clinics and health centers, which comprise 94 percent of facilities. County health development plans are being prepared by County Health Teams with components addressing HIV and AIDS in collaboration with districts, health facilities, communities and local partners including private sector and faith-based partners.

${ }^{16}$ The Government will also launch, in cooperation with the private sector, an HIV and AIDS at the Workplace Program to address issues relating to prevention, treatment and care, with the goal of reducing the loss of workers, productivity, and revenue.

${ }_{17}$ The workplace strategy will also extend to teachers and school support staff. The education sector plays a vital role in HIV prevention activities among pupils and teachers, having potential to affect the most impact in reducing the incidence of HIV infection among the age group 15-24 years. This goal impacts all sectors by ensuring a new generation of healthy workers to contribute to the economic development of the country. The Government will design and implement a comprehensive national HIV and AIDS and reproductive health curriculum with age-appropriate information for each level of education from primary school through university; provide thorough training and material development (handbooks on HIV and AIDS and other written materials, posters, pamphlets, video and audio cassettes on specific topics) for all teachers on how to teach the curriculum and introduce this topic to students; enforce the teaching of the curriculum in all schools; decentralize the responsibility of ensuring that the Education for All goal incorporates measures to allow orphans and OVC to attend school, including the provision of school supplies and uniforms.

87 MoHSW, National Health Plan 2007-2011, 2007. 


\section{Cross-Cutting Issue Strategy Brief: Children and Youth}

\section{Introduction}

${ }^{1}$ This annex collects and expands on the content of the PRS related to children and youth, a cross-cutting issue featured under all four Pillars. The Government of Liberia is strongly committed to reducing and laying the groundwork for eliminating child poverty as a key feature of the PRS. With an overall poverty rate of about $64 \%$, children are at high risk of becoming the next generation of impoverished citizens unless substantive measures are taken to break the intergenerational cycle of poverty. In order to transform this vicious cycle into a virtuous one, the nation recognizes that its poverty reduction efforts must have children at the core.

${ }^{2}$ While this Annex mirrors most of the content of the PRS that specifically refers to issues affecting children and youth, the strategies and actions discussed here are not the only PRS interventions with positive effects for young people. For example, labor-intensive infrastructure projects such as roads and bridges will help to increase household incomes and lessen the incidence of families resorting to improper child labor, leading to potentially higher primary school enrolment rates.

\section{Context}

${ }^{3}$ Children and youth constitute 55 percent of Liberia's population. At present, around 17 percent of child deaths are attributable to malaria and another 20 percent to preventable environmental diseases such as diarrhea and cholera. Almost 40 percent of Liberian children are growth-stunted from poor nutrition, about one-third of under-fives are severely underweight; recent estimates indicate that one in five deaths in children under-five is attributable to malnutrition. 88 Less than half of all births are delivered by a health professional, which contributes to an unacceptably high (and apparently rising) maternal mortality rate. 89

${ }^{4}$ Furthermore, young female citizens suffer the brunt of Liberia's epidemic of gender based violence (GBV). The majority of Liberian girls have their first child before reaching the age of 18 due to forced early marriages and rape. As a result, the HIV infection rate among pregnant female adolescents and young women was 5.7 percent in 2007.90

${ }^{5}$ The majority of Liberia's young people have spent more time engaged in war than in school. Almost 35 percent of the population has never attended school, including nearly 44 percent of females. Illiteracy rates among children and young people remain high at 68 percent (male 55 percent and female 81 percent).

${ }^{6}$ Today only 45 percent of classrooms in the public sector are in good condition.91 Only 22 percent of public and community schools have seats, and only one-third of public and community schools have

\footnotetext{
88 Unless otherwise noted, statistics in this paragraph come from MoHSW/AED/World Food Program, Nutrition Policy Analysis using PROFILES: Investing in Nutrition to Reduce Poverty, December 2007.

${ }^{89}$ From 578 deaths per 100,000 live births in the year 2000, to 994 deaths per 100,000 live births in 2007. See Table 3.3. Source: LDHS, 2000 \& 2007

90 Based on the results of sentinel surveillance among pregnant women attending ten antenatal care (ANC) clinics in urban areas. A later study, the 2007

DHS, was the first to use population-based testing to determine HIV prevalence. It sampled a total of over 7,000 households and estimates prevalence at 1.5 percent, or 1.8 percent for females and 1.2 percent for males. The seemingly disparate conclusions are the cause of some controversy, and further study will be conducted during the PRS period. (See Annex 4).

91 As a result, the ratio of public and community school students to classrooms in good condition is more than 300:1.
} 
functioning pit latrines or flush toilets. Textbooks are scarce at a ratio of one for every 27 students. With educational levels low, inadequate facilities, and youth unemployment on the increase, Liberia's young people lack the necessary tools to make productive contributions to the social and economic development of the nation.

${ }^{7}$ Children and youth also have limited access to justice or the protection and enforcement of their rights under the legal system. Protecting the rights of children will contribute to achieving poverty reduction goals and ensure the active participation of children and young people in supporting good governance and the growth agenda over the long term.

${ }^{8}$ The Government will make special efforts to ensure that its institutions, policies and processes consider the needs of children and youth as a priority by implementing a human rights approach to development and an inclusive and participatory governance structure. Since the implementation of the "150 Day Plan" and the iPRS, the Government has made many efforts to support the development of children and young adults in Liberia, including:

- rebuilding and reopening many schools nationwide and in some of the most underserved areas and equipping them with over 13,000 pieces of school furniture;

- abolishing tuition and fees for public primary schools, and significantly reducing tuition and fees for public secondary schools, leading to a 44 percent increase in school enrolment;

- restoring services to over 350 health facilities around the country, and rehabilitating more than 20 clinics and several hospitals and health centers;

- immunizing over 95 percent of children under five against measles, distributing over 125,000 mosquito nets, and training over 3,500 health workers in malaria case management; and

- providing HIV and AIDS prevention services to the general population, particularly to high risk groups, as well as treatment and care services to people living with AIDS.

\section{Pillar I: National Security}

${ }^{9}$ All children and young people, but particularly girls and young women, must receive protection from physical, psychological and sexual harassment and abuse, in addition to legal protection and support from the Government to exercise their rights under the law. To these ends, the PRS calls for:

- implementing the National Plan of Action against Gender Based Violence;

- conducting gender-sensitive training for all stakeholders and especially security personnel;

- strengthening the Women and Children Protection unit in LNP and its units at the county level;

- training LNP and judicial staff in appropriately handling cases of sexual exploitation and abuse;

- developing clear guidelines for referral and case management of GBV cases for medical and psychosocial support;

- aiming for at least 20 percent of security forces to be women, and for women to be represented appropriately at all levels of authority. It will ensure that all training curricula fully incorporate gender considerations and issues, and place special emphasis on protection of women and children. 


\section{Pillar II: Economic Revitalization}

${ }^{10}$ In order for young people to contribute fully to the revitalization of the Liberian economy, economic stability, and the maintenance of basic subsistence, they must have increased access to the education, skills, and capital needed to take advantage of employment opportunities. Toward these goals, the PRS commits the Government to:

- improving food security and nutrition, especially for vulnerable groups, including pregnant and lactating women and children under five to increase productivity, socio-economic development and poverty reduction;

- providing greater opportunities for women and youth in agriculture, especially in the formal sector;

- enhancing access to credit for both the formal and informal sectors in order for youth to access employment and business opportunities; and

- developing and launching a Liberian National Youth Employment Action Plan in the context of the National Youth Policy.

\section{Pillar III: Governance and the Rule of Law}

${ }^{11}$ In the interest of fostering a more inclusive society based on wide citizen participation, children and young people will be involved in governance and development planning through the establishment of child-centered bodies such as the child parliament, child councils, and youth centers at various levels. The legal and judicial systems will take steps to understand and respond to the needs of children and youth. To these ends, the PRS offers a mandate to:

- support children and young people to participate in government processes and civic dialogue through the full range of their education and development;

- undertake a national consultation exercise with children and youth to promote and institutionalize the participation of these groups;

- develop mechanisms for the participation of children and youth in schools and Parent-Teacher Associations, in communities through youth centers and junior councils, and in the Legislature;

- develop and implement measures to ensure protection of vulnerable groups within the justice system, in particular during detention, including addressing the particular needs of children and young people, women, the elderly, and persons with disabilities;

- establish a national policy for crime prevention, with an emphasis on community responsibility and a particular focus on diversion programs for youth; and

- train judges and lawyers to conduct hearings and adjudication for juvenile delinquents and juvenile status offenders, and in methods of effective diversion.

\section{Pillar IV: Infrastructure and Basic Services}

${ }^{12}$ Under Pillar four, the two sectors with the most direct, immediate impact on children and youth are education and health. In the area of education, the PRS calls for strengthening traditional and alternative opportunities which provide literacy, numeracy and a basic understanding of the world as rudimentary tools needed to build productive capacities and healthy attitudes towards life and work. In the health sector, the PRS calls for taking steps that will improve access to the basic services that promote a healthy environment for children to live and thrive, including steps to: 
- upgrade and develop children's playgrounds in eight areas nationwide

- develop a National Social Welfare Policy and Plan to address the needs of the vulnerable and excluded segments of the Liberian population, especially orphans and other vulnerable children;

- increase the primary school net enrolment rate from 37.3 to 44.8 percent as an initial step toward achieving universal primary education by 2015.

- purchase and facilitate the publication of textbooks to improve the learner/textbook ratio in four core subjects and across all public schools to 2:1;

- provide feeding for at least 600,000 students and take-home rations for 30,000 adolescent girls, using locally produced food where feasible, to increase school enrolment, retention and improve cognition;

- create opportunities to train and employ of unemployed youth; and

- lend support to literacy and skills training in youth centers, including the training of young people to work as literacy and skills teachers in their communities. 


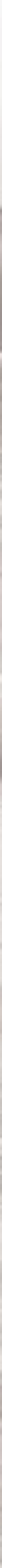

\section{Poverty Reduction Strategy}

Republic of Liberia

April 2008 